UNIVERSIDADE DE SÃO PAULO

INSTITUTO DE ASTRONOMIA, GEOFÍSICA E CIÊNCIAS ATMOSFÉRICAS

DEPARTAMENTO DE CIÊNCIAS ATMOSFÉRICAS

JOSE ANGEL RIANDES GONZÁLEZ

O Impacto dos Fatores de Risco Ambiental na Mortalidade Cardiovascular e Respiratória na Califórnia (1975-2005)

São Paulo

2018 


\section{O Impacto dos Fatores de Risco Ambiental na Mortalidade Cardiovascular e Respiratória na Califórnia (1975-2005)}

Versão Corrigida. O original encontra-se disponível na Unidade

Dissertação apresentada ao Departamento de Ciências Atmosféricas do Instituto de Astronomia, Geofísica e Ciências Atmosféricas da Universidade de São Paulo como requisito parcial para obtenção do título de Mestre em Ciências.

Área de concentração: Biometeorologia

Orientador: Prof. Dr. Fabio Luiz Teixeira Gonçalves

São Paulo 


\section{FOLHA DE APROVAÇÃO}

GOnZAleZ J. A. R. O Impacto dos Fatores de Risco Ambiental na Mortalidade Cardiovascular e Respiratória na Califórnia (1975-2005). 2018. 157 f. Dissertação (Mestrado em Meteorologia) - Instituto de Astronomia, Geofísica e Ciências Atmosféricas, Universidade de São Paulo, São Paulo, 2018.

Aprovado em:

Banca Examinadora

Prof. Dr.

Instituição:

Julgamento:

Prof. Dr.

Instituição:

Julgamento:

Prof. Dr.

Instituição:

Julgamento: 
Ao mais grande neste mundo

O pequeno James 


\section{AGRADECIMENTOS}

A minha esposa Janet pelo apoio, paciência, incentivo e toda sua ajuda neste trabalho.

A meu orientador Fábio Luiz Teixeira Gonçalves por ter compartilhado seus conhecimentos comigo, pela dedicação, confiança e amizade.

A meus pães e meus familiares por tudo, pelo apoio, preocupação e pela força desde a distância.

A todos meus amigos-irmãos pelas alegrias, amizade e ajuda em horas extras.

A meus amigos Maciel e Alia por toda sua ajuda incondicional nesta dissertação.

Aos professores do IAG pelos conhecimentos e amizade.

À CAPES pelo financiamento da bolsa de mestrado. 


\section{RESUMO}

GONZALEZ J. A. R. O Impacto dos Fatores de Risco Ambiental na Mortalidade Cardiovascular e Respiratória na Califórnia (1975-2005). 2018. 157 f. Dissertação (Mestrado em Meteorologia) - Instituto de Astronomia, Geofísica e Ciências Atmosféricas, Universidade de São Paulo, São Paulo, 2018.

O presente trabalho tem como objetivo avaliar a influência das variáveis ambientais na mortalidade de idosos (acima de 65 anos) por doenças cardiovasculares (DCV) e respiratórias (RES), nos condados de Los Angeles, Orange e Santa Bárbara na Califórnia, através de análises estatísticas, em particular de componentes principais (ACP). Para isso foram utilizados dados diários das estações meteorológicas dos condados (temperatura, pressão, umidade e velocidade do vento), de poluição do ar $\left(\mathrm{NO}_{2}, \mathrm{CO}, \mathrm{SO}_{2}\right.$ e $\left.\mathrm{O}_{3}\right)$ e da mortalidade por DCV e RES, durante o período 1975-2005. Além disso, foram calculados 7 índices de conforto térmico e estabelecidas as zonas de conforto para diferentes graus de percepção térmica a partir do índice de Temperatura Efetiva (TE). Os resultados verificaram tendências diferentes na variação temporal das DCV e RES. Enquanto as doenças RES tiveram um aumento bastante leve em todos os condados, as DCV apresentaram uma ligeira diminuição nos condados de Orange e Santa Bárbara, e uma diminuição constante e acentuada no condado de Los Angeles. Também se verificou uma variação sazonal significativa, com evidente aumento do número de óbitos de ambas as doenças durante o inverno e queda durante o verão. Em relação aos poluentes, foram observadas muitas ultrapassagens dos padrões nacionais de qualidade do ar principalmente para o $\mathrm{O}_{3}$, com 1443 vezes para o condado de Los Angeles, 771 para o Orange e 114 para Santa Bárbara. A partir dos índices de conforto térmico notou-se que o mês mais estressante devido ao calor foi setembro principalmente para os condados de Los Angeles e Santa Bárbara, e julho e agosto para o condado de Orange. Analisando a média de óbitos por sensação térmica observou-se um aumento das doenças nos extremos, principalmente quando a sensação é Muito Frio, com médias por doenças RES de 16,42, 3,31 e 0,81 e por DCV de 77,32, 15,37 e 2,92 nos condados de Los Angeles, Orange e Santa Bárbara, respectivamente. Com base na 
análise de correlação entre as variáveis e as doenças, observaram-se as melhores correlações no condado de Los Angeles, tanto para as doenças RES quanto DCV, e as correlações mais baixas foram observadas no condado de Santa Bárbara. Os resultados da ACP nos condados de Los Angeles e Orange verificaram o aumento da mortalidade por DCV no inverno, associadas a correlações positivas com os níveis de poluição principalmente em Los Angeles e ao estresse por frio, umidade e vento (via índice de conforto térmico) em Orange. Por outro lado, a mortalidade por doenças RES esteve mais associada às variações meteorológicas do que às concentrações de poluentes, observando-se associações positivas com o índice de calor (IC). Neste sentido, o condado de Orange apresentou maiores correlações com IC do que o condado de Los Angeles, além de uma variância maior (11,36 \% contra 9,89\%). Por último, no condado de Santa Bárbara os resultados foram muito diferentes, já que tanto episódios de frio quanto de calor não mostraram impactos claros na população idosa, com respeito a ambos os grupos de doenças. $\mathrm{O}$ distintivo foi que os níveis de $\mathrm{SO}_{2}$ tiveram a maior associação positiva à mortalidade principalmente por $\operatorname{DCV}(0,53)$, embora tiver o condado as concentrações mais baixas das estudadas (média de 0,29 ppb). Em suma, os condados possuem estruturas sociais diferentes, apesar da semelhança do clima, fazendo com que os resultados sejam bastante dispares entre os mesmos. As perspectivas destes estudos pretendem colocar estes resultados para climas futuros, pois diversos episódios de ondas de calor ocorreram após o ano de 2005.

Palavras-chave: Doenças Cardiovasculares (DCV). Doenças Respiratórias (RES). Índices de Conforto Térmico. Análises de Componentes Principais (ACP). 


\begin{abstract}
GONZALEZ J. A. R. Impact of Environmental Risk Factors on Cardiovascular and Respiratory Mortality in California (1975-2005). 2018. $157 \mathrm{f}$. Dissertation (Master in Meteorology) - Institute of Astronomy, Geophysics and Atmospheric Sciences, University of São Paulo, 2018.
\end{abstract}

The objective of this study was to evaluate the influence of environmental variables on the mortality of elderly patients (over 65 years) due to cardiovascular diseases (CD) and respiratory diseases (RD) in the counties of Los Angeles, Orange and Santa Bárbara, California; through statistical analyzes, in particular, principal components (PCA). For this purpose, daily data of the meteorological stations of the counties (temperature, pressure, humidity and wind speed), air pollution $\left(\mathrm{NO}_{2}, \mathrm{CO}, \mathrm{SO}_{2}\right.$ and $\left.\mathrm{O}_{3}\right)$ and mortality by $\mathrm{CD}$ and RD were used during the period 1975-2005. In addition, seven thermal comfort indexes were calculated and comfort zones were established for different degrees of thermal perception according to the Effective Temperature index (TE). The results showed different trends in the temporal variation of $\mathrm{CD}$ and $\mathrm{RD}$. While RD diseases had a fairly mild increase in all counties, CD showed a slight decrease in Orange and Santa Barbara counties and a steady decline in Los Angeles county. There was also a significant seasonal variation, with an evident increase in the number of deaths from both diseases during the winter and fall during the summer. In relation to the pollutants, many national standards for air quality were exceeded, mainly for the $\mathrm{O}_{3}$, with 1443 times for Los Angeles, 771 for Orange and 114 for Santa Barbara. From the thermal comfort indexes it was noted that the most stressful month due to the heat was September, mainly for the counties of Los Angeles and Santa Barbara, and July and August for the county of Orange. Analyzing the average number of deaths due to thermal sensation, there was an increase of the illnesses in extreme, especially when the sensation is Very Cold, with RD averages of 16.42, 3.31 and 0.81 and CD average of 77.32, 15.37 and 2.92 in the counties of Los Angeles, Orange and Santa Barbara, respectively. Based on correlation analysis between variables and diseases, the best correlations were found in Los Angeles for both $\mathrm{RD}$ and $\mathrm{CD}$, and the lowest 
correlations were observed in Santa Barbara. The results of PAC in the counties of Los Angeles and Orange showed the increase in CD mortality in winter associated to positive correlations with the levels of pollution mainly in Los Angeles and stress due to cold, humidity and wind (via thermal comfort index) in Orange. On the other hand, mortality due to RD diseases was more associated with meteorological variations than with pollutant concentrations, with positive associations with heat index (HI). In this sense, Orange County presented higher correlations with HI than the county of Los Angeles, in addition to a greater variance (11.36\% vs. 9.89\%). Finally, in Santa Barbara the results were very different, since both episodes of cold and heat did not show clear impacts in the elderly population, regarding both groups of diseases. The difference was that $\mathrm{SO}_{2}$ levels had the highest positive association with $\mathrm{CD}$ mortality (0.53), although this county had the lowest concentrations studied (mean $0.29 \mathrm{ppb}$ ). In sum, counties have different social structures, despite the similarity of the climate, making the results quite different between them. The perspectives of these studies intend to place these results for future climates, since several episodes of heat waves occurred after 2005.

Keywords: Cardiovascular Diseases (CD). Respiratory Diseases (RD). Thermal Comfort Indexes. Principal Component Analysis (PCA). 


\begin{tabular}{|c|c|c|}
\hline \multicolumn{3}{|c|}{ LISTA DE FIGURAS } \\
\hline Fig. & Descrição & Pág. \\
\hline 2.1 & $\begin{array}{l}\text { Posição geográfica do estado da Califórnia. Em amarelo são indicados } \\
\text { os condados de Los Angeles, Santa Bárbara e Orange. }\end{array}$ & 36 \\
\hline 2.2 & $\begin{array}{l}\text { Aumento percentual da população idosa com } 60 \text { anos e mais, } 1990 \text { a } \\
2020 \text { na Califórnia, em particular estão representados os condados de } \\
\text { interesse Santa Barbara, Orange e Los Angeles. (Adaptado do } \\
\text { Departamento de envelhecimento na Califórnia). }\end{array}$ & 39 \\
\hline 2.3 & $\begin{array}{l}\text { Variação sazonal da temperatura média diária (a) da temperatura } \\
\text { mínima diária (b) e da temperatura máxima diária (c), medidos pela } \\
\text { estação meteorológica } 722950 \text { - Aeroporto Internacional de Los } \\
\text { Angeles, durante o período 1975-2005. }\end{array}$ & 42 \\
\hline 2.4 & $\begin{array}{l}\text { Variação sazonal a) da temperatura média diária, b) da temperatura } \\
\text { mínima diária e c) da temperatura máxima diária, medidas pela estação } \\
\text { meteorológica } 722977 \text { - Aeroporto Internacional John Wayne, Orange, } \\
\text { durante o período 1975-2005. }\end{array}$ & 45 \\
\hline 2.5 & $\begin{array}{l}\text { Variação sazonal a) da temperatura média diária, b) da temperatura } \\
\text { mínima diária e c) da temperatura máxima diária, medidas pela estação } \\
723925 \text { - Aeroporto Municipal de Santa Bàrbara, durante o período } \\
\text { 1975-2005. }\end{array}$ & 46 \\
\hline 3.1 & $\begin{array}{l}\text { Variação temporal da mortalidade diária por doenças (a) RES e (b) } \\
\text { DCV no condado de Los Angeles, Califórnia (1975-2005). }\end{array}$ & 60 \\
\hline 3.2 & $\begin{array}{l}\text { Variação temporal da mortalidade diária por doenças (a) RES e (b) } \\
\text { DCV no condado de Orange, Califórnia (1975-2005). }\end{array}$ & 60 \\
\hline 3.3 & $\begin{array}{l}\text { Variação temporal da mortalidade diária por doenças (a) RES e (b) } \\
\text { DCV no condado de Santa Bárbara, Califórnia (1975-2005). }\end{array}$ & 61 \\
\hline 3.4 & $\begin{array}{l}\text { Mortalidade mensal por DCV para indivíduos com mais de } 65 \text { anos } \\
\text { nos condados de a) Santa Barbara, b) Orange e c) Los Angeles }\end{array}$ & 63 \\
\hline 3.5 & $\begin{array}{l}\text { Mortalidade mensal por doenças RES para indivíduos com mais de } 65 \\
\text { anos nos condados de a) Santa Barbara, b) Orange e c) Los Angeles. }\end{array}$ & 64 \\
\hline 3.6 & $\begin{array}{l}\text { Distribuição de DCV por estações do ano, para indivíduos com mais } \\
\text { de } 65 \text { anos nos condados de a) Santa Barbara, b) Orange e c) Los } \\
\text { Angeles. }\end{array}$ & 65 \\
\hline 3.7 & $\begin{array}{l}\text { Distribuição de doenças RES por estações do ano, para indivíduos com } \\
\text { mais de } 65 \text { anos nos condados de a) Santa Barbara, b) Orange e c) Los } \\
\text { Angeles. }\end{array}$ & 66 \\
\hline 3.8 & $\begin{array}{l}\text { Concentrações dos poluentes a) } \mathrm{CO}, \text { b) } \mathrm{SO}_{2} \text {, c) } \mathrm{NO}_{2} \text { e d) } \mathrm{O}_{3} \text {, Los } \\
\text { Angeles (1980-2005). }\end{array}$ & 67 \\
\hline 3.9 & $\begin{array}{l}\text { Concentrações dos poluentes a) } \mathrm{CO} \text {, b) } \mathrm{SO}_{2} \text {, c) } \mathrm{NO}_{2} \text { e d) } \mathrm{O}_{3} \text {, Orange } \\
(1980-2005) \text {. }\end{array}$ & 68 \\
\hline 3.10 & $\begin{array}{l}\text { Concentrações dos poluentes a) } \mathrm{CO}, \text { b) } \mathrm{SO}_{2} \text {, c) } \mathrm{NO}_{2} \text { e d) } \mathrm{O}_{3} \text {, Santa } \\
\text { Bárbara (1980-2005). }\end{array}$ & 69 \\
\hline 3.11 & Número de ultrapassagens mensal do padrão do poluente $\mathrm{NO}_{2}$ em a) & 70 \\
\hline
\end{tabular}




\begin{tabular}{|c|c|c|}
\hline & Los Angeles e b) Orange no período $1980-2005$. & \\
\hline 3.12 & $\begin{array}{l}\text { Número de ultrapassagens do padrão do poluente } \mathrm{NO}_{2} \text { por estações do } \\
\text { ano em a) Los Angeles e b) Orange no período } 1980-2005 \text {. }\end{array}$ & 70 \\
\hline 3.13 & $\begin{array}{l}\text { Número de ultrapassagens do padrão do poluente } \mathrm{O}_{3} \text { por estações do } \\
\text { ano em a) Santa Barbara, b) Orange e c) Los Angeles no período } \\
1980-2005 \text {. }\end{array}$ & 72 \\
\hline 3.14 & $\begin{array}{l}\text { Número de ultrapassagens mensal do padrão do poluente } \mathrm{O}_{3} \text { em a) } \\
\text { Santa Barbara, b) Orange e c) Los Angeles no período } 1980-2005 \text {. }\end{array}$ & 73 \\
\hline 3.15 & $\begin{array}{l}\text { Variação temporal do ID, sob três aspectos diferentes, nos condados } \\
\text { de a) Santa Barbara, b) Orange e c) Los Angeles no período 1980- } \\
2005 \text {. }\end{array}$ & 76 \\
\hline 3.16 & $\begin{array}{l}\text { Variação temporal do IDK, sob três aspectos diferentes, nos condados } \\
\text { de a) Santa Barbara, b) Orange e c) Los Angeles no período 1980- } \\
2005 \text {. }\end{array}$ & 78 \\
\hline 3.17 & $\begin{array}{l}\text { Variação temporal de TE, sob três situações diferentes, nos condados } \\
\text { de a) Santa Barbara, b) Orange e c) Los Angeles no período 1980- } \\
2005 \text {. }\end{array}$ & 80 \\
\hline 3.18 & $\begin{array}{l}\text { Porcentagem de doenças RES e DCV considerando as diferentes } \\
\text { sensações térmicas utilizando o índice TE, nos condados a) Santa } \\
\text { Bárbara, b) Orange e c) Los Angeles, no período 1975-2005. }\end{array}$ & 85 \\
\hline 3.19 & $\begin{array}{l}\text { Variação temporal de TEv, sob três situações diferentes, nos condados } \\
\text { de a) Santa Barbara, b) Orange e c) Los Angeles no período 1980- } \\
2005 \text {. }\end{array}$ & 87 \\
\hline 3.20 & $\begin{array}{l}\text { Variação temporal da TA, sob três aspectos diferentes, nos condados } \\
\text { de a) Santa Barbara, b) Orange e c) Los Angeles no período 1980- } \\
2005 \text {. }\end{array}$ & 89 \\
\hline 3.21 & $\begin{array}{l}\text { Variação temporal do IC, sob três aspectos diferentes, nos condados de } \\
\text { a) Santa Barbara, b) Orange e c) Los Angeles no período 1980-2005. }\end{array}$ & 91 \\
\hline 3.22 & $\begin{array}{l}\text { Variação temporal de H, sob duas situações diferentes, nos condados } \\
\text { de a) Santa Barbara, b) Orange e c) Los Angeles no período 1980- } \\
2005 \text {. }\end{array}$ & 93 \\
\hline 3.23 & $\begin{array}{l}\text { Evolução temporal da temperatura do ar e as doenças RES com } 5 \text { dias } \\
\text { de atraso no condado de Los Angeles (1988-1990). }\end{array}$ & 100 \\
\hline 3.24 & $\begin{array}{l}\text { Evolução temporal da concentração de CO e as DCV sem dias de } \\
\text { atraso no condado de Los Angeles (1988-1990). }\end{array}$ & 100 \\
\hline 3.25 & $\begin{array}{l}\text { Evolução temporal do ID e as doenças RES com } 5 \text { dias de atraso no } \\
\text { condado de Orange (1990-1992). }\end{array}$ & 106 \\
\hline 3.26 & $\begin{array}{l}\text { Evolução temporal da concentração de CO e as DCV com } 3 \text { dias de } \\
\text { atraso no condado de Orange (1983-1985). }\end{array}$ & 106 \\
\hline 3.27 & $\begin{array}{l}\text { Evolução temporal da P e as doenças RES com } 5 \text { dias de atraso no } \\
\text { condado de Santa Bárbara (1990-1992). }\end{array}$ & 112 \\
\hline 3.28 & $\begin{array}{l}\text { Evolução temporal das DCV e о IDK com } 5 \text { dias de atraso no condado } \\
\text { de Santa Bárbara (1983-1985). }\end{array}$ & 112 \\
\hline
\end{tabular}




\begin{tabular}{|c|c|c|}
\hline \multicolumn{3}{|c|}{ LISTA DE TABELAS } \\
\hline Tab. & Descrição & Pág. \\
\hline 1.1 & Efeitos deletérios do envelhecimento. & 21 \\
\hline 1.2 & $\begin{array}{l}\text { Fontes poluidoras e efeitos dos principais poluentes atmosféricos } \\
\text { sobre a saúde humana. }\end{array}$ & 29 \\
\hline 1.3 & $\begin{array}{l}\text { Padrões nacionais de qualidade do ar, tempo de amostragem e } \\
\text { método de medição para os poluentes utilizados na Califórnia. }\end{array}$ & 30 \\
\hline 2.1 & $\begin{array}{l}\text { Estações meteorológicas utilizadas para o período de } 1975-2005 \text {, nos } \\
\text { Condados de Califórnia: Los Angeles, Orange e Santa Bárbara. }\end{array}$ & 41 \\
\hline 2.2 & $\begin{array}{l}\text { Estações ondes foram medidos os poluentes atmosféricos para o } \\
\text { período 1980-2004, nos condados da Califórnia: Los Angeles, } \\
\text { Orange e Santa Bárbara. }\end{array}$ & 47 \\
\hline 2.3 & Índices de estresse térmico selecionados neste estudo. & 53 \\
\hline 2.4 & Níveis de Desconforto gerados por categorias do ID & 53 \\
\hline 2.5 & Nível de desconforto gerado por cada categoria do $\mathrm{ID}_{\mathrm{K}}$ & 54 \\
\hline 2.6 & $\begin{array}{l}\text { Sensação térmica e grau de estresse fisiológico para cada categoria do } \\
\text { TE. }\end{array}$ & 55 \\
\hline 2.7 & Nível de desconforto gerado por cada categoria do $\mathrm{H}$ & 56 \\
\hline 2.8 & Grado de estresse térmico gerado por cada categoria do indice TA. & 57 \\
\hline 2.9 & Categorias do IC e seus respectivos efeitos no corpo. & 58 \\
\hline 3.1 & $\begin{array}{l}\text { Distribuição do número de dias, totais, média e por cento de óbitos } \\
\text { por doenças RES nos tipos de tempo para Los Angeles, durante o } \\
\text { período de } 1980 \text { a } 2005 \text {, utilizando o índice TE. }\end{array}$ & 82 \\
\hline 3.2 & $\begin{array}{l}\text { Distribuição do número de dias, totais, média e por cento de óbitos } \\
\text { por DCV nos tipos de tempo para Los Angeles, durante o período de } \\
1980 \text { a 2005, utilizando o índice TE. }\end{array}$ & 82 \\
\hline 3.3 & $\begin{array}{l}\text { Distribuição do número de dias, de óbitos, média e por cento de } \\
\text { óbitos por doenças RES, nos tipos de tempo para o condado de } \\
\text { Orange, durante o período de } 1980 \text { a } 2005 \text {. }\end{array}$ & 83 \\
\hline 3.4 & $\begin{array}{l}\text { Distribuição do número de dias, de óbitos, média e por cento de } \\
\text { óbitos por DCV, nos tipos de tempo para o condado de Orange, } \\
\text { durante o período de } 1980 \text { a } 2005 \text {. }\end{array}$ & 83 \\
\hline 3.5 & $\begin{array}{l}\text { Distribuição do número de dias, de óbitos, média e por cento de } \\
\text { óbitos por doenças RES, nos tipos de tempo para o condado de Santa } \\
\text { Bárbara, durante o período de } 1980 \text { a } 2005 \text {. }\end{array}$ & 84 \\
\hline 3.6 & $\begin{array}{l}\text { Distribuição do número de dias, de óbitos, média e por cento de } \\
\text { óbitos por DCV, nos tipos de tempo para o condado de Santa } \\
\text { Bárbara, durante o período de } 1980 \text { a } 2005 \text {. }\end{array}$ & 84 \\
\hline 3.7 & $\begin{array}{l}\text { Correlações entre as DCV e as variáveis analisadas para vários dias } \\
\text { com atraso e sem atraso no condado de Los Angeles. }\end{array}$ & 95 \\
\hline 3.8 & Correlações entre as doenças RES e as variáveis analisadas para & 96 \\
\hline
\end{tabular}




\begin{tabular}{|c|c|c|}
\hline & ários dias com atraso e sem atraso no condado de Los Angeles. & \\
\hline 3.9 & $\begin{array}{l}\text { Correlações entre as DCV e as variáveis analisadas sem média móvel } \\
\text { e com média móvel de até } 5 \text { dias (todas variáveis) no condado de Los } \\
\text { Angeles. }\end{array}$ & 98 \\
\hline 3.10 & $\begin{array}{l}\text { Correlações entre as as doenças RES e as variáveis analisadas sem } \\
\text { média móvel e com média móvel de até } 5 \text { dias (todas variáveis) no } \\
\text { condado de Los Angeles. }\end{array}$ & 99 \\
\hline 3.11 & $\begin{array}{l}\text { Correlações entre a mortalidade por DCV e as variáveis analisadas } \\
\text { para vários dias com atraso e sem atraso no condado de Orange. }\end{array}$ & 102 \\
\hline 3.12 & $\begin{array}{l}\text { Correlações entre a mortalidade por doenças RES e as variáveis } \\
\text { analisadas para vários dias com atraso e sem atraso no condado de } \\
\text { Orange. }\end{array}$ & 103 \\
\hline 3.13 & $\begin{array}{l}\text { Correlações entre as DCV e as variáveis analisadas sem média móvel } \\
\text { e com média móvel de até } 5 \text { dias (todas variáveis) no condado } \\
\text { Orange. }\end{array}$ & 104 \\
\hline 3.14 & $\begin{array}{l}\text { Correlações entre as doenças RES e as variáveis analisadas sem } \\
\text { média móvel e com média móvel de até } 5 \text { dias (todas variáveis) no } \\
\text { condado Orange }\end{array}$ & 105 \\
\hline 3.15 & $\begin{array}{l}\text { Correlações entre a mortalidade por DCV e as variáveis analisadas } \\
\text { para vários dias com atraso e sem atraso no condado de Santa } \\
\text { Bárbara. }\end{array}$ & 108 \\
\hline 3.16 & $\begin{array}{l}\text { Correlações entre a mortalidade por doenças RES e as variáveis } \\
\text { analisadas para vários dias com atraso e sem atraso no condado de } \\
\text { Santa. }\end{array}$ & 109 \\
\hline 3.17 & $\begin{array}{l}\text { Correlações entre as DCV e as variáveis analisadas sem média móvel } \\
\text { e com média móvel de até } 5 \text { dias (todas variáveis) condado de Santa } \\
\text { Bárbara. }\end{array}$ & 110 \\
\hline 3.18 & $\begin{array}{l}\text { Correlações entre as doenças RES e as variáveis analisadas sem } \\
\text { média móvel e com média móvel de até } 5 \text { dias no condado de Santa } \\
\text { Bárbara }\end{array}$ & 111 \\
\hline 3.19 & $\begin{array}{l}\text { Pesos das componentes principais após a rotação VARIMAX na } \\
\text { análise de DCV considerando a) dias sim atraso e b) } 5 \text { dias de atraso } \\
\text { para o condado de Los Angeles. }\end{array}$ & 114 \\
\hline 3.20 & $\begin{array}{l}\text { Pesos das componentes principais após a rotação VARIMAX na } \\
\text { análise da mortalidade por doenças RES considerando a) dias sim } \\
\text { atraso e b) } 5 \text { dias de atraso para o condado de Los Angeles. }\end{array}$ & 115 \\
\hline 3.21 & $\begin{array}{l}\text { Pesos das componentes principais após a rotação VARIMAX na } \\
\text { análise de DCV considerando a) dias sim atraso e b) } 5 \text { dias de atraso } \\
\text { para o condado de Orange. }\end{array}$ & 117 \\
\hline 3.22 & $\begin{array}{l}\text { Pesos das componentes principais após a rotação VARIMAX na } \\
\text { análise da mortalidade por doenças RES considerando a) dias sim } \\
\text { atraso e b) } 5 \text { dias de atraso para o condado de Orange. }\end{array}$ & 118 \\
\hline 3.23 & Pesos das componentes principais após a rotação VARIMAX na & 120 \\
\hline
\end{tabular}




\begin{tabular}{|c|c|c|}
\hline & $\begin{array}{l}\text { análise de DCV considerando a) dias sim atraso e b) } 5 \text { dias de atraso } \\
\text { para o condado de Santa Barbara. }\end{array}$ & \\
\hline 3.24 & $\begin{array}{l}\text { Pesos das componentes principais após a rotação VARIMAX na } \\
\text { análise da mortalidade por doenças RES considerando a) dias sim } \\
\text { atraso e b) } 5 \text { dias de atraso para o condado de Santa Bárbara. }\end{array}$ & 121 \\
\hline 3.25 & $\begin{array}{l}\text { Pesos das componentes principais após a rotação VARIMAX } \\
\text { incluindo os índices de conforto térmico na análise da mortalidade } \\
\text { por } \mathrm{DCV} \text {, considerando a) dias sim atraso e b) } 5 \text { dias de atraso para o } \\
\text { condado de Los Angeles. }\end{array}$ & 123 \\
\hline 3.26 & $\begin{array}{l}\text { Pesos das componentes principais após a rotação VARIMAX } \\
\text { incluindo os índices de conforto térmico na análise da mortalidade } \\
\text { por doenças RES, considerando a) dias sim atraso e b) } 5 \text { dias de } \\
\text { atraso para o condado de Los Angeles. }\end{array}$ & 124 \\
\hline 3.27 & $\begin{array}{l}\text { Pesos das componentes principais após a rotação VARIMAX } \\
\text { incluindo os índices de conforto térmico na análise da mortalidade } \\
\text { por DCV, considerando a) dias sim atraso e b) } 5 \text { dias de atraso para o } \\
\text { condado de Orange. }\end{array}$ & 127 \\
\hline 3.28 & $\begin{array}{l}\text { Pesos das componentes principais após a rotação VARIMAX } \\
\text { incluindo os índices de conforto térmico na análise da mortalidade } \\
\text { por doenças RES, considerando a) dias sim atraso e b) } 5 \text { dias de } \\
\text { atraso para o condado de Orange. }\end{array}$ & 128 \\
\hline 3.29 & $\begin{array}{l}\text { Pesos das componentes principais após a rotação VARIMAX } \\
\text { incluindo os índices de conforto térmico na análise da mortalidade } \\
\text { por DCV, considerando a) dias sim atraso e b) } 5 \text { dias de atraso para o } \\
\text { condado de Santa Barbara. }\end{array}$ & 130 \\
\hline 3.30 & $\begin{array}{l}\text { Pesos das componentes principais após a rotação VARIMAX } \\
\text { incluindo os índices de conforto térmico na análise da mortalidade } \\
\text { por doenças RES, considerando a) dias sim atraso e b) } 5 \text { dias de } \\
\text { atraso para o condado de Santa Barbara. }\end{array}$ & 131 \\
\hline 3.31 & $\begin{array}{l}\text { Pesos das componentes principais após a rotação VARIMAX } \\
\text { incluindo os índices de conforto térmico na análise da mortalidade } \\
\text { por DCV, considerando as estações de a) inverno e b) verão para o } \\
\text { condado de Los Angeles. }\end{array}$ & 133 \\
\hline 3.32 & $\begin{array}{l}\text { Pesos das componentes principais após a rotação VARIMAX } \\
\text { incluindo os índices de conforto térmico na análise da mortalidade } \\
\text { por doenças RES, considerando as estações de a) inverno e b) verão } \\
\text { para o condado de Los Angeles. }\end{array}$ & 134 \\
\hline 3.33 & $\begin{array}{l}\text { Pesos das componentes principais após a rotação VARIMAX } \\
\text { incluindo os índices de conforto térmico na análise da mortalidade } \\
\text { por DCV, considerando as estações de a) inverno e b) verão para o } \\
\text { condado de Orange. }\end{array}$ & 135 \\
\hline
\end{tabular}




\begin{tabular}{|c|l|l|c|}
\hline 3.34 & $\begin{array}{l}\text { Pesos das componentes principais após a rotação VARIMAX } \\
\text { incluindo os índices de conforto térmico na análise da mortalidade } \\
\text { por doenças RES, considerando as estações de a) inverno e b) verão } \\
\text { para o condado de Orange. }\end{array}$ & 137 \\
\hline 3.35 & $\begin{array}{l}\text { Pesos das componentes principais após a rotação VARIMAX } \\
\text { incluindo os índices de conforto térmico na análise da mortalidade } \\
\text { por DCV, considerando as estações de a) inverno e b) verão para o } \\
\text { condado de Santa Bárbara. }\end{array}$ & 138 \\
\hline 3.36 & $\begin{array}{l}\text { Pesos das componentes principais após a rotação VARIMAX } \\
\text { incluindo os índices de conforto térmico na análise da mortalidade } \\
\text { por doenças RES, considerando as estações de a) inverno e b) verão } \\
\text { para o condado de Santa Bárbara. }\end{array}$ & 139 \\
\hline
\end{tabular}




\begin{tabular}{|c|c|c|}
\hline \multicolumn{3}{|r|}{ LISTA DE SIGLAS E VARIÁVEIS } \\
\hline Item & $\begin{array}{c}\text { Sigla e } \\
\text { variáveis }\end{array}$ & Descrição \\
\hline 1 & IPCC & Painel Intergovernamental para as Mudanças Climáticas \\
\hline 2 & ONU & Organização das Nações Unidas \\
\hline 3 & RMSP & Região Metropolitana de São Paulo \\
\hline 4 & IBGE & Instituto Brasileiro de Geografia Estatística \\
\hline 5 & TE & Temperatura Efetiva \\
\hline 6 & DCV & Doenças Cardiovasculares \\
\hline 7 & RES & Doenças Respiratórias \\
\hline 8 & EUA & Estados Unidos de América \\
\hline 9 & ID & Índice de Desconforto \\
\hline 10 & $\mathrm{H}$ & Índice Windchill \\
\hline 11 & PMV & Voto Previsto Médio \\
\hline 12 & TA & Temperatura Aparente \\
\hline 13 & TEv & Temperatura Efetiva em função do vento \\
\hline 14 & ${ }^{\circ} \mathrm{C}$ & Graus Célsius \\
\hline 15 & $\mathrm{SO}_{2}$ & Dióxido de Enxofre \\
\hline 16 & $\mathrm{NO}_{2}$ & Dióxido de nitrogênio \\
\hline 17 & $\mathrm{CO}$ & Monóxido de Carbono \\
\hline 18 & $\mathrm{O}_{3}$ & Ozônio \\
\hline 19 & $\mu \mathrm{g}$ & Microgramas \\
\hline 20 & $\mathrm{PM}_{2,5}$ & Material Particulado \\
\hline 21 & NOAA & National Oceanic and Atmospheric Administration \\
\hline 22 & UR & Umidade Relativa \\
\hline 23 & $e$ & Pressão Parcial de Vapor de Agua \\
\hline 24 & $\mathrm{e}_{s}$ & Pressão de Saturação do Vapor de Agua \\
\hline 25 & $q$ & Umidade Específica \\
\hline 26 & $\mathrm{P}$ & Pressão Atmosférica \\
\hline 27 & $\varepsilon$ & $\begin{array}{l}\text { Constante que expressa a razão entre o peso molecular da água e o } \\
\text { peso molecular do ar seco. }\end{array}$ \\
\hline 28 & $\mathrm{~T}$ & Temperatura do Vento \\
\hline 29 & $\mathrm{~T}_{\mathrm{d}}$ & Temperatura de Ponto de Orvalho \\
\hline 30 & $\bar{X}_{j}$ & Estimativa da Média. \\
\hline 31 & $s\left(x_{j}\right)$ & desvio padrão da característica j \\
\hline 32 & $\mathrm{r}$ & Coeficiente de Correlação Pearson \\
\hline 33 & ACP & Análise das Componentes Principais \\
\hline 34 & VARIMAX & Variance Maximizing \\
\hline 35 & $\mathrm{ID}_{\mathrm{K}}$ & Índice de Kawamura \\
\hline 36 & IC & Índice de Calor \\
\hline 37 & $\mathrm{~T}_{\mathrm{w}}$ & Temperatura de bulbo úmido \\
\hline 38 & MF & Muito Frio \\
\hline 39 & FM & Frio Moderado \\
\hline 40 & LF & Ligeiramente frio \\
\hline 41 & $\mathrm{C}$ & Confortável \\
\hline
\end{tabular}




\begin{tabular}{|c|c|l|}
\hline 42 & LQ & Ligeiramente Quente \\
\hline 43 & QM & Quente Moderado \\
\hline 44 & Q & Quente \\
\hline 45 & MQ & Muito Quente \\
\hline 46 & lag & Estruturas de Defasagem \\
\hline 47 & OMS & Organização Mundial da Saúde \\
\hline 48 & ALA & American Lung Association \\
\hline 49 & ppm & Partículas por Milhão \\
\hline 50 & NOx & Óxidos de Nitrogênio \\
\hline 51 & T_MAX $_{-}$ & Temperatura Máxima \\
\hline 52 & T_MIN & Temperatura Mínima \\
\hline 53 & V & Velocidade Média do Vento \\
\hline
\end{tabular}




\section{Sumário}

CAPÍTULO 1: CONSIDERAÇÕES INICIAIS........................................................................... 20

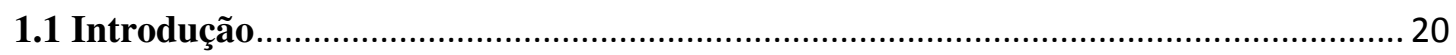

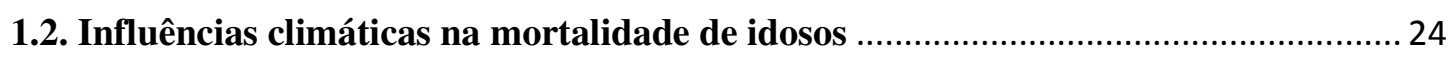

1.3. Índices de conforto térmico ou biometeorológicos ...................................................... 26

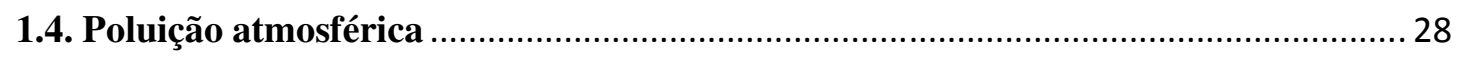

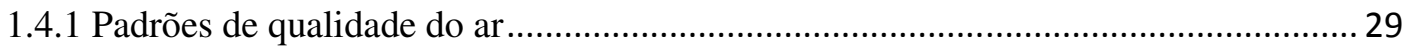

1.4.2. Efeitos meteorotrópicos e de poluição do ar em doenças.............................................. 31

1.5. Caracterização do problema e justificativa ……........................................................... 33

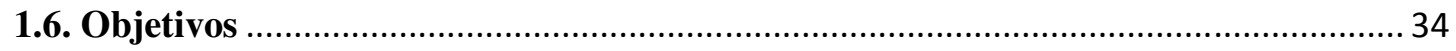

CAPÍTULO 2 - DADOS E METODOLOGIA.......................................................................... 35

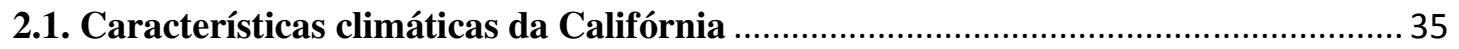

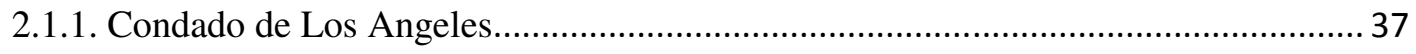

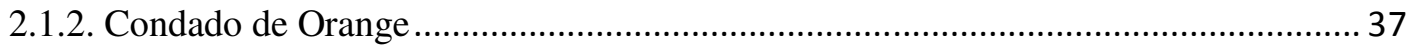

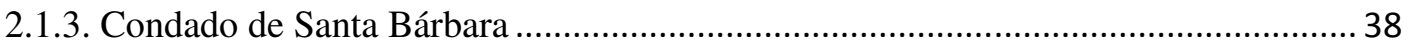

2.2. As faixas etárias da população da Califórnia …………………………........................ 39

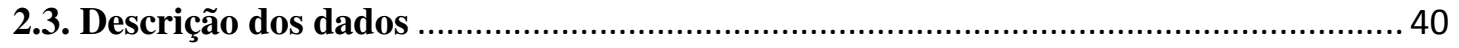

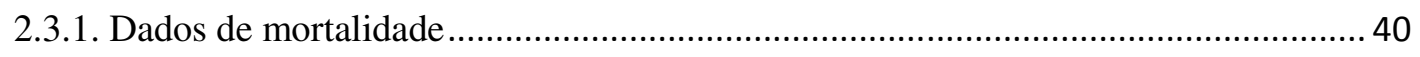

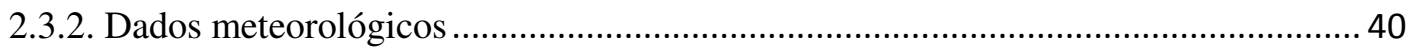

2.3.3. Dados dos poluentes atmosféricos ………….......................................................... 47

2.4. Métodos adotados nas análises................................................................................ 4 .

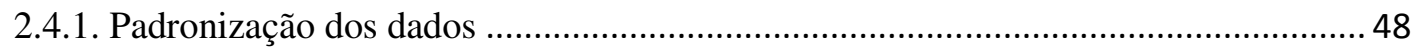

2.4.2. Coeficiente de correlação de Pearson......................................................................... 48

2.4.2.1. Metodologia de bootstrap ................................................................................. 49

2.4.3. Análise das componentes principais.......................................................................... 49

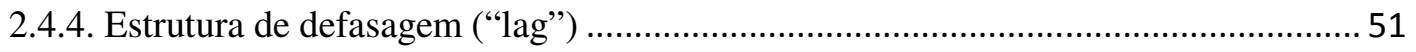

2.5. Cálculo dos índices de conforto térmico …………………............................................. 51

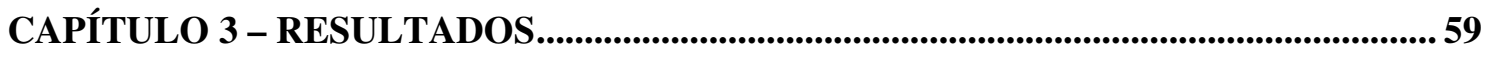

3.1. Panorama geral da mortalidade por DCV e RES nos condados de Orange, Los

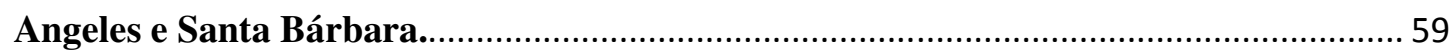

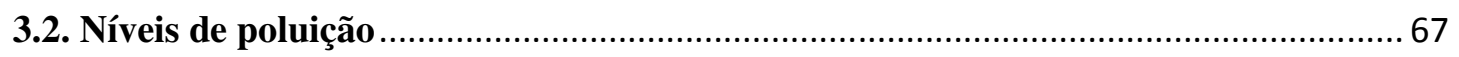

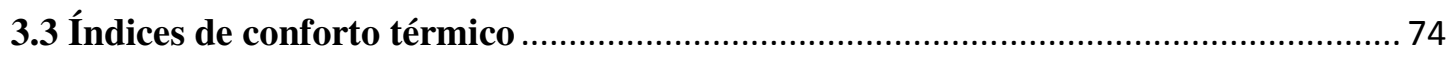

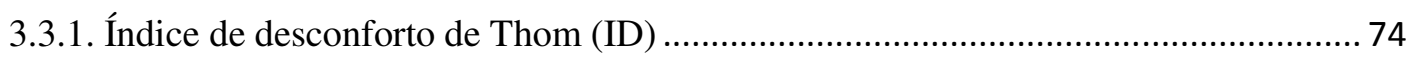

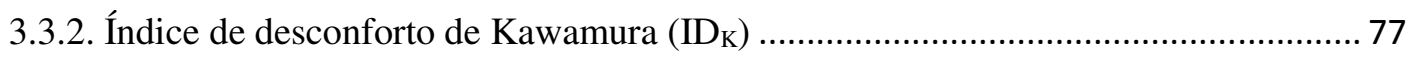




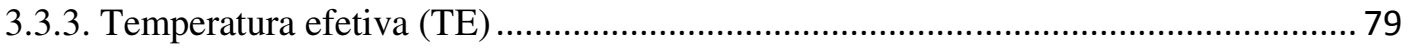

3.3.4. Temperatura efetiva com relação ao vento $\left(\mathrm{TE}_{\mathrm{v}}\right)$...................................................... 86

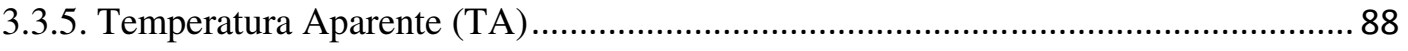

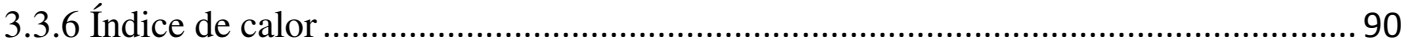

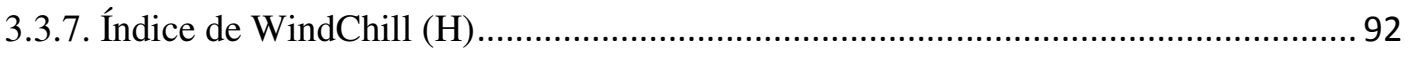

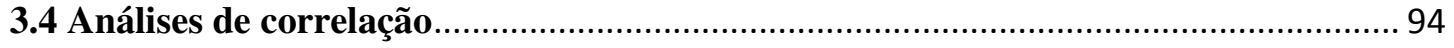

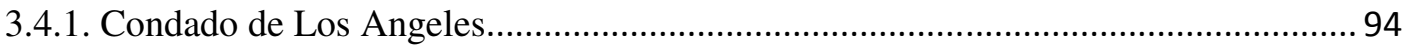

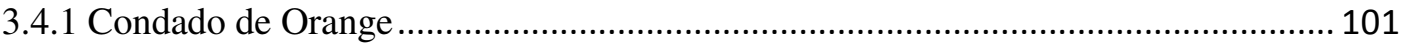

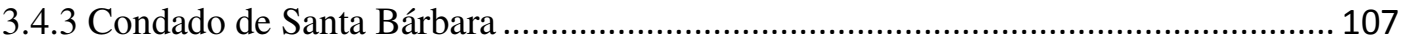

3.5 Análises de componentes principais (ACP) ............................................................. 113

3.5.1 ACP aplicada às variáveis meteorotrópicas ............................................................. 113

3.5.2 ACP aplicada aos Índices de conforto térmico........................................................ 122

3.5.3. ACP aplicado às estações inverno e verão ……….................................................... 132

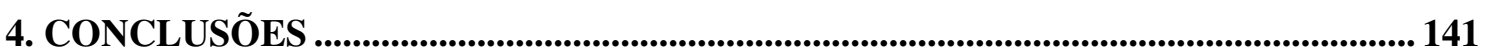

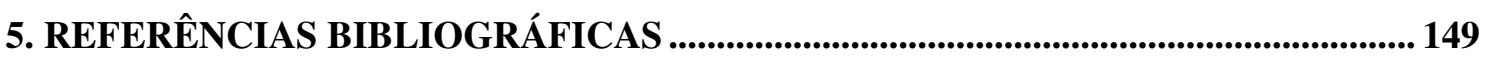




\section{CAPÍTULO 1: CONSIDERAÇÕES INICIAIS}

\subsection{Introdução}

O século XXI tem sido caracterizado por uma discussão significativa sobre as mudanças climáticas, suas origens e suas implicações sobre o ambiente e a humanidade. Neste sentido, no final de 2015 em Paris, no marco da $21^{\text {a }}$ Conferência do Clima, o grupo de representantes da União Europeia e das 19 maiores economias do mundo declarou que as mudanças climáticas representam um dos maiores desafios do nosso tempo.

Por sua vez, muitos cientistas afirmam que a tendência atual de aquecimento global é um ponto importante dentro deste assunto, já que a maior parte é causada pela influência antropogênica, e vem se amplificando a uma taxa sem precedentes nos últimos 1300 anos. O Painel Intergovernamental para as Mudanças Climáticas (IPCC, em inglês), relata que o aquecimento observado durante os últimos 50 anos provavelmente se deve ao aumento do efeito estufa (IPCC, 2007).

No contexto atual, as atividades industriais das quais a nossa civilização moderna depende elevaram os níveis de dióxido de carbono atmosférico de 280 partes por milhão (ppm) a mais de 379 ppm (atualmente) nos últimos 150 anos. O IPCC também concluiu que há uma probabilidade superior a $90 \%$ de que os gases de efeito estufa produzidos pelo homem (como o dióxido de carbono, metano e óxido nitroso) terem causado a maior parte do aumento observado nas temperaturas da Terra nos últimos 50 anos. Diante do cenário, caso as emissões de poluentes continuem nos níveis atuais, a temperatura da Terra deverá subir cerca de três graus Celsius e para os próximos vinte anos, é projetado um aumento de 0,2 graus Celsius por década, (IPCC, 2007).

Por outro lado, as condições atmosféricas exercem forte influência sobre a sociedade e sobre as condições de saúde, sendo as doenças do ser humano uma das manifestações dessa interação. Mas as relações entre clima e saúde humana são complexas porque dependem da intensidade e duração da mudança de tempo (grau de contraste) e sensibilidade do receptor, sendo que esses fatores mudam continuamente de local, indivíduos e populações. 
A capacidade de adaptação não é distribuída de modo uniforme em toda a sociedade, os maiores impactos tendem ser observados nos grupos mais vulneráveis, principalmente nos idosos. Devido a que fisiologicamente, emocionalmente e socioeconomicamente são menos capazes de lidar com os efeitos adversos das mudanças climáticas (Haq et al., 2008).

Do ponto de vista físico, uma pessoa idosa caracteriza-se como 'envelhecida' por apresentar uma degeneração gradual e progressiva dos órgãos, tecidos e metabolismo, perda de energia, alterações na aparência e condições psicológicas, acarretando debilidades nas funções orgânicas. A tabela 1.1, adaptada de Matsudo (1996), lista alguns dos efeitos deletérios do envelhecimento.

Considerando seu aspecto fisiológico, tem sido reconhecido que estas alterações podem ter maiores impactos na sua capacidade de responder aos efeitos negativos, por exemplo, níveis elevados de poluentes, aumento da exposição à radiação solar, episódios de ondas de frio e de calor, que expõem indivíduos como os idosos a condições extremas, às quais não estão comumente adaptados e excedem suas capacidades de regulação (Sartori, 2000).

Tabela 1.1 - Efeitos deletérios do envelhecimento (adaptada de Matsudo, 1996).

\begin{tabular}{|c|c|c|c|c|c|}
\hline $\begin{array}{c}\text { Nível } \\
\text { antropométrico }\end{array}$ & Nível Muscular & $\begin{array}{c}\text { Nível } \\
\text { Pulmonar }\end{array}$ & Nível Neural & $\begin{array}{c}\text { Nível } \\
\text { Cardiovascular }\end{array}$ & Outras \\
\hline $\begin{array}{c}\text { Aumento do } \\
\text { peso corporal/ } \\
\text { gordura. } \\
\text { Diminuição da } \\
\text { estatura e da } \\
\text { massa muscular. } \\
\text { Diminuição da } \\
\text { densidade óssea }\end{array}$ & $\begin{array}{l}\text { Perda de até } \\
10 \% \text { na força } \\
\text { muscular. } \\
\text { Maior índice de } \\
\text { fadiga muscular. } \\
\text { Menor } \\
\text { capacidade para } \\
\text { hipertrofia. } \\
\text { Diminuição na } \\
\text { atividade } \\
\text { oxidativa e dos } \\
\text { estoques de } \\
\text { fontes } \\
\text { energéticas } \\
\text { (ATP/CP/Glico- } \\
\text { gênio). } \\
\text { Diminuição na } \\
\text { velocidade de } \\
\text { condução e na } \\
\text { capacidade de } \\
\text { regeneração. }\end{array}$ & $\begin{array}{c}\text { Diminuição } \\
\text { da } \\
\text { capacidade } \\
\text { vital e da } \\
\text { capacidade } \\
\text { de difusão } \\
\text { pulmonar. } \\
\text { Aumento do } \\
\text { volume } \\
\text { residual e da } \\
\text { ventilação } \\
\text { durante o } \\
\text { exercício. } \\
\text { Menor } \\
\text { mobilidade } \\
\text { da parede } \\
\text { torácica }\end{array}$ & $\begin{array}{l}\text { Diminuição no } \\
\text { número e no } \\
\text { tamanho dos } \\
\text { neurônios. } \\
\text { Diminuição na } \\
\text { velocidade de } \\
\text { condução } \\
\text { nervosa. } \\
\text { Aumento do } \\
\text { tecido } \\
\text { conetivo nos } \\
\text { neurônios. } \\
\text { Menor tempo } \\
\text { de reação e } \\
\text { velocidade de } \\
\text { movimento. } \\
\text { Diminuição no } \\
\text { fluxo } \\
\text { sanguíneo } \\
\text { cerebral. }\end{array}$ & $\begin{array}{c}\text { Diminuição do } \\
\text { gasto energético } \\
\text { e da frequência } \\
\text { cardíaca } \\
\text { Diminuição do } \\
\text { volume sistólico } \\
\text { e da utilização } \\
\text { de } \mathrm{O}_{2} \text { pelos } \\
\text { tecidos. }\end{array}$ & $\begin{array}{c}\text { Diminuição } \\
\text { da agilidade, } \\
\text { coordenação } \\
\text { e do } \\
\text { equilíbrio. } \\
\text { Diminuição } \\
\text { da } \\
\text { flexibilidade } \\
\text { e mobilidade } \\
\text { articular. } \\
\text { Aumento da } \\
\text { rigidez da } \\
\text { cartilagem, } \\
\text { dos tendões } \\
\text { e dos } \\
\text { ligamentos. }\end{array}$ \\
\hline
\end{tabular}


Em geral, o homem é um animal homeotérmico, ou seja, capaz de manter a temperatura corporal interna constante, independentemente das variações de temperatura do meio externo. Neste sentido, os seres humanos desenvolveram um sistema de termorregulação (permitindo manter o calor interno do corpo entre $36,5^{\circ} \mathrm{C}$ e $37,5^{\circ} \mathrm{C}$ ). Este sistema mantém o equilíbrio térmico do corpo pela produção de calor como um subproduto dos processos metabólicos (termogênese) ou pela perda de calor para o ambiente (termólise). Dessa forma, quando o calor do ambiente excede a taxa de dissipação do corpo - a sensação produzida é de calor —, o sistema termorregulador trabalha para que ocorra perda de calor; nesse caso, é acionado o sistema de resfriamento do corpo, como por exemplo, o suor. No caso que a taxa de dissipação exceda o calor do ambiente — sensação de frio —, o sistema termorregulador trabalha para que haja manutenção do calor interno do organismo e, então, é acionado o sistema de produção de calor, como por exemplo, o calafrio. Em ambas as situações, a sensação é de desconforto (Moran, 1994; Frota e Schiffer, 2001).

No entanto, as pessoas idosas apresentam mudanças na sua termorregulação corporal. Estas mudanças estão associadas ao fato de que a resposta termorregulatória a uma determinada condição térmica é iniciada pelos sinais emitidos ao cérebro por termosensores presentes no corpo; mas com o passar dos anos verifica-se uma redução na percepção térmica, ocasionada especialmente pelo envelhecimento da pele e consequente redução na densidade dos termorreceptores e do fluxo sanguíneo (Blatteis, 2011).

A eficiência da termorregulação e a capacidade de resistir à exposição ao frio e a tolerância ao calor ficam reduzidas com a idade (Sugarek et al., 1986; Inoue et al., 1992; Goldman et al., 1978; Belding et al., 1970). No caso do frio os principais instrumentos de manutenção da temperatura corporal (vasoconstrição e tremores) são menos eficientes no idoso com respeito às pessoas mais jovens (Khan et al., 1992).

Por outra parte, durante a exposição ao calor, o fenômeno de sudação é mais tardio, bem como o tempo de recuperação necessário para alcançar a temperatura normal, sendo as pessoas idosas as que reagem ao calor com um maior fluxo de sangue periférico, mas a sua capacidade máxima é inferior e, por isto, elas podem alcançar o golpe de calor mais cedo (Davies, 1979). 
Neste sentido, é comum observar na literatura pesquisas que estabelecem relação entre a mortalidade de idosos e as variáveis meteorológicas, considerando apenas os registros de óbitos ligados às doenças cardiovasculares (DCV) ou respiratórias (RES). Devido à exposição ao frio que pode aumentar a suscetibilidade a infecções pulmonares (Schaanning et al., 1986) e casos de gripe, além de aumentar o estresse sobre o sistema cardiovascular por mudanças na pressão sanguínea e vasoconstrição. Por outro lado, a exposição ao calor pode aumentar o estresse sobre o sistema termorregulatório (Alberdi et al., 1998). Por exemplo, Kunst et al. (1993) mencionam que altas temperaturas tendem a aumentar a viscosidade do sangue, fator biológico que é relacionado ao incremento no risco de eventos cardiovasculares junto à pouca ingestão de líquidos, como doença cardíaca isquêmica e acidente vascular cerebral (Lowe et al., 1997).

Outro aspecto relevante que gera ainda mais importância aos estudos e análises das influências climáticas nesta faixa etária é que globalmente existe um fenômeno conhecido como envelhecimento populacional. O aumento da população idosa está crescendo a uma taxa de 3,26 \% por ano. Somente no ano 2015, o número aproximado de pessoas com 60 anos ou mais foi de 901 milhões, compreendendo $12 \%$ da população global. Estimativas das Nações Unidas (United Nations, 2015) preveem que até 2050, com a exceção da África, os demais continentes do mundo terão quase um quarto ou mais de suas populações acima de 60 anos. O número de pessoas idosas no mundo deverá ser de 1,4 bilhão em 2030 e de 2,1 bilhões em 2050 e pode ascender a 3,2 bilhões em 2100 .

Não restam dúvidas de que as alterações do clima irão impactar de alguma forma nas partes vulneráveis da população, principalmente nas megacidades. Isto pode levar ao aumento ou diminuição da mortalidade por DCV ou RES, associadas com as influências ambientais (variáveis meteorológicas e de poluição) devido ao calor e ao frio, pronunciados nas regiões subtropicais e extratropicais de forma majoritária durante os verões e invernos, respectivamente. Nesse sentido, é importante fazer uma análise sobre essas influências em diferentes regiões e megacidades com intuito de tomarem-se medidas de mitigação ou adaptação para futuros cenários climáticos.

Segundo a Organização das Nações Unidas (ONU), as megacidades são aquelas que abrigam elevada densidade populacional, com mais de 10 milhões de habitantes. As maiorias das megacidades fazem parte de países emergentes ou subdesenvolvidos, onde 
seu crescimento pode ocorrer de forma descontrolada e sem planejamento, o que leva a diversos problemas sociais e urbanos, entre eles destaca a poluição atmosférica. Devido à continuidade das emissões antropogênicas de gases de efeito estufa principalmente dióxido de carbono $\left(\mathrm{CO}_{2}\right)$, metano $\left(\mathrm{CH}_{4}\right)$ e óxido nitroso $\left(\mathrm{N}_{2} \mathrm{O}\right)$, prevê-se nas camadas inferiores da atmosfera terrestre um incremento da temperatura em mais de $4^{\circ} \mathrm{C}$ para finais do século XXI. Se nada for feito para alterar essa trajetória climática, os seres humanos serão confrontados por um amplo espectro de desafios ambientais radicais e poderão provocar uma série de impactos que deixarão vulneráveis milhões de pessoas, especialmente as crianças e os idosos, sendo os maiores afetados durante períodos de estresse ambiental severo, causando um grande número de óbitos.

Entre as principais megacidades do mundo, destaca a região metropolitana de São Paulo (RMSP), Brasil, com uma população de aproximadamente 21,3 milhões de habitantes (estimativa IBGE, 2017) com uma densidade populacional de $2691,84 \mathrm{hab} . / \mathrm{km}^{2}$. Também sobressai o condado de Los Angeles na Califórnia, Estados Unidos de América (EUA), com uma densidade populacional perto de mil hab./km². Tal como em outras regiões do planeta, estas cidades deverão enfrentar uma série de desafios relacionados às mudanças climáticas globais. Os efeitos à saúde da população devido à exposição aos fatores ambientais são diversos, exibindo diferentes níveis de intensidade e manifestando-se com tempos diferenciados de latência: efeitos comportamentais e cognitivos, inflamação pulmonar e sistêmica, alterações das vias aéreas, do tônus vascular e do controle do ritmo cardíaco, alterações reprodutivas, morbidade e mortalidade por doenças cardiorrespiratórias e aumento da incidência de neoplasias (Souza e Macedo, 2010).

\subsection{Influências climáticas na mortalidade de idosos}

Diante deste contexto, a bibliografia dos impactos das variáveis meteorológicas na mortalidade de idosos é bastante vasta. A seguir são apresentados alguns dos trabalhos importantes.

Braun (2003) utilizou análises de componentes principais para estabelecer as influências meteorotrópicas nas DCV na cidade de São Paulo. Verificou-se uma variação sazonal significativa da mortalidade por DCV, com evidente aumento do número de óbitos durante o inverno e queda durante o verão. Outra conclusão importante foi que as condições térmicas relacionadas ao frio são responsáveis, segundo o índice de conforto 
'Temperatura Efetiva'(TE) por 45,29\% dos óbitos, enquanto que os relacionados ao calor são responsáveis por $23,88 \%$ dos óbitos.

Por sua vez, Batista (2017) analisou o risco de mortalidade por DCV e RES na população idosa na RMSP e sua projeção a partir de simulações do modelo climático regional considerando um cenário pessimista de emissões de gases de efeito estufa. Os resultados mostraram que maior parte da mortalidade de idosos por doenças RES e DCV, de 1996 a 2014, é registrada nos dias quentes e úmidos ou frios e secos. As projeções do modelo climático indicaram que no futuro haverá um aumento dramático no número de dias enquadrados na zona de risco quente (aproximadamente 150), em detrimento da zona de risco frio, que praticamente deixa de ser verificada. Foram identificados 42 eventos com característica térmica similar à onda de calor de 2014, nos dados de 2065-2099, indicando que no futuro, eventos desse tipo podem ocorrer com maior frequência na RMSP, aumentando de forma significativa a mortalidade de idosos locais.

Larsen (1990) avaliou a influência das flutuações mensais da temperatura na mortalidade, em seis estados dos EUA (Massachusetts, Michigan, Washington, Utah, Carolina do Norte e Mississippi) de 1921 a 1985, utilizando um modelo de defasagem. $\mathrm{O}$ autor mostrou que temperaturas acima do normal no verão e abaixo do normal no inverno estavam associadas ao aumento da mortalidade. Por exemplo, uma queda da temperatura de um grau na temperatura média em 1921 está associada a um aumento de mais de 3,5\% na taxa de mortalidade de fevereiro em Mississippi e Carolina do Norte e um aumento de menos de $1 \%$ nos quatro outros estados examinados.

Zanobetti et al. (2012) propôs que a variabilidade da temperatura (desvio padrão) durante o verão poderia ter relação com a sobrevivência de idosos internados em hospitais, em 135 cidades americanas, onde incluem os condados de Los Angeles e Orange. Os autores construíram coortes de pessoas hospitalizadas com doença crônica pulmonar, diabetes, insuficiência cardíaca congestiva e infarto do miocárdio, utilizando os dados de 1985 a 2006 do Medicare (um programa governamental de saúde americano que cobre a hospitalização de pessoas com idade maior ou igual aos 65 anos). De modo geral, os resultados demonstram que o aumento no desvio padrão de $1^{\circ} \mathrm{C}$ aumentaria a causa de mortalidade em 5\%, associado a um menor tempo de sobrevivência de idosos, especialmente com idade superior a 75 anos. 
Green et al. (2009) examinaram a associação entre a temperatura aparente diária média e as internações hospitalares de várias doenças (incluindo doenças RES e DCV) em nove condados da Califórnia de maio a setembro entre 1999 - 2005. Seus resultados indicam que um aumento na temperatura aparente media de $10^{\circ} \mathrm{F}$ têm importantes impactos na saúde pública sobre a morbidade, ou seja, esta associada a um aumento de 3,5\% [95\% de intervalo de confiança 1,5-5,6] no AVC isquêmico, aumentando em vários resultados específicos de doenças, incluindo todas as doenças RES (2,0\%, intervalo de confiança $95 \%$ 0,7-3,2), pneumonia $(3,7 \%$, intervalo de confiança $95 \%$ 1,7$3,7)$.

Hoshiko et al. (2010) estimaram o excesso de mortalidade devido às ondas de calor da Califórnia de 2006 nos meses de junho - agosto. Foram verificadas 655 mortes em excesso por todas as causas, com um aumento de $6 \%$ (intervalo de confiança de $95 \%$, 3-9\%), impactando diversas regiões geográficas.

Os trabalhos acima verificam que é muito difícil expressar respostas humanas para o ambiente térmico, dependendo de um único fator ambiental (temperatura, umidade relativa ou a velocidade do ar, por exemplo), na realidade, afetam o corpo em forma simultaneamente, e a influência de uma depende dos níveis dos outros. Também não é possível analisar todos os fatores que afetam as respostas fisiológicas e sensoriais humanas. A intenção de representar esses efeitos conjuntos em uma única variável levou a criação dos índices de conforto térmico, abordados a seguir.

\section{3. Índices de conforto térmico ou biometeorológicos}

Os índices são modelos biometeorológicos os quais descrevem, a partir de observações experimentais ou empíricas, como o ambiente atmosférico atua sobre o organismo humano. Estes índices, que podem ser expressos em termos meteorológicos ou fisiológicos, têm ampla aplicação na arquitetura, onde, desde o século passado foram desenvolvidos centenas de índices, como o Índice de Desconforto (ID) (Thom, 1959), a Temperatura Aparente (TA) de Steadman (1979), o Índice Windchill (H) de Siple e Passel (1945), o Voto Previsto Médio (do inglês Predicted Mean Vote - PMV) de Fanger (1970); a TE de Giles et al. (1990), o atual índice adaptativo de Humphreys e Nicol (1998), que considera a capacidade adaptativa de uma determinada população em 
relação às alterações do clima. Uma revisão bastante completa sobre esses e outros índices foi apresentadas por Gobo (2018).

Também na medicina estes índices foram muito utilizados (Tromp, 1963a, 1963b, 1964; Munn, 1970; Jendritzky, 1977; Jendritzky e al., 1979) assim como na avaliação dos bioclimas regionais (Brazol, 1954; Wilson, 1963; Oyarzun, 1978; Hajek 1981; Hajek e Rubio, 1982). Em geral a bibliografia é bastante vasta, a seguir destacam-se alguns trabalhos importantes com enfoque em diversas partes do mundo, incluindo na Califórnia.

Maia (2002) analisou cinco índices biometeorológicos para São Paulo, e encontrou que os índices ID, TE e o índice temperatura efetiva em função do vento $\left(\mathrm{TE}_{\mathrm{v}}\right)$ representam satisfatoriamente o clima desta cidade. A partir de uma classificação bioclimática, feita com base ao índice TEv, foi observado que os meses de janeiro, fevereiro, março e dezembro são mais estressantes devido ao calor e os meses de maio a outubro são mais estressantes devido ao frio.

Coronato (1993) utilizando a fórmula do Windchill proposta por Siple e Pasel observou sobre a Patagônia uma queda da temperatura anual média de $4,2^{\circ} \mathrm{C}$. Devido às velocidades do vento maiores durante o verão, o efeito de resfriamento do vento, somando ambas variáveis, é maior na estação, com uma queda aparente na sensação de temperatura. Alguns anos mais tarde, em 1995, Coronato encontrou uma queda considerável na temperatura, mesmo sob condições térmicas favoráveis devido ao vento sobre a Patagônia.

Kalkstein e Valimont (1986) avaliaram o desconforto de verão sobre os EUA, usando o índice de estresse do tempo. Este índice tem por objetivo avaliar a frequência e magnitude das mais desconfortáveis condições de tempo, e dados de entrada são a temperatura do ar, do ponto de orvalho e a velocidade do vento. Os resultados indicam que a região central e centro-sul dos EUA experimentam os maiores valores de estresse com relação ao calor. Esta condição ocorre quando o fluxo de superfície desloca ar marinho, enquanto que em $500 \mathrm{hPa}$ uma crista intensifica a subsidência atmosférica no centro dos EUA. A combinação destes dois eventos quase nunca ocorre no deserto sudoeste e, por isso, os valores de estresse não alcançam os níveis encontrados na região central dos EUA. 
Smoyer (1998) realizou uma análise das ondas de calor em St. Louis, Missouri, nos anos 1980 e 1995, em associação com a mortalidade, para pessoas com mais de 64 anos. Neste trabalho as ondas de calor foram definidas nos dias onde a temperatura aparente excedeu os $40,6^{\circ} \mathrm{C}$. Os resultados mostraram que a onda de calor de 1980 foi mais severa e teve maior associação com a mortalidade do que a onda de calor de 1995.

Lee (2015) mostrou que a variabilidade do dia-a-dia nas DCV está correlacionada com várias variáveis meteorológicas diferentes, que podem variar geograficamente. $\mathrm{O}$ artigo examina a relação entre a mortalidade por DCV em inverno e os tipos de clima para diferentes regiões climáticas dos EUA. Seus resultados indicam que, para todos os locais examinados, durante o inverno, um clima seco e frio está significativamente relacionado ao aumento da mortalidade por DCV. Em contraste, o clima úmido e quente exibiu uma relação significativa e oposta à do frio e do seco. Esse resultado pode estar relacionado às diferenças climáticas entre as regiões.

Na Califórnia, destaca-se, o trabalho de Guo et al. (2011), que mostraram como apenas a queda da temperatura em mais de $3^{\circ} \mathrm{C}$ em Los Angeles, esteve significativamente associada à mortalidade cardiovascular. Outro exemplo, está discutido em Basu et al. (2008) que examinaram a associação entre a temperatura aparente diária média e a mortalidade não acidental em 9 condados em toda a Califórnia de maio a setembro de 1999-2003, onde um aumento de $10^{\circ} \mathrm{F}$ na média da temperatura aparente diária pode contribuir num aumento de $2,3 \%$ na mortalidade.

Por outro lado, estudos na literatura também sugerem que exista uma associação entre poluição atmosférica com problemas na saúde humana, uma vez que a exposição a ela ocorre simultaneamente à da temperatura. Níveis elevados nas concentrações de poluentes contribuem para o aumento da mortalidade e morbidade, principalmente por doenças RES e DCV. Mais detalhes são abordados nos seguintes itens.

\subsection{Poluição atmosférica}

Os poluentes atmosféricos constituem gases e partículas sólidas (poeiras, pós e fumos) resultantes das atividades humanas e de fenômenos naturais, dispersos no ar atmosférico. Desta forma, classificam-se nessa categoria, os gases e partículas expelidos por veículos e indústrias e também aqueles oriundos da degradação da matéria orgânica, vulcanismos e outros fenômenos naturais. Incluem-se nesta lista as substâncias 
formadas pela reação de certos poluentes com a radiação advinda do sol. Pela sua concentração possa tornar-se impróprio, nocivo ou ofensivo à saúde humana, inconveniente ao bem-estar público, danoso aos materiais, à fauna e a flora.

A tabela 1.2 apresenta um quadro geral dos principais poluentes atmosféricos encontrados nos grandes centros urbanos, suas fontes e seus efeitos adversos sobre a saúde humana.

Tabela 1.2 - Fontes poluidoras e efeitos dos principais poluentes atmosféricos sobre a saúde humana (Adaptada de Braun, 2003).

\begin{tabular}{|c|c|c|}
\hline POLUENTE & FONTES PRINCIPAIS & $\begin{array}{l}\text { EFEITOS SOBRE A SAÚDE } \\
\text { HUMANA }\end{array}$ \\
\hline $\begin{array}{c}\text { Dióxido de } \\
\text { Enxofre }\left(\mathrm{SO}_{2}\right)\end{array}$ & $\begin{array}{l}\text { Processos que utilizam queima } \\
\text { de óleo combustível, refinaria } \\
\text { de petróleo, veículos a diesel. }\end{array}$ & $\begin{array}{l}\text { Desconforto na respiração, doenças } \\
\text { RES, agravamento de doenças RES e } \\
\text { DCV já existentes. Pessoas com asma, } \\
\text { doenças crônicas de coração e pulmão } \\
\text { são mais sensíveis ao } \mathrm{SO}_{2} \text {. } \\
\text { Especialmente em idosos, aumenta o } \\
\text { risco de pneumonia e gripe (Martins et } \\
\text { al., 2002). }\end{array}$ \\
\hline $\begin{array}{c}\text { Dióxido de } \\
\text { nitrogênio }\left(\mathrm{NO}_{2}\right)\end{array}$ & $\begin{array}{c}\text { Processo de combustão } \\
\text { envolvendo veículos } \\
\text { automotores, processos } \\
\text { industriais, usinas térmicas que } \\
\text { utilizam óleo ou gás, } \\
\text { incinerações. } \\
\end{array}$ & $\begin{array}{l}\text { Aumento dos problemas respiratórios } \\
\text { reduz a resistência às infecções } \\
\text { respiratórias, maior sensibilidade à asma } \\
\text { e à bronquite, (Coelho, 2007). }\end{array}$ \\
\hline $\begin{array}{l}\text { Monóxido de } \\
\text { Carbono (CO) }\end{array}$ & $\begin{array}{l}\text { Combustão incompleta em } \\
\text { veículos automotores. }\end{array}$ & $\begin{array}{l}\text { Inibe a troca de oxigênio do sangue com } \\
\text { os tecidos vitais e, em concentrações } \\
\text { elevadas, pode provocar a morte por } \\
\text { envenenamento, afetando } \\
\text { principalmente o sistema cardiovascular } \\
\text { e nervoso, (Coelho, 2007). }\end{array}$ \\
\hline Ozônio $\left(\mathbf{O}_{3}\right)$ & $\begin{array}{l}\text { Não é emitido diretamente à } \\
\text { atmosfera. É produzido } \\
\text { fotoquimicamente pela } \\
\text { radiação solar sobre os óxidos } \\
\text { de nitrogênio e compostos } \\
\text { orgânicos voláteis (evaporam } \\
\text { com facilidade). }\end{array}$ & $\begin{array}{l}\text { Irritação nos olhos e vias respiratórias, } \\
\text { diminuição da capacidade pulmonar. } \\
\text { Exposição a altas concentrações pode } \\
\text { resultar em sensações de aperto no peito, } \\
\text { tosse e chiado na respiração. }\end{array}$ \\
\hline
\end{tabular}

\subsubsection{Padrões de qualidade do ar}

Quando se determina a concentração de um poluente na atmosfera, mede-se o grau e exposição dos receptores (seres humanos, animais, plantas, materiais) como resultado do processo de lançamento deste poluente na atmosfera por suas fontes de emissão e 
suas interações na atmosfera, do ponto de vista físico (diluição (diminuição da concentração)) e químico (reações químicas).

É importante frisar que, mesmo mantidas as emissões, a qualidade do ar pode mudar em função das condições meteorológicas que determinam uma maior ou menor diluição dos poluentes. É por isso que a qualidade do ar piora com relação aos parâmetros $\mathrm{CO}$ e $\mathrm{SO}_{2}$ durante os meses de inverno, quando as condições meteorológicas são mais desfavoráveis à dispersão dos poluentes, mesmo em climas diversos como no sul da Califórnia e a Grande São Paulo. A interação entre as fontes de poluição e a atmosfera vai definir o nível de qualidade do ar, que determina por sua vez o surgimento de efeitos adversos da poluição sobre os receptores.

Um padrão de qualidade do ar define legalmente o limite máximo para a concentração de um componente atmosférico que garanta a proteção da saúde e do bem-estar das pessoas. Os padrões de qualidade do ar estão baseados em estudos científicos dos efeitos produzidos por poluentes específicos e são fixados em níveis que possam propiciar uma margem de segurança adequada.

Na tabela 1.3 são apresentados os padrões nacionais de qualidade do ar adotados na Califórnia, assim como o tempo de amostragem e o método de medição para os poluentes regulamentados considerados neste trabalho.

Tabela 1.3 - Padrões nacionais de qualidade do ar, tempo de amostragem e método de medição para os poluentes utilizados na Califórnia (Fonte: ARB, 2011).

\begin{tabular}{cccc}
\hline POLUENTE & $\begin{array}{c}\text { TEMPO DE } \\
\text { AMOSTRAGEM }\end{array}$ & Padrão & MÉTODO DE MEDIÇÃo \\
\hline $\mathbf{S O}_{2}$ & $24 \mathrm{~h}$ & $0,04 \mathrm{ppm}$ & Pararosanilina \\
$\mathbf{N O}_{2}$ & $1 \mathrm{~h}$ & $0,18 \mathrm{ppm}$ & Quimiluminescência \\
$\mathbf{C O}$ & $1 \mathrm{~h}$ & $20 \mathrm{ppm}$ & Infravermelho não dispersivo \\
$\mathbf{O}_{3}$ & $1 \mathrm{~h}$ & $0,09 \mathrm{pm}$ & Quimiluminescência \\
\hline
\end{tabular}

No entanto, mesmo quando os poluentes se encontram abaixo dos níveis determinados pela legislação, estes são capazes de provocar efeitos na saúde das pessoas (Laden et al., 2006; Krewski et al., 2009; Jerrett et al., 2013); principalmente para as crianças e os idosos. Pessoas que já sofrem de problemas respiratórios também se tornam mais 
suscetíveis a sofrer com a elevação nos níveis de poluentes atmosféricos (Martins et al., 2001; Silva et al., 2013). A situação piora em situações de frios e ondas de calor. Tal relevância é evidenciada pelos trabalhos citados nos próximos parágrafos.

\subsubsection{Efeitos meteorotrópicos e de poluição do ar em doenças.}

Entenda-se por efeitos meteoro-trópicos aqueles que ocorrerem de forma sincrônica em um grande território, sob a influência das mesmas condições de tempo e afetar significativamente a população local (Revista de Saúde Meio Ambiente e Sustentabilidade, 2011). De acordo com a sociedade, os efeitos ambientais são considerados meteoro-trópicos quando uma ou mais variáveis ambientais (meteorológicas ou climáticas, incluso poluição do ar) afetam um ou mais indivíduos de uma população.

Os efeitos meteoro-trópicos específicos do clima sobre a saúde humana ocorrem em uma sequência de ações inter-relacionadas (chuvas torrenciais, inundações, contaminação das águas que resultam em surtos de doenças diarreicas e aumento de populações de vírus e vetores) as quais contibuiem a um aumento de doenças transmissíveis (Lecha, 2009).

Sanhueza et al. (1999) analisaram o efeito da exposição ao ar poluído na mortalidade por DCV e RES para pessoas com mais de 65 anos, em Santiago, no Chile, de 1988 a 1993. O trabalho mostrou uma associação significativa entre a mortalidade e as variáveis meteorológicas e poluentes (principalmente para o $\mathrm{PM}_{10}$ e o $\mathrm{SO}_{2}$ ) do dia e dias anteriores.

Gouveia et al. (2006) identificaram na cidade de São Paulo associação de material particulado inalável ao incremento de 4,6\% nas internações por asma em crianças, de $4,3 \%$ por doença pulmonar obstrutiva crônica em idosos e de 1,5\% por doença isquêmica do coração também em idosos.

Pinheiro et al. (2014) analisaram o efeito da poluição atmosférica e da temperatura nos casos de mortalidade por DCV e RES, em São Paulo, entre 1998 e 2008. Os resultados das pesquisas demonstraram que um aumento de $10 \mu \mathrm{g} / \mathrm{m} 3$ na concentração do material particulado possui um risco relativo de $0,85 \%$ para DCV e $1,60 \%(0,74 ; 2,46)$ para doenças RES. 
Gurjat et al. (2010) avaliaram os riscos para a saúde em megacidades em termos de mortalidade e morbidade devido à poluição do ar para Los Angeles, Nova York, Osaka, Kobe, São Paulo, Tóquio, Daca, Pequim, Carachi, Cairo e Deli.

Carey et al. (2013) encontraram associações da mortalidade com exposição prolongada à poluição atmosférica na Inglaterra durante 2003-2007, os resultados reforçaram que as associações mais fortes foram com a mortalidade por doenças RES não sendo consistente com a maioria dos estudos norte-americanos em que as associações com causas cardiovasculares de morte tendem a predominar.

Nos EUA, Shumway et al. (1988) estudaram os impactos dos poluentes atmosféricos para Los Angeles e mais recentemente Jerrett et al. (2009) demonstraram um aumento significativo no risco de morte por causas respiratórias em associação com o aumento da concentração de ozônio, também Fuentes et al. (2010) fizeram uma análise do impacto no ozônio para as cidades do sudeste de EUA.

Schwartz (2000) estudou a correlação entre as mortes diárias em Filadélfia e as concentrações de partículas de $\mathrm{SO}_{2}$ no ar, durante os anos 1974-1988. Seus resultados mostram que não houve associação significativa entre $\mathrm{o} \mathrm{SO}_{2} \mathrm{e}$ as mortes diárias. Embora, nos períodos em que a matéria particulada estava menos correlacionada com $\mathrm{SO}_{2}$, sua associação com óbitos diários foi maior.

Por sua vez Jerrett et al. (2013) avaliaram a associação entre poluição do ar (partículas finas $\left(\mathrm{PM}_{2,5}\right), \mathrm{O}_{3}$ e $\left.\mathrm{NO}_{2}\right)$ e várias causas de morte, incluindo $\mathrm{DCV}$, doença cardíaca isquêmica, acidente vascular cerebral, doenças RES e câncer de pulmão, em um grande grupo de adultos na Califórnia usando análises de exposição individualizados. Os resultados mostraram associações positivas de material particulado fino, $\mathrm{O}_{3}$ e $\mathrm{NO}_{2}$ com a mortalidade. Por outro lado, as associações positivas de $\mathrm{NO}_{2}$ sugerirem também que a poluição veicular está relacionada com a morte prematura, embora existam outras contribuições como as fontes industriais ou aquecimento, em particular devido às concentrações geralmente maiores de $\mathrm{NO}_{2}$ durante o inverno quando o aquecimento doméstico contribui para a emissão de precursores de $\mathrm{NO}_{2}$ (Spengler et al., 1994).

Também a cidade de Los Angeles, no contexto das ondas de calor ocorridas de 1975 a 2005 é foco de um estudo em andamento por parte de Gonçalves e colaboradores. Os resultados, até então preliminares, apontam que apesar de possuir um caráter secundário 
o ozônio age no sentido de elevar o risco de mortalidade por doenças RES ocorridas durante um evento de onda de calor.

No entanto, na literatura existem poucos trabalhos que enfatizem os impactos na saúde da população, com vistas à mortalidade na população idosa, a partir das associações entre os poluentes do ar e as variáveis meteorológicas que incidem no conforto térmico humano, e que dizem respeito à mudança real do tempo e do clima na Califórnia, principalmente nos condados de Orange, Santa Bárbara e Los Angeles.

\subsection{Caracterização do problema e justificativa}

A população idosa tem aumentado consideravelmente em todo o mundo. Somente no ano de 2015, o número aproximado de pessoas com 60 anos ou mais foi de 901 milhões, compreendendo $12 \%$ da população global. Estimativas das Nações Unidas (United Nations, 2015) preveem que o número de pessoas idosas no mundo deverá ser de 1,4 bilhão em 2030 e de 2,1 bilhões em 2050 e pode ascender a 3,2 bilhões em 2100 .

De acordo com o Bureau de Censo dos Estados Unidos (US Census Bureau) em 2016, 15,2 \% da população dos EUA, o que equivale a 49,2 milhões de pessoas, já tinha completado 65 anos, enquanto no ano 2000 a percentagem era de 12,4\%, ou cerca de 35 milhões de pessoas. Por sua vez na Califórnia, a população idosa está crescendo mais de duas vezes mais rápido que a população total do estado e esse crescimento variarão de acordo com a região. Por exemplo, o aumento percentual para os idosos de 1990 a 2020 nos condados de Santa Bárbara e Los Angeles é de 50-99,9\%, entretanto para o condado de Orange é de 100-149\%.

Por outro lado, os idosos constituem uns dos grupos mais vulneráveis aos efeitos adversos das mudanças climáticas. Devido a serem fisiologicamente, financeiramente e emocionalmente menos capazes de se adaptar em curto prazo com variações ambientais que excedem suas capacidades de regulação. Neste sentido, o desenvolvimento de pesquisas relacionadas com as influências do clima na saúde desta faixa etária, tem despertado a atenção da comunidade acadêmica, principalmente em regiões como a Santa Bárbara e Orange na Califórnia, onde pouco se conhece ou se sabe dessas interações ambientais (variáveis de poluição do ar e meteorológicas) e seus efeitos na mortalidade. 


\subsection{Objetivos}

Este trabalho forma parte de um projeto multidisciplinar, que enfatiza os impactos na saúde da população, com vistas à mortalidade, associadas com as variáveis meteorológicas e poluentes do ar que incidem no conforto térmico humano, e que dizem respeito à mudança real do tempo e do clima em alguns condados da Califórnia: Santa Bárbara, Orange e Los Angeles.

O objetivo principal desta pesquisa é avaliar a influência das variáveis ambientais na mortalidade por DCV e RES nos condados da Califórnia: Santa Bárbara, Orange e Los Angeles, utilizando o emprego da modelagem estatística através da análise de coeficientes multivariada.

Com o fim de mostrar aparição das doenças RES e DCV em função dos poluentes do ar, variáveis meteorológicas e índices de conforto térmico (tais como temperaturas efetivas), tem-se como objetivos específicos: Analisar o efeito dos índices de conforto térmico, das variáveis meteorológicas e níveis de poluição atmosférica sobre a mortalidade por DCV e RES em pessoas com mais de 65 anos, utilizando ferramentas estatísticas (Análise de correlação e Análise de componentes principais). 


\section{CAPÍTULO 2 - DADOS E METODOLOGIA}

Este capítulo é dividido em 4 partes: em 2.1 é apresentada uma caracterição climática do Estado da Califórnia, com enfase nos condados Los Angeles, Orange e Santa Barbara. Em 2.2 são abordadas as características da população idosa na Califórnia. Já em 2.3 é dada uma descrição dos dados utilizados, relativos à mortalidade, variáveis meteorológicas e de poluição atmosférica; logo em 2.4 são feitas as considerações sobre dos métodos e análises usados; e por último em 2.5 são apresentadas as equações para cálculo dos índices de conforto térmico utilizados.

\subsection{Características climáticas da Califórnia}

O estado da Califórnia, localizado na região do Pacífico dos EUA, constitui o terceiro mais extenso por área depois do Alasca e do Texas, sendo o estado mais populoso do país com 39,5 milhões de habitantes de acordo com o US Census Bureau. Dada a sua grande extensão e sua diversidade geográfica, a Califórnia é caracterizada por uma grande variedade de climas. Diferentes regiões possuem diferentes condições climáticas, e isto varia de acordo com a latitude, distância em relação ao oceano, altitude e presença de obstáculos geográficos (como serras e cadeias de montanhas).

A temperatura média da Califórnia no verão é de $25^{\circ} \mathrm{C}$. As menores temperaturas médias são registradas nas regiões de maior altitude, no nordeste e ao longo do litoral. Nestas regiões, a temperatura média é inferior a $20^{\circ} \mathrm{C}$. Estas regiões possuem mínimas variando entre $6^{\circ} \mathrm{C}$ e $18^{\circ} \mathrm{C}$, e máximas variando entre $20^{\circ} \mathrm{C}$ e $34^{\circ} \mathrm{C}$. Já o leste e particularmente o sudeste possuem altas temperaturas médias no verão com valores superiores aos $33^{\circ} \mathrm{C}$. Nestas regiões semidesérticas as mínimas podem chegar até $2^{\circ} \mathrm{C}$, e as máximas podem atingir os $50^{\circ} \mathrm{C}$ (LaDochy et al 2007)..

No entanto, a maior parte do estado possui um clima temperado mediterrâneo, com apenas duas estações bem definidas, com invernos chuvosos e verões secos especialmente no Sul e ao longo do litoral. A proximidade do Oceano Pacífico torna os verões mais frios e os invernos mais amenos. Por sua vez, no interior do Estado caracteriza-se por ter verões muito quentes e invernos frios (McADie, 1902; Gershunov e Guirguis, 2012).. 
Um dos eventos mais importantes que afetam a Califórnia são os ventos Santa Ana, sendo este um tipo de vento föhn. Estes ventos são quentes e fortes que sopram das montanhas do leste e desertos para a costa sul da Califórnia, geralmente na primavera e no outono. Eles são o resultado do aumento de pressão formado em elevadas altitudes da Grande Bacia entre a Serra Nevada e as Montanhas Rochosas. À medida que o ar flui das montanhas mais elevadas até o nível do mar, devido à compressão adiabática, ele aquece e a umidade cai para menos de $15 \%$ ou até $10 \%$, geralmente é mais quente ao longo da costa do que nos desertos (Westerling et al. 2011). Como os ventos de Santa Ana são canalizados através das passagens de montanha, eles podem se aproximar da força do furacão. Esta combinação de velocidade, calor, secura e a vegetação seca, formada por arbustos pequenos, atuam como um combustível na formação e propagação de incêndios florestais.

Na figura 2.1, destaca-se que os três condados de interesse (Los Angeles, Orange e Santa Barbara), se encontram ao longo do litoral sul do estado da Califórnia e apresentam características climáticas muito similares, tendo um clima com invernos amenos e úmidos e verões secos e quentes.

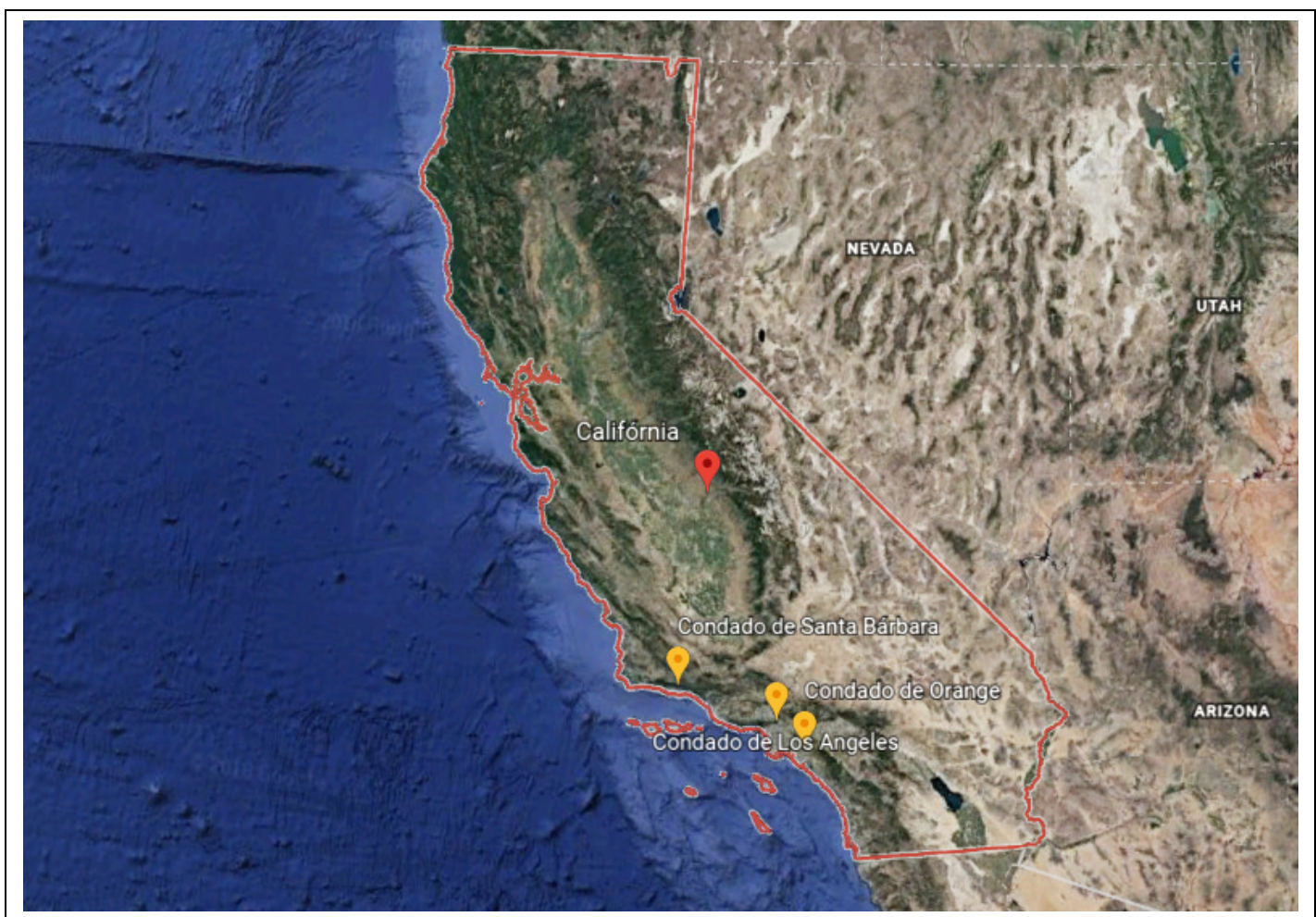

Figura 2.1. Posição geográfica do estado da Califórnia. Em amarelo são indicados os condados de Los Angeles, Santa Bárbara e Orange. 


\subsubsection{Condado de Los Angeles}

De acordo com o US Census Bureau, o Condado tem uma área total de $12307.6 \mathrm{~km}^{2}$, dos quais 10517,9 km² são terrestres e 1789,7 km² (14.55\%) são de água. A população no ano 2015 era de 10.17 milhões sendo a cidade de Los Angeles a mais populosa com aproximadamente 3,5 milhões.

O condado possui um clima bastante agradável, em comparação a outras grandes cidades americanas. A temperatura média no inverno é de $13^{\circ} \mathrm{C}$, registrando a média da temperatura mínima em $9^{\circ} \mathrm{C}$, e as médias das máximas nos $20^{\circ} \mathrm{C}$. Entretanto a temperatura média no verão é de $23^{\circ} \mathrm{C}$, com as médias das temperaturas mínimas entre $16^{\circ} \mathrm{C}$ e $18^{\circ} \mathrm{C}$, e máximas entre $26^{\circ} \mathrm{C}$ e $29^{\circ} \mathrm{C}$.

As maiores temperaturas sempre são registradas nos meses de agosto e setembro $\left(35^{\circ} \mathrm{C}\right.$ e $37^{\circ} \mathrm{C}$ respectivamente), principalmente em presença de vento Santa Ana, onde a umidade relativa do ar chega a ficar abaixo dos $10 \%$, como supracitado, por vários dias e as temperaturas alcançam valores de até $37^{\circ} \mathrm{C}$ na cidade de Los Angeles e a mais de $41^{\circ} \mathrm{C}$ nas cidades mais ao interior do estado, como Riverside e San Bernardino.

A precipitação cai na maioria das vezes em forma de chuva, embora no inverno algumas vezes cai em forma de neve nas montanhas próximas à cidade. Porém, a maior parte da neve acaba derretendo rapidamente na atmosfera ou no solo. A taxa de precipitação média anual na cidade é de 379,2 mm, sendo a maioria nos meses de inverno com uma média mensal de $78,3 \mathrm{~mm}$ e no verão só tem uma taxa média de $1,7 \mathrm{~mm}$ de chuva. (Disponíveis no site da Administração Oceânica e Atmosférica dos EUA (NOAA)).

\subsubsection{Condado de Orange}

O Condado tem uma área total de $2460 \mathrm{~km}^{2}$, dos quais $2050 \mathrm{~km}^{2}$ são terrestres e 410 $\mathrm{km}^{2}$ são de água. Por sua área constitui o menor condado do sul da Califórnia, além disso, tem uma população de 3,17 milhões tornando-se o terceiro município mais populoso da Califórnia. O clima de Orange apresenta um comportamento muito similar ao clima de Los Angeles, com temperaturas que geralmente variam nas médias mínimas e máximas de $7^{\circ} \mathrm{C}$ a $29^{\circ} \mathrm{C}$, de inverno e verão respectivamente, e onde rara vez desce menos de $4^{\circ} \mathrm{C}$ ou sobe a mais de $34^{\circ} \mathrm{C}$, sendo as maiores temperaturas registradas nos meses de agosto e setembro, também devido aos mesmos ventos de Santa Ana. 
A taxa de precipitação média anual no condado é de $385 \mathrm{~mm}$, que ocorre principalmente durante o inverno. A poluição atmosférica é comum em grande parte do Condado de Orange, assim como em Los Angeles, embora a costa geralmente tenha um ar mais limpo devido aos ventos oceânicos. No entanto, o uso extensivo de veículos pela população (com uma frota veicular de 2 901123) e a geografia da cidade, com montanhas cercando toda a região mais densamente habitada faz com que a cidade sofra bastante de poluição atmosférica. Muitas das emissões geradas pelos veículos acabam ficando retida por causa das montanhas, bem como as emissões geradas pelas indústrias (Xerex Corp, Lasco Bathare INC, Gallade Chemical INC) ali localizadas.

\subsubsection{Condado de Santa Bárbara}

O Condado tem uma área total de $9810 \mathrm{~km}^{2}$, dos quais $7080 \mathrm{~km}^{2}$ são terrestres e 2754 $\mathrm{km}^{2}(27,8 \%)$ são de água, a população no ano 2015 era de 444779 de acordo o US Census Bureau (2015).

Santa Barbara experimenta um clima mediterrâneo de verão quente (Köppen: Csb) característico da Califórnia costeira, como os dois condados acima. Como a cidade fica ao longo do oceano, as brisas são um moderador da temperatura com uma média anual de $15,8^{\circ} \mathrm{C}$, comparado com Los Angeles de $18,2^{\circ} \mathrm{C}$ e Orange de $17,8^{\circ} \mathrm{C}$, resultando em invernos amenos e verões menos quentes em comparação com lugares mais distantes do interior.

No inverno, sistemas frontais trazem tempestades à Califórnia, algumas das quais com fortes chuvas. Os totais de precipitação local podem ser aprimorados pelo levantamento orográfico quando as tempestades são acompanhadas por fluxo do sul que empurra o ar úmido sobre as montanhas de Santa Ynez, produzindo maiores chuvas do que em outras áreas costeiras (Harris e Carvalho 2017), tendo uma média anual de $429 \mathrm{~mm}$, sendo o mês de fevereiro o de maior acumulado de chuva com média de $99 \mathrm{~mm}$ e o mês de junho o mais seco quase sem precipitações. Adicionalmente, os verões no sul da Califórnia são principalmente sem precipitação devido à presença de uma área de alta pressão sobre o Pacífico oriental que estabelece forte subsidência, o que impede os movimentos verticais do ar. Este sistema é conhecido como semipermanente e apenas muda de posição com as estações de inverno e verão. 


\subsection{As faixas etárias da população da Califórnia}

De acordo com o US Census Bureau (2016), 15,2 \% da população dos EUA, o que equivale a 49,2 milhões de pessoas, já tinha completado 65 anos, enquanto no ano 2000 a percentagem era de 12,4 \%, ou cerca de 35 milhões de pessoas. Em alguns subgrupos, o crescimento entre adultos maiores foi enorme: as pessoas com idades entre 85 e 94 anos tiveram um aumento de 29,9 \% (5,1 milhões com relação a 3,9 milhões 10 anos atrás), e 30,4 \% as pessoas entre 65 e 69 anos (12,4 milhões em comparação com 9,5 milhões há uma década).

Em particular na Califórnia, espera-se que a população idosa cresça mais de duas vezes mais rápido que a população total e esse crescimento varia de acordo com a região. Segundo os dados do Departamento de Envelhecimento na Califórnia a faixa etária dos idosos terá um aumento global de 112 \% durante o período de 1990 a 2020 (Figura 2.2). Destaca-se que mais da metade dos municípios terão mais de $100 \%$ de aumento nesta faixa etária, 11 desses municípios terão taxas de crescimento superiores a $150 \%$. Por outro lado, espera-se que o aumento seja mais forte entre 2000 e 2020.

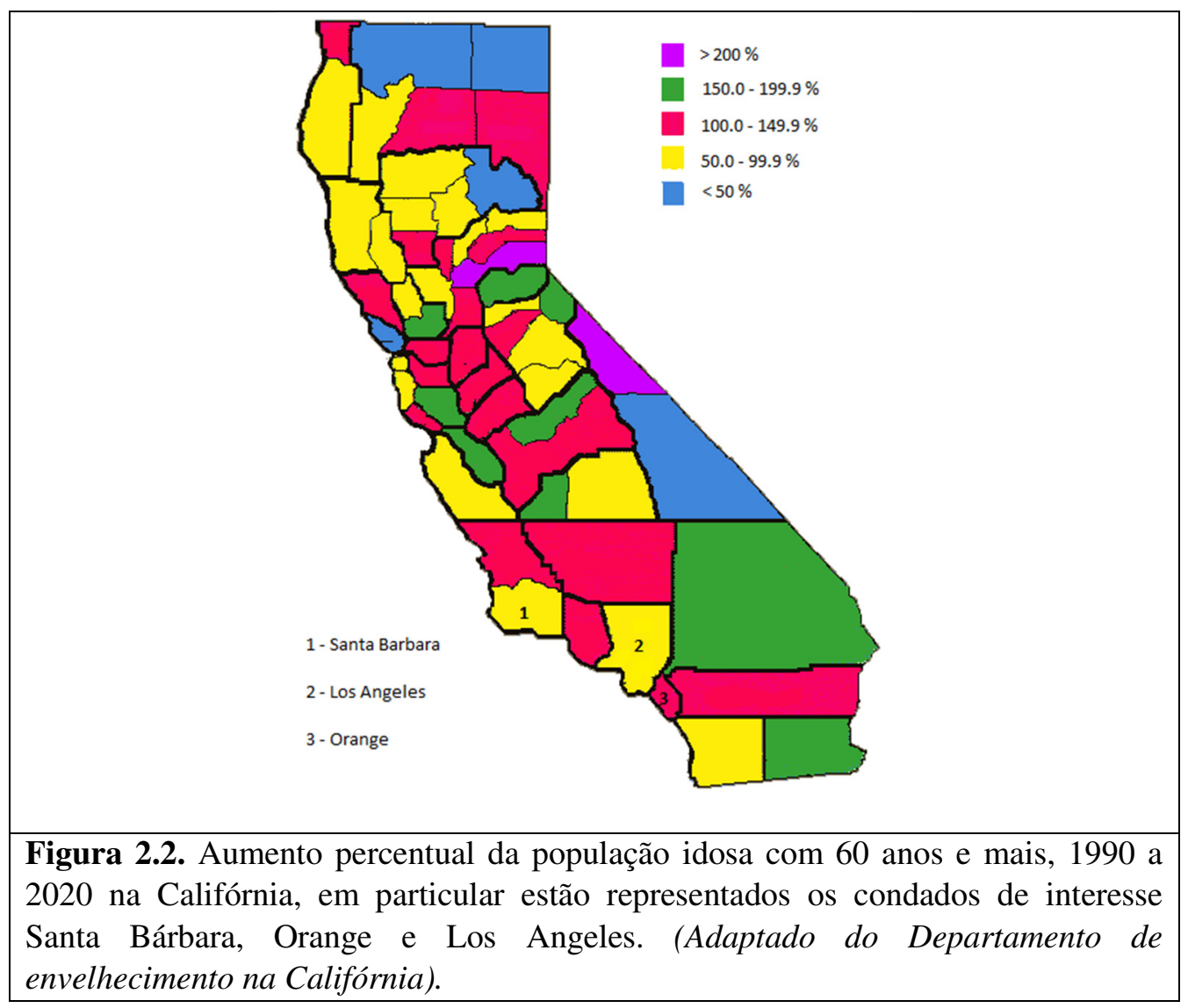




\subsection{Descrição dos dados}

Os dados estão subdivididos em três categorias: A seção 2.3.1 corresponde aos dados de mortalidade por DCV e RES (utilizados na avaliação quantitativa das influências meteorológicas nos idosos dos condados da Califórnia: Los Angeles, Orange e Santa Bárbara); a 2.3.2 dados observacionais (usados no estabelecimento da relação entre as variáveis meteorológicas e mortalidade, bem como no cálculo dos índices de conforto térmico) e em 2.3.3 dados de poluição atmosférica (usados na análise dos padrões de qualidade do ar nos condados de interesse, assim como no estabelecimento das correlações com a mortalidade).

\subsubsection{Dados de mortalidade}

Os dados de mortalidade dos condados de Los Angeles, Orange e Santa Bárbara foram fornecidos pelo Centro Nacional de Estatísticas de Saúde dos respectivos condados, para o período 1975-2005. Na base de dados final são mantidos apenas os registros de óbitos cujas iniciais na Classificação Internacional de Doenças (CID-9 e CID-10) correspondem a cada uma das duas causas, DCV (CID10 "I", CID9: 390-459) e doenças RES (CID10 “J”, CID-9: 460-519). As alterações do código em 1999 também estão incluídas nesta análise. Além disso, para manter a mortalidade apenas de idosos foram considerados óbitos de pessoas com 65 anos ou mais. Todos os dados foram corrigidos pelo aumento da população com base nos dados dos censos feitos entre os anos 1970 e 2010, como tendência linear por ano, tomados do Departamento de Comércio do US Census Bureau (1970, 1980, 1990, 2000 e 2010).

\subsubsection{Dados meteorológicos}

Foram utilizados dados diários das seguintes variáveis: temperatura do ar (média diária, máxima e mínima), temperatura do ponto de orvalho (média diária, máxima e mínima), umidade relativa (média diária, máxima e mínima), umidade específica (média diária, máxima e mínima), pressão atmosferica e velocidade do vento, para o período de 19752005. A seguir na tabela 2.1 é dada uma lista das estações meteorológicas onde foram coletados os dados. 
Tabela 2.1 - Estações meteorológicas utilizadas para o período 1975-2005, nos condados de Califórnia: Los Angeles, Orange e Santa Bárbara.

\begin{tabular}{|c|c|c|c|}
\hline Condado & Estação & Latitude & Longitude \\
\hline Los Angeles & $\begin{array}{c}722950 \text { - Aeroporto Internacional de Los } \\
\text { Angeles }\end{array}$ & 33.93 & -118.38 \\
\hline Orange & $\begin{array}{c}722977 \text { - Aeroporto Internacional John Wayne } \\
\text { NewPort }\end{array}$ & $\begin{array}{l}33.68 \\
33.62\end{array}$ & $\begin{array}{l}-117.86 \\
-117.94\end{array}$ \\
\hline Santa Bárbara & $\begin{array}{c}723925 \text { - Aeroporto Municipal de Santa } \\
\text { Bàrbara }\end{array}$ & 34.42 & -119.84 \\
\hline
\end{tabular}

Nesta análises a umidade relativa (UR) foi calculada como a razão entre a pressão parcial de vapor d'água (e) e a pressão de saturação do vapor d'água $\left(e_{s}\right)$.

$$
\mathrm{UR}=\frac{\mathrm{e}}{\mathrm{e}_{\mathrm{s}}} 100
$$

Por sua vez, a umidade específica $(q)$ foi calculada a partir da pressão parcial do vapor d'água $(e)$ e da pressão atmosférica $(P)$ :

$$
\mathrm{q}=\frac{\varepsilon \mathrm{e}}{\mathrm{P}-\mathrm{e}(1-\varepsilon)}
$$

Onde $\varepsilon=0.622$ é uma constante que expressa a razão entre o peso molecular da água e o peso molecular do ar seco.

Os dados de $\mathrm{e}_{\mathrm{s}}$ foram obtidos a partir da integração da equação de Clausius-Clapeyron, a qual estabelece uma relação direta entre $e_{s}$ e a temperatura $\left(e_{s}=f(T)\right)$, (Bolton, 1980):

$$
e_{s}=6.11 \exp \left(\frac{17,67 T}{T+243,5}\right)
$$

Onde T é a temperatura do ar $\left({ }^{\circ} \mathrm{C}\right)$.

A equação 2.3 também foi usada para o cálculo de $e$, já que em um mesmo nível isobárico e $(\mathrm{T})=\mathrm{e}_{\mathrm{s}}\left(\mathrm{T}_{\mathrm{d}}\right)$. Logo:

$$
e=6.11 \exp \left(\frac{17,67 T_{d}}{T_{d}+243,5}\right)
$$

Onde $T_{d}$ é a temperatura de ponto de orvalho $\left({ }^{\circ} \mathrm{C}\right)$. 
Nas figuras 2.3 (a), (b) e (c) é ilustrada a variabilidade térmica obtida a partir das medições da estação 722950 - Aeroporto Internacional de Los Angeles, relativas às temperaturas média, mínima e máxima, respectivamente. Por outro lado, observa-se no diagrama de caixa da figura 2.3 (a) como a temperatura média no inverno é $13^{\circ} \mathrm{C}$, entretanto no verão é perto aos $20^{\circ} \mathrm{C}$. Por sua vez, a média da temperatura mínima (figura 2.3 b) e máxima (figura $2.3 \mathrm{c}$ ) em inverno é de $9^{\circ} \mathrm{C}$ e $18^{\circ} \mathrm{C}$, respectivamente. Os valores em outono também refletem altos valores da temperatura, associados à influência do vento Santa Ana. Embora os termos médios das variáveis apontem para um clima ameno os "outliers" das figuras indicam que de forma menos frequente observam-se ainda temperaturas maiores e menores, ou seja, no decorrer de um ano podem ser verificados extremos de temperatura consideráveis, associadas, por exemplo, com a entrada de massas de ar frio ou a ocorrência de ondas de calor.

A variabilidade térmica representada pela estação concorda com os dados climáticos característicos do condado de Los Angeles (ver secção 2.1.1), ou seja, os dados utilizados nesta pesquisa para a análise das influências meteorológicas na mortalidade por doenças RES e DCV, são representativos do Condado de Los Angeles. Resultados similares foram encontrados para o condado de Orange e Santa Bárbara (figure 2.4 e 2.5).

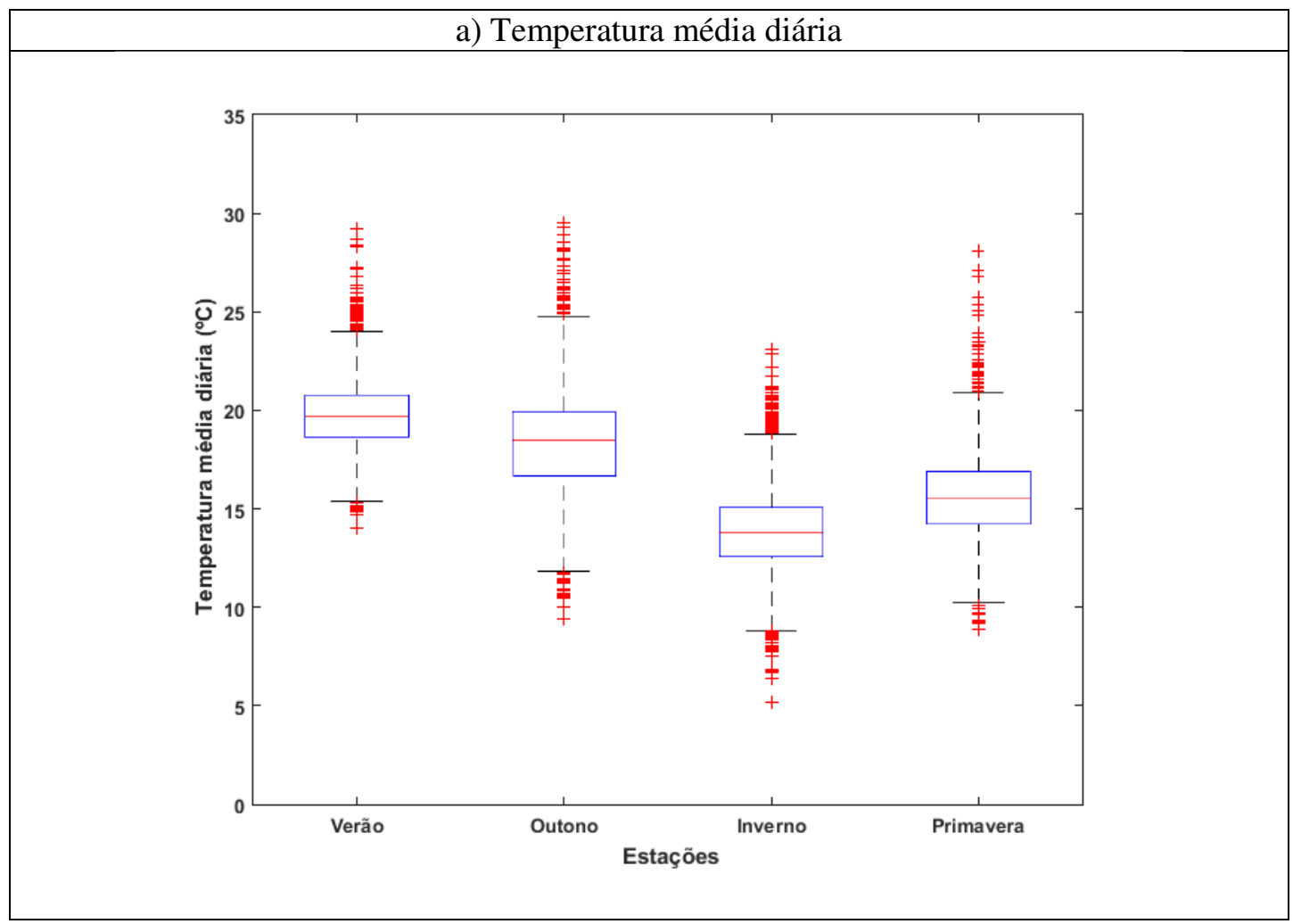




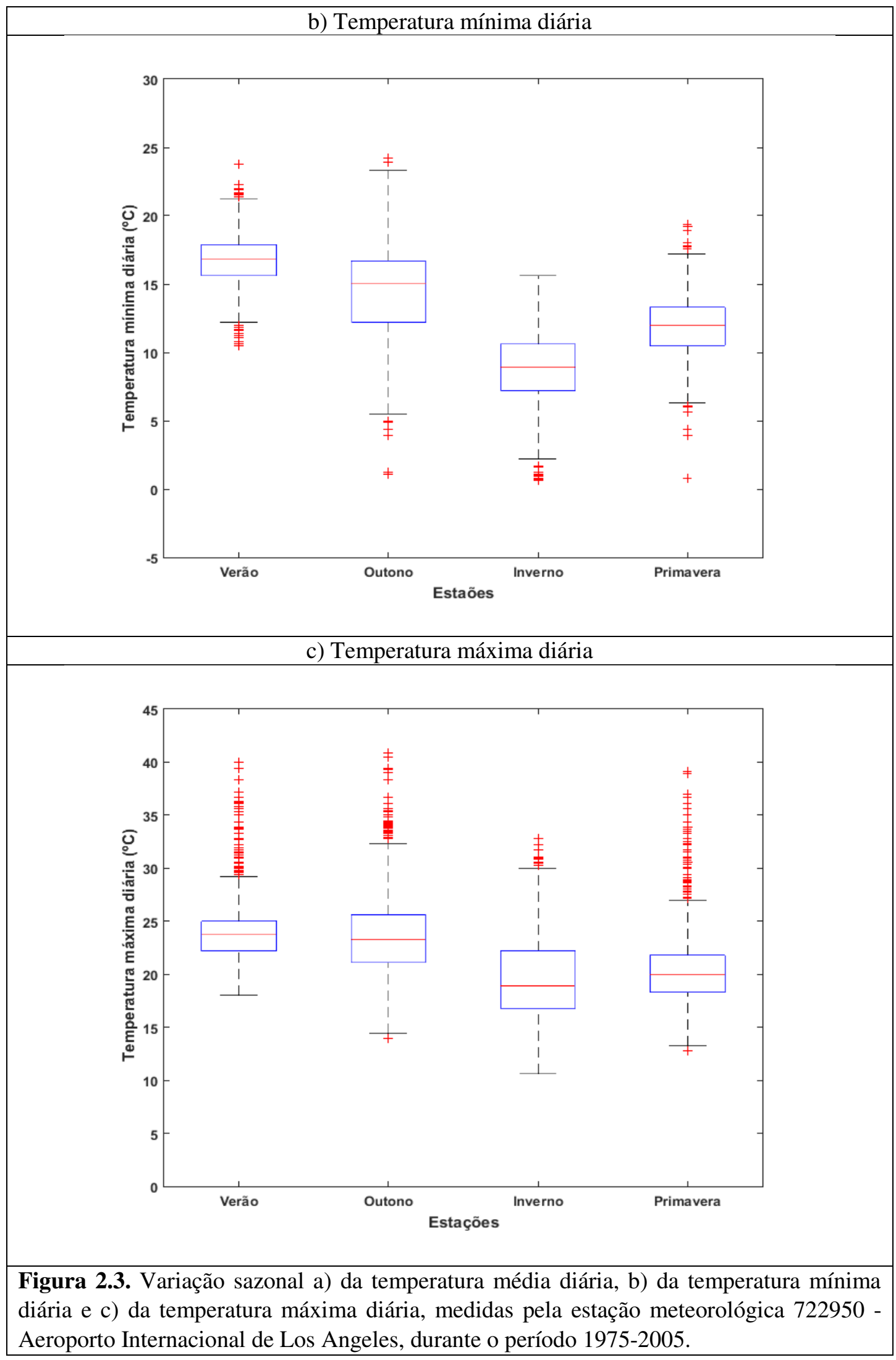




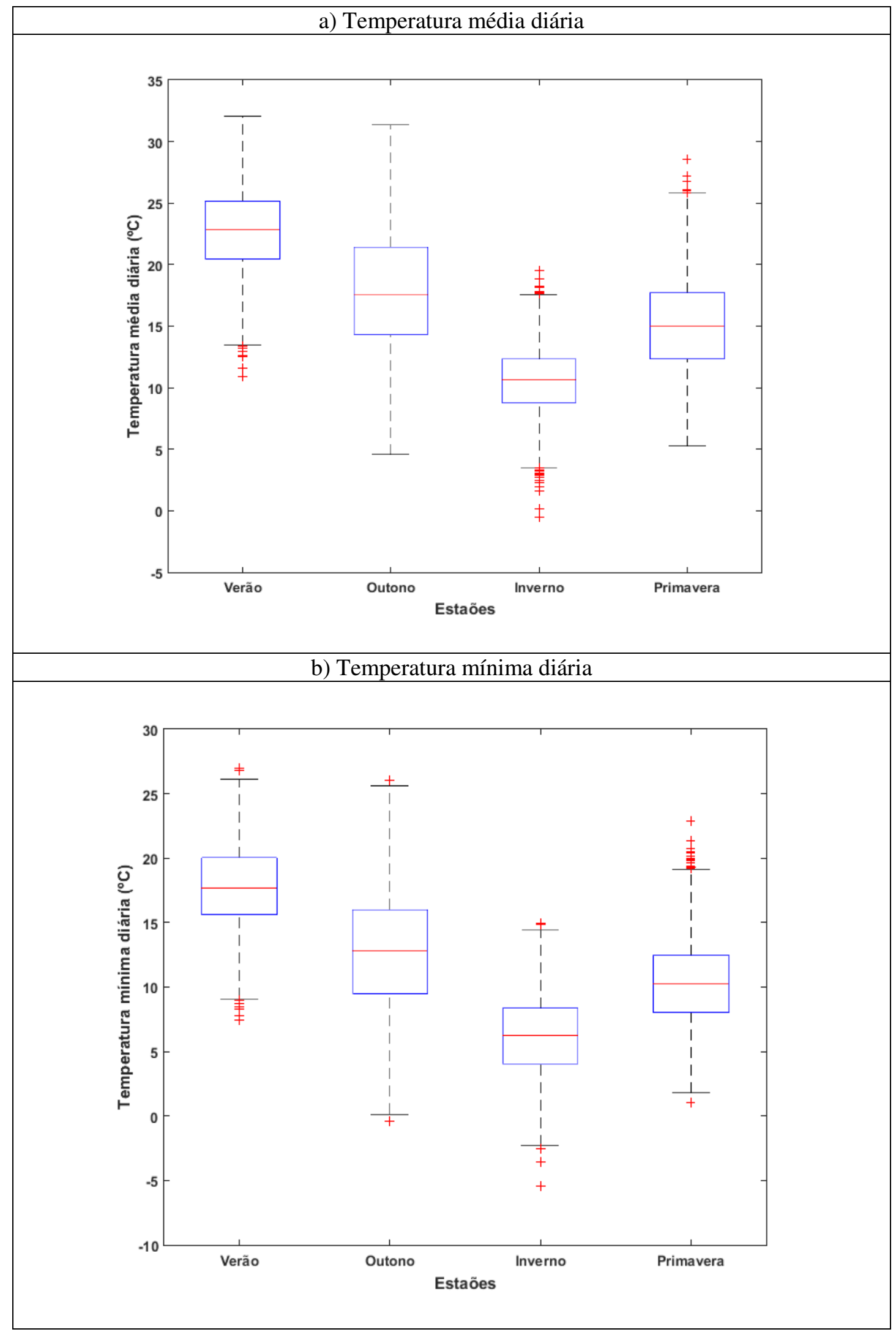




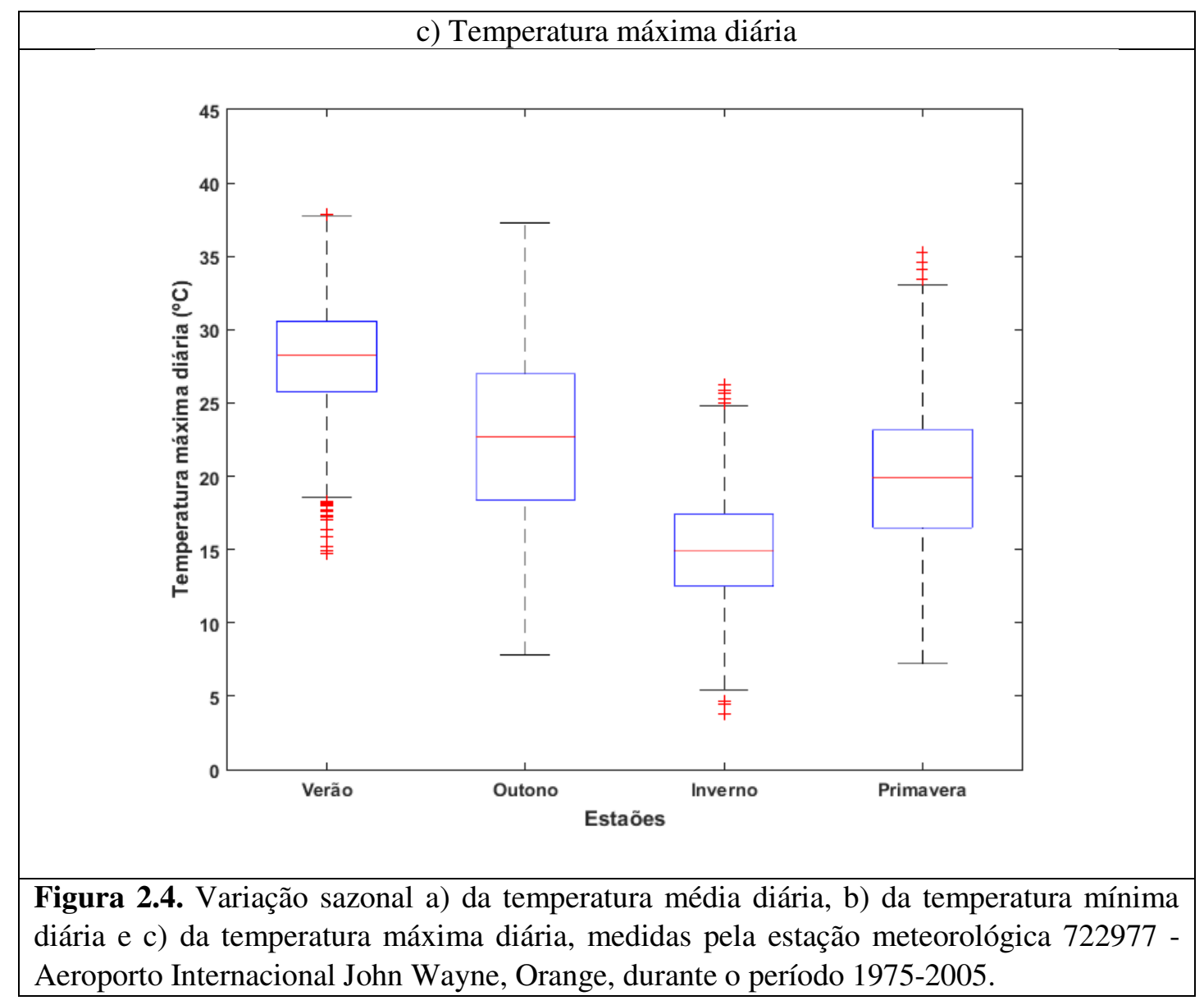

a) Temperatura média diária

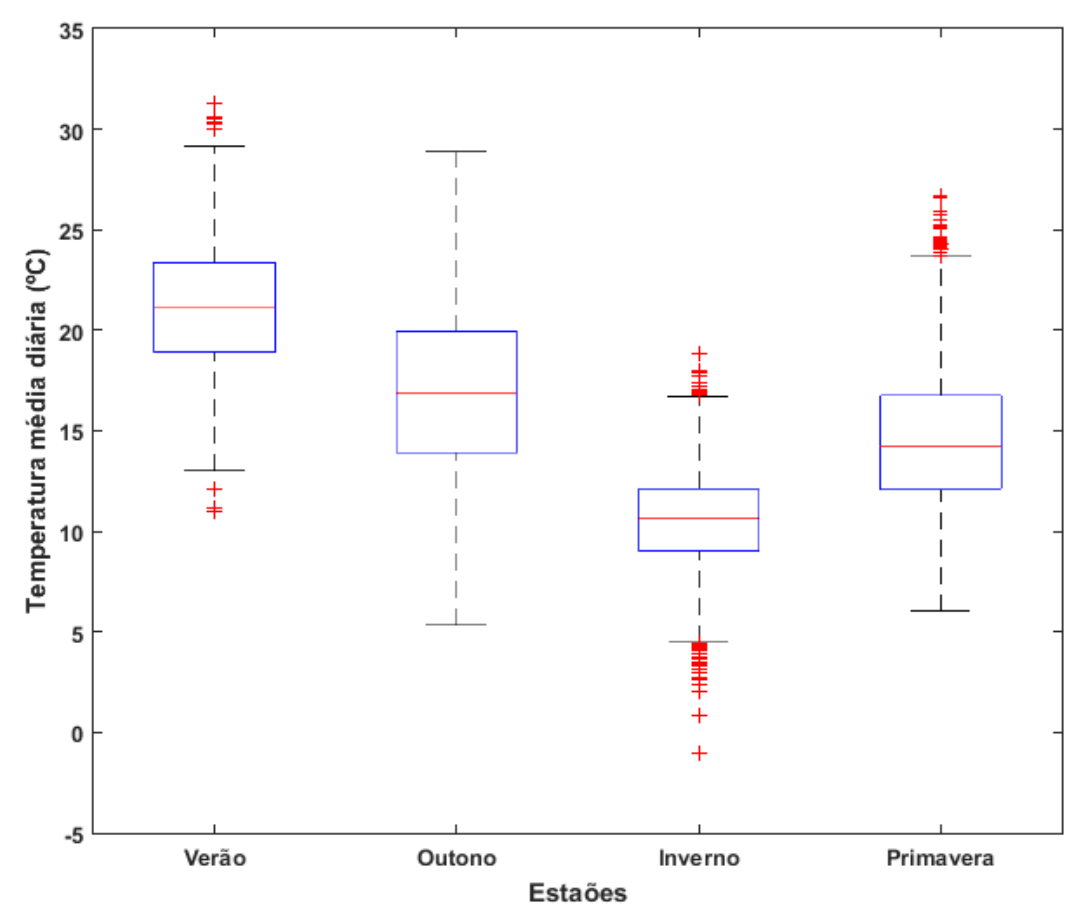




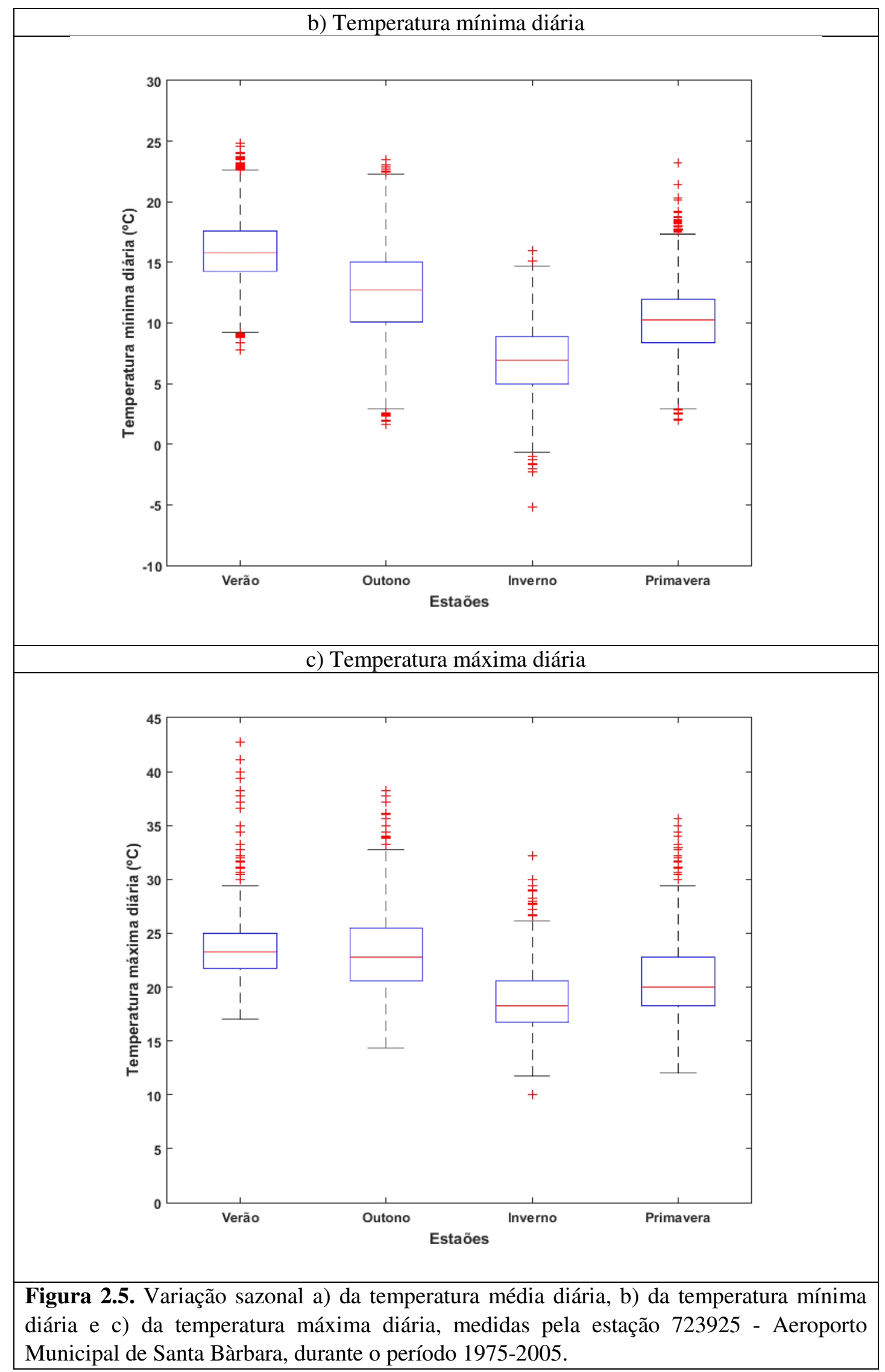




\subsubsection{Dados dos poluentes atmosféricos}

Foram estudadas as concentrações máximas diárias dos gases $\mathrm{O}_{3}, \mathrm{NO}_{2}$ e $\mathrm{CO}$, e as médias diárias de $\mathrm{SO}_{2}$ coletados em diversas estações fixas espalhadas pelos três condados de interesse. A tabela 2.2 apresenta as estações onde os poluentes atmosféricos foram medidos. Estes dados foram comparados com os padrões de qualidade do ar da Califórnia.

Tabela 2.2 - Estações ondes foram medidos os poluentes atmosféricos para o período 1980-2004, nos condados da Califórnia: Los Angeles, Orange e Santa Bárbara.

\begin{tabular}{cccc}
\hline Condado & Estação & Latitude & Longitude \\
\hline \multirow{2}{*}{ Los Angeles } & Lynwood & 33.92 & -118.21 \\
& LA-North Main Street & 34.06 & -118.22 \\
& WLA-Robertson & 34.05 & -118.38 \\
\hline Orange & La Habra & 33.92 & -117.95 \\
& El Toro & 33.62 & -117.69 \\
& Costa Mesa & 33.67 & -117.92 \\
\hline \multirow{2}{*}{ Santa Bárbara } & Goleta-Fairview & 34.44 & -119.82 \\
& Lompoc-S H Street & 34.63 & -120.45 \\
\hline
\end{tabular}

Com o propósito de reduzir o banco de dados a um valor diário para cada poluente por condado, foi calculado o coeficiente de correlação linear (de Pearson) entre as estações de cada condado. No caso onde observou-se correlação $(>0,70)$ foram feitas as médias entre estas estações.

\subsection{Métodos adotados nas análises}

O detalhamento dos métodos adotados é dada da seguinte forma: em 2.4.1 é apresentada a equação utilizada para a padronização dos dados, nos próximos 2 itens são abordadas as ferramentas estatísticas utilizadas, coeficiente de correlação de Pearson (cálculo da matriz de correlação) e a análise multivariada no caso, de componentes principais. Já 
em 2.4.4 é provida uma explicação a respeito da utilização de estruturas de defasagem como médias móveis.

\subsubsection{Padronização dos dados}

O conjunto de dados (poluentes, parâmetros meteorológicos e mortalidade), por possuírem unidades físicas (escalas) diferentes, foram normalizados, com a finalidade de remover a influência da localização e extensão deste conjunto. Neste processo, as unidades físicas do conjunto de dados são canceladas, tornando-as quantidades adimensionais. Com esse fim, foi utilizada a seguinte equação:

$$
z_{i j}=\frac{x_{i j}-\overline{x_{j}}}{s\left(x_{j}\right)}, \quad i=1,2, \cdots, p \quad \text { e } \quad j=1,2, \cdots, p
$$

onde, $\bar{X}_{j}$ e $s\left(x_{j}\right)$ são, respectivamente, a estimativa da média e o desvio padrão da característica j.

A partir de este processo cada observação dos dados originais é convertido em um valor padronizado, ou seja, onde a média é igual a zero e o desvio padrão e a variância são iguais a 1.

\subsubsection{Coeficiente de correlação de Pearson}

O coeficiente de correlação Pearson (r), também chamado coeficiente de correlação, mede o grau de dependência linear entre duas variáveis da amostra, pode variar entre -1 (correlação negativa perfeita) e +1 (correlação positiva perfeita). Se existe relação direta, é positivo. Se a relação é inversa, é negativo. Um valor de $r=0$ representa ausência de correlação.

O coeficiente de correlação é o resultado da divisão da covariância amostral de X e Y, pela raiz quadrada do produto das variâncias amostrais de $\mathrm{X}$ e $\mathrm{Y}$, ou:

$$
r=\frac{\sum(\mathrm{X}-\overline{\mathrm{X}})(\mathrm{Y}-\overline{\mathrm{Y}})}{\sqrt{\sum(\mathrm{X}-\overline{\mathrm{X}})^{2} \sum(\mathrm{Y}-\overline{\mathrm{Y}})^{2}}}
$$

onde X e Y são variáveis (Bunchaft e Kellner, 1999). 
Logo é possível escrever a matriz de correlação $\mathbf{R}$ para o conjunto de dados como:

$$
\mathbf{R}=\left|\begin{array}{ccc}
1 & r(x, y) & r(x, z) \\
r(y, x) & 1 & r(y, z) \\
r(z, x) & r(z, y) & 1
\end{array}\right|
$$

Onde r é o coeficiente de correlação.

\subsubsection{Metodologia de bootstrap}

Para determinar a existência de correlações significativamente diferente de zero, foram analisadas as variáveis usando a metodologia de bootstrap (Efron, 1979). O objetivo da aplicação do método neste trabalho é realizar contrastes de hipóteses sobre o parâmetros de interesse (o coeficiente de correlação) ré-amostrando da própria amostra observada. Foram simuladas 5000 amostras de tamanho 1000 cada uma, com reposição, ou seja, uma observação pode estar em duas amostras diferentes, mas não pode estar mas de uma vez na mesma amostra. Foi calculado o teste de correlação de Pearson para as variáveis em cada amostra, utilizando como nível de significância $\alpha=0,001$. Finalmente as variáveis que resultaram significativas mas do $90 \%$ das simulações (>4500 vezes) são as assumidas com correlação estatisticamente diferente de zero. Para realizar as simulações usou-se o programa $\mathrm{R}$.

\subsubsection{Análise das componentes principais}

A análise das componentes principais (ACP) é uma técnica da estatística multivariada introduzido por Karl Pearson (1901), com o objetivo principal de captar a estrutura de variância-covariância de um vetor aleatório, através da construção de combinações lineares das variáveis originais. Estas combinações lineares chamados componentes principais não estão correlacionadas. Ou seja, a ACP consiste em transformar um conjunto de variáveis originais em outro conjunto de variáveis de mesma dimensão, estimados com o propósito de reter, em ordem de estimação, o máximo de informação, em termos da variação total contida nos dados; desta maneira identificar os padrões de dados, expressando a data de tal forma que se poda realçar suas semelhanças e diferenças. Outra vantagem principal da ACP é que uma vez encontrado o padrão nos dados, pode-se reduzir o número de dimensões, sem muita perda de informações. A qualidade da aproximação depende da quantidade dos componentes retidos no sistema e 
pode ser medida através da avaliação da proporção da variância total capturado por estes componentes.

Neste trabalho, o objetivo da ACP consiste em transformar $\mathrm{p}$ variáveis originais correlacionadas (mortalidade, parâmetros meteorológicos e poluentes) em $\mathrm{k}$ componentes ortogonais (não correlacionadas), sendo estas componentes combinações lineares das variáveis originais, conservando-se a variância original.

A análise foi feita usando a matriz de correlação R. Os componentes principais foram determinados resolvendo-se a equação característica da matriz $(\operatorname{det}(R-\lambda I) v=0)$. A partir das raízes da equação característica (os autovalores $\lambda_{i}$, onde $\lambda_{1}>\lambda_{2}>$ $\lambda_{3} \cdots, \lambda_{i}$ ), obteve-se os autovetores $v_{i}$ os quais são normalizados, isto é, a soma dos quadrados dos coeficientes é igual a 1, e ainda são ortogonais entre si, logo o i-ésimo componente principal foi dado por:

$$
\mathrm{Y}=a_{i 1} X_{1}+a_{i 2} X_{2}+\cdots+a_{i p} X_{p}
$$

O peso dos fatores (factor loadings), uma das mais importantes informações da ACP, foi obtido a partir da correlação entre cada $X_{j}$ e o componente $Y_{i}$ :

$$
\operatorname{corr}\left(Y_{i},\left[X_{1}, \cdots, X_{P}\right]\right)=\sqrt{\frac{\lambda_{\mathrm{i}}}{s_{p}}} \mathrm{v}_{\mathrm{i}}
$$

onde $s_{p}$ é a variância das variáveis originais (igual a 1 quando utilizamos a matriz de correlação) (Jackson, 1991).

A importância de um componente principal é avaliada por meio de sua contribuição, isto é, pela proporção de variância total explicada pelo componente. A soma dos primeiros $\mathrm{k}$ autovalores representa a proporção de informação retida na redução de $\mathrm{p}$ para $\mathrm{k}$ dimensões. Com essa informação podemos decidir quantos componente vamos usar na análise, isto é, quantos componentes serão utilizados para diferenciar os indivíduos. Não existe um modelo estatístico que ajude nesta decisão. Segundo Regazzi (2000) para aplicações em diversas áreas do conhecimento o número de componentes utilizados tem sido aquele que acumula $70 \%$ ou mais de proporção da variância total.

$$
\frac{\widehat{\operatorname{Var}}\left(\mathrm{Y}_{1}\right)+\cdots \widehat{\operatorname{Var}}\left(\mathrm{Y}_{\mathrm{k}}\right)}{\sum_{\mathrm{i}=1}^{\mathrm{k}} \widehat{\operatorname{Var}}\left(\mathrm{Y}_{\mathrm{i}}\right)} \cdot 100 \geq 70 \% \quad \text { onde } \mathrm{k}<p
$$


É possível rotacionar cada um dos novos eixos para novas posições, otimizando-as, ou seja, objetivando a maximização da variância da "nova variável" (componente). A técnica mais usual é a rotação VARIMAX (VARIance MAXimizing) Normalizada (Dien, 2010).

\subsubsection{Estrutura de defasagem ("lag")}

As manifestações biológicas dos efeitos da poluição e das variáveis meteorológicas sobre a saúde, aparentemente, apresentam um comportamento que mostra uma defasagem em relação à exposição do indivíduo a estes agentes, ou seja, as doenças observadas em um dia específico devem estar relacionadas à poluição e a condições sinóticas do referido dia, como também os observados nos dias anteriores. Para uma adequada definição do modelo a ser utilizado, a determinação de uma estrutura de defasagem adequada é de fundamental importância (Conde, 2001).

Optou-se por utilizar dois diferentes tipos de defasagem: 1) médias móveis para todas as variáveis, variando de 2 até 5 dias; e 2) adiantando as doenças RES e DCV para o dia anterior, também variando até 5 dias.

Define-se uma média móvel de ordem N como aquela que é obtida pela sequência das médias aritméticas:

$$
\frac{y_{1}+y_{2}+\cdots+y_{N}}{N} ; \frac{y_{2}+y_{3}+\cdots+y_{N+1}}{N} ; \frac{y_{3}+y_{4}+\cdots+y_{N+2}}{N}
$$

\subsection{Cálculo dos índices de conforto térmico}

O conforto térmico foi definido por Hensen, (1991) como "um estado em que não há impulsos de condução para corrigir o ambiente pelo comportamento", a Sociedade Americana de Engenheiros de Aquecimento, Refrigeração e Ar Condicionado (ASHRAE) a definiu como "a condição da mente em que a satisfação é expressa com o ambiente térmico", muitos autores expressam que há "conforto térmico" quando as pessoas não experimentam uma sensação de calor ou frio; isto é, quando as condições de temperatura, umidade e movimentos do ar são favoráveis à atividade que desenvolvem. 
Avaliar o conforto térmico é uma tarefa complexa, uma vez que a avaliação das sensações sempre carrega uma carga subjetiva importante; no entanto, existem algumas variáveis modificáveis que influenciam as trocas térmicas entre o indivíduo e o ambiente e contribuem para a sensação de conforto, são elas: a temperatura do ar, a umidade de ar, atividade física, o tipo de vestimenta e a velocidade do ar.

Atualmente, coexistem duas abordagens diferentes para a definição de conforto térmico: a abordagem racional ou de equilíbrio de calor e a abordagem adaptativa (Doherty, 1988). A abordagem racional usa dados de estudos de câmara climática para apoiar sua teoria, melhor caracterizada pelos trabalhos de Fanger. Por sua parte a abordagem adaptativa usa estudos de campo, tendo como objetivo analisar a real aceitabilidade do ambiente térmico (Ogbonna e Harris , 2008; Hwang e Lin, 2007; Cena e Dear, 2001). A principal diferença entre estudos de ambientes internos e externos está dada na forma de avaliaçao das condições térmicas, devido as complejadade das variações das variáveis ambientais no contexto externo e como similitude é que os indices desenvolvidos para condições internas podem ser aplicados nos ambientes externos.

O conforto térmico é essencial para manter a saúde humana. Quando alguém realiza uma forte atividade esportiva, o conforto térmico é um fator que determina um maior ou menor desempenho do organismo humano. Muitos autores desenvolveram algumas equações matemáticas a partir da uma análise de regressão múltipla, envolvendo 2 ou mais variáveis meteorológicas correlacionados de acordo com a proposta do estudo.

A correlação de múltiplas variáveis é comumente realizada por meio de regressões lineares, como pode ser verificado em numerosos trabalhos (Conceição et al., 2001; Givoni e Noguchi, 2004, Nikolopoulu, 2004; Tadano et al., 2009; Ferreira 2013; Gonçalves et al., 2015), os grupos de índices resultantes definem o conforto humano como função do ambiente térmico, sendo apropriados para estudos de longo prazo. Ou seja, os índices são utilizados então para identificar os limites fisiológicos da sensibilidade. Estas equações medem a oscilação compartimentar do corpo expostas por diferentes parâmetros meteorológicos.

Alguns dos índices mais utilizados para ambientes externos, e utilizados nesse trabalho, dependem apenas de variáveis ambientais e são apresentados na tabela 2.3.

Tabela 2.3 - Índices de estresse térmico selecionados neste estudo 
Índice de Esstresse Térmico

Índice de desconforto (ID)

Índice de Kawamura $\left(\mathrm{ID}_{\mathrm{K}}\right)$

Índice de Temperatura Efetiva (TE)

Índice Temperatura Efetiva dependendo do Vento $\left(\mathrm{TE}_{\mathrm{V}}\right)$,

Temperatura Aparente (AP)

Índice de Calor (IC)

Índice de temperatura e resfriamento pelo o vento "Windchill" $(\mathrm{H})$

\section{Referência}

Thom (1959)

Ono and Kawamura (1991)

Missenard (1937)

Suping et al. (1992)

Steadman (1984)

Steadman (1979)

Siple and Passel (1945)

Court (1948)

O ID foi proposto inicialmente por Thom em 1959, baseado em um simples ajuste linear aplicado à média das leituras da temperatura do bulbo seco (T) e do úmido (Tw). Nos anos seguintes, várias versões deste índice foram criadas. Nesta pesquisa usa-se a forma (Giles et al., 1990):

$$
\mathrm{ID}=\mathrm{T}-0.55(1-0.01 \mathrm{UR})(\mathrm{T}-14.5)
$$

Onde:

- ID é o índice de desconforto em $\left({ }^{\circ} \mathrm{C}\right)$

- Té a temperatura do ar $\left({ }^{\circ} \mathrm{C}\right)$

A partir da classificação de Thom 1959 o ID é dividido em 6 categorias, as quais são mostradas na tabela 2.4 .

Tabela 2.4 - Níveis de Desconforto gerados por categorias do ID (Thom, 1959)

\begin{tabular}{cc}
\hline ID $\left({ }^{\circ} \mathbf{C}\right)$ & Nível de Desconforto \\
\hline$<21$ & Sem desconforto \\
21 a 24 & Menos de 50\% da população tem desconforto \\
24 a 27 & Mais de 50\% da população tem desconforto \\
27 a 29 & A maioria da população tem desconforto \\
\hline
\end{tabular}




\begin{tabular}{cc}
29 a 32 & Estresse severo \\
$>32$ & Estado de emergência \\
\hline
\end{tabular}

O $\mathrm{ID}_{\mathrm{k}}$ é também baseado na fórmula de Thom (1959), só que utiliza a temperatura do ponto de orvalho em vez da temperatura do bulbo úmido (Ono e Kawamura, 1991):

$$
\mathrm{ID}_{\mathrm{k}}=0.99 \mathrm{~T}+0.36 \mathrm{~T}_{\mathrm{d}}+41.5
$$

Onde:

- $\quad \mathrm{ID}_{\mathrm{k}}$ é o índice de desconforto de Kawamura $\left({ }^{\circ} \mathrm{C}\right)$

- T é a temperatura do ar $\left({ }^{\circ} \mathrm{C}\right)$

- $\mathrm{T}_{\mathrm{d}}$ é a temperatura do ponto de orvalho $\left({ }^{\circ} \mathrm{C}\right)$

A seguir na tabela 2.6 o indice $\mathrm{ID}_{\mathrm{K}}$ é dividido em 4 categorias a partir da classificação de Thom (1959).

Tabela 2.5 - Nível de desconforto gerado por cada categoria do IDk (Ono and Kawamura, 1991)

\begin{tabular}{cc}
\hline ID $\left({ }^{\circ} \mathbf{C}\right)$ & Nível de Desconforto \\
\hline$<55$ & Muito Frio \\
55 a 60 & Deconfortavelmente Frio \\
60 a 75 & Confortavel \\
75 a 80 & Deconfortavelmente Quente \\
$>80$ & Muito Quente \\
\hline
\end{tabular}

O índice TE proposto por Missenard (1937) e utilizado para avaliar o estresse térmico em ambientes abertos em condições de calor (Pallotta et al., 2015), estabelece uma relação entre a temperatura do ar e a umidade:

$$
\mathrm{TE}=\mathrm{T}-0.4(1-\mathrm{UR} / 100)(\mathrm{T}-10)
$$

Onde:

- TE é a temperatura efetiva $\left({ }^{\circ} \mathrm{C}\right)$

- T é a temperatura do ar $\left({ }^{\circ} \mathrm{C}\right)$ 
- UR é a humidade relativa (\%)

As zonas de conforto para diferentes graus de percepção térmica e suas respostas fisiológicas a partir de TE foram estabelecidos por Fanger (1970).

Tabela 2.6 - Sensação térmica e grau de estresse fisiológico para cada categoria do TE (Fanger, 1970).

\section{TE ou TEv ( $\left({ }^{\circ} \mathrm{C}\right) \quad$ Sensação térmica (Tipo de CT) Grau de estresse fisiológico}

\begin{tabular}{lll}
\hline$<13$ & Muito Frio (MF) & Extremo estresse ao frio \\
13 a 16 & Frio (MF) & Forte estresse ao frio \\
16 a 19 & Frio Moderado (FM) & Estresse moderado ao frio \\
19 a 22 & Ligeiramente frio (LF) & Ligero estresse ao frio \\
22 a 25 & Confortável (C) & Neutralidade térmica \\
25 a 28 & Ligeiramente Quente (LQ) & Ligeiro estresse ao calor \\
28 a 31 & Quente Moderado (QM) & Estresse moderado ao calor \\
31 a 34 & Quente (Q) & Forte estresse ao calor \\
$>34$ & Muito Quente (MQ) & Extremo estresse ao calor \\
\hline
\end{tabular}

Por sua parte, o índice TEv foi encontrado por Suping et al. (1992), calcula a sensação térmica da temperatura, que é percebida dependendo da magnitude do vento e umidade relativa:

$$
\mathrm{TE}_{\mathrm{v}}=37-\frac{37-\mathrm{T}}{\left[0.68-0.0014 \mathrm{UR}+\frac{1}{1.76+1.4 \mathrm{v}^{0.75}}\right]}-0.29 \mathrm{~T}\left(1-\frac{\mathrm{UR}}{100}\right)
$$

Onde:

- TEv é a temperatura efetiva em função do vento $\left({ }^{\circ} \mathrm{C}\right)$

- T é a temperatura do ar $\left({ }^{\circ} \mathrm{C}\right)$

- UR é a humidade relativa (\%)

- v é a velocidade do vento $(\mathrm{m} / \mathrm{s})$ 
O intervalo de valores do TEV, bem como a sensação térmica e o grau de estresse fisiológico para cada um desses intervalos é o mesmo do TE (tabela 2.7) (Pallotta et al., 2015).

A fórmula de "windchill" também avalia a influência do vento sobre o conforto térmico humano, além da temperatura do ar. Este índice foi proposto inicialmente por Siple and Passel (1945) para climas polares, sendo que expressa o poder de resfriamento do vento para várias combinações de temperatura e velocidade do vento. Alguns anos mais tarde, Court (1948) modificou a fórmula proposta por Siple para climas mais amenos (Tromp, 1980). Esta equação de perda de calor, similar a original, será utilizada neste trabalho:

$$
H=(9+10.9 \sqrt{v}-v)(33-T)
$$

Onde:

- H é a perda de calor em (Kcalm-2hr-1)

- T é a temperatura do ar $\left({ }^{\circ} \mathrm{C}\right)$

- UR é a humidade relativa (\%)

- v é a velocidade do vento $(\mathrm{m} / \mathrm{s})$

A seguir na tabela 2.6 o indice $\mathrm{H}$ é dividido em 4 categorias a partir da classificação de Thom (1980).

Tabela 2.7 - Nível de desconforto gerado por cada categoria do H (Thom, 1980).

H (Kcalm-2hr-1) Efeitos

\begin{tabular}{cc}
\hline & Algum frescor \\
$>600$ & Agradável enquanto protegido com bastantes roupas \\
$>1000$ & Condições agradáveis para movimentar-se cessam \\
$>2500$ & Estresse devido ao frio \\
\hline
\end{tabular}

A TA, proposto por Steadman (1984) para medir sensações térmicas em ambientes quentes e úmidos foi aplicado inicialmente nos EUA e na Austrália (Zhao et al., 2015). O mesmo considera o efeito combinado da temperatura e da umidade do ar, a partir dos dados da pressão de vapor. Hoje é utilizado pela Australian Bureau of Meteorology. 
Este índice é dado pela seguinte fórmula:

$$
\mathrm{TA}=0.92 \mathrm{~T}+0.22 \mathrm{e}-1.3
$$

Onde:

- TA é a temperatura aparente $\left({ }^{\circ} \mathrm{C}\right)$

- T é a temperatura do $\operatorname{ar}\left({ }^{\circ} \mathrm{C}\right)$

- e é a pressão de vapor

Na tabela 2.8 são apresentados os valores de TA e o tipo de estresse térmico causante nas pessoas.

Tabela 2.8 - Grado de estresse térmico gerado por cada categoria do indice TA (Adaptado de Steadman (1984)).

\begin{tabular}{cc}
\hline TA $\left({ }^{\circ} \mathbf{C}\right)$ & Estresse térmico \\
\hline$<28$ & Ausente \\
28 a 32 & Leve \\
32 a 35 & Moderado \\
35 a 40 & Forte \\
$>40$ & Extremo \\
\hline
\end{tabular}

Por último o IC é derivado do índice Humidex desenvolvido por Winterling no ano 1978 e adaptado com base aos trabalhos de Stadman (1979) a partir de um ajuste linear utilizando os dados de temperatura do ar e a umidade relativa. O IC é amplamente utilizado pela NOAA e é descrito pela seguinte equação:

$$
\begin{gathered}
I C=c_{1}+c_{2} T+c_{3} U R+c_{4} T U R+c_{5} T^{2}+c_{6} R^{2}+c_{7} T^{2} U R+c_{8} T U R^{2} \\
+c_{9} T^{2} U R^{2}
\end{gathered}
$$

Onde:

- T é a temperatura do ar $\left({ }^{\circ} \mathrm{C}\right)$

- UR umidade relativa $(\%)$

- $\mathrm{c}_{1}=-8.784695, \mathrm{c}_{2}=1,61139411, \mathrm{c}_{3}=2.338549, \mathrm{c}_{4}=-0,14611605, \mathrm{c}_{5}=-$ $1.2308094 * 10^{-2}, \mathrm{c}_{6}=-1.6424828 * 10^{-2}, \mathrm{c}_{7}=2,211732 * 10^{-3}, \mathrm{c}_{8}=$ $7,2546 * 10^{-4}$, e c $9=-3,582 * 10^{-6}$. 
Segundo a NOAA (2015), este índice não deve ser utilizado para temperaturas abaixo de $27{ }^{\circ} \mathrm{C}$ e umidade relativa inferior a $40 \%$. A seguir na tabela 2.8 são apresentados os intervalos de valores do IC, bem como sua clasificação e efeitos causados no corpo.

Tabela 2.9 - Categorias do IC e seus respectivos efeitos no corpo (NOAA, 2015).

\begin{tabular}{ccc}
\hline IC $\left({ }^{\mathbf{}} \mathbf{C}\right)$ & Classificação & Efeitos causados no corpo \\
\hline 27 a 32 & Cuidado & Fadiga é possível com prolongada exposição \\
& e/ou atividade física. \\
32 a 41 & Extrema cautela & $\begin{array}{r}\text { Insolação, câimbras ou exaustão é possível com } \\
\text { exposição e/ou atividade física. }\end{array}$ \\
41 a 54 & Perigo & Câimbras ou exaustão pelo calor \\
& & provavelmente, e insolação é possível com \\
& & exposição prolongada e/ou atividade física. \\
& & Insolação altamente possível \\
\hline
\end{tabular}

É importante destacar que os índices propostos acima, onde há uma combinação entre a umidade e a temperatura, foram calculados de três maneiras diferentes. Na primeira análise foram usados apenas os valores médios da temperatura e umidade relativa. $\mathrm{Na}$ segunda, foram empregando a temperatura mínima e umidade relativa máxima, e por último, a partir da temperatura máxima e umidade relativa mínima. a segunda análise representa uma situação característica $\operatorname{logo}$ ao amanhecer, quando normalmente observam-se as menores temperaturas e os maiores valores de umidade relativa, entretanto a terceira análise é observada no início da tarde, quando a situação se inverte, com maiores valores de temperatura e baixos valores de umidade relativa. Ou seja, nestas duas situações são consideradas as condições extremas que devam afetar de forma mais pronunciada o conforto humano. Com relação aos índices que envolvem a velocidade do vento, somente foi utilizado o valor médio diário desta variável. 


\section{CAPÍTULO 3 - RESULTADOS}

Neste capítulo 3 serão apresentados os resultados obtidos e os mesmos se encontram divididos em 5 itens. Em 3.1 será feita uma análise descritiva da mortalidade de idosos por DCV e RES nos condados de Los Angeles, Orange e Santa Bárbara. A seguir, em 3.2 serão apresentadas as distribuições dos níveis de poluição durante o período de estudo (1980-2005). Em 3.3 será abordado o comportamento dos índices de conforto térmicos adotados (tabela 2.3), neste sentido, são estabelecidas as zonas de conforto para diferentes graus de percepção térmica. Já em 3.4, será tratada a análise de correlação entre as variáveis estudadas (mortalidade por DCV e RES, variáveis meteorológicas, níveis de poluição e índices de conforto), inclusive utilizando as estruturas de defasagem ("lag"). Por último, no item 3.5 serão apresentados os resultados obtidos na ACP a todo conjunto de dados.

\subsection{Panorama geral da mortalidade por DCV e RES nos condados de Orange, Los Angeles e Santa Bárbara.}

As séries temporais das DCV e RES durante o período 1975-2005 nos condados de Los Angeles, Orange e Santa Bárbara são mostradas nas figuras 3.1, 3.2 e 3.3, respectivamente. Observa-se como a mortalidade por DCV e RES no condado de Los Angeles refletem tendências opostas. Enquanto as doenças RES têm um aumento bastante lento, cerca de 1 caso por década, as DCV apresentam uma diminuição constante, 14 casos por década. Resultados similares foram obtidos nos condados de Orange e Santa Bárbara; embora em estes dois últimos condados a diminuição das DCV por década não seja tão marcada como no condado de Los Angeles, com aproximadamente 1 caso por década em cada.

A tendência de diminuição das DCV ao longo das últimas décadas é provavelmente devido a processos de adaptação, existe um conjunto de fatores influentes desta queda, por exemplo, melhores cuidados da saúde a partir da adoção de políticas de prevenção, o desenvolvimento da tecnologia e a criação de fármacos mais eficazes (Jemal et al., 2005). Neste sentido o relatório global da Organização Mundial da Saúde (OMS) em 2005 estima que, de 1970 a 2000, 14 milhões de mortes por DCV foram evitadas apenas nos EUA. Além disso, existe uma maior conscientização da população sobre os impactos biofísicos da exposição tanto do frio quanto ao calor (Davis et al., 2003). 
Contudo o relatório "World Health Statistics" (2018) divulgado pela OMS corrobora que ainda as enfermidades cardiovasculares constituem uma das principais causas de morte tanto nos condados da análise, quanto no mundo.
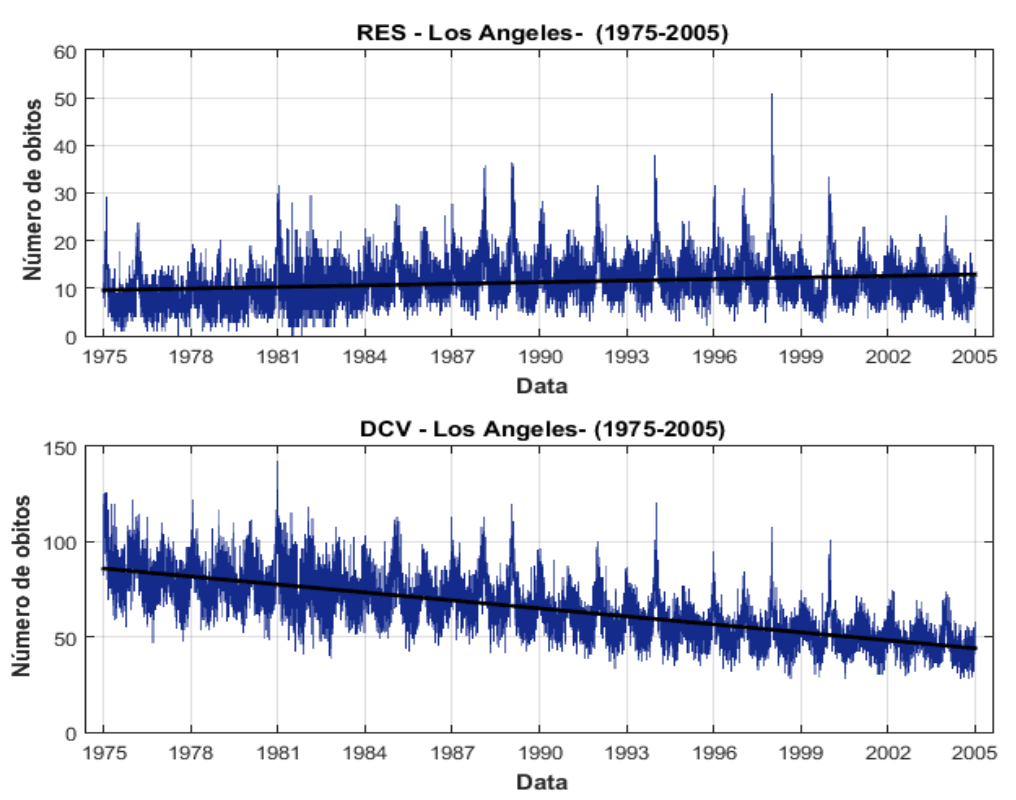

Figura 3.1. Variação temporal da mortalidade diária por doenças (a) RES e (b) DCV no condado de Los Angeles, Califórnia (1975-2005).
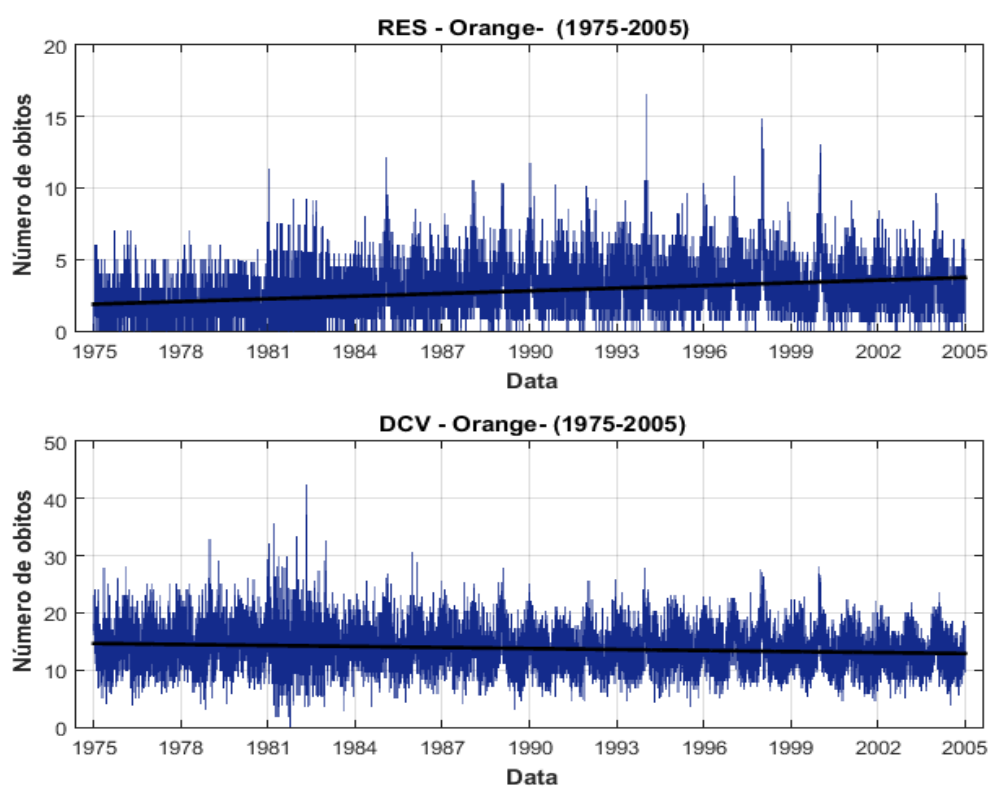

Figura 3.2. Variação temporal da mortalidade diária por doenças (a) RES e (b) DCV no condado de Orange, Califórnia (1975-2005). 

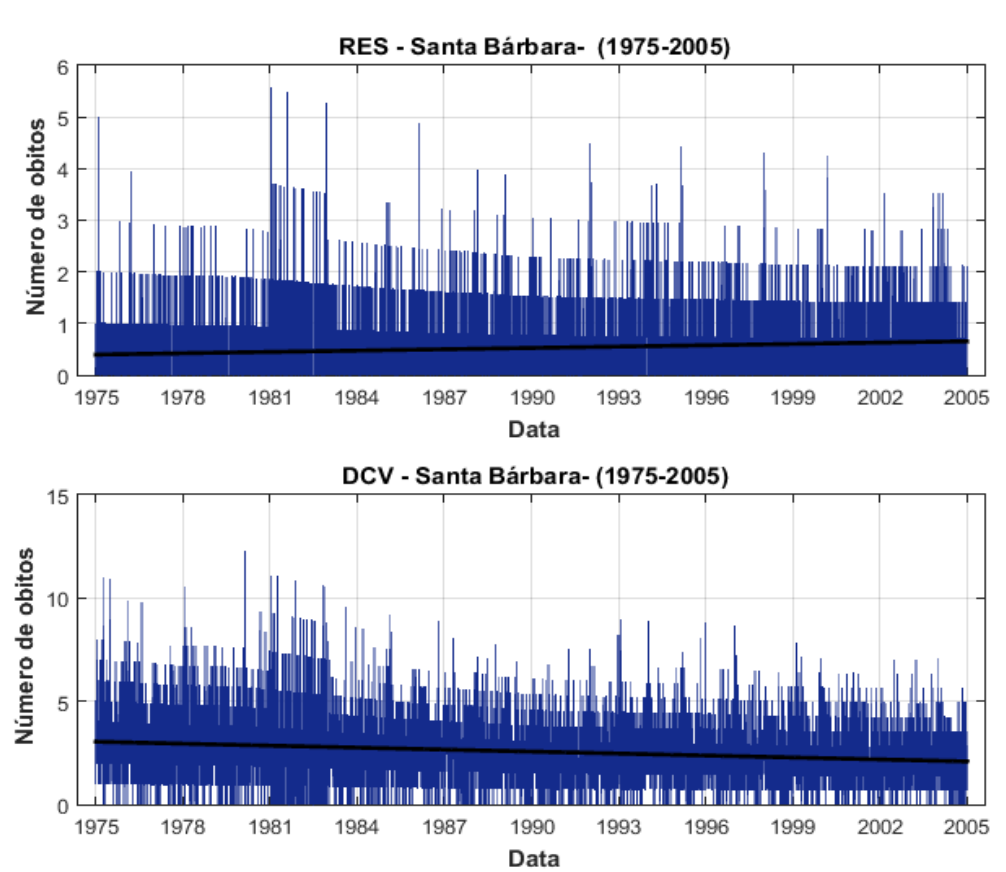

Figura 3.3. Variação temporal da mortalidade diária por doenças (a) RES e (b) DCV no condado de Santa Bárbara, Califórnia (1975-2005).

Por sua parte, o ligeiro aumento de mortalidade por doenças RES nos 30 anos de estudo pode ser devido tanto a diferentes fatores sociais quanto ambientais. Um exemplo é o aumento do tabagismo, a qual constitui primeira causa de doenças no aparato respiratório, câncer de pulmão, obstruções pulmonares crônicas, assim como também um auge de doenças infecciosas (tuberculoses, pneumonia), também as enfermidades que diminuem o sistema imunológico, tudo isso pode ter sido acompanhado por variações das condições climáticas. (OMS, 2012; Gutierres, 2011).

No entanto, é importante ressaltar que na última década os resultados corroboram uma leve tendência à diminuição da mortalidade por doenças RES nestes condados. Isso pode estar associado, por exemplo, à diminuição do consumo de cigarros na Califórnia a partir de 1989, logo de implantado o programa de controle do tabaco. Segundo o relatório sobre o tabaco do Departamento de Saúde na Califórnia (2018), a prevalência de fumantes adultos diminuiu 55,7\% entre 1988 e 2015, de 23,7\% para 10,5\%, o que representa aproximadamente 3,3 milhões de fumantes adultos na Califórnia.

Nas figuras 3.4 e 3.5 observa-se a variação mensal da mortalidade por DCV e RES para indivíduos com mais de 65 anos, durante todo o período de estudo nos condados de Santa Bárbara, Orange e Los Angeles, respectivamente. Observa-se o maior número de óbitos tanto de DCV quanto RES presentes no condado de Los Angeles, o que era 
esperado levando em conta o nível de habitantes, urbanização e industrialização do condado; embora nos três condados seja possível perceber um padrão em forma de $\mathrm{U}$ com um aumento nas doenças durante os meses de inverno e no mês que prenuncia a chegada desta estação (marca a transição entre as duas estações), ou seja, de dezembro e janeiro, no Hemisfério Norte, e uma queda durante os meses de verão (junho a agosto). Este padrão é consistente em grande parte do mundo (Rogot e Padgett, 1976; Sharovsky, 2001; Braga, 2002; Braun, 2003; Kalkstein, 2013). Os mecanismos causais específicos são muito complexos, tendo diversos fatores de risco associados com a mudança sazonal nas doenças, exemplo deles é a chegada do inverno, a qual está marcada por uma queda das temperaturas e da luz solar, assim como uma diminuição das atividades físicas e um aumento das concentrações de poluentes (Barnett et al., 2008).

Anderson (2009) sugere que as temperaturas mais baixas afetam mais a mortalidade do que o calor devido ao grande número de doenças infecciosas, que são mais comuns nos países industrializados com o clima mais frio. Além disso, as condições típicas do inverno contribuem a uma menor dispersão de poluentes, ou seja, as pessoas estão expostas a níveis mais elevados de poluição. Os resultados são ainda maiores em grandes megacidades onde normalmente existe um grande deterioro da qualidade do ar (mais detalhes no item 3.2).

Para quantificar as doenças, nas figuras 3.6 e 3.7 novamente tem-se o número de óbitos para os condados, mas desta vez separado por estações do ano. Os meses foram distribuídos da seguinte maneira dentro de cada estação: Inverno (dezembro a fevereiro), Primavera (março a maio), Verão (junho a agosto) e Outono (setembro a novembro). Observa-se novamente que os máximos de ocorrência de doenças foram nos meses de inverno e os mínimos no verão. É importante destacar que embora no inverno ocorra o maior número de óbitos, no verão os números não deixam de serem importantes, por exemplo, ao longo de toda a série, no verão os óbitos por DCV e RES foram de 128580 e 22760 no condado de Los Angeles, 28545 e 5791 no condado de Orange, e 5198 e 1106 no condado de Santa Bárbara, respectivamente. 


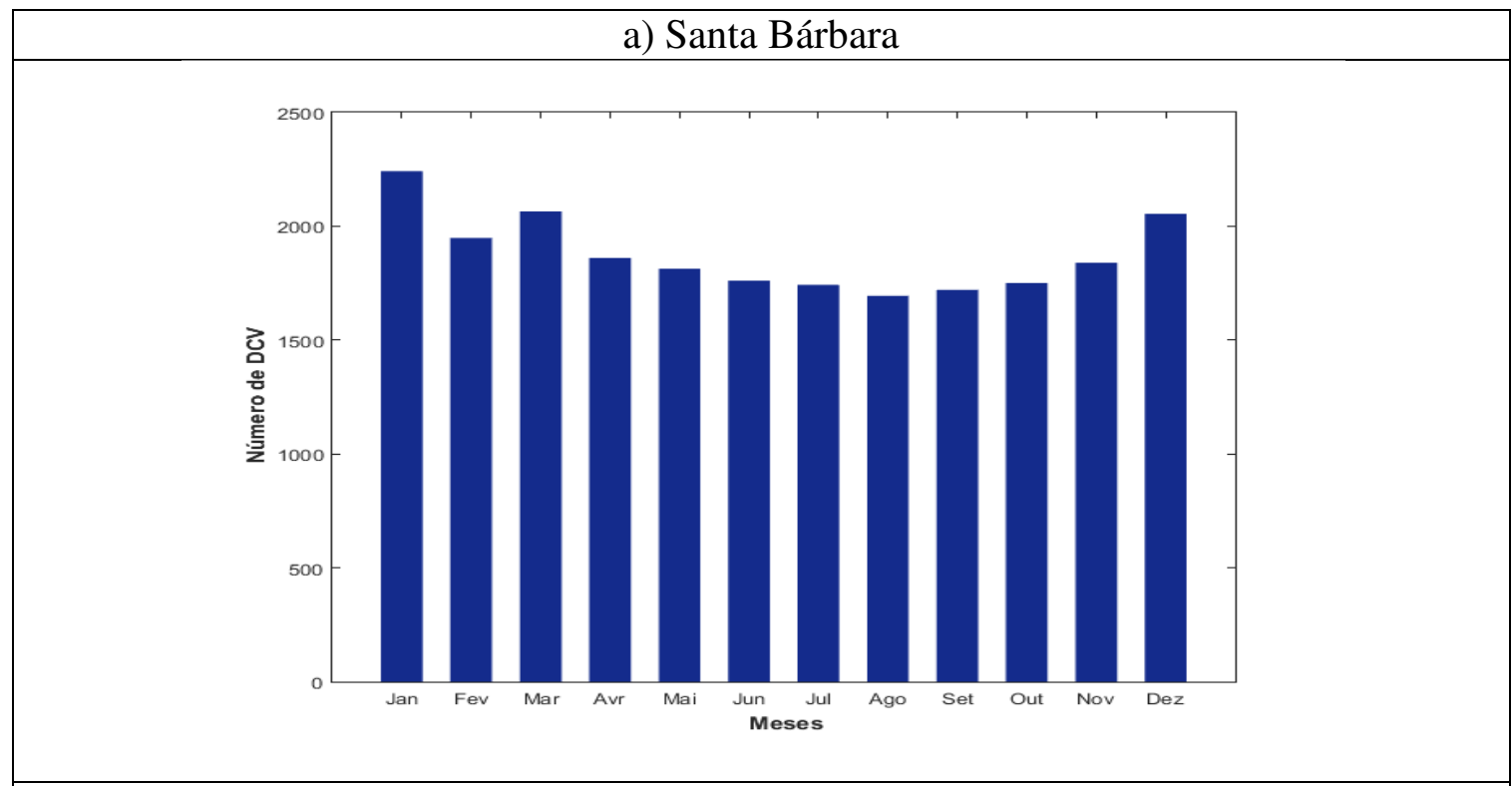

b) Orange

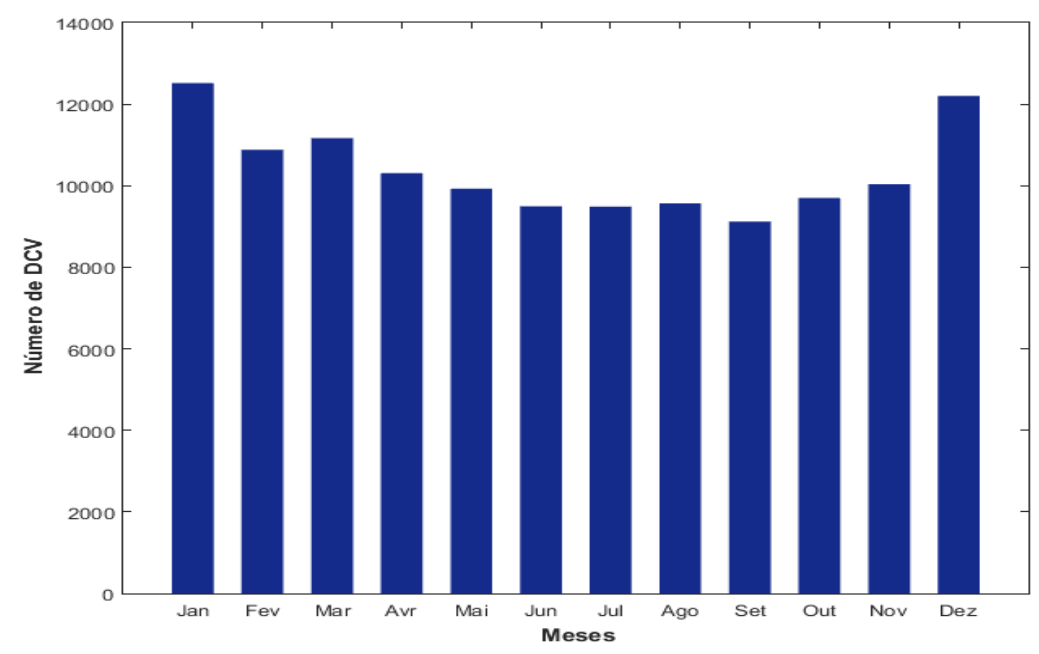

c) Los Angeles

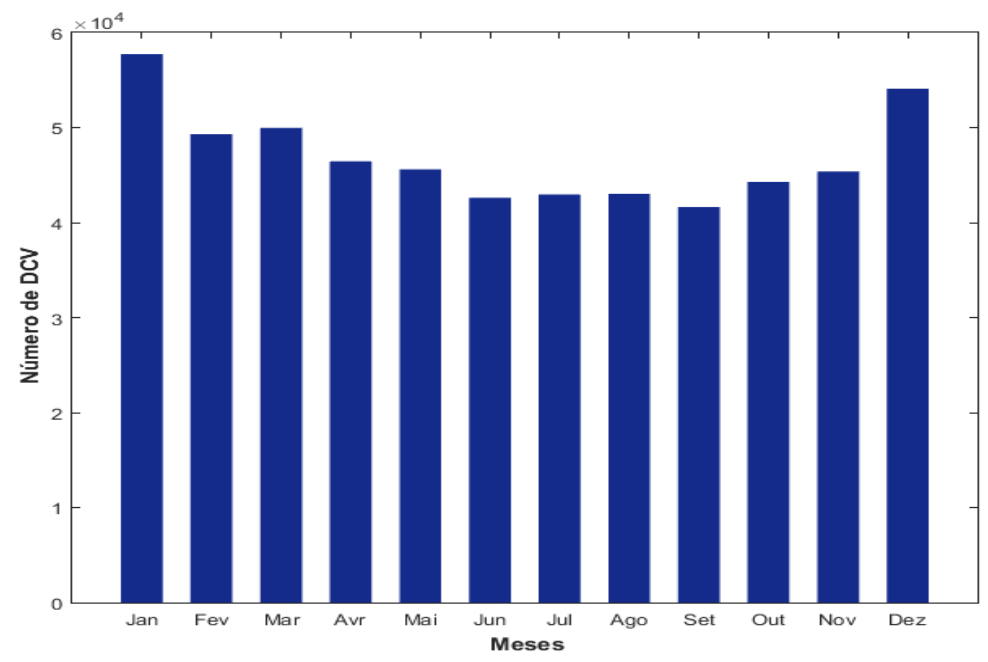

Figura 3.4. Mortalidade mensal por DCV para indivíduos com mais de 65 anos nos condados de a) Santa Bárbara, b) Orange e c) Los Angeles. 


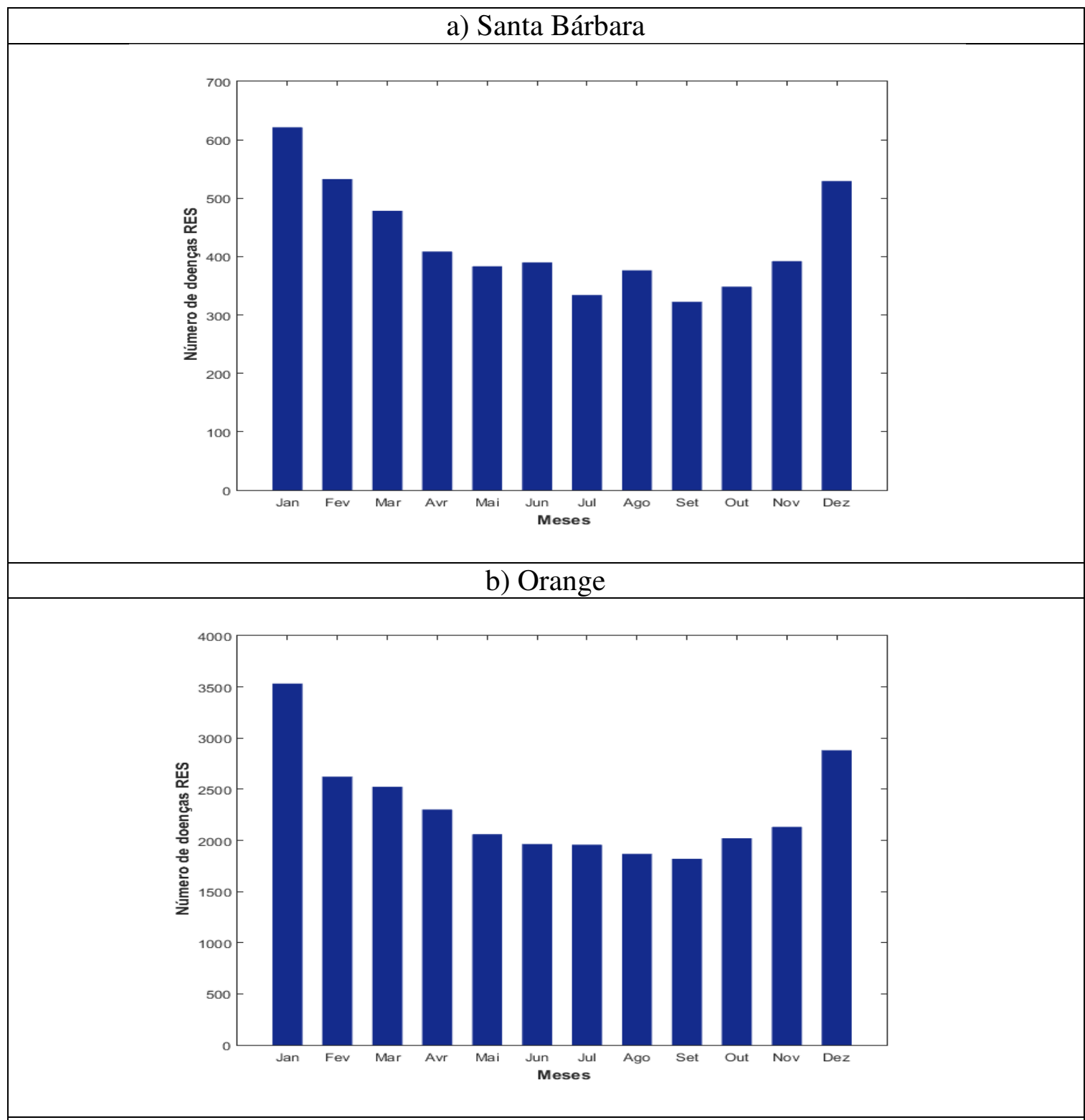

c) Los Angeles

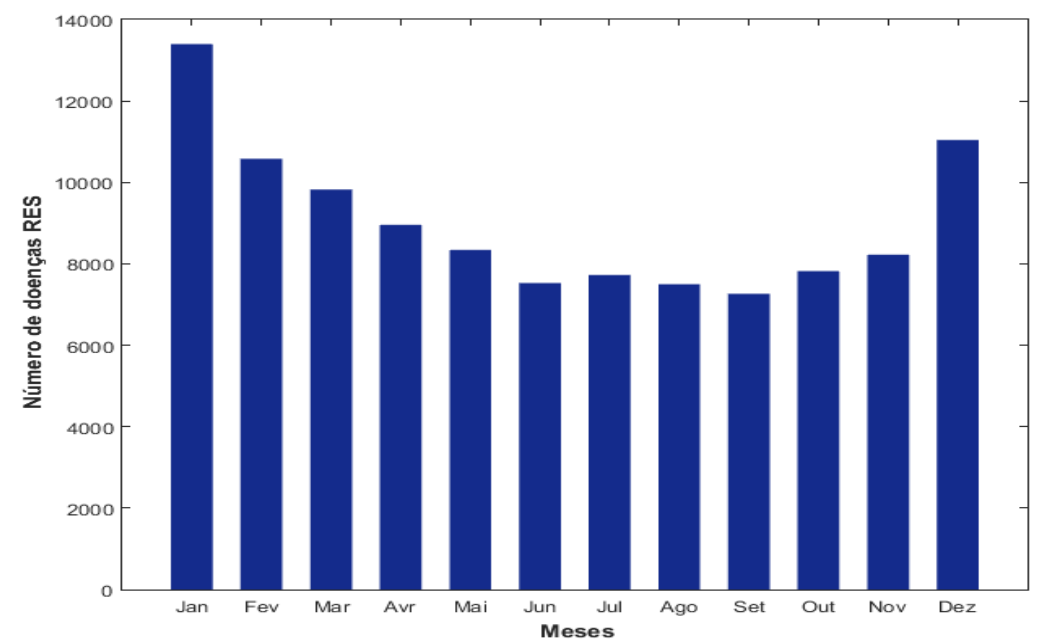

Figura 3.5. Mortalidade mensal por doenças RES para indivíduos com mais de 65 anos nos condados de a) Santa Bárbara, b) Orange e c) Los Angeles. 


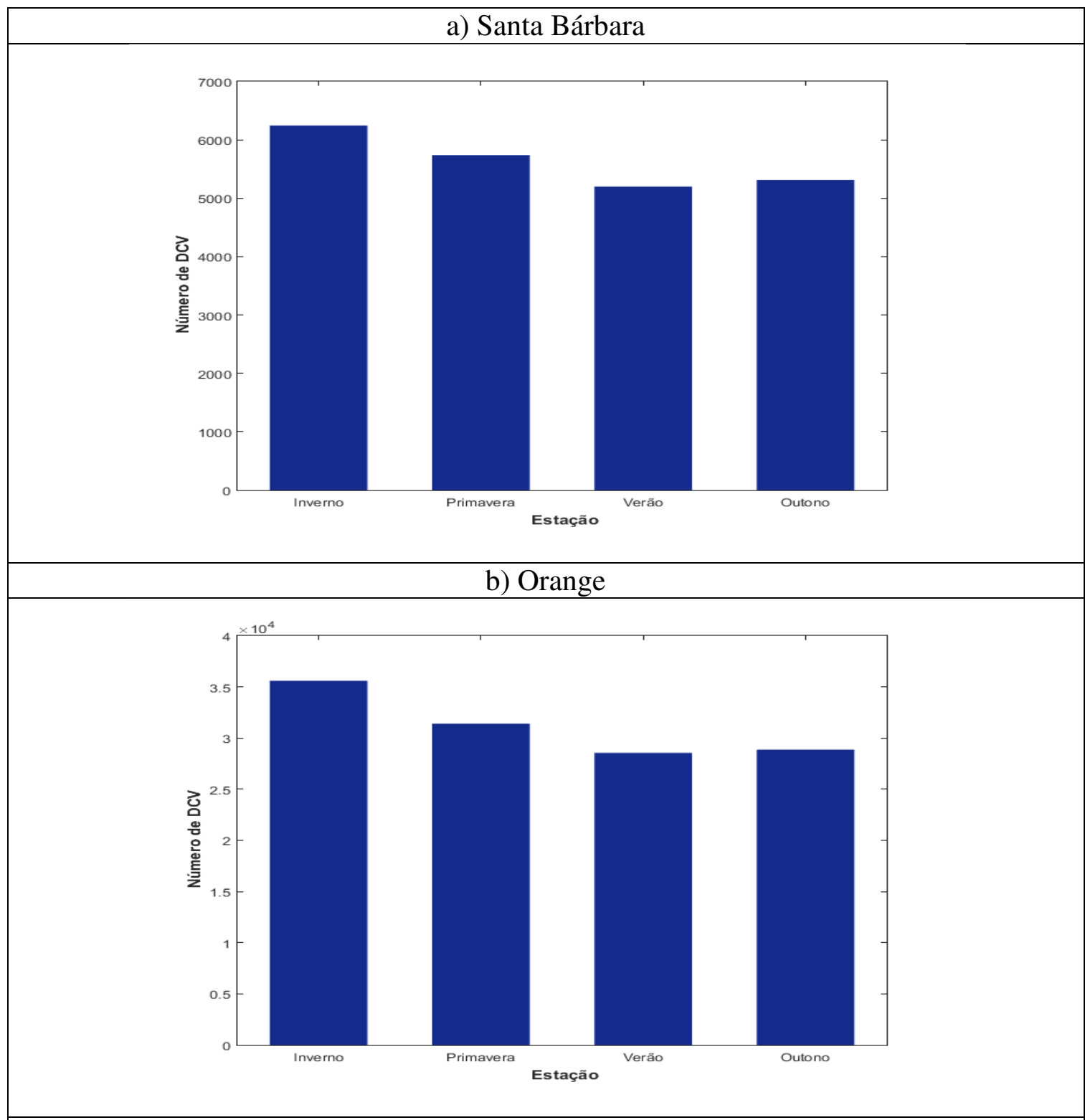

c) Los Angeles

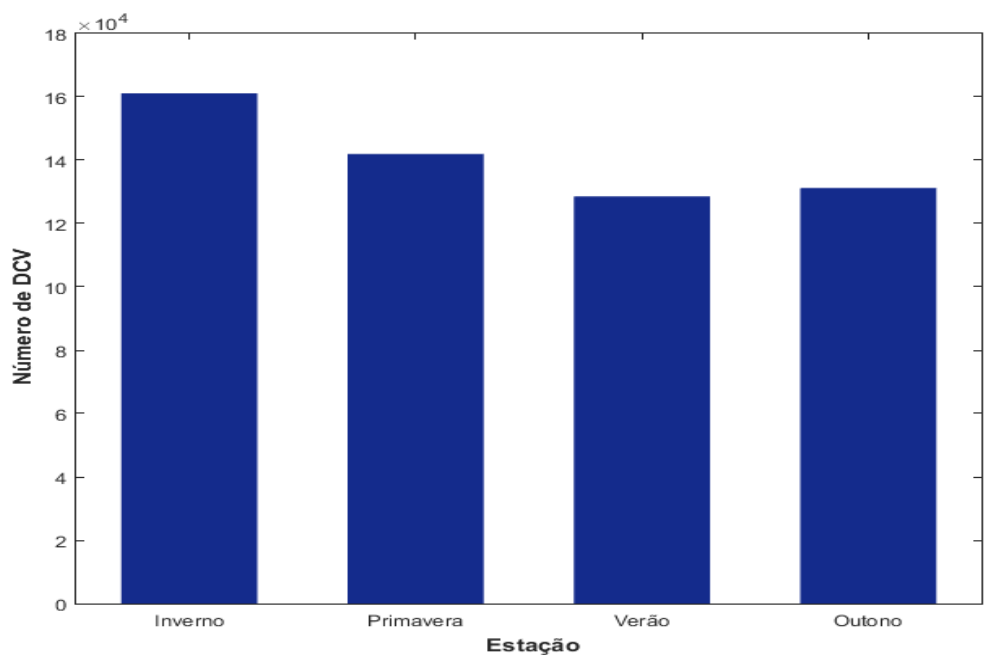

Figura 3.6. Distribuição de DCV por estações do ano, para indivíduos com mais de 65 anos nos condados de a) Santa Bárbara, b) Orange e c) Los Angeles. 


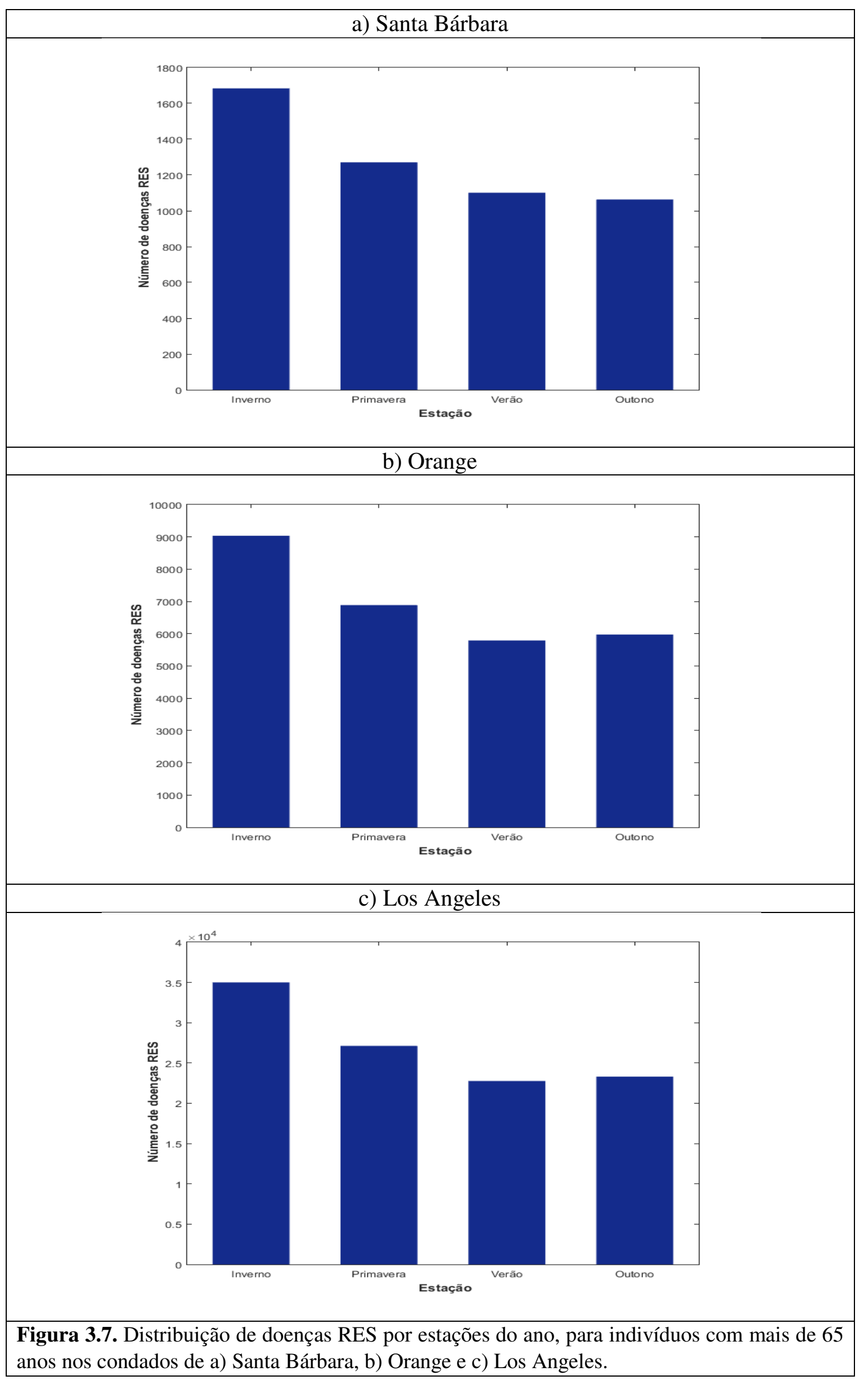




\subsection{Níveis de poluição}

Os principais efeitos da poluição do ar na saúde variam desde alterações na função pulmonar, problemas cardíacos e outros sintomas de desconforto, até o aumento do número de óbitos e internações hospitalares, especialmente devido a causas respiratórias e cardiovasculares. O relatório sobre a "Condição do Ar" (2016) da American Lung Association (ALA) indica que mais de $80 \%$ dos californianos ainda estão em situação de risco devido a um ar prejudicial à saúde. Neste sentido é muito importante ter um controle da poluição atmosférica, conhecer o período que ocorre essa deposição, assim como das condições atmosféricas favoráveis/desfavoráveis à dispersão de poluentes, com o objetivo de tomar medidas tanto de adaptação quanto de mitigação nos diferentes cenários.

Seguindo os padrões da qualidade do ar para os condados de Los Angeles, Orange, e Santa Bárbara, foram analisadas as distribuições dos níveis de poluição $\left(\mathrm{CO}, \mathrm{SO}_{2}, \mathrm{NO}_{2}\right.$, e $\mathrm{O}_{3}$ ) durante o período de estudo (figuras 3.8 - 3.14). Observa-se a queda dos níveis generalizada para todos os poluentes por condado. Por outro lado, houve também muitas ultrapassagens do padrão estabelecido, especialmente para o $\mathrm{O}_{3}$, seguido do $\mathrm{NO}_{2}$, sobretudo no condado de Los Angeles. Os resultados concordam com os reportes da ALA, que situam a Los Angeles como umas das áreas mais contaminadas por seus elevados níveis de ozônio, comparado com o condado de Santa Bárbara, o qual apresentou apenas ultrapassagens nas concentrações de $\mathrm{O}_{3}$, principalmente na década $\operatorname{dos} 80$.

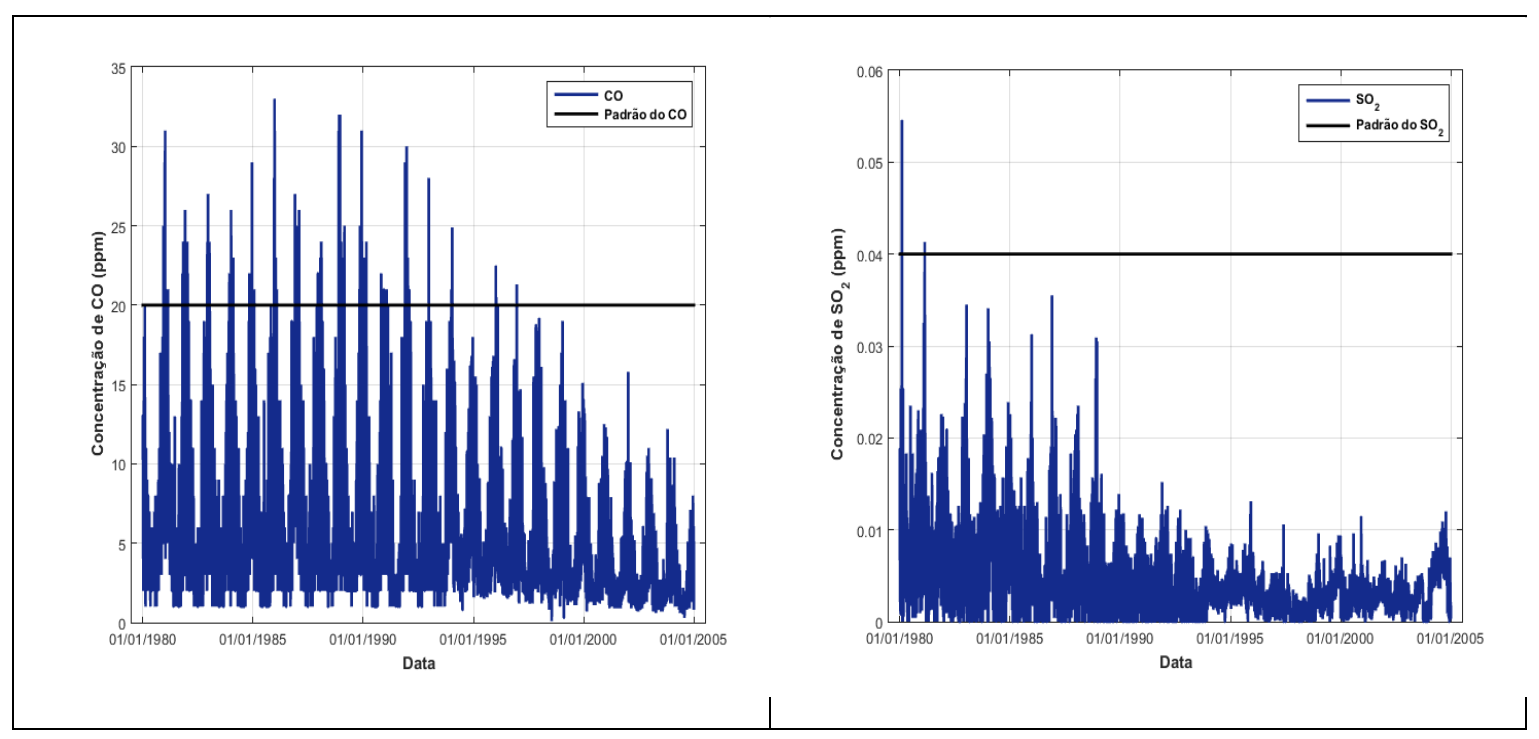



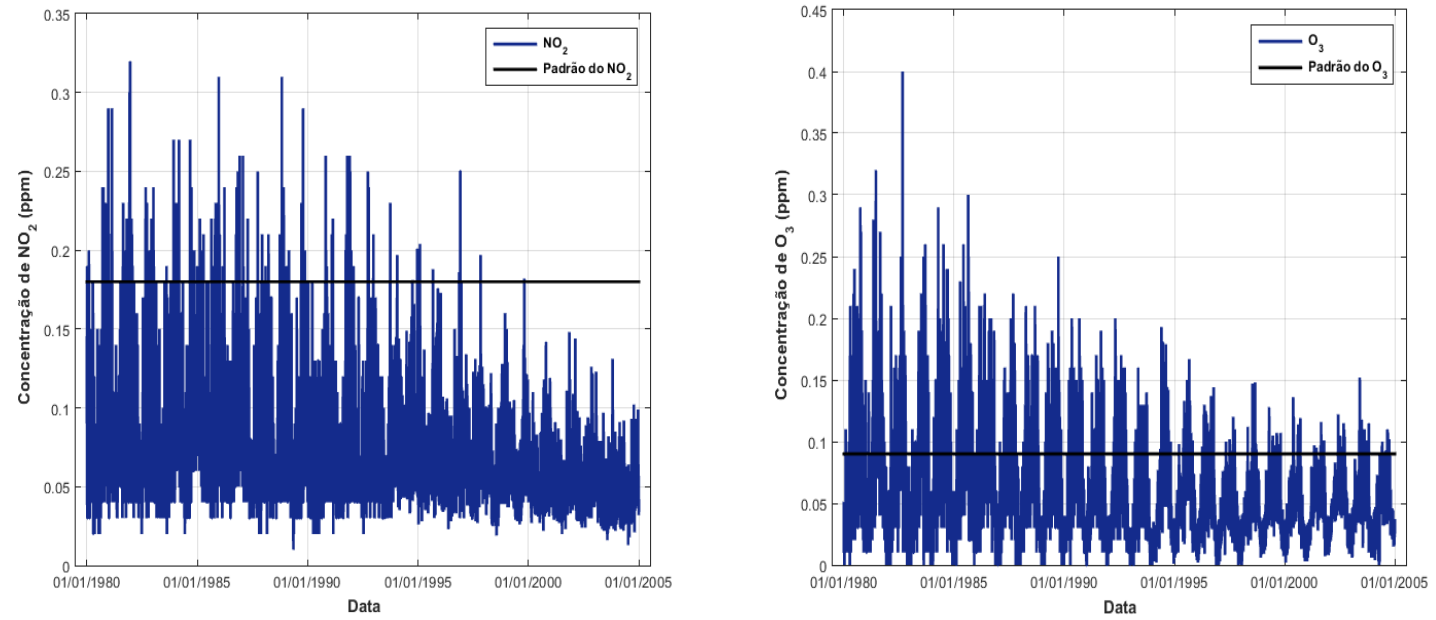

Figura 3.8. Concentrações dos poluentes a) $\mathrm{CO}$, b) $\mathrm{SO}_{2}$, c) $\mathrm{NO}_{2}$ e d) $\mathrm{O}_{3}$, Los Angeles (19802005).
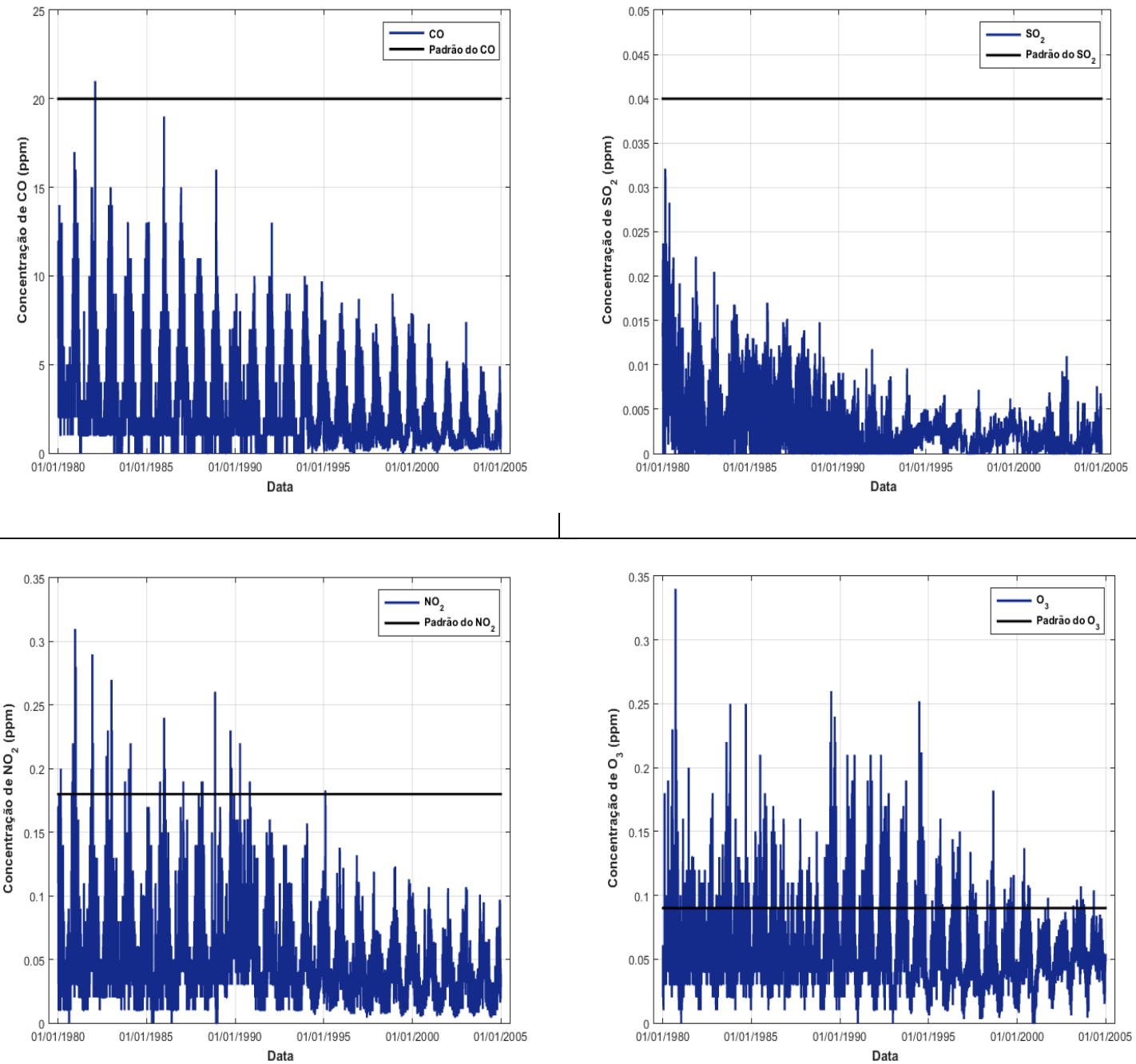

Figura 3.9. Concentrações dos poluentes a) $\mathrm{CO}$, b) $\mathrm{SO}_{2}$, c) $\mathrm{NO}_{2}$ e d) $\mathrm{O}_{3}$, Orange (1980-2005). 


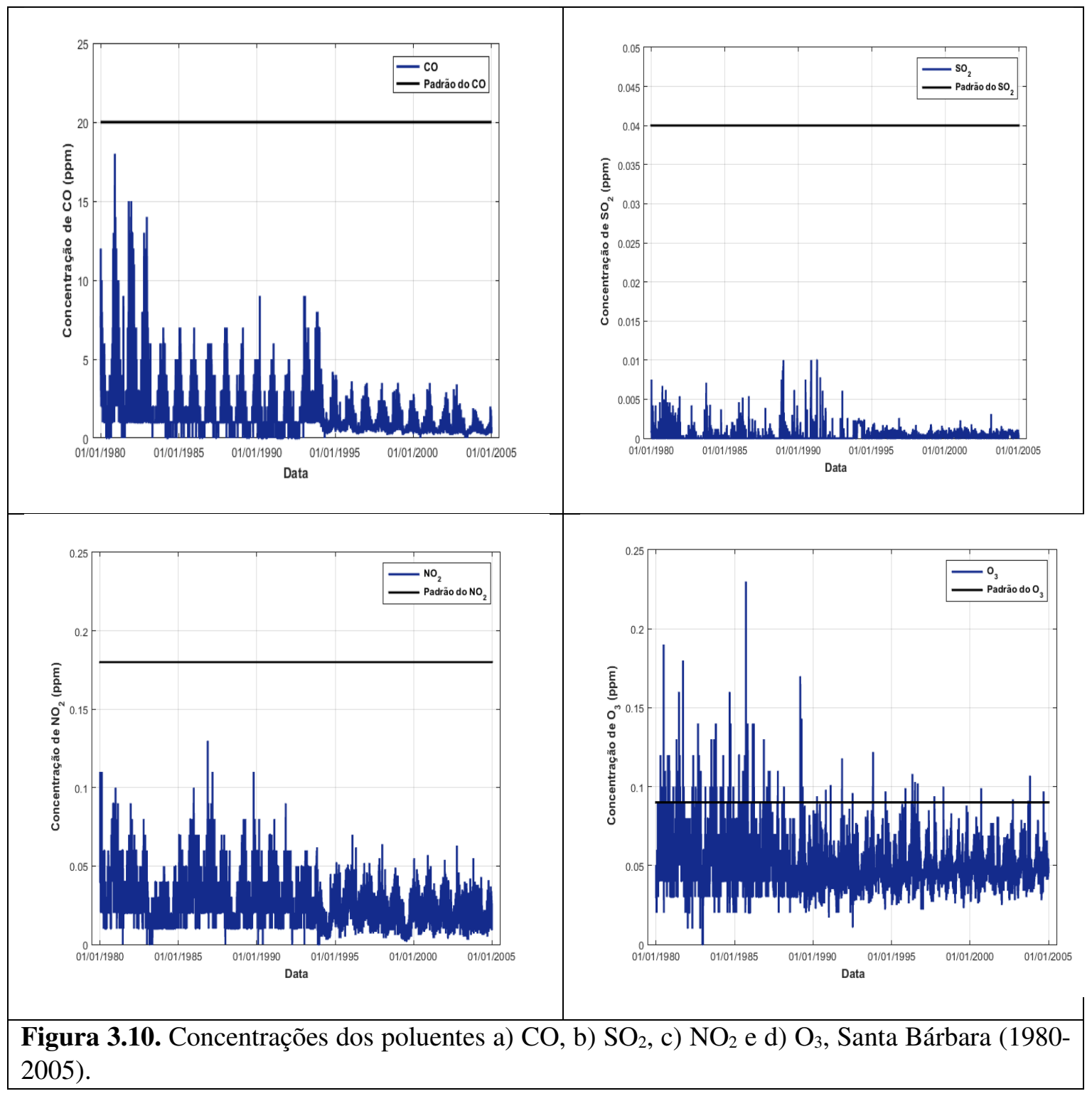

No condado de Los Angeles as concentrações de CO ultrapassa os padrões nacionais de qualidade do ar (20 ppm) 136 vezes no período, o valor máximo ocorreu no dia 23 de dezembro de 1985 com 33 ppm. No condado de Orange foi ultrapassado o padrão só uma vês com um valor de 21 ppm o dia 2 de fevereiro de 1982, já no caso de Santa Bárbara não houve nenhuma ultrapassagem. Em geral, a Agência de Proteção Ambiental dos EUA em seu inventário nacional de emissões de 1998 considerou os veículos automotores como a maior fonte individual dos principais poluentes atmosféricos, contribuindo com $60 \%$ da emissão de CO. No entanto, apesar do crescente número de veículos, observa-se uma tendência de decréscimo das concentrações médias de $\mathrm{CO}$ nos últimos anos, devido possivelmente à significativa modernização da frota. 
Por sua parte, a concentração de $\mathrm{NO}_{2}$ teve 154 ultrapassagens do padrão nacional de qualidade do ar $(0.19 \mathrm{ppm})$ no condado de Los Angeles e 43 no condado de Orange, a maior concentração foi no dia 19 de dezembro de 1981 com 0,32 ppm no condado de Los Angeles. Durante todo o período da análise, o número maior de ultrapassagens nos dois condados foi observado no mês de dezembro, seguido do mês de outubro (figura 3.11). Em total houve 70 ultrapassagens tanto em inverno quanto em outono para Los Angeles, assim como 22 e 15 em Orange, respectivamente (figura 3.12).
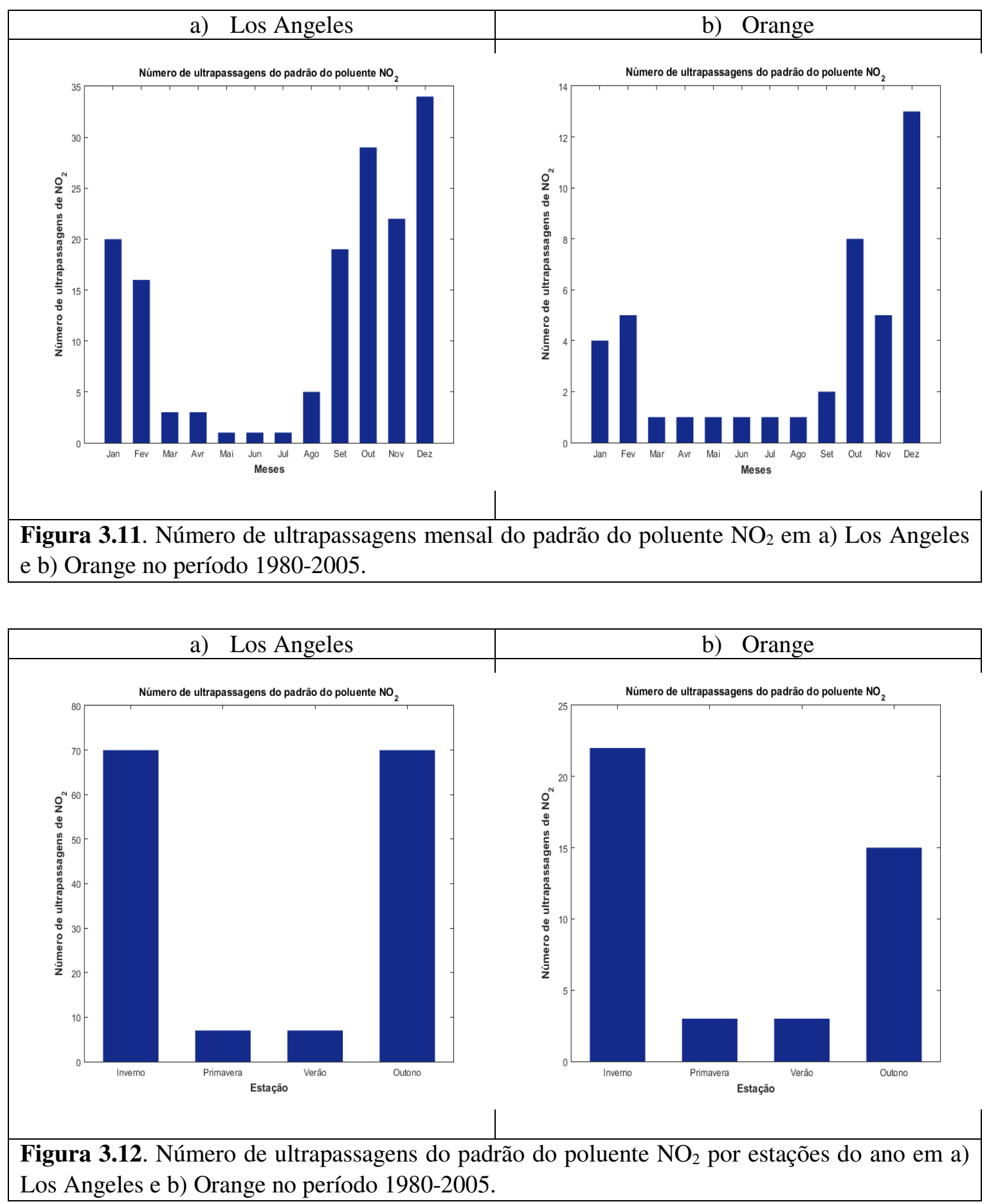
As principais fontes dos óxidos de nitrogênio $\left(\mathrm{NO}_{\mathrm{X}}\right)$ (óxido nítrico $(\mathrm{NO})$ e dióxido de nitrogênio $\left(\mathrm{NO}_{2}\right)$ ) são os motores de automóveis (contribuindo com um 31\%) assim como as indústrias que utilizam combustíveis fósseis. No entanto, na última década, as emissões de NOx diminuíram nos EUA, devido às tecnologias de controle de emissões empregadas em veículos rodoviários (por exemplo o catalisador) (Behrentz, 2005).

$\mathrm{O} \mathrm{NO}_{2}$, na presença de luz solar, hidrocarbonetos e oxigênio, transforma-se em ozônio $\left(\mathrm{O}_{3}\right)$, sendo um dos principais precursores deste poluente na troposfera. Ainda, devido a sua baixa solubilidade, $\mathrm{o} \mathrm{NO}_{2}$ quando é inalado atinge as porções mais profundas do sistema respiratório (alvéolos pulmonares) (Pereira, 1999). De acordo com Rosenlund et al., (2009) as associações mais fortes com a mortalidade por DCV parecem ser as exposições a longo prazo.

Diferentemente dos poluentes analisados até agora, onde a maior concentração se dá no período de inverno, o $\mathrm{O}_{3}$ apresentou uma distribuição temporal entre as estações correlacionadas diferente dos demais. Observaram-se as maiores concentrações durante o verão/outono nos condados de Los Angeles e Orange com média de 0,25/0,18 ppm e 0,19/0,18 ppm respectivamente, e em outono/primavera para o condado de Santa Bárbara com média de 0,16/015 ppm. Esses resultados indicam uma aparente queda durante no inverno, com média de 0,08 ppm para o condado de Los Angeles, 0,11 ppm para o condado de Orange e 0,13 ppm para o condado de Santa Bárbara. Além disso, foram identificados muitos dias com ultrapassagens, 114 em Santa Bárbara, 771 em Orange e 1443 em Los Angeles (figura 3.13). Note-se que o número de dias com ultrapassagens no condado de Los Angeles quase dobra aos do condado de Orange. Nesta região as principais fontes emissoras são os milhões de carros e caminhões que circulam diariamente, junto com as emissões nos portos de Long Beach e Los Angeles, refinarias, plantas de fabricação e a queima de madeira em residências.

Em geral, no condado de Santa Bárbara o mês com maior número de ultrapassagens foi setembro com 22, seguido de outubro e abril com 19 e 17 respectivamente. O mês de setembro em Orange também apresentou maiores valores de ultrapassagens com 153, seguido de agosto e julho com 130 e 113, respectivamente; já no caso de Los Angeles, setembro resultou ser o terceiro mês com maior número de ultrapassagens (253), o primeiro e segundo foram agosto e julho com 291 e 264, respectivamente (figura 3.14). 


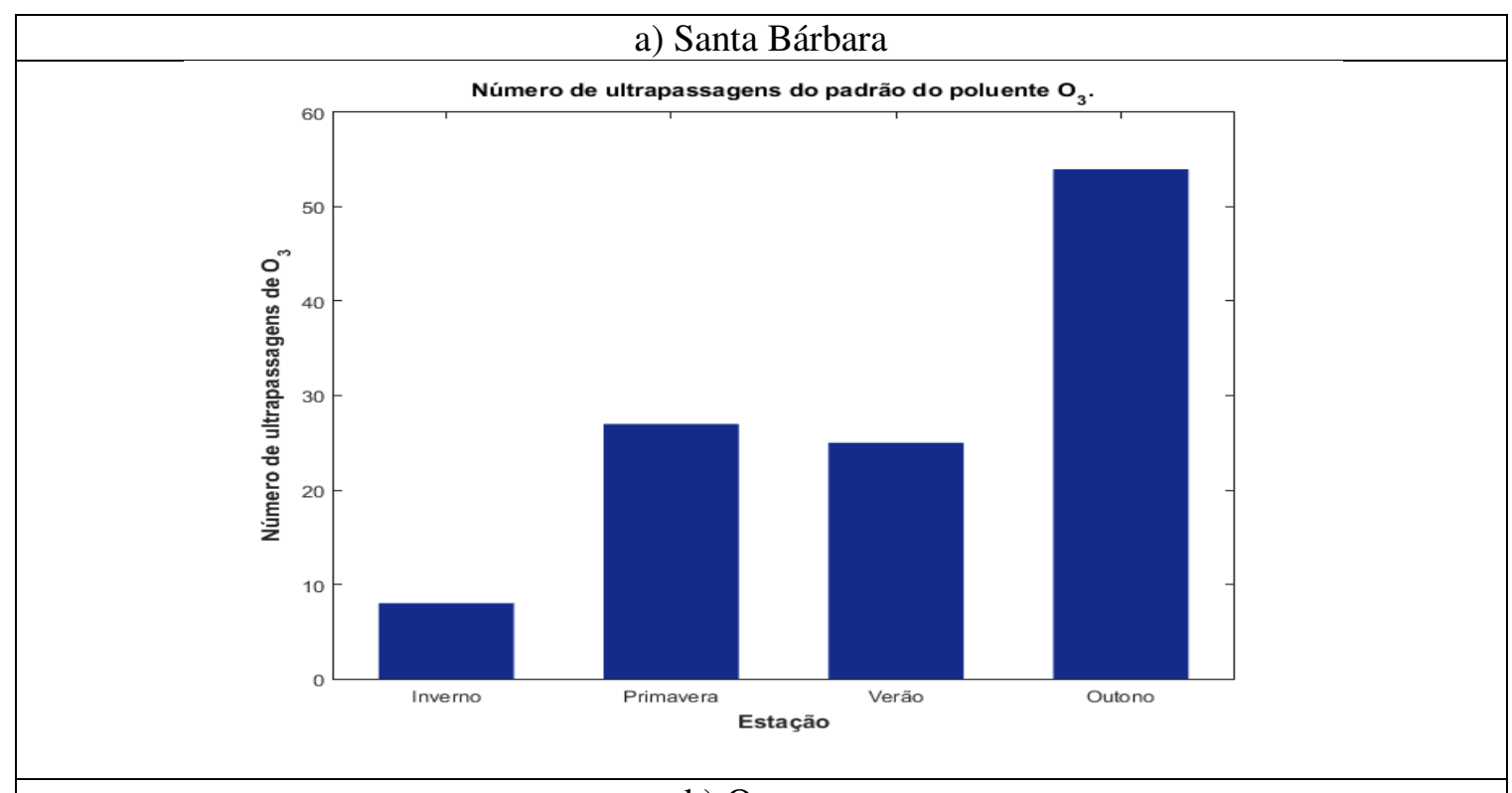

b) Orange

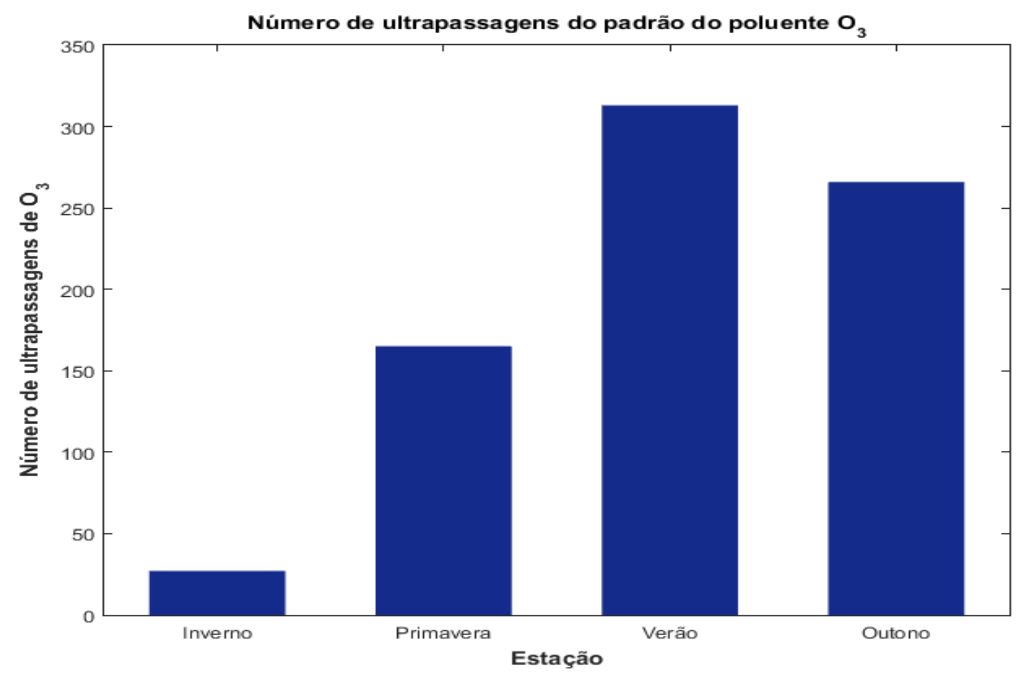

c) Los Angeles

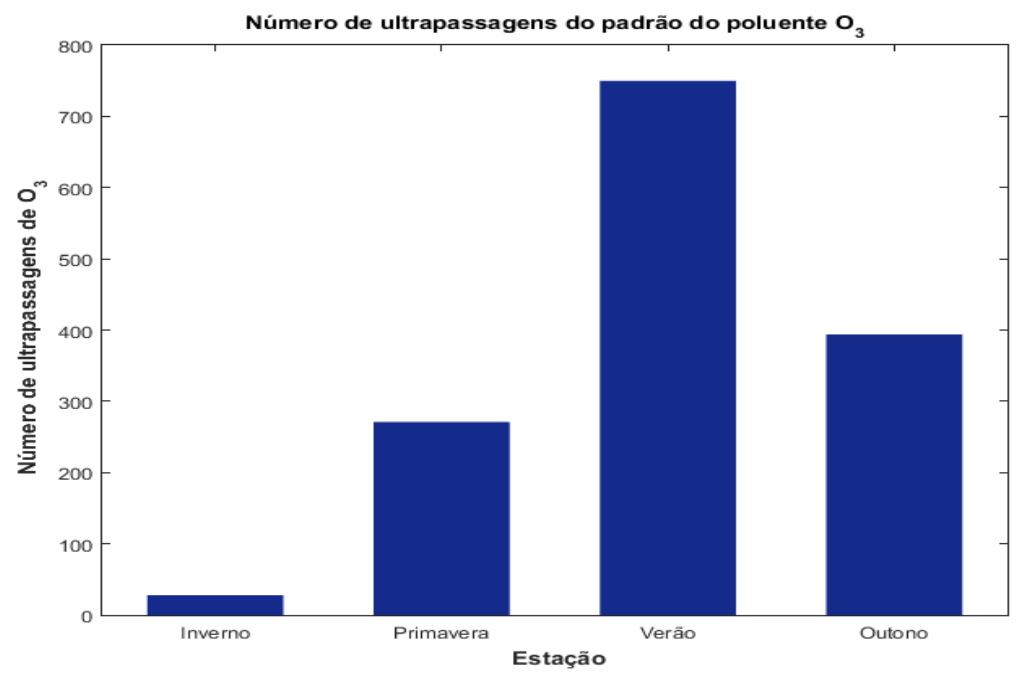

Figura 3.13. Número de ultrapassagens do padrão do poluente $\mathrm{O}_{3}$ por estações do ano em a) Santa Bárbara, b) Orange e c) Los Angeles no período 1980-2005. 


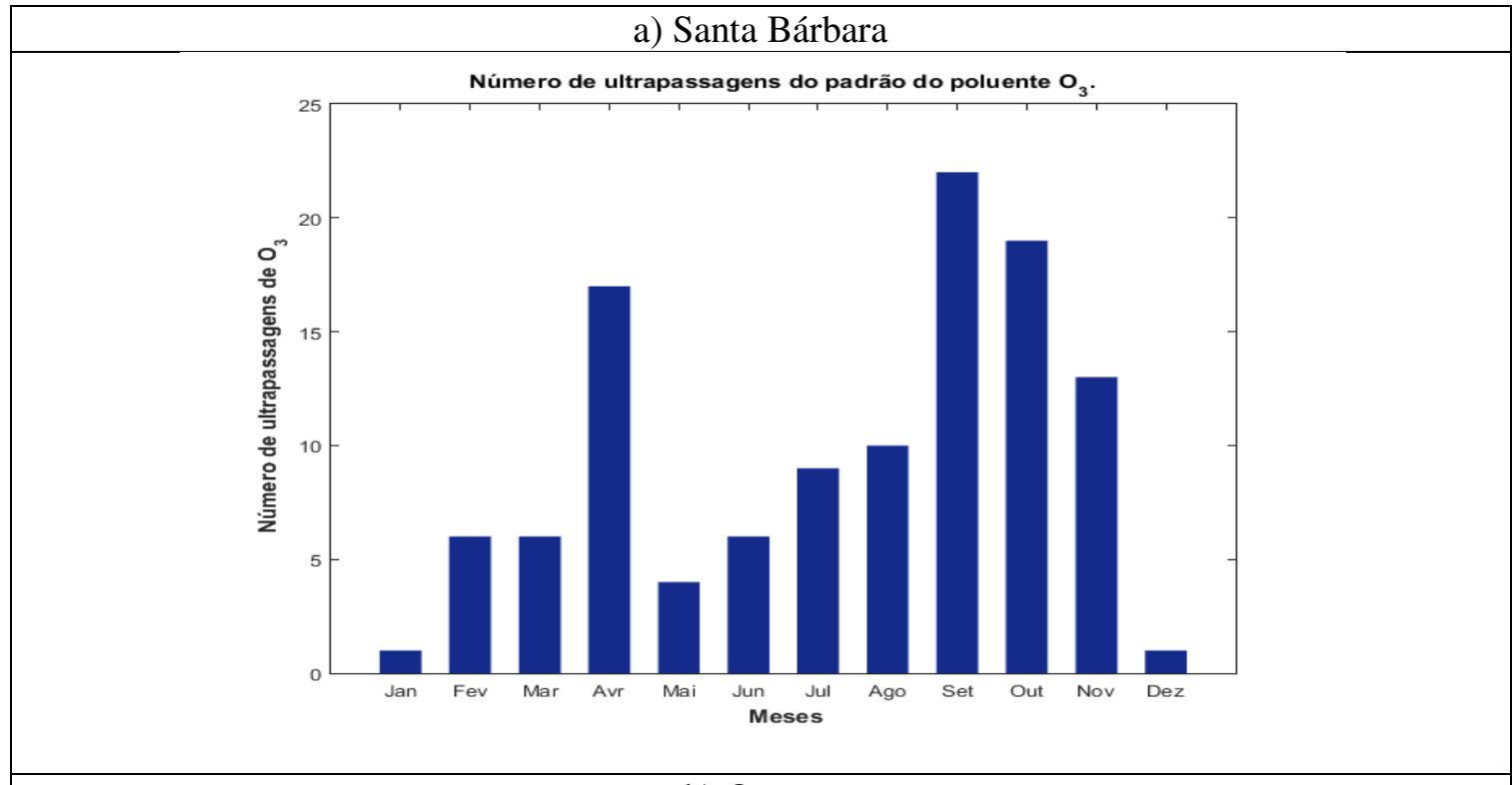

\section{b) Orange}

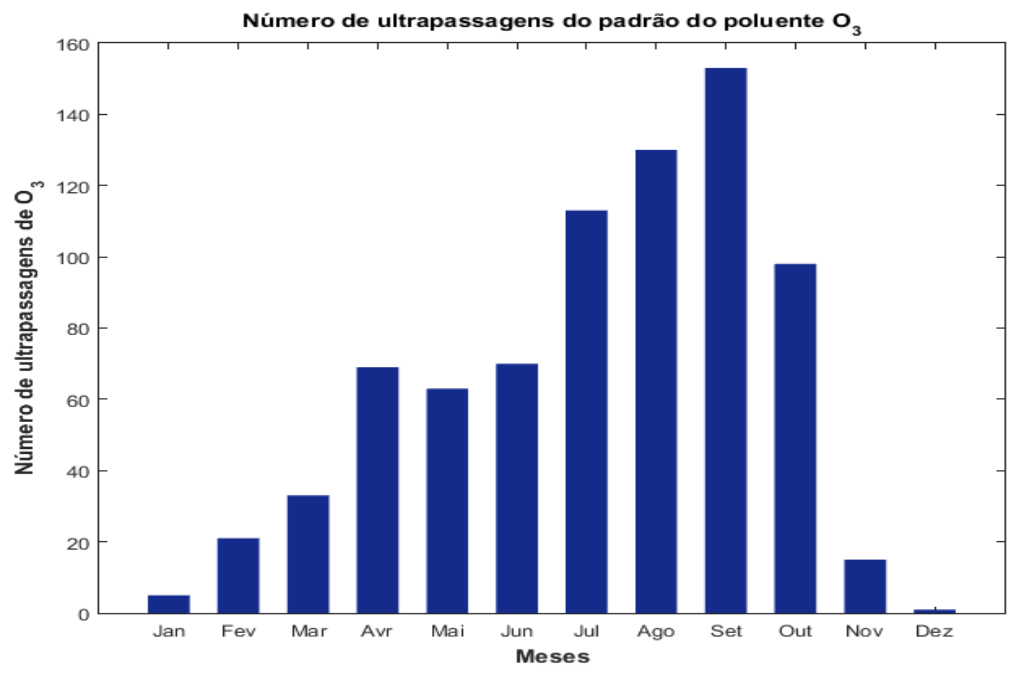

c) Los Angeles

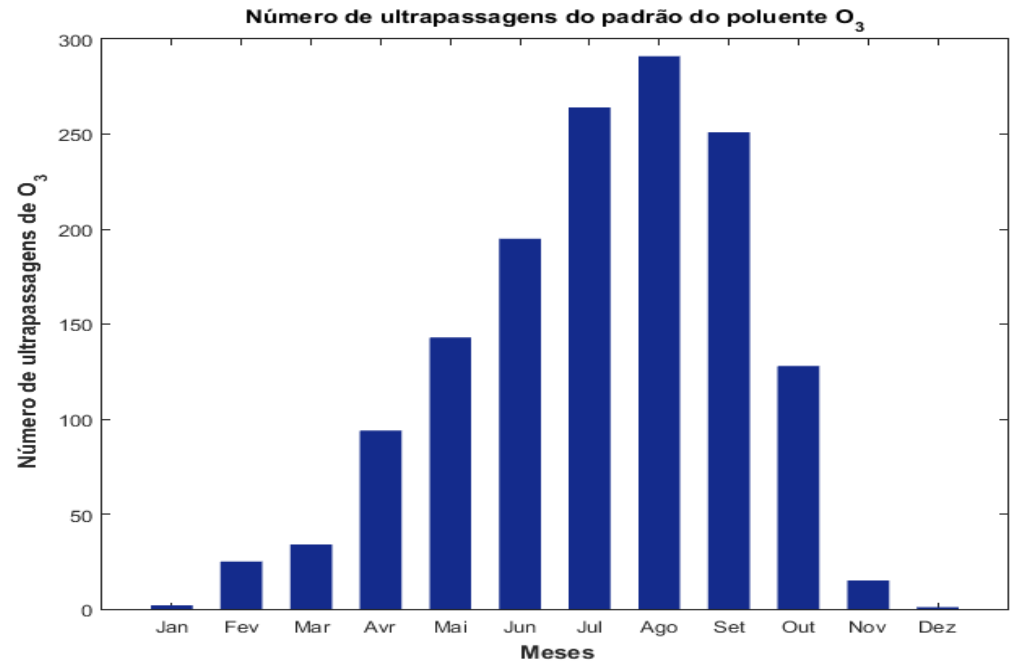

Figura 3.14. Número de ultrapassagens mensal do padrão do poluente $\mathrm{O}_{3}$ em a) Santa Bárbara, b) Orange e c) Los Angeles no período 1980-2005. 
Os resultados obtidos para Los Angeles mostram uma menor frequência de ultrapassagem nos meses de outubro-março, época de menores temperaturas e insolação. A partir de abril, com o aumento da temperatura e da insolação, a frequência de ultrapassagens do padrão de $\mathrm{O}_{3}$ aumenta.

$\mathrm{O}_{3}$ é um poluente secundário, formado por uma série de reações catalisadas pela luz do sol (raios ultravioletas) envolvendo, como precursores, óxidos de nitrogênio (NOx) e hidrocarbonetos, derivados de fontes de combustão móveis, como os veículos. Por essas razões é que suas maiores concentrações ocorrem tanto nos meses mais quentes, devido à elevada intensidade da radiação solar, quanto nos meses mais frios, devido ao período de inversões térmicas e as altas concentrações dos poluentes primários precursores do O3 (Braga, 1998; Colbeck e Mackenzie, 1994). Isso pode explicar que nos outros condados, principalmente no outono e na primavera se apresentem também elevadas concentrações de $\mathrm{O}_{3}$, pois existem as condições intermediárias para que isto ocorra: poluentes primários e radiação solar.

\section{3 Índices de conforto térmico}

A seguir são apresentados os resultados obtidos para cada índice de conforto térmico utilizado (ID, ID, TE, TEV, AT, IC e H) nos condados Los Angeles, Orange e Santa Bárbara. Também são estabelecidas as zonas de conforto térmico para os três condados utilizando o índice TE.

\subsection{1. Índice de desconforto de Thom (ID)}

Na figura 3.15, observa-se a variação temporal do ID nos condados de Santa Bárbara, Orange e Los Angeles, sob três situações diferentes. Na primeira consideram-se os valores médios da temperatura do ar e umidade relativa, na segunda utiliza-se a temperatura do ar mínima e a umidade relativa máxima, representando o período da manhã, e por último a temperatura do ar máxima e umidade relativa mínima, representando o período da tarde.

Este índice representa o grau de calor observado em diferentes combinações de temperatura e umidade. Em geral se o índice ultrapassa os $24^{\circ} \mathrm{C}$, mais da metade das pessoas sentem-se desconfortáveis. Quando está variando entre $27^{\circ} \mathrm{C}$ e $29^{\circ} \mathrm{C}$ é um indicador de que a maioria das pessoas sente-se desconfortáveis e, já quando o índice 
passa acima deste valor, todas as pessoas sentem um severo estresse. Em particular, ID acima de $32^{\circ} \mathrm{C}$ indica estado de emergência médica (Thom, 1959).

Nota-se, que no período do verão e outono há vários dias que são desconfortáveis com relação ao calor, pois se percebe valores de ID acima de $24^{\circ} \mathrm{C}$. Já no período de inverno os valores deste índice foram menores, indicando um menor estresse devido ao calor neste período. É possível perceber que a combinação de altas temperaturas com baixa umidade relativa produz altos valores de ID e que, na situação contrária, o ID apresenta menores valores.

A partir deste índice, observa-se como o condado de Los Angeles apresenta o maior estresse devido ao calor, com 74 dias acima do limite crítico de $29{ }^{\circ} \mathrm{C}, 4$ dias inclusive acima de $32^{\circ} \mathrm{C}$, ou seja, em estado de emergência. Ocorrendo principalmente quando são combinadas as altas temperaturas com a baixa umidade relativa. Neste sentido, o mês mais estressante foi setembro de 1988 alcançando valores ID de até $33,42^{\circ} \mathrm{C}$.

O condado de Santa Bárbara também apresentou dias onde todas as pessoas estiveram desconfortáveis com relação ao calor (30 dias), principalmente no mês de setembro (8 dias). Além disso, neste condado houve 11 dias com estresse severo, principalmente no mês de julho (4 dias).

Embora o condado de Orange não tenha tantos extremos como os outros dois condados; foi onde o ID mostrou maior quantidade de casos onde $50 \%$ das pessoas sentiram-se desconfortáveis, com um total de 1095, seguido de Los Angeles com 1017 e Santa Bárbara com 293, sendo os meses quentes e secos os de maior estresse.

Em geral durante o período de estudo o índice ID ultrapassa os $27^{\circ} \mathrm{C}$, principalmente durante o período de verão no condado de Orange (23), e nos condados de Santa Bárbara e Los Angeles no período de outono, com 14 e 135 casos respectivamente. Contudo, na maioria dos casos o índice achasse na faixa sem desconforto (ID < 21) para os três condados durante todo o período de estudo. 


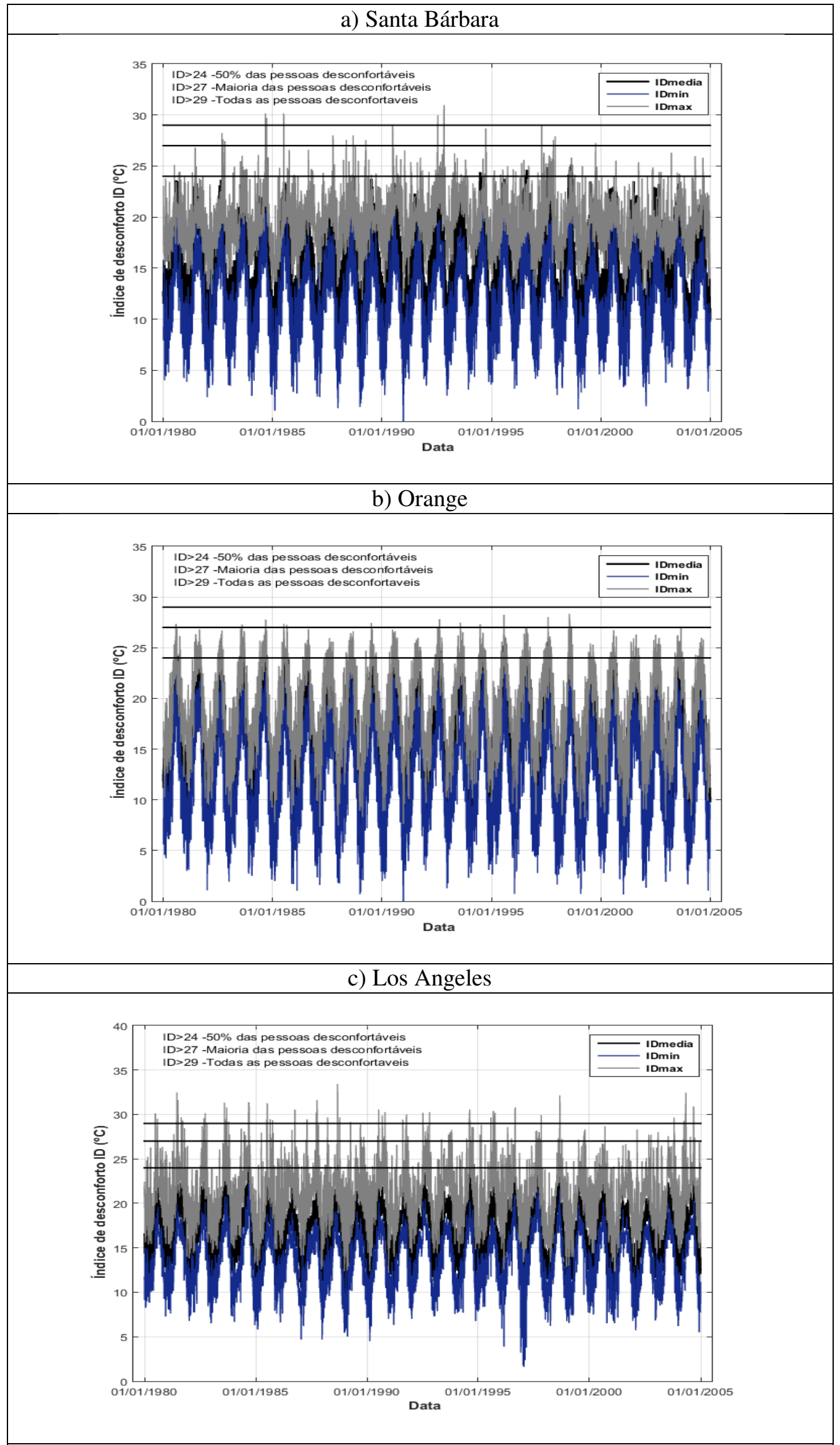

Figura 3.15. Variação temporal do ID, sob três aspectos diferentes, nos condados de a) Santa Bárbara, b) Orange e c) Los Angeles no período 1980-2005. 


\subsection{2. Índice de desconforto de Kawamura (IDK)}

O $\mathrm{IDK}_{\mathrm{K}}$ foi calculado com base nos valores médios, máximos e mínimos da temperatura do ponto de orvalho. Na figura 3.16 é apresentada sua variação temporal nos três condados. Em geral sob as três situações o comportamento é bem semelhante, resultando em valores altos do índice no período de verão e valores menores durante o inverno. Segundo Kawamura (1965) valores do índice variando entre $75^{\circ} \mathrm{C}$ e $80{ }^{\circ} \mathrm{C}$ são um indicador de desconforto respeito ao calor, em particular quando o $\mathrm{ID}_{\mathrm{K}}$ ultrapassa os $80^{\circ} \mathrm{C}$ todas as pessoas sentem insuportável calor, IDK entre 60 e $75{ }^{\circ} \mathrm{C}$ indica que as pessoas sentem-se confortáveis; para valores abaixo de $60^{\circ} \mathrm{C}$ as pessoas sentem frescor, enquanto que com valores abaixo de $55^{\circ} \mathrm{C}$ as pessoas sentem frio (Ono e Kawamura, 1991).

Observa-se que existem alguns períodos em que o índice excede os $75^{\circ} \mathrm{C}$, o que indica que as pessoas se sentiram desconfortáveis com relação ao calor. Novamente o condado de Los Angeles apresenta o maior estresse devido ao calor quando comparado com Orange e Santa Bárbara. Observam-se inclusive 65 dias com valores superiores a $80^{\circ} \mathrm{C}$, sobretudo nos meses de setembro (23) e agosto (10). Por sua parte os outros dois condados nunca excederam os $80^{\circ} \mathrm{C}$ e na faixa de desconfortavelmente quente se registraram um total de 91 dias em Orange seguido de Santa Bárbara com 27, principalmente no mês de agosto. A partir ID $_{\mathrm{K}}$ o dia mais estressante devido ao calor foi o 5 de setembro de 1988 com 87,8 $8^{\circ} \mathrm{C}$ em Los Angeles, coincidindo também com o dia de maiores valores de ID.

Porém, percebe-se que em praticamente todos os invernos o $\mathrm{IDK}_{\mathrm{K}}$ cai abaixo de $55^{\circ} \mathrm{C}$ nos três condados, ou seja, as pessoas tendem a sentir mais estresse com relação ao frio quando comparado com calor, principalmente quando é usada para o cálculo a $T_{d}$ mínima. Durante o inverno de 1990 o IDK alcançou seu valor mínimo, chegando no condado de Orange até os $33,9^{\circ} \mathrm{C}(23 / 12 / 90$, dia em que houve a menor temperatura mínima do período de estudo com $-5.4^{\circ} \mathrm{C}$, também nesse condado). Em geral, nota-se nos condados de Santa Bárbara e Orange como a maioria dos casos os três testes de índices encontram-se relacionados com os dias onde a sensação é de muito frio com um total de 1625 e 1728 na estação de inverno, respectivamente. 


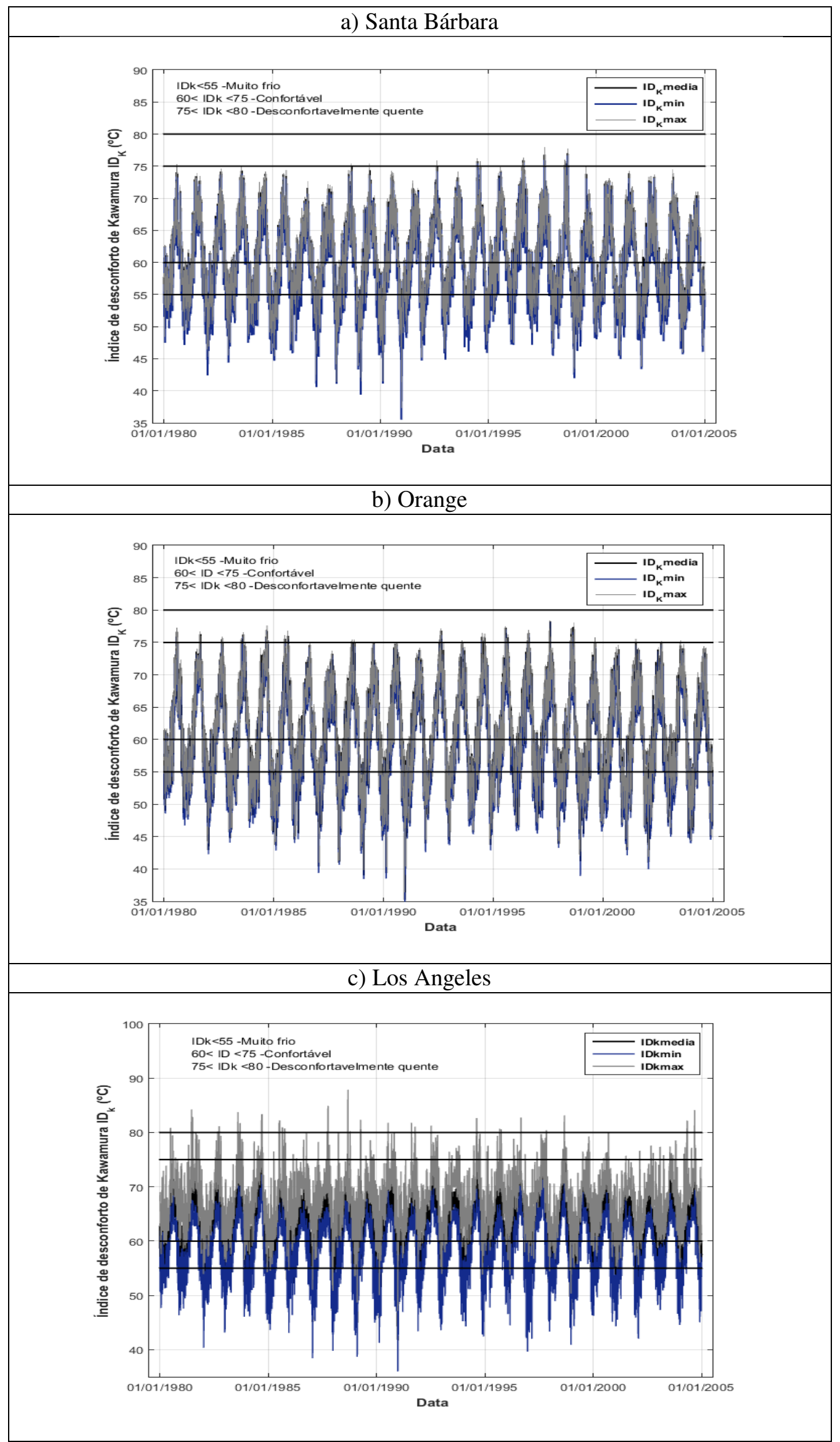

Figura 3.16. Variação temporal do $\mathrm{ID}_{\mathrm{K}}$, sob três aspectos diferentes, nos condados de a) Santa Bárbara, b) Orange e c) Los Angeles no período 1980-2005. 


\subsubsection{Temperatura efetiva (TE)}

$\mathrm{Na}$ figura 3.17 observa-se a variação temporal do índice TE, assim como os valores limites que indicam os graus de desconforto nos três condados. $\mathrm{O}$ índice foi calculado com base a três situações, na primeira consideram-se os valores médios da temperatura do ar e umidade relativa, na segunda e na terceira é usada a temperatura máxima e a umidade relativa mínima, e a temperatura mínima e a umidade relativa máxima, respectivamente. Quando o índice varia entre 22 e $25^{\circ} \mathrm{C}$ as pessoas sentem-se confortáveis. Por outro lado, valores maiores de $25^{\circ} \mathrm{C}$ e menores de $22^{\circ} \mathrm{C}$ são indicadores de desconforto devido ao calor ou ao frio.

Do mesmo modo que o índice proposto por Thom, o índice TE também apresenta resultados interessantes quando o objetivo é analisar o desconforto devido ao calor. Observa-se na figura 3.12 que durante o período de estudo o índice TE ultrapassa os 25 ${ }^{\circ} \mathrm{C}$, principalmente durante o período de verão no condado de Orange (568). Entretanto os condados de Santa Bárbara e Los Angeles no período de outono apresentaram 82 e 375 casos respectivamente. Novamente setembro resultou ser o mês mais estressante respeito ao calor, com um total de 277 ultrapassagens em Orange, seguido de $187 \mathrm{em}$ Los Angeles e 40 em Santa Bárbara. Valores de até $34.5^{\circ} \mathrm{C}$ foram observados durante o mês de setembro de 1990 (Los Angeles), o que indica, de acordo com a classificação de Fanger, sensação de muito calor.

A partir do cálculo de TE usando a temperatura máxima e a umidade relativa mínima, os condados de Los Angeles e Orange resultaram ser os mais estressantes devido ao calor, com um total de 798 dias no caso de Los Angeles e 747 dias para Orange, onde é ultrapassado o limite de $25^{\circ} \mathrm{C}$, por sua vez Santa Bárbara apresentou somente 186 dias.

Por outro lado, o índice TE também representa o estresse com relação ao frio. Verifacam-se valores inferiores a $13^{\circ} \mathrm{C}$ constantes durante todo o período, que segundo a classificação de Fanger é um indicador de extremo estresse ao frio (deve-se ressaltar que estes valores são para ambientes internos). Utilizando a temperatura mínima e a umidade relativa máxima, o dia mais frio nos condados de Santa Bárbara e Orange foi o 22 de dezembro de 1990 com um valor de TE de $-2.5^{\circ} \mathrm{C}$, para Los Angeles o mínimo de TE foi o 9 de janeiro de $1997 \mathrm{com} 1,2^{\circ} \mathrm{C}$. 


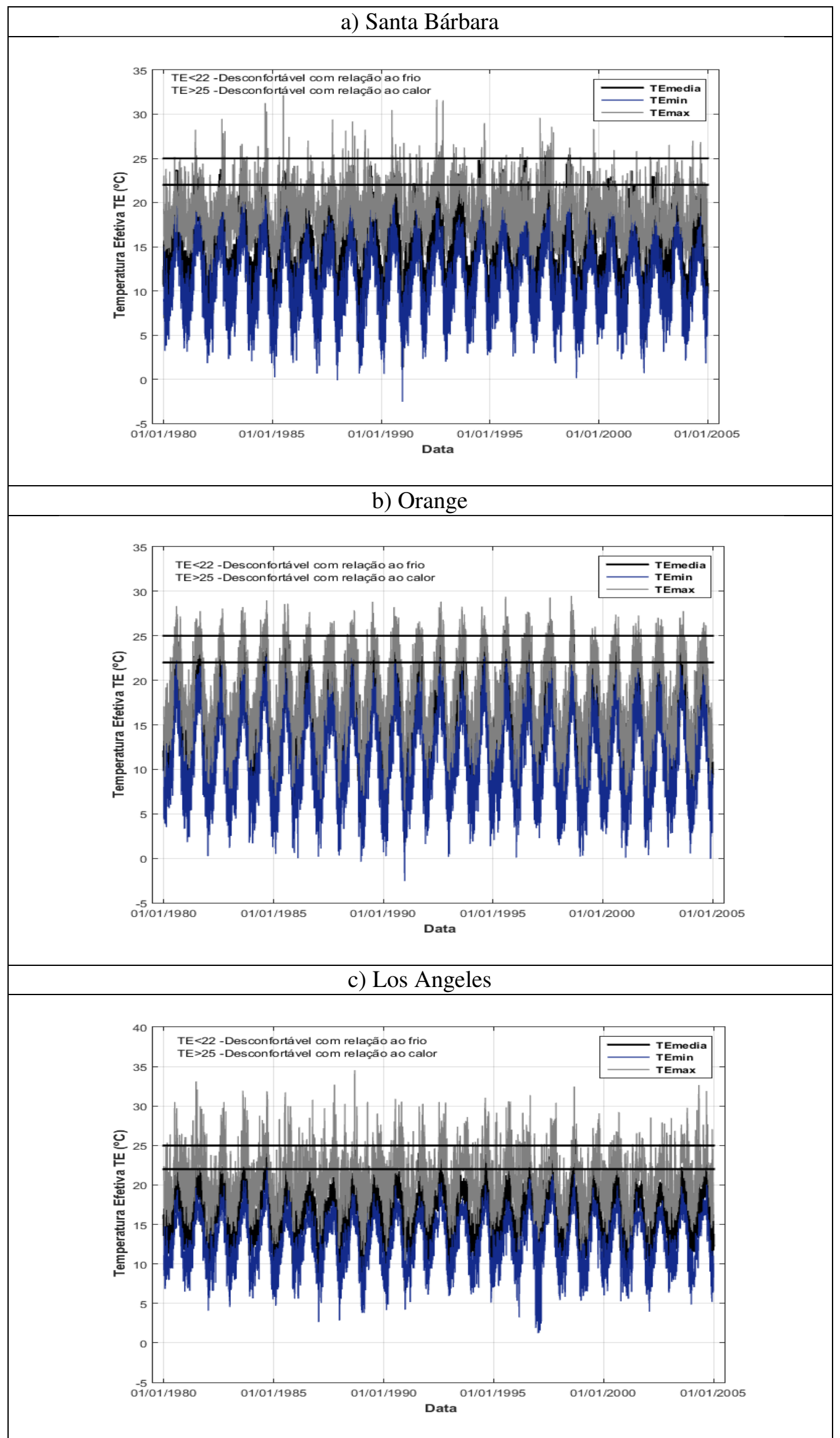

Figura 3.17. Variação temporal de TE, sob três situações diferentes, nos condados de a) Santa Bárbara, b) Orange e c) Los Angeles no período 1980-2005. 
Para classificar as condições térmicas dos condados de interesse foi utilizada a classificação das zonas de conforto para diferentes graus de percepção térmica e suas respostas fisiológicas estabelecidas por Fanger (1970) (tabela 2.6) aplicadas ao índice de TE. Com o objetivo de representar melhor o período onde o estresse por calor é mais intenso foi escolhida a combinação de temperatura máxima e umidade relativa mínima.

Nas tabelas 3.1 - 3.6 estão distribuídos os números de dias para cada sensação térmica, bem como o total, média e a porcentagem de óbitos por DCV e RES, para os três condados: Los Angeles, Orange e Santa Bárbara, respectivamente.

Observa-se como a maioria de óbitos para as duas doenças ocorrem quando a sensação é Ligeiramente Frio (35816 e 188707) seguido de Frio Moderado (28696 e 145213) no condado de Los Angeles, para Orange a maior quantidade de óbitos acontece quando a sensação térmica é de Frio (6295 e 27427), seguido de Frio Moderado (5702 e 24812), entretanto para Santa Bárbara a sensação térmica que apresenta maior quantidade de óbitos é a de Frio Moderado (1989 e 8423) seguido de Ligeiramente Frio (1675 e 7951 ). No entanto estes resultados refletem os tipos de tempo predominantes para cada condado.

Analisando a média de óbitos por sensação térmica nota-se que há um aumento das doenças nos extremos, principalmente quando a sensação é Muito Fria com valores médios por doenças RES de 16,42, 3,31 e 0,81, e por DCV de 77,32, 15,37 e 2,92 para os condados de Los Angeles, Orange e Santa Bárbara, respectivamente. Em relação ao calor o condado de Los Angeles teve 18 dias quente e um dia muito quente onde a media para doenças RES foi de 10,32 e 11,88 respectivamente, por sua vez a média de óbitos por DCV foi de 67,91 e 89,12 respectivamente. O condado de Santa Bárbara teve 5 dias quente, onde houveram 17 óbitos por DCV, sob esta sensação térmica ocorreu a maior média com 3,49. Já o condado de Orange não teve nenhum dia com condições quente ou muito quente, no entanto apresentou 720 dias com uma sensação Ligeiramente Quente e 22 dias com Quente Moderado, com uma média de 2,46 e 2,61 de óbitos por doenças RES e de 12,57 e 13,00 de óbitos por DCV, respectivamente.

As porcentagens por doenças RES e DCV para o período de estudo considerando os diferentes tipos de sensações térmicas, utilizando o índice TE podem também ser visualizados na figura 3.18. 
Tabela 3.1 - Distribuição do número de dias, totais, média e por cento de óbitos por doenças RES nos tipos de tempo para Los Angeles, durante o período de 1980 a 2005 , utilizando o índice TE.

\begin{tabular}{|c|c|c|c|c|}
\hline Sensação Térmica & $\begin{array}{c}\text { Número de } \\
\text { dias }\end{array}$ & $\begin{array}{c}\text { Número de } \\
\text { óbitos RES }\end{array}$ & $\begin{array}{c}\text { Média de óbitos } \\
\text { RES }\end{array}$ & \% Óbitos RES \\
\hline Muito Frio & 51 & 837 & 16,42 & 0,77 \\
\hline Frio & 761 & 10841 & 14,25 & 10,02 \\
\hline Frio moderado & 2239 & 28696 & 12,82 & 26,52 \\
\hline Ligeiramente frio & 3145 & 35816 & 11,39 & 33,10 \\
\hline Confortável & 2138 & 23478 & 10,98 & 21,70 \\
\hline Ligeiramente quente & 623 & 6695 & 10,75 & 6,19 \\
\hline Quente moderado & 156 & 1666 & 10,68 & 1,54 \\
\hline Quente & 18 & 185 & 10,32 & 0,17 \\
\hline Muito quente & 1 & 12 & 11,88 & 0,01 \\
\hline
\end{tabular}

Tabela 3.2 - Distribuição do número de dias, totais, média e por cento de óbitos por DCV nos tipos de tempo para Los Angeles, durante o período de 1980 a 2005, utilizando o índice TE.

\begin{tabular}{|c|c|c|c|c|}
\hline Sensação Térmica & $\begin{array}{c}\text { Número de } \\
\text { dias }\end{array}$ & $\begin{array}{c}\text { Número de } \\
\text { óbitos DCV }\end{array}$ & $\begin{array}{c}\text { Média de óbitos } \\
\text { DCV }\end{array}$ & \% Óbitos DCV \\
\hline Muito Frio & 51 & 3943 & 77,32 & 0,70 \\
\hline Frio & 761 & 51281 & 67,39 & 9,11 \\
\hline Frio moderado & 2239 & 145213 & 64,86 & 25,80 \\
\hline Ligeiramente frio & 3145 & 188707 & 60,00 & 33,52 \\
\hline Confortável & 2138 & 125686 & 58,79 & 22,33 \\
\hline Ligeiramente quente & 623 & 36841 & 59,13 & 6,54 \\
\hline Quente moderado & 156 & 9978 & 63,96 & 1,77 \\
\hline Quente & 18 & 1222 & 67,91 & 0,22 \\
\hline Muito quente & 1 & 89 & 89,12 & 0,02 \\
\hline
\end{tabular}


Tabela 3.3 - Distribuição do número de dias, de óbitos, média e por cento de óbitos por doenças RES, nos tipos de tempo para o condado de Orange, durante o período de 1980 a 2005 .

\begin{tabular}{|c|c|c|c|c|}
\hline Sensação Térmica & $\begin{array}{c}\text { Número de } \\
\text { dias }\end{array}$ & $\begin{array}{c}\text { Número de } \\
\text { óbitos RES }\end{array}$ & $\begin{array}{c}\text { Média de óbitos } \\
\text { RES }\end{array}$ & \% Óbitos RES \\
\hline Muito Frio & 1182 & 4507 & 3,81 & 16,28 \\
\hline Frio & 1861 & 6295 & 3,38 & 22,74 \\
\hline Frio moderado & 1793 & 5702 & 3,18 & 20,60 \\
\hline Ligeiramente frio & 1712 & 4677 & 2,73 & 16,90 \\
\hline Confortável & 1842 & 4676 & 2,5 & 16,89 \\
\hline Ligeiramente quente & 720 & 1770 & 2,46 & 6,39 \\
\hline Quente moderado & 22 & 57 & 2,61 & 0,21 \\
\hline Quente & 0 & 0 & 0,00 & 0,00 \\
\hline Muito quente & 0 & 0 & 0,00 & 0,00 \\
\hline
\end{tabular}

Tabela 3.4 - Distribuição do número de dias, de óbitos, média e por cento de óbitos por DCV, nos tipos de tempo para o condado de Orange, durante o período de 1980 a 2005.

\begin{tabular}{|c|c|c|c|c|}
\hline Sensação Térmica & $\begin{array}{c}\text { Número de } \\
\text { dias }\end{array}$ & $\begin{array}{c}\text { Número de } \\
\text { óbitos DCV }\end{array}$ & $\begin{array}{c}\text { Média de óbitos } \\
\text { DCV }\end{array}$ & \% Óbitos DCV \\
\hline Muito Frio & 1182 & 18166 & 15,37 & 14,60 \\
\hline Frio & 1861 & 27427 & 14,74 & 22,05 \\
\hline Frio moderado & 1793 & 24812 & 13,84 & 19,94 \\
\hline Ligeiramente frio & 1712 & 21999 & 12,85 & 17,68 \\
\hline Confortável & 1842 & 22674 & 12,31 & 18,23 \\
\hline Ligeiramente quente & 720 & 9048 & 12,57 & 7,27 \\
\hline Quente moderado & 22 & 286 & 13,00 & 0,23 \\
\hline Quente & 0 & 0 & 0,00 & 0,00 \\
\hline Muito quente & 0 & 0 & 0,00 & 0,00 \\
\hline
\end{tabular}


Tabela 3.5 - Distribuição do número de dias, de óbitos, média e por cento de óbitos por doenças RES, nos tipos de tempo para o condado de Santa Bárbara, durante o período de 1980 a 2005.

\begin{tabular}{|c|c|c|c|c|}
\hline Sensação Térmica & $\begin{array}{c}\text { Número de } \\
\text { dias }\end{array}$ & $\begin{array}{c}\text { Número de } \\
\text { óbitos RES }\end{array}$ & $\begin{array}{c}\text { Média de óbitos } \\
\text { RES }\end{array}$ & \% Óbitos RES \\
\hline Muito Frio & 61 & 53 & 0,88 & 1,04 \\
\hline Frio & 1129 & 762 & 0,68 & 14,89 \\
\hline Frio moderado & 3359 & 1989 & 0,59 & 38,87 \\
\hline Ligeiramente frio & 3351 & 1675 & 0,50 & 32,74 \\
\hline Confortável & 1047 & 549 & 0,52 & 10,73 \\
\hline Ligeiramente quente & 159 & 77 & 0,49 & 1,51 \\
\hline Quente moderado & 21 & 9 & 0,41 & 0,17 \\
\hline Quente & 5 & 2 & 0,47 & 0,05 \\
\hline Muito quente & 0 & 0 & 0,00 & 0,00 \\
\hline
\end{tabular}

Tabela 3.6 - Distribuição do número de dias, de óbitos, média e por cento de óbitos por DCV, nos tipos de tempo para o condado de Santa Bárbara, durante o período de 1980 a 2005 .

\begin{tabular}{|c|c|c|c|c|}
\hline Sensação Térmica & $\begin{array}{c}\text { Número de } \\
\text { dias }\end{array}$ & $\begin{array}{c}\text { Número de } \\
\text { óbitos DCV }\end{array}$ & $\begin{array}{c}\text { Média de óbitos } \\
\text { DCV }\end{array}$ & \% Óbitos DCV \\
\hline Muito Frio & 61 & 178 & 2,92 & 0,79 \\
\hline Frio & 1129 & 3052 & 2,70 & 13,57 \\
\hline Frio moderado & 3359 & 8423 & 2,50 & 37,45 \\
\hline Ligeiramente frio & 3351 & 7951 & 2,37 & 35,35 \\
\hline Confortável & 1047 & 2453 & 2,34 & 10,91 \\
\hline Ligeiramente quente & 159 & 366 & 2,30 & 1,63 \\
\hline Quente moderado & 21 & 52 & 2,49 & 0,23 \\
\hline Quente & 5 & 17 & 3,49 & 0,08 \\
\hline Muito quente & 0 & 0 & 0,00 & 0,00 \\
\hline
\end{tabular}




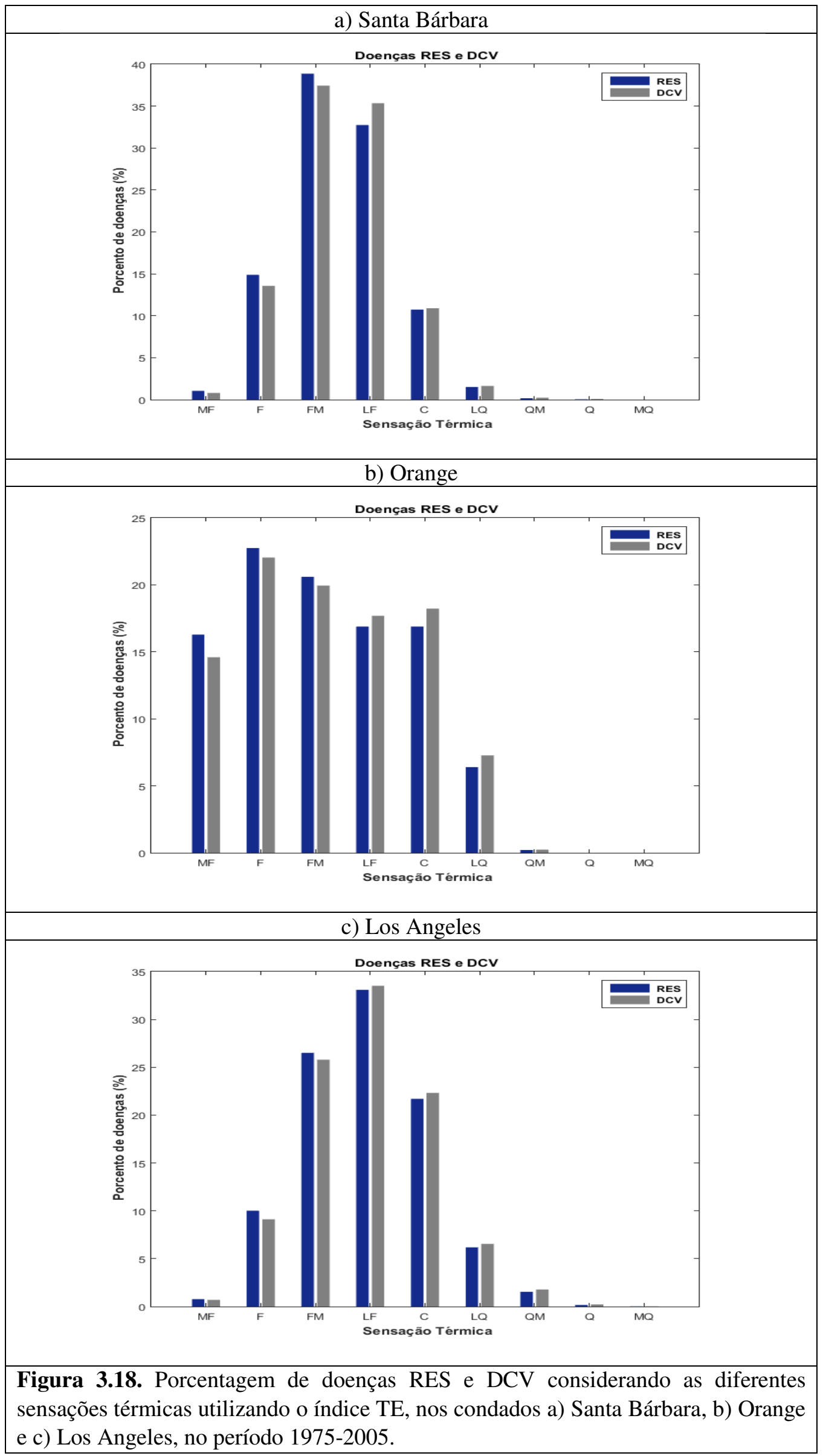




\subsubsection{Temperatura efetiva com relação ao vento $\left(T_{E_{v}}\right)$}

Na figura 3.19 são apresentados os resultados do índice proposto por Suping et al. (1992) para incluir a variável vento no cálculo do estresse humano $\left(\mathrm{TE}_{\mathrm{v}}\right)$. Do mesmo modo que os índices anteriores, este índice foi calculado para três situações diferentes, na primeira consideram-se os valores médios da temperatura do ar, umidade relativa e velocidade do vento, na segunda e na terceira mantém-se a velocidade do vento médio, mais é usada a temperatura máxima e a umidade relativa mínima, e a temperatura mínima e a umidade relativa máxima, respectivamente. Os limites de desconforto usando $\mathrm{TE}_{\mathrm{v}}$ coincidem com os de TE.

Observa-se que $\mathrm{TE}_{\mathrm{v}}$ tem dias em que houve desconforto com relação ao calor, principalmente no período do verão, no condado de Orange (99), entretanto os condados de Santa Bárbara e Los Angeles no período de outono apresentaram 24 e 84 dias respectivamente. $\mathrm{O}$ condado de Los Angeles resultou ser o mais estressante respeito ao calor com 154 dias em que $\mathrm{TE}_{\mathrm{v}}$ ultrapassa os $25^{\circ} \mathrm{C}$, seguido de Orange com 136 e Santa Bárbara com 51.

Com relação à $\mathrm{TE}_{\mathrm{v}}$ os meses de setembro e outubro foram os mais estressantes devido ao calor nos condados de Los Angeles e Santa Bárbara com um total de 80 e 21 cada. Por sua vez, o condado de Orange apresentou mais estresse por calor nos meses de julho e agosto com um total de 89 dias com ultrapassagens.

Valores de até $36,9^{\circ} \mathrm{C}$ em Los Angeles foram observados durante o setembro de 1988 , assim como de $35,4^{\circ} \mathrm{C}$ em Santa Bárbara em julho de 1985, o que indica, de acordo com a classificação de Fanger, sensação de muito calor. Já no caso de Orange o máximo foi de $29,5^{\circ} \mathrm{C}$ em julho de 1998 , indicando uma sensação de estresse por calor moderada.

No entanto, durante todo o período a maior concentração de dias estressantes se deu com relação ao frio, com um total de 8890 em Santa Bárbara chegando inclusive aos $29,5^{\circ} \mathrm{C}$.. Em Orange e Los Angeles o comportamento foi muito similar com 8811 e 8800 repetivamente. Note-se também que quando foram utilizados os valores médios e mínimos da temperatura, todos os valores encontrados ficaram dentro ou abaixo da zona de conforto, indicando não ser esta uma boa maneira de avaliar o estresse. 


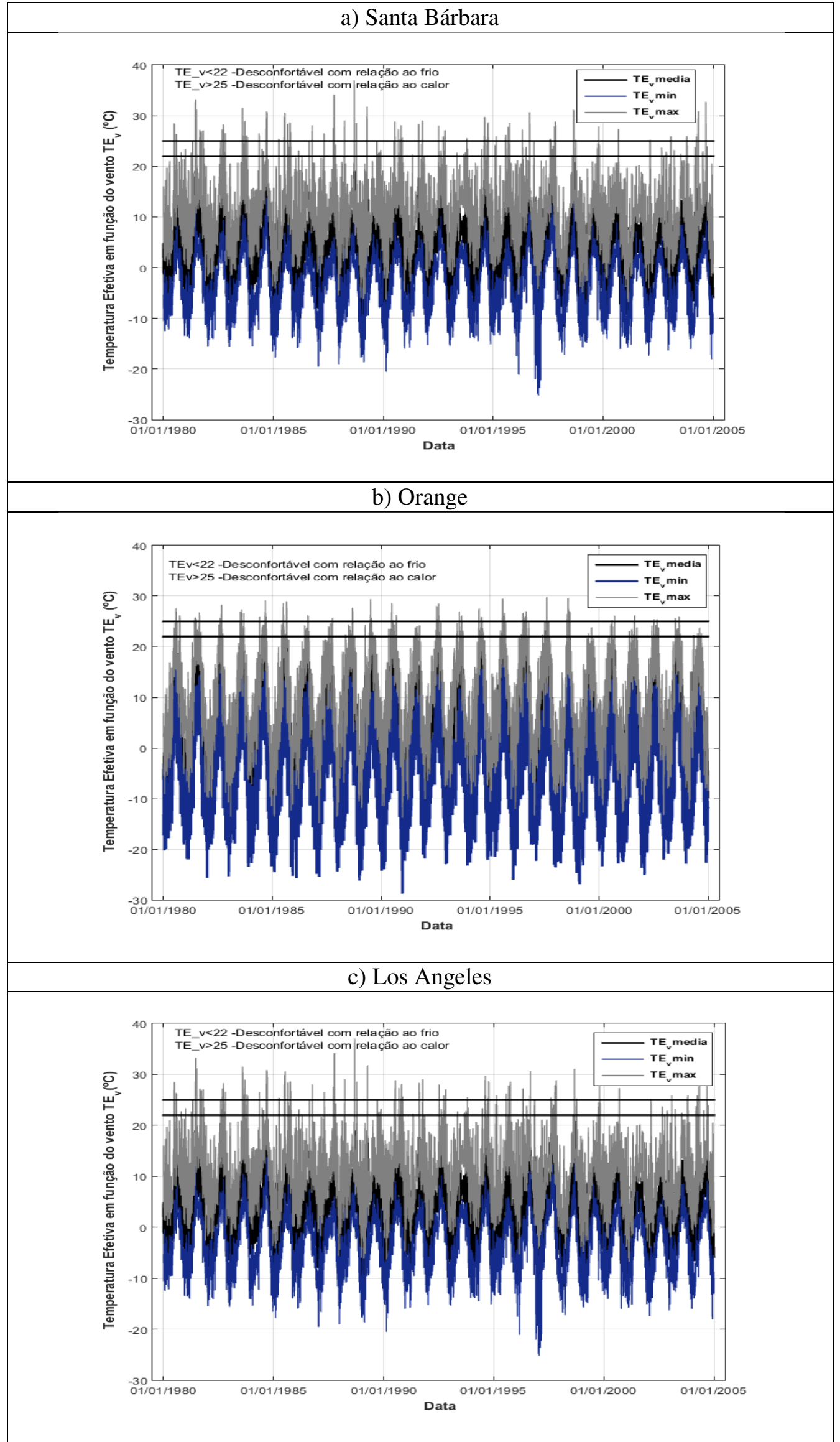

Figura 3.19. Variação temporal de $\mathrm{TE}_{\mathrm{v}}$, sob três situações diferentes, nos condados de a) Santa Bárbara, b) Orange e c) Los Angeles no período 1980-2005. 


\subsubsection{Temperatura Aparente (TA)}

O índice TA foi calculado com base nos valores médios, máximos da temperatura do ponto de orvalho. Este índice constitui a base do índice de calor usado pelo Serviço Meteorológico Nacional dos EUA na emissão de alertas de calor. Na figura 3.20 é apresentada sua variação temporal nos três condados. Em geral sob as duas situações o comportamento é bem semelhante, resultando em valores altos do índice no período de verão e valores menores durante o inverno. Segundo Steadman (1984) o índice foi desenvolvido para medir sensações térmicas em ambientes quentes e úmidos nos EUA. Quando os valores do índice são menores que $28^{\circ} \mathrm{C}$ o grado de estresse térmico é ausente, quando o valor do índice está entre $28^{\circ} \mathrm{C}$ e $32^{\circ} \mathrm{C}$ o estresse é leve, entre $32^{\circ} \mathrm{C}$ e $35^{\circ} \mathrm{C}$ e moderado, entre $35^{\circ} \mathrm{C}$ e $40^{\circ} \mathrm{C}$ é forte, chegando a ter um estresse térmico extremo quando os valores de TA excedam o valor de $40^{\circ} \mathrm{C}$.

Observa-se que existem apenas dois dias em todo o período onde o índice excede os $40^{\circ} \mathrm{C}$, o que indica que as pessoas sentiram um estresse extremo com relação ao calor; ocorridos nos condados de Los Angeles e Santa Bárbara nos dias 5 de setembro de 1988 e 2 de julho de 1985, respectivamente. O intervalo de forte estresse foi atingido um total de 15 vezes em Santa Bárbara, principalmente no mês de julho (5), 17 vezes em Orange, com o maior número de ultrapassagem em julho (7) e 22 vezes em Los Angeles, tendo o máximo de dias no mês de setembro (9). Com respeito ao estresse moderado o número de casos foi de 22 em Santa Bárbara, 220 em Orange e 106 em Los Angeles. Por último com estresse leve a maioria dos casos ocorre nos meses de setembro (435) e agosto (553) com ultrapassagem em todos os condados.

Porém percebe-se que durante quase todo o período nos três condados o índice fica na faixa de estresse ausente tanto para as temperaturas máximas como médias, devido ao clima mais seco na região sudoeste da Califórnia, o que diminui/ameniza o índice.

O trabalho de Davis et al., (2003) também utilizou a TA, neste caso para examinar as mudanças por décadas nas relações entre a mortalidade humana e o clima quente e úmido em 28 cidades dos EUA. Para isso foi estabelecido um limiar da TA para cada cidade a partir do qual a mortalidade é significativamente elevada. Analisando logo as taxas de mortalidade nos dias onde o limiar foi excedido. Os resultados mostraram que embora existam pequenas variações dentro das regiões analisadas, as cidades com verões mais quentes e mais úmidos tendem a ter o maior limiar da TA enquanto localidades caracteristicamente mais frias têm limites muito mais baixos. 


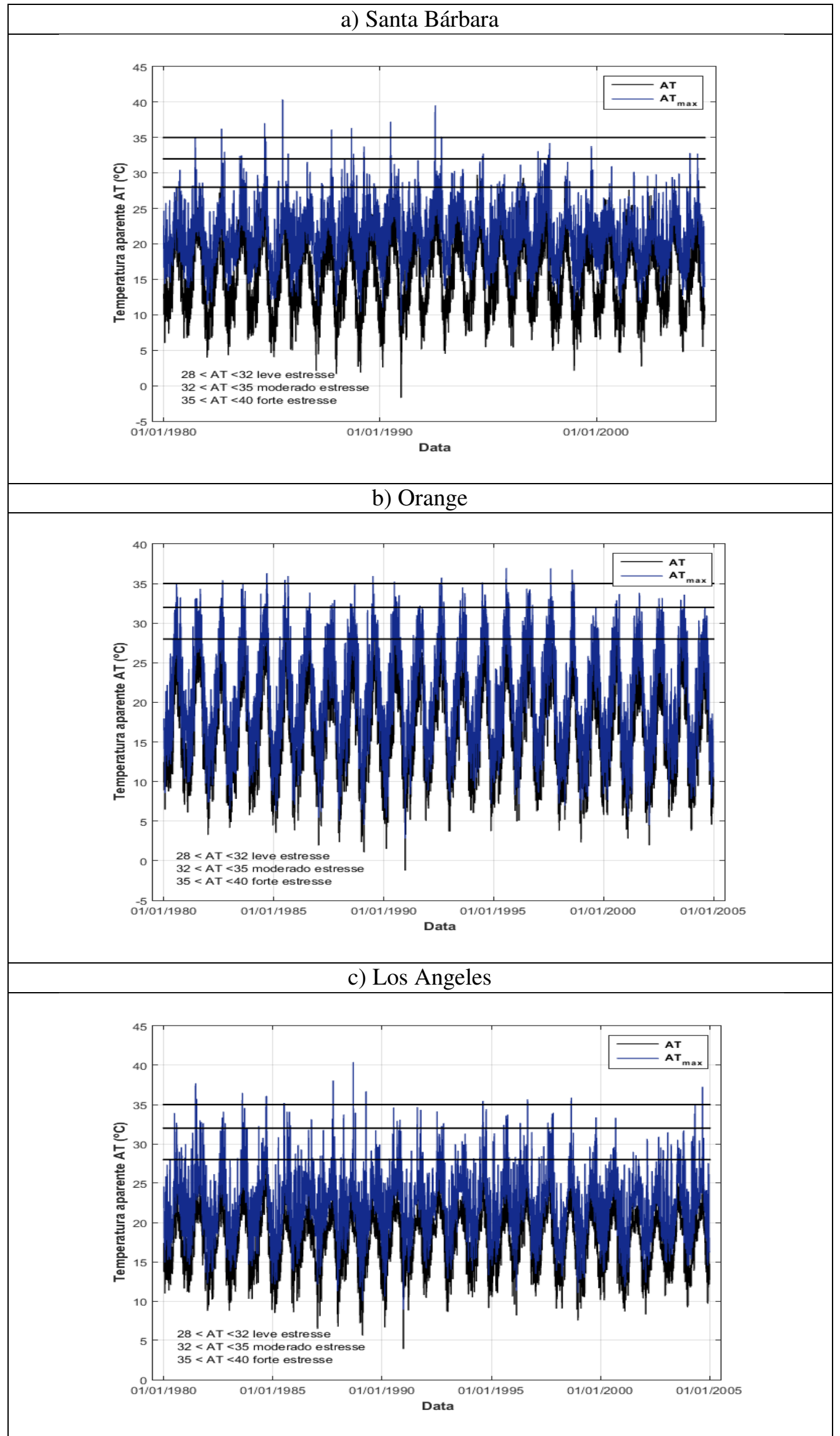

Figura 3.20. Variação temporal da TA, sob três aspectos diferentes, nos condados de a) Santa Bárbara, b) Orange e c) Los Angeles no período 1980-2005. 


\subsection{6 Índice de calor}

O IC foi calculado a partir de um ajuste linear utilizando os dados de temperatura do ar e a umidade relativa apresentada por Steadman (1979). Este índice é muito utilizado por a NOAA a partir do ano 2015 nos EUA. Na figura 3.21 é observada sua variação temporal nos três condados tomando a temperatura máxima e UR média. De acordo com a clasificaçao da NOAA pelos efeitos causados no corpo (ver tabela 2.8), os valores do índice entre $27^{\circ} \mathrm{C}$ e $32^{\circ} \mathrm{C}$ estão na faixa de cuidado, entre $32^{\circ} \mathrm{C}$ e $41^{\circ} \mathrm{C}$ em extrema cautela, entre $41^{\circ} \mathrm{C}$ e $54^{\circ} \mathrm{C}$ em perigo e quando é maior que $54^{\circ} \mathrm{C}$ em extremo perigo.

Observa-se que durante todo o período de estudo houve muitos dias desconfortável em relação ao calor, chegando apresentar 6 dias de extremo perigo sendo 3 dias em Santa Bárbara durante o ano 1992 (nos dias 2, 3 de novembro e 7 de julho), onde as temperaturas médias foram de $37,6^{\circ} \mathrm{C}$ e a UR ficou no $62,1 \%$, por sua parte em Los Angeles também registraram-se 3 dias (18 de Junho de 1981, 5 de setembro de 1988 e 4 de maio de 2004) onde a temperatura máxima média foi de $37,5^{\circ} \mathrm{C}$ e a UR de $64,3 \%$. Os dias com perigo foram um total de 122 com o maior número de casos em Los Angeles com 60, seguido de Orange com 34 e Santa Bárbara com 18. Por sua parte, quando o índice é de extrema cautela foram observados 1460 dias de ultrapassagens, sendo a segunda faixa com mais casos depois de cuidado com 5311, sendo os meses de agosto e setembro os de maiores ultrapassagens durante o período de estudo nos três condados.

O IC também foi calculado para cidade de Los Angeles, no período de 1975 a 2005 em um estudo em andamento por parte de Gonçalves e colaboradores. Os resultados, até então preliminares, indicam que o IC calculado a partir da temperatura máxima não apresenta tendências significativas durante todo o período; com um aumento bastante baixo na primeira década, constante na segunda década e nenhum aumento na última década. Por outro lado, devido ao fato que o índice inclui a temperatura e umidade, foi usada para analisar os impactos de eventos quentes e úmidos, na mortalidade por DCV e RES nesta cidade. 


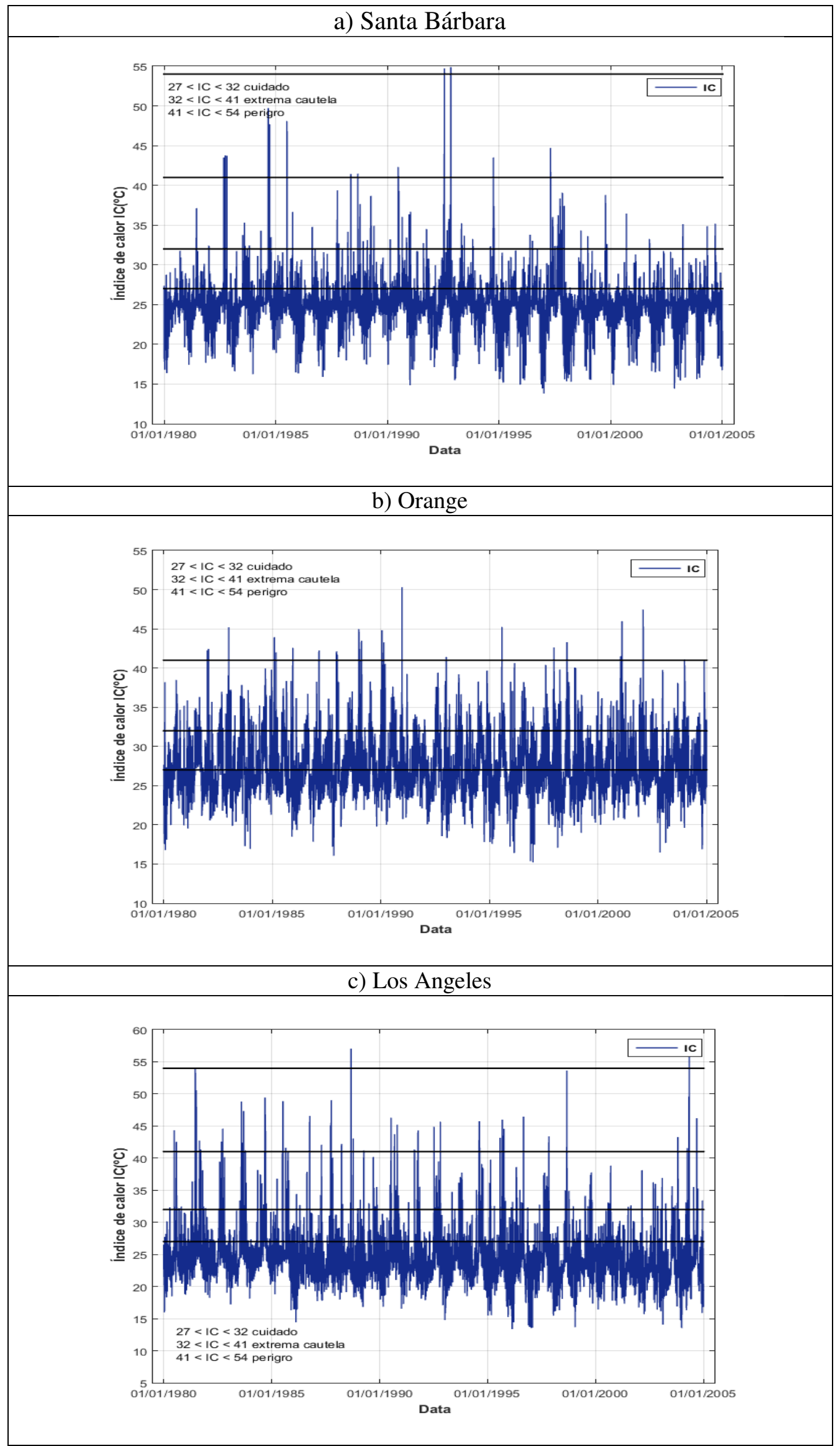

Figura 3.21. Variação temporal do IC, sob três aspectos diferentes, nos condados de a) Santa Bárbara, b) Orange e c) Los Angeles no período 1980-2005. 


\subsection{7. Índice de WindChill $(\mathrm{H})$}

A variação temporal do índice $H$ nos condados é apresentada na figura 3.22. Neste casso foram utilizadas duas situações diferentes: na primeira, valores médios de temperatura do ar e velocidade do vento e na segunda, temperatura mínima e velocidade do vento médio. É importante destacar que diferentemente dos índices analisados até o momento, que representam o estresse devido ao calor, o $\mathrm{H}$ é utilizado para determinar o poder de resfriamento. Neste sentido, valores acima de $400 \mathrm{Kcalm}^{-2} \mathrm{hr}^{-1}$ indicam algum frescor; a partir de $600 \mathrm{Kcalm}^{-2} \mathrm{hr}^{-1}$ as condições são confortáveis quando se está protegido com roupa de baixo de lã, meias, luvas, botas de esqui, touca e roupa de algodão; já acima de $1000 \mathrm{Kcalm}^{-2} \mathrm{hr}^{-1}$ as condições agradáveis para movimentar-se cessam, logo acima de $2500 \mathrm{Kcalm}^{-2} \mathrm{hr}^{-1}$ temos intenso estresse devido ao frio.

Os resultados mostram que utilizando a combinação de temperatura mínima e vento médio no cálculo do índice $\mathrm{H}$, houve muitos dias com condições desconfortáveis, ultrapassando o limite de $600 \mathrm{Kcalm}^{-2} \mathrm{hr}^{-1}$. Neste sentido, o condado com maior número de dias de ultrapassagens foi Orange com $2663 \mathrm{Kcalm}^{-2} \mathrm{hr}^{-1}$, seguido de Santa Bárbara com $1863 \mathrm{Kcalm}^{-2} \mathrm{hr}^{-1}$ e Los Angeles com $1809 \mathrm{Kcalm}^{-2} \mathrm{hr}^{-1}$. Ainda Orange teve 15 dias onde foi excedido o limite de $1000 \mathrm{Kcalm}^{-2} \mathrm{hr}^{-1}$, apresentando valores de até 1067.9 Kcalm $^{-2} \mathrm{hr}^{-1}$ e $1014.6 \mathrm{Kcalm}^{-2} \mathrm{hr}^{-1}$ nos dias 5 e 6 de fevereiro de 1997. Para Santa Bárbara e Los Angeles os máximos ficaram em $992.39 \mathrm{Kcalm}^{-2} \mathrm{hr}^{-1}$ e $987.3 \mathrm{Kcalm}^{-2} \mathrm{hr}^{-1}$, correspondentes aos dias 8 de fevereiro de 1990 e 28 de fevereiro de 1997, respectivamente.

Além disso, pela figura observa-se como o índice nos três condados apresenta uma evidente variação anual com um aumento em inverno e diminuição no verão, ou seja, no inverno o poder de resfriamento é maior do que no período de verão. Para o condado de Orange o mês que resultou ter mais dias com ultrapassagens foi janeiro com 453, seguido de dezembro e março com 443 e 441, cada. Em Los Angeles dezembro apresentou 363 dias, janeiro 357 e fevereiro 352, por enquanto em Santa Bárbara o mês com mais ultrapassagens foi fevereiro com 324 seguido de janeiro e março com 317 e 316 cada.

A partir destes resultados verificam-se que os meses de verão e outono constituem o período mais estressante por calor, sobretudo no período da tarde, e os meses de inverno os mais estressantes por frio, principalmente no período da manhã. 


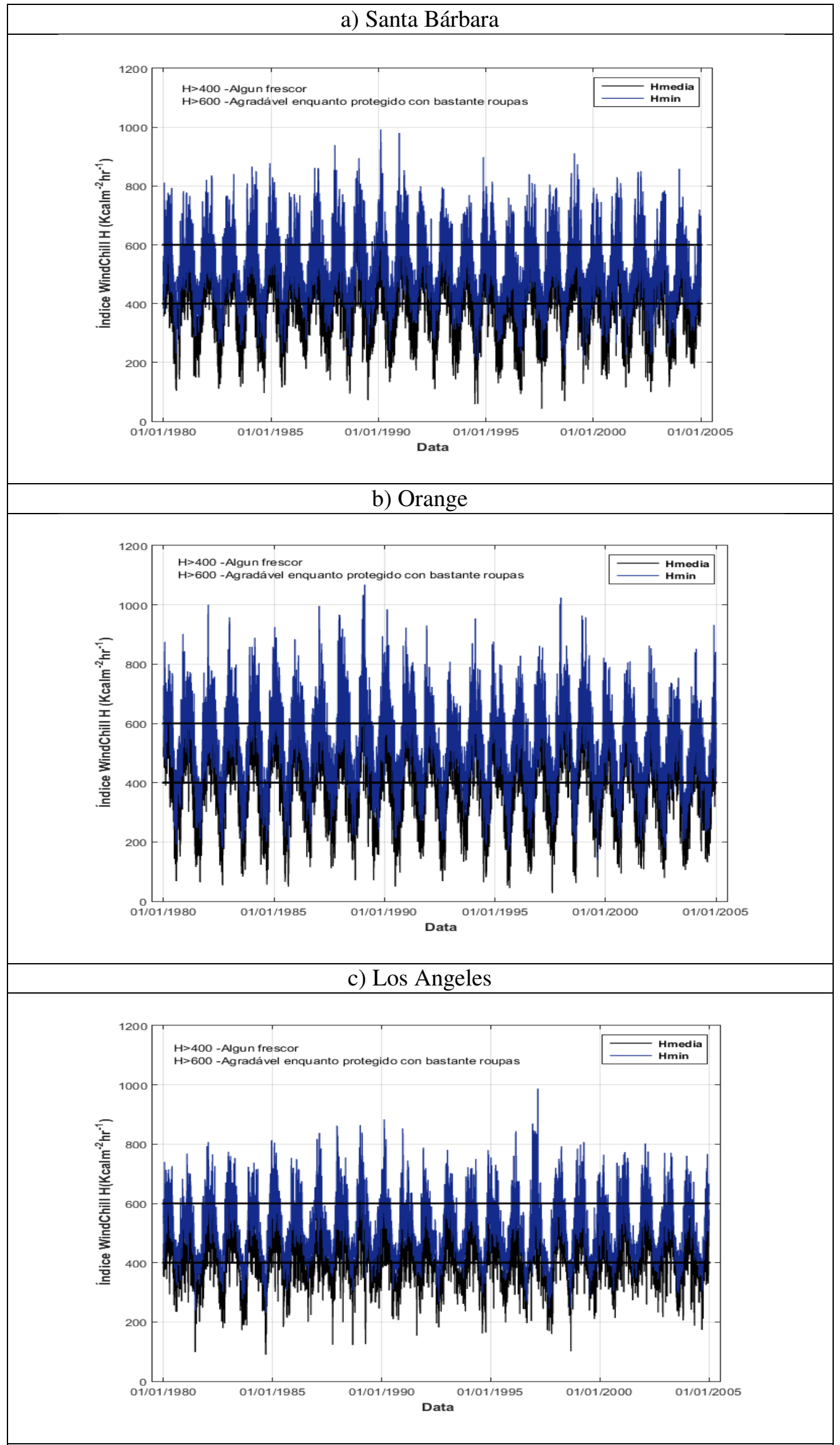

Figura 3.22. Variação temporal de $\mathrm{H}$, sob duas situações diferentes, nos condados de a) Santa Bárbara, b) Orange e c) Los Angeles no período 1980-2005. 


\subsection{Análises de correlação}

A seguir são apresentados os resultados obtidos na análise de correlação, como uma primeira análise exploratória, entre as variáveis estudadas (mortalidade por DCV e RES, parâmetros meteorológicos, níveis de poluição e índices de conforto), inclusive utilizando as estruturas de defasagem ("lag"), para cada um dos condados de interesse. Para cada conjunto de variável da análise foi aplicado a metodologia de bootstrap, com o objetivo de determinar a existência de correlações significativamente diferente de zero.

\subsubsection{Condado de Los Angeles}

As correlações obtidas no condado de Los Angeles entre as variáveis estudadas e as DCV e RES utilizando o intervalo de confiança $\mathrm{p}<0,05$, são apresentados nas tabelas 3.7 e 3.8, respectivamente. Inicialmente foram calculadas as correlações sem dias atraso e logo com vários dias de atraso (até cinco dias). Posteriormente foi feito a análise após aplicar média móvel ao conjunto de variáveis.

Na tabela 3.7 observam-se valores relativamente elevados do coeficiente de correlação, para os poluentes $\mathrm{CO}$ e $\mathrm{NO}_{2}$ com as $\mathrm{DCV}$ sem dias de atraso e com vários dias de atraso (até cinco dias) para $\mathrm{p}<0,05$, principalmente no próprio dia em questão $(\mathrm{r}=0,446 \mathrm{e}$ $\mathrm{r}=0,380$ ). De forma geral as variáveis meteorológicas estão mais bem correlacionadas para 2 dias de atraso (com exceção da temperatura máxima ( $T_{-}$MAX) e média $(T)$, no quinto dia) com maiores correlações para a temperatura mínima ( $\left.T_{-} \mathrm{MIN}\right)(\mathrm{r}=-0,375), \mathrm{T}_{\mathrm{d}}$ $(\mathrm{r}=-0,389)$ e $\mathrm{q}(-0,407)$. Por sua vez os índices de conforto estão mais bem correlacionados para o quinto dia, exceto quando são calculados usando a T_MIN, neste caso as correlações maiores são para o segundo e terceiro dia. Por exemplo, para a TA tem-se $\mathrm{r}=-0,352$ para o quinto dia, entretanto para o $\mathrm{ID}_{\mathrm{K} \_\mathrm{MIN}}$ tem-se $\mathrm{r}=-0,399$ para o segundo e terceiro dia.

Por outro lado os valores negativos indicam relação inversa entre as variáveis, ou seja, enquanto o número de óbitos por DCV cresce estas variáveis tendem a diminuir (por exemplo, índices e as temperaturas (média, mínima e máxima)), como era de se esperar, estresse por frio pode gerar mortalidade. Em contrapartida, para os poluentes atmosféricos com exceção do ozônio, os valores são positivos, indicando relação direta, o que é igualmente esperado. 
Tabela 3.7 - Correlações entre as DCV e as variáveis analisadas* para vários dias com atraso e sem atraso no condado de Los Angeles. Valores das variáveis estatísticamente significativos para $p<0,05$. Em negrito os valores estatísticamente não significativos.

\begin{tabular}{|c|c|c|c|c|c|c|}
\hline Variáveis & Sem atraso & $\begin{array}{c}1 \text { dia } \\
\text { atraso }\end{array}$ & $\begin{array}{l}2 \text { dias } \\
\text { atraso }\end{array}$ & $\begin{array}{l}3 \text { dias } \\
\text { atraso }\end{array}$ & $\begin{array}{l}4 \text { dias } \\
\text { atraso }\end{array}$ & $\begin{array}{l}5 \text { dias } \\
\text { atraso }\end{array}$ \\
\hline $\mathrm{CO}$ & 0,446 & 0,445 & 0,443 & 0,446 & 0,435 & 0,435 \\
\hline $\mathrm{O}_{3}$ & $-0,015$ & $-0,015$ & $-0,018$ & $-0,041$ & $-0,054$ & $-0,058$ \\
\hline $\mathrm{NO}_{2}$ & 0,380 & 0,372 & 0,360 & 0,347 & 0,332 & 0,333 \\
\hline $\mathrm{SO}_{2}$ & 0,109 & 0,109 & 0,108 & 0,107 & 0,106 & 0,105 \\
\hline $\mathbf{P}$ & 0,226 & 0,237 & 0,245 & 0,239 & 0,237 & 0,241 \\
\hline$T_{-}$MAX & $-0,099$ & $-0,111$ & $-0,133$ & $-0,144$ & $-0,153$ & $-0,156$ \\
\hline T_MIN & $-0,349$ & $-0,364$ & $-0,375$ & $-0,375$ & $-0,372$ & $-0,372$ \\
\hline $\mathbf{T}$ & $-0,268$ & $-0,279$ & $-0,295$ & $-0,305$ & $-0,307$ & $-0,308$ \\
\hline$T_{d}$ & $-0,364$ & $-0,382$ & $-0,389$ & $-0,387$ & $-0,382$ & $-0,385$ \\
\hline UR & $-0,273$ & $-0,289$ & $-0,287$ & $-0,279$ & $-0,273$ & $-0,274$ \\
\hline $\mathbf{q}$ & $-0,384$ & $-0,400$ & $-0,407$ & $-0,406$ & $-0,403$ & $-0,405$ \\
\hline v & $-0,064$ & $-0,054$ & $-0,044$ & $-0,035$ & $-0,026$ & $-0,031$ \\
\hline ID & $-0,295$ & $-0,305$ & $-0,320$ & $-0,327$ & $-0,328$ & $-0,329$ \\
\hline ID_mAX & $-0,172$ & $-0,186$ & $-0,206$ & $-0,213$ & $-0,222$ & $-0,225$ \\
\hline ID_MIN & $-0,340$ & $-0,352$ & $-0,362$ & $-0,362$ & $-0,359$ & $-0,360$ \\
\hline ID $\mathrm{D}_{\mathrm{K}}$ & $-0,339$ & $-0,354$ & $-0,368$ & $-0,375$ & $-0,374$ & $-0,375$ \\
\hline ID ${ }_{\text {K_MIN }}$ & $-0,373$ & $-0,389$ & $-0,399$ & $-0,399$ & $-0,395$ & $-0,396$ \\
\hline ID K_MAX $_{\text {MAX }}$ & $-0,223$ & $-0,240$ & $-0,261$ & $-0,269$ & $-0,275$ & $-0,278$ \\
\hline TE & $-0,312$ & $-0,323$ & $-0,338$ & $-0,345$ & $-0,346$ & $-0,347$ \\
\hline TE_mAX & $-0,173$ & $-0,188$ & $-0,209$ & $-0,217$ & $-0,225$ & $-0,228$ \\
\hline TE_MIN & $-0,357$ & $-0,371$ & $-0,380$ & $-0,380$ & $-0,377$ & $-0,377$ \\
\hline TA & $-0,315$ & $-0,327$ & $-0,343$ & $-0,351$ & $-0,351$ & $-0,352$ \\
\hline TA_max & $-0,173$ & $-0,188$ & $-0,209$ & $-0,219$ & $-0,226$ & $-0,229$ \\
\hline IC & 0,072 & 0,069 & 0,053 & 0,042 & 0,032 & 0,033 \\
\hline $\mathrm{TEV}_{\mathrm{v}}$ & $-0,246$ & $-0,254$ & $-0,270$ & $-0,280$ & $-0,282$ & $-0,283$ \\
\hline TEv_max & $-0,111$ & $-0,123$ & $-0,144$ & $-0,154$ & $-0,163$ & $-0,165$ \\
\hline TEv_MIN & $-0,320$ & $-0,331$ & $-0,343$ & $-0,345$ & $-0,343$ & $-0,342$ \\
\hline H & 0,225 & 0,238 & 0,257 & 0,269 & 0,273 & 0,273 \\
\hline H_MIN & 0,312 & 0,328 & 0,343 & 0,346 & 0,346 & 0,345 \\
\hline
\end{tabular}

*Onde: P (Pressão atmosférica), T (Temperatura), UR (Umidade relativa), q (Umidade específica), V (Velocidade do vento), Índices: MAX (Máxima) e MIN (Mínima). 
Tabela 3.8 - Correlações entre as doenças RES e as variáveis analisadas* para vários dias com atraso e sem atraso no condado de Los Angeles. Valores das variáveis estatíticamente significativos para $\mathrm{p}<0,05$. Em negrito os valores estatísticamente não significativos.

\begin{tabular}{|c|c|c|c|c|c|c|}
\hline Variáveis & $\begin{array}{c}\text { Sem } \\
\text { atraso }\end{array}$ & $\begin{array}{c}1 \text { dia } \\
\text { atraso }\end{array}$ & $\begin{array}{l}2 \text { dias } \\
\text { atraso }\end{array}$ & $\begin{array}{l}3 \text { dias } \\
\text { atraso }\end{array}$ & $\begin{array}{l}4 \text { dias } \\
\text { atraso }\end{array}$ & $\begin{array}{l}5 \text { dias } \\
\text { atraso }\end{array}$ \\
\hline CO & 0,288 & 0,305 & 0,308 & 0,311 & 0,305 & 0,307 \\
\hline $\mathrm{O}_{3}$ & $-0,272$ & $-0,272$ & $-0,269$ & $-0,282$ & $-0,283$ & $-0,289$ \\
\hline $\mathrm{NO}_{2}$ & 0,100 & 0,113 & 0,110 & 0,097 & 0,088 & 0,091 \\
\hline $\mathrm{SO}_{2}$ & 0,082 & 0,085 & 0,086 & 0,089 & 0,093 & 0,096 \\
\hline $\mathbf{P}$ & 0,271 & 0,285 & 0,294 & 0,302 & 0,299 & 0,294 \\
\hline$T_{-} \operatorname{mAX}$ & $-0,177$ & $-0,177$ & $-0,177$ & $-0,183$ & $-0,192$ & $-0,204$ \\
\hline T_MIN & $-0,378$ & $-0,389$ & $-0,398$ & $-0,400$ & $-0,401$ & $-0,409$ \\
\hline$T$ & $-0,328$ & $-0,328$ & $-0,337$ & $-0,343$ & $-0,346$ & $-0,355$ \\
\hline$T_{d}$ & $-0,308$ & $-0,326$ & $-0,337$ & $-0,348$ & $-0,353$ & $-0,351$ \\
\hline UR & $-0,136$ & $-0,155$ & $-0,167$ & $-0,178$ & $-0,179$ & $-0,170$ \\
\hline$q$ & $-0,323$ & $-0,337$ & $-0,349$ & $-0,359$ & $-0,362$ & $-0,361$ \\
\hline v & $-0,094$ & $-0,104$ & $-0,098$ & $-0,097$ & $-0,076$ & $-0,090$ \\
\hline ID & $-0,345$ & $-0,346$ & $-0,354$ & $-0,358$ & $-0,362$ & $-0,370$ \\
\hline ID_mAX & $-0,226$ & $-0,230$ & $-0,231$ & $-0,239$ & $-0,249$ & $-0,259$ \\
\hline ID_MIN & $-0,375$ & $-0,383$ & $-0,390$ & $-0,390$ & $-0,392$ & $-0,401$ \\
\hline$I_{k}$ & $-0,357$ & $-0,365$ & $-0,376$ & $-0,384$ & $-0,389$ & $-0,394$ \\
\hline ID $\mathrm{K}_{\text {KMIN }}$ & $-0,374$ & $-0,387$ & $-0,397$ & $-0,403$ & $-0,405$ & $-0,410$ \\
\hline ID ${ }_{\text {K_MAX }}$ & $-0,264$ & $-0,272$ & $-0,276$ & $-0,285$ & $-0,295$ & $-0,303$ \\
\hline TE & $-0,350$ & $-0,353$ & $-0,362$ & $-0,368$ & $-0,372$ & $-0,379$ \\
\hline$T E_{-} \operatorname{MAX}$ & $-0,224$ & $-0,229$ & $-0,230$ & $-0,238$ & $-0,249$ & $-0,258$ \\
\hline TE_MIN & $-0,378$ & $-0,388$ & $-0,397$ & $-0,398$ & $-0,400$ & $-0,407$ \\
\hline TA & $-0,348$ & $-0,352$ & $-0,362$ & $-0,369$ & $-0,373$ & $-0,380$ \\
\hline TA_mAX & $-0,230$ & $-0,233$ & $-0,236$ & $-0,243$ & $-0,252$ & $-0,262$ \\
\hline IC & $-0,070$ & $-0,075$ & $-0,061$ & $-0,059$ & $-0,063$ & $-0,075$ \\
\hline TEv & $-0,316$ & $-0,314$ & $-0,320$ & $-0,324$ & $-0,329$ & $-0,338$ \\
\hline TEv_mAX & $-0,187$ & $-0,188$ & $-0,187$ & $-0,193$ & $-0,203$ & $-0,214$ \\
\hline TEv_MIN & $-0,368$ & $-0,375$ & $-0,381$ & $-0,382$ & $-0,384$ & $-0,393$ \\
\hline H & 0,271 & 0,268 & 0,278 & 0,283 & 0,293 & 0,297 \\
\hline H_MIN & 0,329 & 0,335 & 0,345 & 0,348 & 0,356 & 0,360 \\
\hline
\end{tabular}

*Onde: P (Pressão atmosférica), T (Temperatura), UR (Umidade relativa), q (Umidade específica), V (Velocidade do vento), Índices: MAX (Máxima) e MIN (Mínima). 
Já os resultados obtidos para as doenças RES (tabela 3.8) sem dias de atraso e com até cinco dias, verificam melhores correlações embora negativas com a T_MIN $(r=-0,409), o$ índice ID_MIN $(r=-0,401)$ e ID K_MIN $_{-}(\mathrm{r}=-0,410)$ para o quinto dia de atraso. Igualmente, os valores médios das variáveis são mais bem correlacionadas para o quinto dia de atraso (com exceção da pressão atmosférica $(\mathrm{P})$, no terceiro dia), significando que as temperaturas, umidade e índices de conforto de 5 dias atrás podem ser os que mais afetam a mortalidade por doenças RES do dia em questão. No entanto, é importante destacar que as correlações entre variáveis e a mortalidade por doenças RES no dia, comparado com até cinco dias de atraso, apresentaram variações de apenas 0,05 , sendo todas muito similares.

Observa-se, nas tabelas 3.9 e 3.10, as correlações entre as doenças DCV e RES, respectivamente, com as variáveis utilizadas neste trabalho, para médias móveis de até 5 dias. Devido ao processo de suavização verifica-se que os coeficientes de correlação tendem a crescer à medida que aumentamos o número de termos da média móvel. Por exemplo, para a correlação entre as $\mathrm{DCV}$ e o poluente $\mathrm{CO}$, para o caso sem média móvel, tem-se coeficiente de correlação (r) de 0,446. Quando se calcula o coeficiente de correlação para os casos com média móvel, tem-se para média móvel de 2 dias $\mathrm{r}=$ 0,506, para média móvel de 3 dias $\mathrm{r}=0,538$, para média móvel de 4 dias $\mathrm{r}=0,559$ e para média móvel de 5 dias $r=0,574$, comportamento similar para o resto das variáveis e índices de conforto térmico.

A seguir apresentam-se a evolução temporal de algumas das variáveis melhor correlacionadas com a mortalidade por DCV ou RES. Nas quais é possível também observar o comportamento refletido nas tabelas analisadas. Por exemplo, na figura 3.23 observa-se a variação temporal de doenças RES e a T para o caso onde foram utilizados 5 dias com atraso. O coeficiente de correlação neste caso foi de $-0,355$, com $\mathrm{p}<0,05$. No entanto, note-se que há uma tendência de variação inversa na maioria do período entre estas duas variáveis, indicada pelo sinal negativo da correlação, durante o período apresentado.

Por sua vez, as DCV mostraram correlações significativas para o poluente CO quando não se utilizaram dias de atraso $(\mathrm{r}=0,435)$. Neste sentido na figura 3.24 são apresentadas as variações temporais das concentrações de $\mathrm{CO}$ e $\mathrm{DCV}$, onde se observa como as variáveis tendem a apresentar um comportamento sazonal semelhante, ou seja, quando o CO aumenta, a mortalidade por DCV também aumenta. 
Tabela 3.9 - Correlações entre as DCV e as variáveis analisadas* sem média móvel e com média móvel de até 5 dias (todas variáveis) no condado de Los Angeles com $\mathrm{p}<0,05$. Em negrito os valores estatísticamente não significativos.

\begin{tabular}{|c|c|c|c|c|c|}
\hline Variáveis & $\begin{array}{l}\text { Sem média } \\
\text { móvel }\end{array}$ & $\begin{array}{c}\text { Média } \\
\text { móvel } 2 \\
\text { dias }\end{array}$ & $\begin{array}{c}\text { Média } \\
\text { móvel } 3 \\
\text { dias }\end{array}$ & $\begin{array}{c}\text { Média } \\
\text { móvel } 4 \\
\text { dias }\end{array}$ & $\begin{array}{c}\text { Média } \\
\text { móvel } 5 \\
\text { dias }\end{array}$ \\
\hline CO & 0,446 & 0,506 & 0,538 & 0,559 & 0,574 \\
\hline $\mathrm{O}_{3}$ & $-0,015$ & $-0,118$ & $-0,121$ & $-0,123$ & $-0,124$ \\
\hline $\mathrm{NO}_{2}$ & 0,380 & 0,428 & 0,463 & 0,489 & 0,509 \\
\hline $\mathrm{SO}_{2}$ & 0,109 & $-0,118$ & $-0,121$ & $-0,123$ & $-0,124$ \\
\hline $\mathbf{P}$ & 0,226 & 0,259 & 0,284 & 0,304 & 0,318 \\
\hline$T_{-}$MAX & $-0,099$ & $-0,116$ & $-0,130$ & $-0,144$ & $-0,156$ \\
\hline T_MIN & $-0,349$ & $-0,383$ & $-0,399$ & $-0,409$ & $-0,416$ \\
\hline$T$ & $-0,268$ & $-0,298$ & $-0,316$ & $-0,329$ & $-0,339$ \\
\hline$T_{d}$ & $-0,364$ & $-0,407$ & $-0,432$ & $-0,449$ & $-0,461$ \\
\hline UR & $-0,273$ & $-0,316$ & $-0,345$ & $-0,368$ & $-0,387$ \\
\hline $\mathbf{q}$ & $-0,384$ & $-0,425$ & $-0,446$ & $-0,460$ & $-0,470$ \\
\hline v & $-0,064$ & $-0,073$ & $-0,077$ & $-0,078$ & $-0,079$ \\
\hline ID & $-0,295$ & $-0,325$ & $-0,342$ & $-0,353$ & $-0,362$ \\
\hline ID_mAX & $-0,172$ & $-0,196$ & $-0,213$ & $-0,228$ & $-0,240$ \\
\hline ID_MIN & $-0,340$ & $-0,373$ & $-0,388$ & $-0,398$ & $-0,404$ \\
\hline$I D_{k}$ & $-0,339$ & $-0,372$ & $-0,389$ & $-0,401$ & $-0,409$ \\
\hline ID $\mathrm{K}_{\text {_MIN }}$ & $-0,373$ & $-0,408$ & $-0,425$ & $-0,435$ & $-0,443$ \\
\hline ID $\mathrm{K}_{\text {KMAX }}$ & $-0,223$ & $-0,252$ & $-0,270$ & $-0,285$ & $-0,297$ \\
\hline TE & $-0,312$ & $-0,343$ & $-0,359$ & $-0,371$ & $-0,379$ \\
\hline TE_MAX & $-0,173$ & $-0,198$ & $-0,215$ & $-0,230$ & $-0,243$ \\
\hline TE_MIN & $-0,357$ & $-0,391$ & $-0,407$ & $-0,416$ & $-0,423$ \\
\hline TA & $-0,315$ & $-0,346$ & $-0,363$ & $-0,375$ & $-0,384$ \\
\hline TA_mAX & $-0,173$ & $-0,197$ & $-0,215$ & $-0,229$ & $-0,242$ \\
\hline IC & 0,072 & 0,081 & 0,083 & 0,083 & 0,081 \\
\hline $\mathrm{TE}_{\mathrm{v}}$ & $-0,246$ & $-0,274$ & $-0,291$ & $-0,304$ & $-0,314$ \\
\hline TEv_max & $-0,111$ & $-0,129$ & $-0,144$ & $-0,157$ & $-0,169$ \\
\hline TEv_Min & $-0,320$ & $-0,352$ & $-0,367$ & $-0,377$ & $-0,384$ \\
\hline H & 0,225 & 0,255 & 0,274 & 0,289 & 0,301 \\
\hline H_MIN $_{\text {M }}$ & 0,312 & 0,347 & 0,366 & 0,377 & 0,386 \\
\hline
\end{tabular}

*Onde: P (Pressão atmosférica), T (Temperatura), UR (Umidade relativa), q (Umidade específica), V (Velocidade do vento), Índices: MAX (Máxima) e MIN (Mínima). 
Tabela 3.10 - Correlações entre as as doenças RES e as variáveis analisadas* sem média móvel e com média móvel de até 5 dias (todas variáveis) no condado de Los Angeles com $\mathrm{p}<0,05$. Em negrito os valores estatísticamente não significativos.

\begin{tabular}{|c|c|c|c|c|c|}
\hline Variáveis & $\begin{array}{l}\text { Sem } \\
\text { média } \\
\text { móvel }\end{array}$ & $\begin{array}{c}\text { Média } \\
\text { móvel } 2 \\
\text { dias }\end{array}$ & $\begin{array}{c}\text { Média } \\
\text { móvel } 3 \\
\text { dias }\end{array}$ & $\begin{array}{c}\text { Média } \\
\text { móvel } 4 \\
\text { dias }\end{array}$ & $\begin{array}{l}\text { Média } \\
\text { móvel } \\
5 \text { dias }\end{array}$ \\
\hline $\mathrm{CO}$ & 0,288 & 0,353 & 0,389 & 0,412 & 0,428 \\
\hline $\mathrm{O}_{3}$ & $-0,272$ & $-0,327$ & $-0,357$ & $-0,380$ & $-0,398$ \\
\hline $\mathrm{NO}_{2}$ & 0,100 & 0,124 & 0,138 & 0,147 & 0,152 \\
\hline $\mathrm{SO}_{2}$ & 0,082 & $-0,118$ & $-0,121$ & $-0,123$ & $-0,124$ \\
\hline $\mathbf{P}$ & 0,271 & 0,333 & 0,376 & 0,409 & 0,434 \\
\hline$T_{-}$MAX & $-0,177$ & $-0,214$ & $-0,238$ & $-0,258$ & $-0,276$ \\
\hline T_MIN & $-0,378$ & $-0,441$ & $-0,474$ & $-0,495$ & $-0,509$ \\
\hline$T$ & $-0,328$ & $-0,384$ & $-0,416$ & $-0,438$ & $-0,453$ \\
\hline$T_{d}$ & $-0,308$ & $-0,369$ & $-0,405$ & $-0,431$ & $-0,451$ \\
\hline UR & $-0,136$ & $-0,170$ & $-0,194$ & $-0,214$ & $-0,232$ \\
\hline$q$ & $-0,323$ & $-0,381$ & $-0,413$ & $-0,436$ & $-0,453$ \\
\hline v & $-0,094$ & $-0,122$ & $-0,140$ & $-0,152$ & $-0,160$ \\
\hline ID & $-0,345$ & $-0,400$ & $-0,431$ & $-0,452$ & $-0,467$ \\
\hline ID_mAX & $-0,226$ & $-0,272$ & $-0,299$ & $-0,321$ & $-0,339$ \\
\hline ID_MIN & $-0,375$ & $-0,437$ & $-0,469$ & $-0,489$ & $-0,502$ \\
\hline$I D_{K}$ & $-0,357$ & $-0,415$ & $-0,447$ & $-0,468$ & $-0,483$ \\
\hline ID $D_{\text {K_MIN }}$ & $-0,374$ & $-0,436$ & $-0,468$ & $-0,490$ & $-0,505$ \\
\hline ID ${ }_{K}$ MAX & $-0,264$ & $-0,315$ & $-0,345$ & $-0,367$ & $-0,385$ \\
\hline TE & $-0,350$ & $-0,406$ & $-0,437$ & $-0,458$ & $-0,472$ \\
\hline TE_MAX & $-0,224$ & $-0,270$ & $-0,297$ & $-0,319$ & $-0,337$ \\
\hline TE_MIN & $-0,378$ & $-0,440$ & $-0,472$ & $-0,492$ & $-0,506$ \\
\hline TA & $-0,348$ & $-0,405$ & $-0,436$ & $-0,456$ & $-0,471$ \\
\hline TA_mAX & $-0,230$ & $-0,275$ & $-0,302$ & $-0,324$ & $-0,342$ \\
\hline IC & $-0,070$ & $-0,091$ & $-0,102$ & $-0,112$ & $-0,121$ \\
\hline $\mathrm{TE}_{\mathrm{v}}$ & $-0,316$ & $-0,370$ & $-0,401$ & $-0,423$ & $-0,439$ \\
\hline$T E_{v_{-} \max }$ & $-0,187$ & $-0,226$ & $-0,251$ & $-0,271$ & $-0,288$ \\
\hline$T E_{v_{-} \text {MIN }}$ & $-0,368$ & $-0,430$ & $-0,462$ & $-0,482$ & $-0,496$ \\
\hline $\mathbf{H}$ & 0,271 & 0,321 & 0,351 & 0,373 & 0,389 \\
\hline H_MIN & 0,329 & 0,389 & 0,420 & 0,441 & 0,456 \\
\hline
\end{tabular}

*Onde: P (Pressão atmosférica), T (Temperatura), UR (Umidade relativa), q (Umidade específica), V (Velocidade do vento), Índices: MAX (Máxima) e MIN (Mínima). 


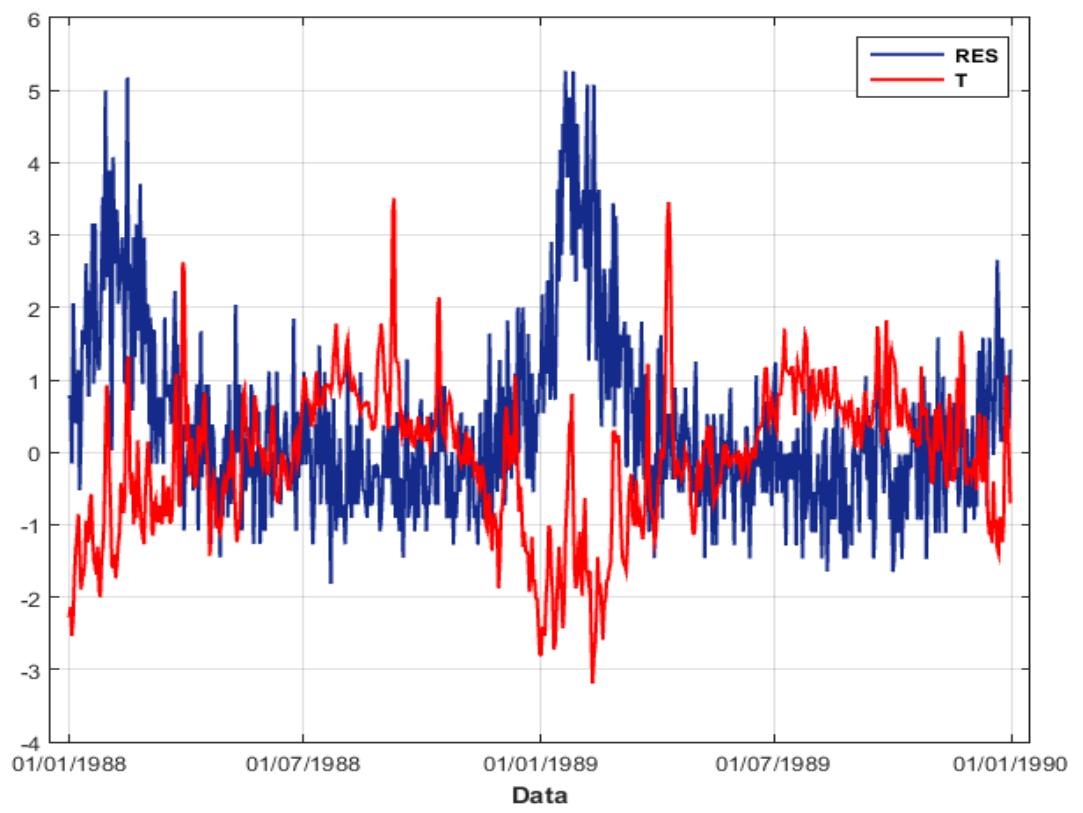

Figura 3.23. Evolução temporal da temperatura média do ar e as doenças RES com 5 dias de atraso no condado de Los Angeles (1988-1990).

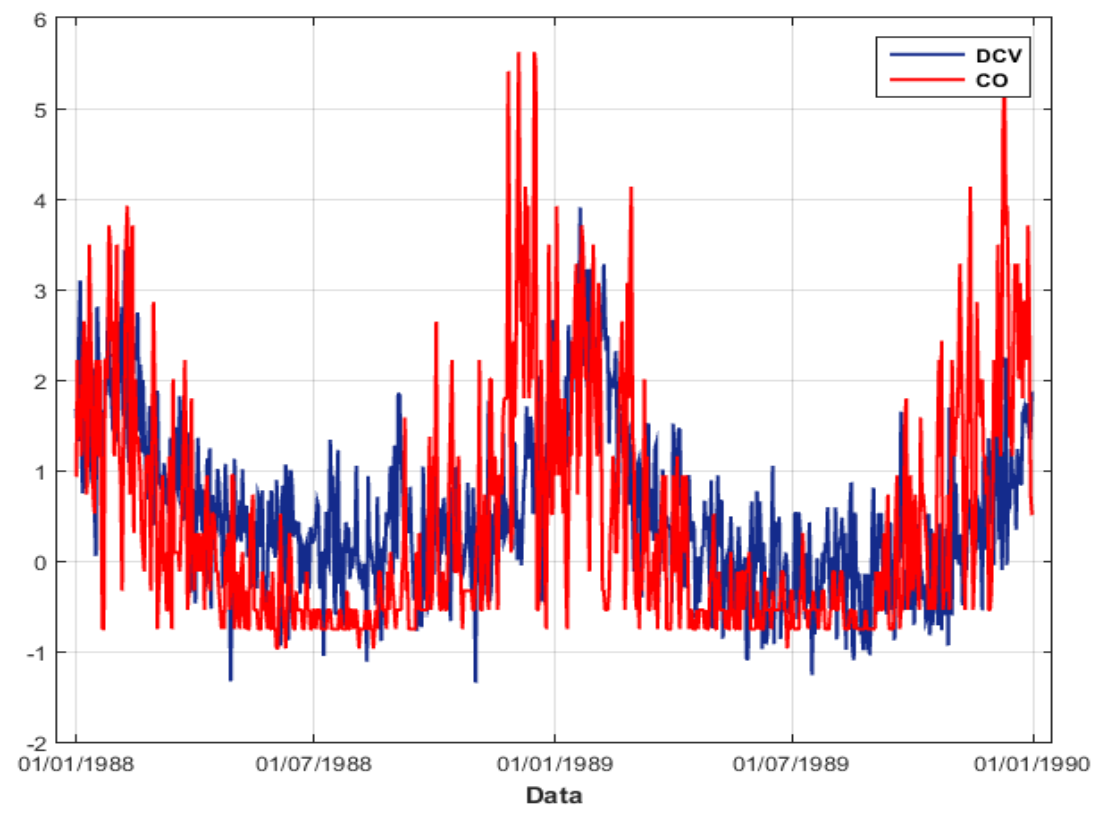

Figura 3.24. Evolução temporal das concentrações de $\mathrm{CO}$ e as DCV sem dias de atraso no condado de Los Angeles (1988-1990). 


\subsubsection{Condado de Orange}

Fazendo a mesma análise para o condado de Orange observam-se valores de correlações entre as diversas variáveis utilizadas e as DCV e RES ligeiramente mais baixos que no condado de Los Angeles.

Na tabela 3.11 são apresentadas as correlações entre as variáveis meteorotrópicas e índices de conforto térmico com a mortalidade por DCV, mostrando as maiores correlações com os índices de conforto térmico (exceção do IC) e a temperatura do ar com valores de $r$ entre 0,28 e 0,31 para 4 e 5 dias de atraso. Para os poluentes a correlação foi mais fraca do que no condado de Los Angeles, sendo o $\mathrm{CO}$ o maior correlacionado com os óbitos por DCV principalmente com 3 dias de atraso $(r=0,254)$. As diferenças de $r$ entre os dias sem atraso e até o quinto dia não passaram de 0,015.

Por sua vez, na tabela 3.12 são apresentadas as correlações obtidas das variáveis de interesse com respeito à mortalidade por doenças RES, sem dias atraso e com vários dias de atraso (até 5 dias), verifica-se melhores associações com a $(r=-0,264)$, os índices ID, ID $_{\mathrm{K}}$ e TE, com valores de $\mathrm{r}=-0,268,-0,270$ e $-0,269$ respectivamente, quando utilizamos 5 dias de atraso, todos com significância estatística. Este resultado significa que as temperaturas e índices, de 5 dias atrás podem afetar a mortalidade no condado de Orange.

Quando se utilizam médias móveis, tanto no caso em que média móvel é aplicada ao conjunto de variável, quando é aplicado apenas às doenças por mortalidade RES ou DCV os resultados são similares (tabelas 3.13 e 3.14). Observa-se, de mesmo modo ao condado de Los Angeles, que os coeficientes de correlação tendem a crescer à medida que aumentamos o número de termos da média móvel, tornando-se os maiores valores das variáveis para média móvel de 5 dias.

Por exemplo, para a correlação entre DCV e a T_MIN, para o caso sem média móvel, temos coeficiente de correlação (r) de $-0,287$. Quando se calcula o coeficiente de correlação para os casos com média móvel, tem-se para média móvel de 2 dias $\mathrm{r}=$ 0,379, para média móvel de 3 dias $r=-0,431$, para média móvel de 4 dias $-0,471$ e para média móvel de 5 dias $-0,503$. 
Tabela 3.11 - Correlações entre a mortalidade por DCV e as variáveis analisadas* para vários dias com atraso e sem atraso no condado de Orange com $p<0.05$. Em negrito os valores estatísticamente não significativos.

\begin{tabular}{|c|c|c|c|c|c|c|}
\hline Variáveis & $\begin{array}{c}\text { Sem } \\
\text { atraso }\end{array}$ & $\begin{array}{c}1 \text { dia } \\
\text { atraso }\end{array}$ & $\begin{array}{l}2 \text { dias } \\
\text { atraso }\end{array}$ & $\begin{array}{l}3 \text { dias } \\
\text { atraso }\end{array}$ & $\begin{array}{l}4 \text { dias } \\
\text { atraso }\end{array}$ & $\begin{array}{l}5 \text { dias } \\
\text { atraso }\end{array}$ \\
\hline CO & 0,246 & 0,244 & 0,251 & 0,254 & 0,252 & 0,251 \\
\hline $\mathrm{O}_{3}$ & $-0,168$ & $-0,160$ & $-0,166$ & $-0,174$ & $-0,171$ & $-0,180$ \\
\hline $\mathrm{NO}_{2}$ & 0,178 & 0,176 & 0,175 & 0,179 & 0,172 & 0,166 \\
\hline $\mathrm{SO}_{2}$ & 0,121 & 0,122 & 0,118 & 0,112 & 0,116 & 0,118 \\
\hline $\mathbf{P}$ & 0,165 & 0,181 & 0,185 & 0,186 & 0,175 & 0,168 \\
\hline$T_{\text {MAX }}$ & $-0,271$ & $-0,271$ & $-0,277$ & $-0,283$ & $-0,290$ & $-0,289$ \\
\hline$T_{-}$MIN & $-0,287$ & $-0,293$ & $-0,296$ & $-0,303$ & $-0,303$ & $-0,299$ \\
\hline$T$ & $-0,287$ & $-0,291$ & $-0,295$ & $-0,303$ & $-0,306$ & $-0,305$ \\
\hline$T_{d}$ & $-0,249$ & $-0,256$ & $-0,254$ & $-0,257$ & $-0,258$ & $-0,257$ \\
\hline UR & 0,063 & 0,057 & 0,063 & 0,069 & 0,073 & 0,076 \\
\hline$q$ & $-0,254$ & $-0,260$ & $-0,258$ & $-0,259$ & $-0,260$ & $-0,257$ \\
\hline v & $-0,065$ & $-0,082$ & $-0,069$ & $-0,080$ & $-0,060$ & $-0,067$ \\
\hline ID & $-0,293$ & $-0,296$ & $-0,299$ & $-0,306$ & $-0,310$ & $-0,310$ \\
\hline ID_mAX & $-0,280$ & $-0,279$ & $-0,284$ & $-0,290$ & $-0,297$ & $-0,297$ \\
\hline ID_MIN & $-0,288$ & $-0,293$ & $-0,295$ & $-0,303$ & $-0,304$ & $-0,300$ \\
\hline$I_{\mathrm{K}}$ & $-0,297$ & $-0,302$ & $-0,305$ & $-0,311$ & $-0,314$ & $-0,313$ \\
\hline ID $\mathrm{K}_{-}$MIN & $-0,296$ & $-0,301$ & $-0,305$ & $-0,311$ & $-0,314$ & $-0,313$ \\
\hline ID $D_{\text {K_MAX }}$ & $-0,295$ & $-0,300$ & $-0,302$ & $-0,309$ & $-0,312$ & $-0,312$ \\
\hline $\mathrm{TE}$ & $-0,295$ & $-0,299$ & $-0,302$ & $-0,309$ & $-0,313$ & $-0,312$ \\
\hline TE_mAX & $-0,281$ & $-0,280$ & $-0,285$ & $-0,291$ & $-0,298$ & $-0,298$ \\
\hline TE_MIN & $-0,291$ & $-0,297$ & $-0,299$ & $-0,306$ & $-0,307$ & $-0,303$ \\
\hline TA & $-0,293$ & $-0,297$ & $-0,301$ & $-0,308$ & $-0,311$ & $-0,310$ \\
\hline TA_mAX & $-0,280$ & $-0,281$ & $-0,287$ & $-0,292$ & $-0,298$ & $-0,298$ \\
\hline IC & 0,003 & 0,003 & 0,006 & 0,001 & 0,016 & 0,017 \\
\hline $\mathrm{TEv}_{\mathrm{v}}$ & $-0,284$ & $-0,285$ & $-0,290$ & $-0,297$ & $-0,302$ & $-0,301$ \\
\hline$T_{E_{\text {V_MAX }}}$ & $-0,271$ & $-0,269$ & $-0,274$ & $-0,281$ & $-0,288$ & $-0,288$ \\
\hline TEv_MIN & $-0,281$ & $-0,284$ & $-0,288$ & $-0,295$ & $-0,297$ & $-0,293$ \\
\hline H & 0,265 & 0,262 & 0,271 & 0,275 & 0,284 & 0,281 \\
\hline H_MIN $_{-}$ & 0,259 & 0,257 & 0,267 & 0,269 & 0,277 & 0,270 \\
\hline
\end{tabular}

*Onde: P (Pressão atmosférica), T (Temperatura), UR (Umidade relativa), q (Umidade específica), V (Velocidade do vento), Índices: MAX (Máxima) e MIN (Mínima). 
Tabela 3.12 - Correlações entre a mortalidade por doenças RES e as variáveis analisadas* para vários dias com atraso e sem atraso no condado de Orange com $\mathrm{p}<0.05$. Em negrito os valores estatísticamente não significativos.

\begin{tabular}{|c|c|c|c|c|c|c|}
\hline Variáveis & $\begin{array}{c}\text { Sem } \\
\text { atraso }\end{array}$ & $\begin{array}{l}1 \text { dia } \\
\text { atraso }\end{array}$ & $\begin{array}{l}2 \text { dias } \\
\text { atraso }\end{array}$ & $\begin{array}{l}3 \text { dias } \\
\text { atraso }\end{array}$ & $\begin{array}{l}4 \text { dias } \\
\text { atraso }\end{array}$ & $\begin{array}{l}5 \text { dias } \\
\text { atraso }\end{array}$ \\
\hline $\mathrm{CO}$ & 0,116 & 0,154 & 0,177 & 0,195 & 0,208 & 0,132 \\
\hline $\mathrm{O}_{3}$ & $-0,164$ & $-0,160$ & $-0,160$ & $-0,163$ & $-0,173$ & $-0,179$ \\
\hline $\mathrm{NO}_{2}$ & 0,087 & 0,099 & 0,096 & 0,090 & 0,085 & 0,098 \\
\hline $\mathrm{SO}_{2}$ & $-0,063$ & $-0,061$ & $-0,060$ & $-0,075$ & $-0,067$ & $-0,066$ \\
\hline $\mathbf{P}$ & 0,168 & 0,174 & 0,188 & 0,190 & 0,180 & 0,182 \\
\hline$T_{-}$MAX & $-0,232$ & $-0,234$ & $-0,237$ & $-0,244$ & $-0,250$ & $-0,254$ \\
\hline T_MIN & $-0,241$ & $-0,247$ & $-0,252$ & $-0,253$ & $-0,257$ & $-0,257$ \\
\hline $\mathbf{T}$ & $-0,244$ & $-0,247$ & $-0,251$ & $-0,256$ & $-0,261$ & $-0,264$ \\
\hline$T_{d}$ & $-0,206$ & $-0,210$ & $-0,219$ & $-0,224$ & $-0,226$ & $-0,218$ \\
\hline UR & 0,061 & 0,058 & 0,055 & 0,054 & 0,054 & 0,071 \\
\hline$q$ & $-0,209$ & $-0,213$ & $-0,219$ & $-0,224$ & $-0,227$ & $-0,218$ \\
\hline V & $-0,105$ & $-0,103$ & $-0,099$ & $-0,099$ & $-0,104$ & $-0,103$ \\
\hline ID & $-0,247$ & $-0,251$ & $-0,255$ & $-0,260$ & $-0,264$ & $-0,268$ \\
\hline ID_mAX & $-0,240$ & $-0,242$ & $-0,245$ & $-0,253$ & $-0,258$ & $-0,262$ \\
\hline ID_MIN & $-0,241$ & $-0,247$ & $-0,252$ & $-0,252$ & $-0,257$ & $-0,258$ \\
\hline$I_{K}$ & $-0,250$ & $-0,254$ & $-0,260$ & $-0,265$ & $-0,269$ & $-0,270$ \\
\hline ID ${ }_{\text {K_MIN }}$ & $-0,250$ & $-0,254$ & $-0,259$ & $-0,265$ & $-0,270$ & $-0,270$ \\
\hline ID K_MAX $_{\text {M }}$ & $-0,250$ & $-0,254$ & $-0,259$ & $-0,264$ & $-0,268$ & $-0,269$ \\
\hline TE & $-0,249$ & $-0,253$ & $-0,257$ & $-0,262$ & $-0,266$ & $-0,269$ \\
\hline$T E_{-} \operatorname{mAX}$ & $-0,240$ & $-0,242$ & $-0,246$ & $-0,254$ & $-0,259$ & $-0,263$ \\
\hline TE_MIN & $-0,243$ & $-0,249$ & $-0,255$ & $-0,255$ & $-0,260$ & $-0,259$ \\
\hline TA & $-0,248$ & $-0,251$ & $-0,256$ & $-0,261$ & $-0,265$ & $-0,267$ \\
\hline AT_MAX & $-0,239$ & $-0,241$ & $-0,245$ & $-0,252$ & $-0,258$ & $-0,261$ \\
\hline IC & $-0,008$ & 0,003 & 0,000 & 0,005 & 0,017 & 0,006 \\
\hline $\mathrm{TEv}_{\mathrm{v}}$ & $-0,238$ & $-0,241$ & $-0,244$ & $-0,249$ & $-0,253$ & $-0,258$ \\
\hline TEV_mAX & $-0,229$ & $-0,231$ & $-0,234$ & $-0,241$ & $-0,246$ & $-0,251$ \\
\hline$T E_{v_{-} \text {MIN }}$ & $-0,233$ & $-0,239$ & $-0,243$ & $-0,243$ & $-0,248$ & $-0,249$ \\
\hline H & 0,208 & 0,212 & 0,217 & 0,220 & 0,224 & 0,228 \\
\hline H_MIN & 0,197 & 0,202 & 0,209 & 0,209 & 0,213 & 0,212 \\
\hline
\end{tabular}

*Onde: P (Pressão atmosférica), T (Temperatura), UR (Umidade relativa), q (Umidade específica), $\mathrm{V}$ (Velocidade do vento), Índices: MAX (Máxima) e MIN (Mínima). 
Tabela 3.13 - Correlações entre as DCV e as variáveis analisadas* sem média móvel e com média móvel de até 5 dias (todas variáveis) no condado Orange $(\mathrm{p}<0,05)$. Em negrito os valores estatísticamente não significativos.

\begin{tabular}{|c|c|c|c|c|c|}
\hline Variáveis & $\begin{array}{c}\text { Sem } \\
\text { média } \\
\text { móvel }\end{array}$ & $\begin{array}{c}\text { Média } \\
\text { móvel } 2 \\
\text { dias }\end{array}$ & $\begin{array}{c}\text { Média } \\
\text { móvel } 3 \\
\text { dias }\end{array}$ & $\begin{array}{c}\text { Média } \\
\text { móvel } 4 \\
\text { dias }\end{array}$ & $\begin{array}{c}\text { Média } \\
\text { móvel } 5 \\
\text { dias }\end{array}$ \\
\hline CO & 0,246 & 0,335 & 0,392 & 0,435 & 0,469 \\
\hline $\mathrm{O}_{3}$ & $-0,168$ & $-0,235$ & $-0,282$ & $-0,318$ & $-0,348$ \\
\hline $\mathrm{NO}_{2}$ & 0,178 & 0,243 & 0,287 & 0,322 & 0,350 \\
\hline $\mathrm{SO}_{2}$ & 0,121 & 0,162 & 0,186 & 0,206 & 0,223 \\
\hline $\mathbf{P}$ & 0,165 & 0,231 & 0,283 & 0,327 & 0,363 \\
\hline$T_{-} \operatorname{mAX}$ & $-0,271$ & $-0,355$ & $-0,409$ & $-0,448$ & $-0,479$ \\
\hline T_MIN & $-0,287$ & $-0,379$ & $-0,436$ & $-0,477$ & $-0,509$ \\
\hline $\mathbf{T}$ & $-0,287$ & $-0,376$ & $-0,431$ & $-0,471$ & $-0,503$ \\
\hline$T_{d}$ & $-0,249$ & $-0,331$ & $-0,384$ & $-0,424$ & $-0,456$ \\
\hline UR & 0,063 & 0,090 & 0,109 & 0,126 & 0,140 \\
\hline$q$ & $-0,254$ & $-0,335$ & $-0,387$ & $-0,425$ & $-0,455$ \\
\hline $\mathbf{v}$ & $-0,065$ & $-0,099$ & $-0,121$ & $-0,139$ & $-0,152$ \\
\hline ID & $-0,293$ & $-0,383$ & $-0,439$ & $-0,478$ & $-0,510$ \\
\hline ID_mAX & $-0,280$ & $-0,367$ & $-0,420$ & $-0,460$ & $-0,490$ \\
\hline ID_MIN & $-0,288$ & $-0,380$ & $-0,437$ & $-0,478$ & $-0,510$ \\
\hline$I D_{k}$ & $-0,297$ & $-0,388$ & $-0,444$ & $-0,484$ & $-0,515$ \\
\hline ID $\mathrm{D}_{\text {_MIN }}$ & $-0,296$ & $-0,387$ & $-0,443$ & $-0,483$ & $-0,515$ \\
\hline ID $\mathrm{D}_{\text {K_MAX }}$ & $-0,295$ & $-0,386$ & $-0,442$ & $-0,482$ & $-0,514$ \\
\hline TE & $-0,295$ & $-0,386$ & $-0,441$ & $-0,481$ & $-0,512$ \\
\hline TE_mAX & $-0,281$ & $-0,367$ & $-0,421$ & $-0,460$ & $-0,491$ \\
\hline TE_MIN & $-0,291$ & $-0,384$ & $-0,441$ & $-0,482$ & $-0,514$ \\
\hline TA & $-0,293$ & $-0,383$ & $-0,438$ & $-0,478$ & $-0,509$ \\
\hline AT_mAX & $-0,280$ & $-0,367$ & $-0,421$ & $-0,460$ & $-0,491$ \\
\hline IC & 0,003 & 0,001 & 0,000 & $-0,002$ & $-0,004$ \\
\hline $\mathrm{TE}_{\mathrm{v}}$ & $-0,284$ & $-0,372$ & $-0,427$ & $-0,466$ & $-0,498$ \\
\hline TEv_max & $-0,271$ & $-0,355$ & $-0,408$ & $-0,447$ & $-0,479$ \\
\hline TEV_MIN & $-0,281$ & $-0,371$ & $-0,427$ & $-0,468$ & $-0,500$ \\
\hline H & 0,265 & 0,349 & 0,403 & 0,443 & 0,476 \\
\hline H_MIN $_{\text {M }}$ & 0,259 & 0,344 & 0,399 & 0,440 & 0,473 \\
\hline
\end{tabular}

*Onde: P (Pressão atmosférica), T (Temperatura), UR (Umidade relativa), q (Umidade específica), V (Velocidade do vento), Índices: MAX (Máxima) e MIN (Mínima). 
Tabela 3.14 - Correlações entre as doenças RES e as variáveis analisadas* sem média móvel e com média móvel de até 5 dias (todas variáveis) no condado Orange $(\mathrm{p}<0,05)$. Em negrito os valores estatísticamente não significativos.

\begin{tabular}{|c|c|c|c|c|c|}
\hline Variáveis & $\begin{array}{l}\text { Sem } \\
\text { média } \\
\text { móvel }\end{array}$ & $\begin{array}{c}\text { Média } \\
\text { móvel } 2 \\
\text { dias }\end{array}$ & $\begin{array}{c}\text { Média } \\
\text { móvel } 3 \\
\text { dias }\end{array}$ & $\begin{array}{c}\text { Média } \\
\text { móvel } 4 \\
\text { dias }\end{array}$ & $\begin{array}{c}\text { Média } \\
\text { móvel } 5 \\
\text { dias }\end{array}$ \\
\hline $\mathrm{CO}$ & 0,116 & 0,154 & 0,177 & 0,195 & 0,208 \\
\hline $\mathrm{O}_{3}$ & $-0,164$ & $-0,225$ & $-0,265$ & $-0,295$ & $-0,319$ \\
\hline $\mathrm{NO}_{2}$ & 0,087 & 0,117 & 0,136 & 0,148 & 0,158 \\
\hline $\mathrm{SO}_{2}$ & $-0,063$ & $-0,088$ & $-0,101$ & $-0,112$ & $-0,119$ \\
\hline $\mathbf{P}$ & 0,168 & 0,222 & 0,266 & 0,302 & 0,330 \\
\hline$T_{-M A X}$ & $-0,232$ & $-0,293$ & $-0,329$ & $-0,355$ & $-0,374$ \\
\hline T_MIN & $-0,241$ & $-0,306$ & $-0,344$ & $-0,370$ & $-0,389$ \\
\hline $\mathbf{T}$ & $-0,244$ & $-0,307$ & $-0,343$ & $-0,369$ & $-0,388$ \\
\hline$T_{d}$ & $-0,206$ & $-0,264$ & $-0,301$ & $-0,328$ & $-0,349$ \\
\hline UR & 0,061 & 0,081 & 0,094 & 0,106 & 0,114 \\
\hline$q$ & $-0,209$ & $-0,267$ & $-0,302$ & $-0,327$ & $-0,346$ \\
\hline v & $-0,105$ & $-0,141$ & $-0,166$ & $-0,185$ & $-0,200$ \\
\hline ID & $-0,247$ & $-0,311$ & $-0,348$ & $-0,373$ & $-0,392$ \\
\hline ID_mAX & $-0,240$ & $-0,303$ & $-0,339$ & $-0,365$ & $-0,384$ \\
\hline ID_MIN & $-0,241$ & $-0,307$ & $-0,345$ & $-0,371$ & $-0,390$ \\
\hline ID $\mathrm{D}_{\mathrm{K}}$ & $-0,250$ & $-0,315$ & $-0,352$ & $-0,378$ & $-0,397$ \\
\hline ID ${ }_{\text {K_MIN }}$ & $-0,250$ & $-0,314$ & $-0,352$ & $-0,377$ & $-0,397$ \\
\hline ID ${ }_{\text {K_MAX }}$ & $-0,250$ & $-0,314$ & $-0,352$ & $-0,378$ & $-0,397$ \\
\hline TE & $-0,249$ & $-0,313$ & $-0,350$ & $-0,375$ & $-0,394$ \\
\hline TE_mAX & $-0,240$ & $-0,303$ & $-0,340$ & $-0,366$ & $-0,385$ \\
\hline TE_MIN & $-0,243$ & $-0,309$ & $-0,347$ & $-0,373$ & $-0,392$ \\
\hline TA & $-0,248$ & $-0,311$ & $-0,348$ & $-0,373$ & $-0,392$ \\
\hline AT_mAX & $-0,239$ & $-0,301$ & $-0,338$ & $-0,363$ & $-0,382$ \\
\hline IC & $-0,008$ & $-0,005$ & $-0,004$ & $-0,005$ & $-0,005$ \\
\hline TEv & $-0,238$ & $-0,299$ & $-0,336$ & $-0,361$ & $-0,380$ \\
\hline$T E_{v \_m A X}$ & $-0,229$ & $-0,290$ & $-0,326$ & $-0,352$ & $-0,371$ \\
\hline TEv_MIN & $-0,233$ & $-0,297$ & $-0,334$ & $-0,360$ & $-0,379$ \\
\hline $\mathbf{H}$ & 0,208 & 0,266 & 0,301 & 0,325 & 0,344 \\
\hline H_MIN & 0,197 & 0,254 & 0,289 & 0,314 & 0,332 \\
\hline
\end{tabular}

*Onde: P (Pressão atmosférica), T (Temperatura), UR (Umidade relativa), q (Umidade específica), V (Velocidade do vento), Índices: MAX (Máxima) e MIN (Mínima). 
Apresentam-se também a evolução temporal de algumas das variáveis mais bem correlacionadas com a mortalidade por DCV ou RES. Por exemplo, na figura 3.25 apresenta-se a variação temporal de doenças RES e o ID para o caso onde foram utilizados 5 dias com atraso. Observa-se, que há uma tendência de variação inversa na maioria do período entre estas duas variáveis, indicada pelo sinal negativo da correlação, durante o período apresentado.

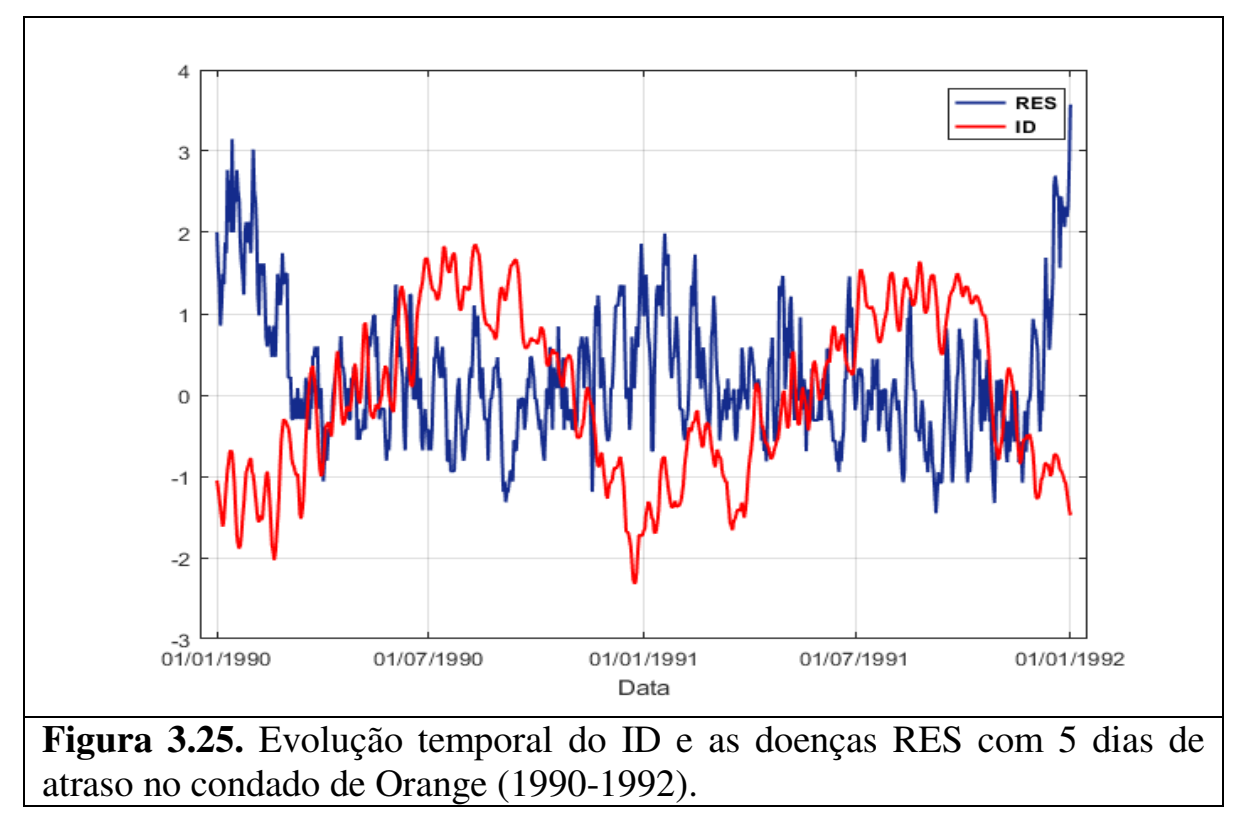

Na figura 3.26 apresentam-se a evolução temporal das DCV e a concentração de CO, para o caso onde foram utilizados 3 dias com atraso. Neste caso o coeficiente de correlação foi pouco significativo, apresentando valor de 0,245. Mesmo assim, as variáveis tendem a apresentar um comportamento sazonal semelhante, ou seja, quando as concentrações de $\mathrm{CO}$ aumentam, as DCV também parecem aumentar.

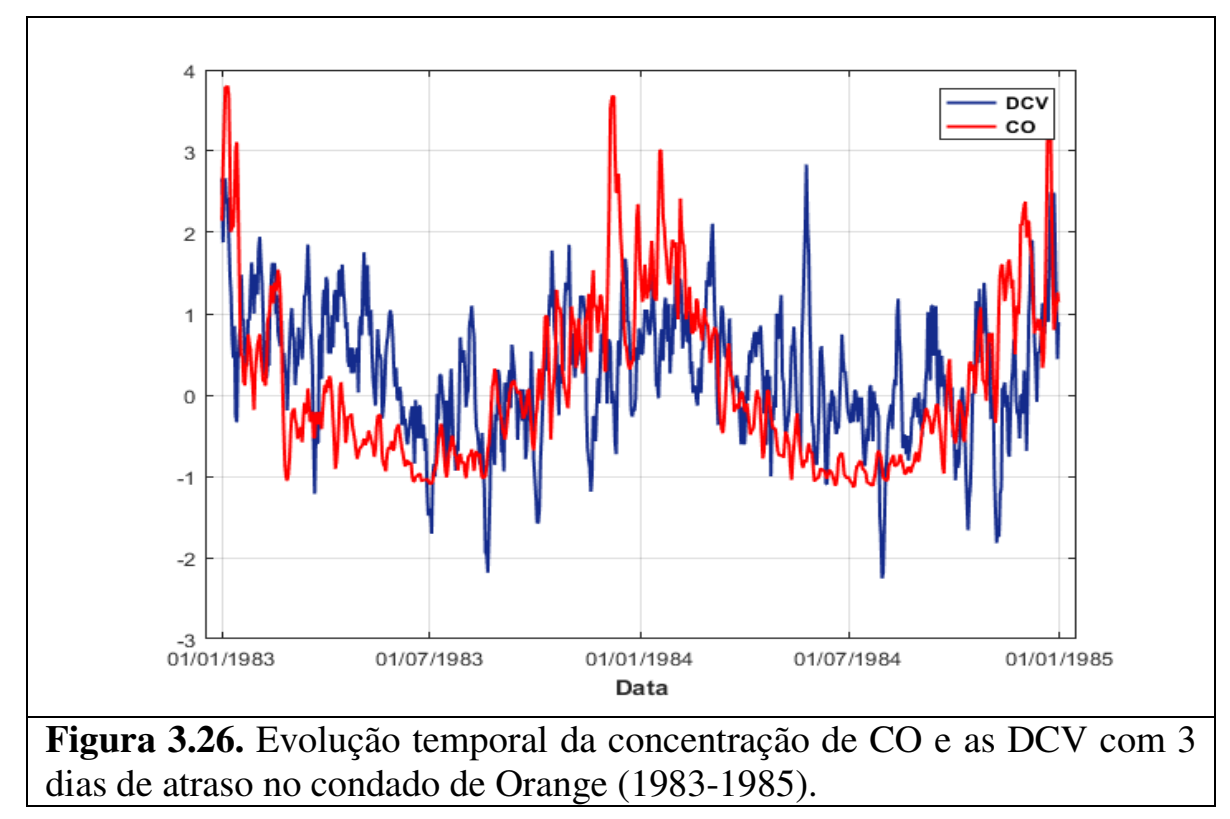




\subsubsection{Condado de Santa Bárbara}

A análise de correlação feita para o condado de Santa Bárbara entre as diversas variáveis utilizadas e as doenças tanto DCV quanto RES mostraram correlações bem menores para todos os casos, comparado com os condados de Los Angeles e Orange. Embora as maiores correlações também estivessem relacionadas com o quinto dia de atraso (tabelas 3.15 e 3.16).

Nota-se que as maiores correlações entre DCV e variáveis ambientais jamais excede a 0,132, de forma geral as correlações menos baixas foram para os poluentes $\mathrm{CO}$ e $\mathrm{NO}_{2}$, com valores de $\mathrm{r}$ no quinto dia de atraso de 0,132 e 0,88 respectivamente, a T_MIN no segundo dia de atraso $(\mathrm{r}=-0,126)$ e os índices de conforto térmico (com exceção do IC) oscilando entre $0,102<|\mathrm{r}|<0,132$. Também se observa que a correlação entre as variáveis e mortalidade por DCV tanto sem dias de atraso quanto com 5 dias de atraso tem valores muito similares variando apenas em 0,02 .

No caso das correlações das variáveis e as doenças RES observa-se na tabela 3.16 que o comportamento foi bem similar ao obtido para as DCV, com a exceção dos poluentes onde a associação foi mais fraca, a $\mathrm{T}$, a $\mathrm{T}_{\mathrm{d}} \mathrm{e}$ índices de conforto oscilaram entre $0,102<|\mathrm{r}|<0,133$, a maior correlação correspondeu ao índice $\operatorname{ID}_{\mathrm{K}}(-0,133)$. Embora as correlações entre as variáveis ambientais e índices de conforto respeito às DVC e RES ficarem não estatisticamente significativos, os maiores valores foram relacionados com as temperaturas mínimas e medias, ou seja, o estresse por frio influencia mais no aumento do número de óbitos neste condado do que as concentrações de poluentes.

Igualmente o estudo feito utilizando médias móveis neste condado mostrou o efeito da suavização dos dados, o que condiciona maiores correlações entre as variáveis e mortalidade tanto para DCV, quanto RES, na media móvel para 5 dias (tabelas 3.17 e $3,18)$.

Por exemplo, para a correlação entre as doenças RES e o ID, para o caso sem média móvel, temos coeficiente de correlação (r) de -0,123. Quando se calcula o coeficiente de correlação para os casos com média móvel, tem-se para média móvel de 2 dias $\mathrm{r}=$ 0,172, para média móvel de 3 dias $r=-0,207$, para média móvel de 4 dias $-0,238$ e para média móvel de 5 dias $-0,264$. 
Tabela 3.15 - Correlações entre a mortalidade por DCV e as variáveis analisadas* para vários dias com atraso e sem atraso no condado de Santa Bárbara com $p<0.05$. Em negrito os valores estatísticamente não significativos.

\begin{tabular}{|c|c|c|c|c|c|c|}
\hline Variáveis & $\begin{array}{c}\text { Sem } \\
\text { atraso }\end{array}$ & $\begin{array}{c}1 \text { dia } \\
\text { atraso }\end{array}$ & $\begin{array}{l}2 \text { dias } \\
\text { atraso }\end{array}$ & $\begin{array}{l}3 \text { dias } \\
\text { atraso }\end{array}$ & $\begin{array}{l}4 \text { dias } \\
\text { atraso }\end{array}$ & $\begin{array}{l}5 \text { dias } \\
\text { atraso }\end{array}$ \\
\hline CO & 0,122 & 0,123 & 0,124 & 0,117 & 0,124 & 0,132 \\
\hline $\mathrm{O}_{3}$ & 0,021 & 0,030 & 0,025 & 0,020 & 0,018 & 0,014 \\
\hline $\mathrm{NO}_{2}$ & 0,099 & 0,087 & 0,093 & 0,091 & 0,090 & 0,088 \\
\hline $\mathrm{SO}_{2}$ & 0,021 & 0,017 & 0,016 & 0,024 & 0,017 & 0,025 \\
\hline $\mathbf{P}$ & 0,074 & 0,080 & 0,076 & 0,070 & 0,070 & 0,075 \\
\hline$T_{-}$MAX & $-0,073$ & $-0,079$ & $-0,082$ & $-0,076$ & $-0,076$ & $-0,083$ \\
\hline T_MIN & $-0,110$ & $-0,125$ & $-0,126$ & $-0,120$ & $-0,116$ & $-0,121$ \\
\hline $\mathbf{T}$ & $-0,106$ & $-0,115$ & $-0,119$ & $-0,119$ & $-0,116$ & $-0,120$ \\
\hline$T_{d}$ & $-0,092$ & $-0,112$ & $-0,114$ & $-0,099$ & $-0,090$ & $-0,094$ \\
\hline UR & 0,036 & 0,023 & 0,026 & 0,045 & 0,050 & 0,053 \\
\hline $\mathbf{Q}$ & $-0,093$ & $-0,112$ & $-0,115$ & $-0,099$ & $-0,091$ & $-0,093$ \\
\hline v & $-0,020$ & $-0,014$ & $-0,010$ & 0,001 & $-0,002$ & $-0,013$ \\
\hline ID & $-0,108$ & $-0,117$ & $-0,121$ & $-0,121$ & $-0,118$ & $-0,122$ \\
\hline ID_mAX & $-0,076$ & $-0,086$ & $-0,086$ & $-0,076$ & $-0,074$ & $-0,082$ \\
\hline ID_MIN & $-0,111$ & $-0,125$ & $-0,127$ & $-0,121$ & $-0,118$ & $-0,122$ \\
\hline$I D_{K}$ & $-0,109$ & $-0,121$ & $-0,125$ & $-0,121$ & $-0,117$ & $-0,121$ \\
\hline ID $\mathrm{K}_{-}$MIN & $-0,110$ & $-0,122$ & $-0,126$ & $-0,122$ & $-0,118$ & $-0,122$ \\
\hline ID $\mathrm{D}_{-}$MAX & $-0,108$ & $-0,120$ & $-0,123$ & $-0,120$ & $-0,115$ & $-0,119$ \\
\hline $\mathrm{TE}$ & $-0,109$ & $-0,118$ & $-0,123$ & $-0,122$ & $-0,118$ & $-0,122$ \\
\hline TE_MAX & $-0,075$ & $-0,085$ & $-0,085$ & $-0,075$ & $-0,073$ & $-0,081$ \\
\hline TE_MIN & $-0,112$ & $-0,126$ & $-0,129$ & $-0,122$ & $-0,118$ & $-0,122$ \\
\hline TA & $-0,108$ & $-0,118$ & $-0,122$ & $-0,121$ & $-0,117$ & $-0,121$ \\
\hline AT_MAX & $-0,084$ & $-0,093$ & $-0,096$ & $-0,088$ & $-0,086$ & $-0,094$ \\
\hline IC & $-0,031$ & $-0,025$ & $-0,025$ & $-0,031$ & $-0,029$ & $-0,036$ \\
\hline $\mathrm{TEv}_{\mathrm{v}}$ & $-0,105$ & $-0,112$ & $-0,116$ & $-0,118$ & $-0,117$ & $-0,119$ \\
\hline$T_{E_{\text {V_MAX }}}$ & $-0,073$ & $-0,079$ & $-0,081$ & $-0,076$ & $-0,076$ & $-0,082$ \\
\hline TEv_MIN & $-0,108$ & $-0,121$ & $-0,123$ & $-0,119$ & $-0,118$ & $-0,119$ \\
\hline H & 0,091 & 0,101 & 0,105 & 0,110 & 0,108 & 0,106 \\
\hline H_MIN & 0,089 & 0,106 & 0,108 & 0,108 & 0,107 & 0,102 \\
\hline
\end{tabular}

*Onde: P (Pressão atmosférica), T (Temperatura), UR (Umidade relativa), q (Umidade específica), V (Velocidade do vento), Índices: MAX (Máxima) e MIN (Mínima). 
Tabela 3.16 - Correlações entre a mortalidade por doenças RES e as variáveis analisadas* para vários dias com atraso e sem atraso no condado de Santa Bárbara com $\mathrm{p}<0.05$. Em negrito os valores estatísticamente não significativos.

\begin{tabular}{|c|c|c|c|c|c|c|}
\hline Variáveis & $\begin{array}{c}\text { Sem } \\
\text { atraso }\end{array}$ & $\begin{array}{c}1 \text { dia } \\
\text { atraso }\end{array}$ & $\begin{array}{l}2 \text { dias } \\
\text { atraso }\end{array}$ & $\begin{array}{l}3 \text { dias } \\
\text { atraso }\end{array}$ & $\begin{array}{l}4 \text { dias } \\
\text { atraso }\end{array}$ & $\begin{array}{l}5 \text { dias } \\
\text { atraso }\end{array}$ \\
\hline $\mathrm{CO}$ & 0,122 & 0,123 & 0,124 & 0,117 & 0,124 & 0,132 \\
\hline $\mathrm{O}_{3}$ & 0,021 & 0,030 & 0,025 & 0,020 & 0,018 & 0,014 \\
\hline $\mathrm{NO}_{2}$ & 0,099 & 0,087 & 0,093 & 0,091 & 0,090 & 0,088 \\
\hline $\mathrm{SO}_{2}$ & 0,021 & 0,017 & 0,016 & 0,024 & 0,017 & 0,025 \\
\hline $\mathbf{P}$ & 0,074 & 0,080 & 0,076 & 0,070 & 0,070 & 0,075 \\
\hline$T_{-}$MAX & $-0,073$ & $-0,079$ & $-0,082$ & $-0,076$ & $-0,076$ & $-0,083$ \\
\hline T_MIN & $-0,110$ & $-0,125$ & $-0,126$ & $-0,120$ & $-0,116$ & $-0,121$ \\
\hline $\mathbf{T}$ & $-0,106$ & $-0,115$ & $-0,119$ & $-0,119$ & $-0,116$ & $-0,120$ \\
\hline$T_{d}$ & $-0,092$ & $-0,112$ & $-0,114$ & $-0,099$ & $-0,090$ & $-0,094$ \\
\hline UR & 0,036 & 0,023 & 0,026 & 0,045 & 0,050 & 0,053 \\
\hline $\mathbf{Q}$ & $-0,093$ & $-0,112$ & $-0,115$ & $-0,099$ & $-0,091$ & $-0,093$ \\
\hline v & $-0,020$ & $-0,014$ & $-0,010$ & 0,001 & $-0,002$ & $-0,013$ \\
\hline ID & $-0,108$ & $-0,117$ & $-0,121$ & $-0,121$ & $-0,118$ & $-0,122$ \\
\hline ID_mAX & $-0,076$ & $-0,086$ & $-0,086$ & $-0,076$ & $-0,074$ & $-0,082$ \\
\hline ID_MIN & $-0,111$ & $-0,125$ & $-0,127$ & $-0,121$ & $-0,118$ & $-0,122$ \\
\hline ID $\mathrm{K}_{\mathrm{K}}$ & $-0,109$ & $-0,121$ & $-0,125$ & $-0,121$ & $-0,117$ & $-0,121$ \\
\hline ID $\mathrm{K}_{-}$MIN & $-0,110$ & $-0,122$ & $-0,126$ & $-0,122$ & $-0,118$ & $-0,122$ \\
\hline ID K_MAX $_{\text {Kax }}$ & $-0,108$ & $-0,120$ & $-0,123$ & $-0,120$ & $-0,115$ & $-0,119$ \\
\hline TE & $-0,109$ & $-0,118$ & $-0,123$ & $-0,122$ & $-0,118$ & $-0,122$ \\
\hline$T E_{-} \operatorname{mAX}$ & $-0,075$ & $-0,085$ & $-0,085$ & $-0,075$ & $-0,073$ & $-0,081$ \\
\hline TE_MIN & $-0,112$ & $-0,126$ & $-0,129$ & $-0,122$ & $-0,118$ & $-0,122$ \\
\hline TA & $-0,108$ & $-0,118$ & $-0,122$ & $-0,121$ & $-0,117$ & $-0,121$ \\
\hline AT_MAX & $-0,084$ & $-0,093$ & $-0,096$ & $-0,088$ & $-0,086$ & $-0,094$ \\
\hline IC & $-0,031$ & $-0,025$ & $-0,025$ & $-0,031$ & $-0,029$ & $-0,036$ \\
\hline $\mathrm{TEv}_{\mathrm{v}}$ & $-0,105$ & $-0,112$ & $-0,116$ & $-0,118$ & $-0,117$ & $-0,119$ \\
\hline$T_{V_{\text {V_MAX }}}$ & $-0,073$ & $-0,079$ & $-0,081$ & $-0,076$ & $-0,076$ & $-0,082$ \\
\hline$T E_{v_{-}}$MIN & $-0,108$ & $-0,121$ & $-0,123$ & $-0,119$ & $-0,118$ & $-0,119$ \\
\hline H & 0,091 & 0,101 & 0,105 & 0,110 & 0,108 & 0,106 \\
\hline H_MIN & 0,089 & 0,106 & 0,108 & 0,108 & 0,107 & 0,102 \\
\hline
\end{tabular}

*Onde: P (Pressão atmosférica), T (Temperatura), UR (Umidade relativa), q (Umidade específica), $\mathrm{V}$ (Velocidade do vento), Índices: MAX (Máxima) e MIN (Mínima). 
Tabela 3.17 - Correlações entre as DCV e as variáveis analisadas* sem média móvel e com média móvel de até 5 dias (todas variáveis) condado de Santa Bárbara $(\mathrm{p}<0,05)$. Em negrito os valores estatísticamente não significativos.

\begin{tabular}{|c|c|c|c|c|c|}
\hline Variáveis & $\begin{array}{c}\text { Sem } \\
\text { média } \\
\text { móvel }\end{array}$ & $\begin{array}{c}\text { Média } \\
\text { móvel } 2 \\
\text { dias }\end{array}$ & $\begin{array}{c}\text { Média } \\
\text { móvel } 3 \\
\text { dias }\end{array}$ & $\begin{array}{c}\text { Média } \\
\text { móvel } 4 \\
\text { dias }\end{array}$ & $\begin{array}{c}\text { Média } \\
\text { móvel } 5 \\
\text { dias }\end{array}$ \\
\hline $\mathrm{CO}$ & 0,122 & 0,179 & 0,221 & 0,255 & 0,286 \\
\hline $\mathrm{O}_{3}$ & 0,021 & 0,039 & 0,051 & 0,058 & 0,064 \\
\hline $\mathrm{NO}_{2}$ & 0,099 & 0,141 & 0,175 & 0,202 & 0,227 \\
\hline $\mathrm{SO}_{2}$ & 0,021 & 0,031 & 0,041 & 0,049 & 0,056 \\
\hline $\mathbf{P}$ & 0,074 & 0,111 & 0,140 & 0,163 & 0,185 \\
\hline$T_{-}$MAX & $-0,073$ & $-0,104$ & $-0,132$ & $-0,156$ & $-0,178$ \\
\hline T_MIN & $-0,110$ & $-0,158$ & $-0,192$ & $-0,219$ & $-0,243$ \\
\hline $\mathbf{T}$ & $-0,106$ & $-0,149$ & $-0,180$ & $-0,207$ & $-0,231$ \\
\hline$T_{d}$ & $-0,092$ & $-0,136$ & $-0,166$ & $-0,190$ & $-0,210$ \\
\hline UR & 0,036 & 0,048 & 0,062 & 0,078 & 0,095 \\
\hline $\mathbf{Q}$ & $-0,093$ & $-0,138$ & $-0,169$ & $-0,194$ & $-0,214$ \\
\hline v & $-0,020$ & $-0,036$ & $-0,044$ & $-0,047$ & $-0,051$ \\
\hline ID & $-0,108$ & $-0,152$ & $-0,184$ & $-0,211$ & $-0,236$ \\
\hline ID_mAX & $-0,076$ & $-0,109$ & $-0,138$ & $-0,163$ & $-0,185$ \\
\hline ID_MIN & $-0,111$ & $-0,159$ & $-0,194$ & $-0,222$ & $-0,246$ \\
\hline ID $D_{K}$ & $-0,109$ & $-0,154$ & $-0,186$ & $-0,213$ & $-0,236$ \\
\hline ID $D_{\text {K_MIN }}$ & $-0,110$ & $-0,155$ & $-0,187$ & $-0,214$ & $-0,238$ \\
\hline ID K_MAX $_{\text {M }}$ & $-0,108$ & $-0,153$ & $-0,185$ & $-0,211$ & $-0,234$ \\
\hline TE & $-0,109$ & $-0,153$ & $-0,185$ & $-0,212$ & $-0,236$ \\
\hline$T E_{-}$mAX & $-0,075$ & $-0,108$ & $-0,137$ & $-0,161$ & $-0,183$ \\
\hline TE_MIN & $-0,112$ & $-0,161$ & $-0,195$ & $-0,223$ & $-0,247$ \\
\hline TA & $-0,108$ & $-0,152$ & $-0,184$ & $-0,210$ & $-0,234$ \\
\hline AT_MAX & $-0,084$ & $-0,121$ & $-0,151$ & $-0,176$ & $-0,200$ \\
\hline IC & $-0,031$ & $-0,044$ & $-0,057$ & $-0,069$ & $-0,081$ \\
\hline $\mathrm{TEv}_{\mathrm{v}}$ & $-0,105$ & $-0,146$ & $-0,178$ & $-0,205$ & $-0,229$ \\
\hline$T E_{v_{-} \text {max }}$ & $-0,073$ & $-0,104$ & $-0,131$ & $-0,156$ & $-0,178$ \\
\hline TEv_MIN & $-0,108$ & $-0,154$ & $-0,188$ & $-0,215$ & $-0,240$ \\
\hline $\mathbf{H}$ & 0,091 & 0,128 & 0,158 & 0,185 & 0,209 \\
\hline$H_{\text {IMIN }}$ & 0,089 & 0,131 & 0,162 & 0,189 & 0,213 \\
\hline
\end{tabular}

*Onde: P (Pressão atmosférica), T (Temperatura), UR (Umidade relativa), q (Umidade específica), V (Velocidade do vento), Índices: MAX (Máxima) e MIN (Mínima). 
Tabela 3.18 - Correlações entre as doenças RES e as variáveis analisadas* sem média móvel e com média móvel de até 5 dias (todas variáveis) condado de Santa Bárbara $(p<0,05)$. Em negrito os valores estatísticamente não significativos.

\begin{tabular}{|c|c|c|c|c|c|}
\hline Variáveis & $\begin{array}{l}\text { Sem } \\
\text { média } \\
\text { móvel }\end{array}$ & $\begin{array}{c}\text { Média } \\
\text { móvel } 2 \\
\text { dias }\end{array}$ & $\begin{array}{c}\text { Média } \\
\text { móvel } 3 \\
\text { dias }\end{array}$ & $\begin{array}{l}\text { Média } \\
\text { móvel } 4 \\
\text { dias }\end{array}$ & $\begin{array}{c}\text { Média } \\
\text { móvel } 5 \\
\text { dias }\end{array}$ \\
\hline $\mathrm{CO}$ & 0,035 & 0,052 & 0,059 & 0,067 & 0,074 \\
\hline $\mathrm{O}_{3}$ & $-0,035$ & $-0,052$ & $-0,070$ & $-0,086$ & $-0,103$ \\
\hline $\mathrm{NO}_{2}$ & 0,022 & 0,034 & 0,043 & 0,052 & 0,058 \\
\hline $\mathrm{SO}_{2}$ & 0,034 & 0,050 & 0,059 & 0,066 & 0,070 \\
\hline $\mathbf{P}$ & 0,089 & 0,122 & 0,150 & 0,177 & 0,203 \\
\hline$T_{-M A X}$ & $-0,089$ & $-0,127$ & $-0,157$ & $-0,183$ & $-0,205$ \\
\hline$T_{-}$MIN & $-0,116$ & $-0,164$ & $-0,199$ & $-0,229$ & $-0,256$ \\
\hline $\mathbf{T}$ & $-0,120$ & $-0,167$ & $-0,202$ & $-0,231$ & $-0,257$ \\
\hline$T_{d}$ & $-0,096$ & $-0,135$ & $-0,165$ & $-0,191$ & $-0,216$ \\
\hline UR & 0,050 & 0,076 & 0,098 & 0,117 & 0,133 \\
\hline $\mathbf{Q}$ & $-0,096$ & $-0,136$ & $-0,166$ & $-0,192$ & $-0,217$ \\
\hline v & $-0,031$ & $-0,042$ & $-0,050$ & $-0,057$ & $-0,066$ \\
\hline ID & $-0,123$ & $-0,172$ & $-0,207$ & $-0,238$ & $-0,264$ \\
\hline ID_mAX & $-0,091$ & $-0,130$ & $-0,160$ & $-0,186$ & $-0,208$ \\
\hline ID_MIN & $-0,119$ & $-0,169$ & $-0,205$ & $-0,235$ & $-0,262$ \\
\hline$I_{\mathrm{K}}$ & $-0,121$ & $-0,169$ & $-0,203$ & $-0,233$ & $-0,259$ \\
\hline ID $\mathrm{K}_{-} \mathrm{MIN}$ & $-0,122$ & $-0,169$ & $-0,204$ & $-0,234$ & $-0,260$ \\
\hline ID ${ }_{K \_ \text {MAX }}$ & $-0,120$ & $-0,168$ & $-0,202$ & $-0,232$ & $-0,258$ \\
\hline TE & $-0,123$ & $-0,171$ & $-0,206$ & $-0,237$ & $-0,263$ \\
\hline TE_MAX & $-0,090$ & $-0,128$ & $-0,158$ & $-0,184$ & $-0,205$ \\
\hline$T_{\text {MIN }}$ & $-0,118$ & $-0,167$ & $-0,203$ & $-0,233$ & $-0,260$ \\
\hline TA & $-0,121$ & $-0,168$ & $-0,203$ & $-0,233$ & $-0,259$ \\
\hline$A T_{-}$MAX & $-0,100$ & $-0,141$ & $-0,173$ & $-0,201$ & $-0,224$ \\
\hline IC & $-0,039$ & $-0,070$ & $-0,094$ & $-0,115$ & $-0,132$ \\
\hline $\mathrm{TE}_{\mathrm{v}}$ & $-0,117$ & $-0,165$ & $-0,200$ & $-0,230$ & $-0,256$ \\
\hline $\mathrm{TEV}_{\mathrm{v}_{-} \mathrm{MAX}}$ & $-0,086$ & $-0,124$ & $-0,154$ & $-0,180$ & $-0,202$ \\
\hline TEv_MIN & $-0,114$ & $-0,163$ & $-0,199$ & $-0,229$ & $-0,255$ \\
\hline $\mathbf{H}$ & 0,098 & 0,142 & 0,176 & 0,205 & 0,230 \\
\hline$H_{-}$MIN & 0,088 & 0,131 & 0,164 & 0,193 & 0,217 \\
\hline
\end{tabular}

*Onde: P (Pressão atmosférica), T (Temperatura), UR (Umidade relativa), q (Umidade específica), V (Velocidade do vento), Índices: MAX (Máxima) e MIN (Mínima). 
Igualmente foi analisada a evolução temporal de algumas das variáveis mais bem correlacionadas com a mortalidade por DCV ou RES. Por exemplo, na figura 3.27 apresentam-se a variação temporal das doenças RES e a P, para o caso onde foram utilizados 5 dias de atraso. Embora o valor de $\mathrm{r}$ foi muito baixo, apresentando um valor de apenas 0,075. Mesmo assim, as variáveis tendem a apresentar um comportamento sazonal semelhante, ou seja, aumentos da pressão estão correlacionados com aumentos das doenças RES.

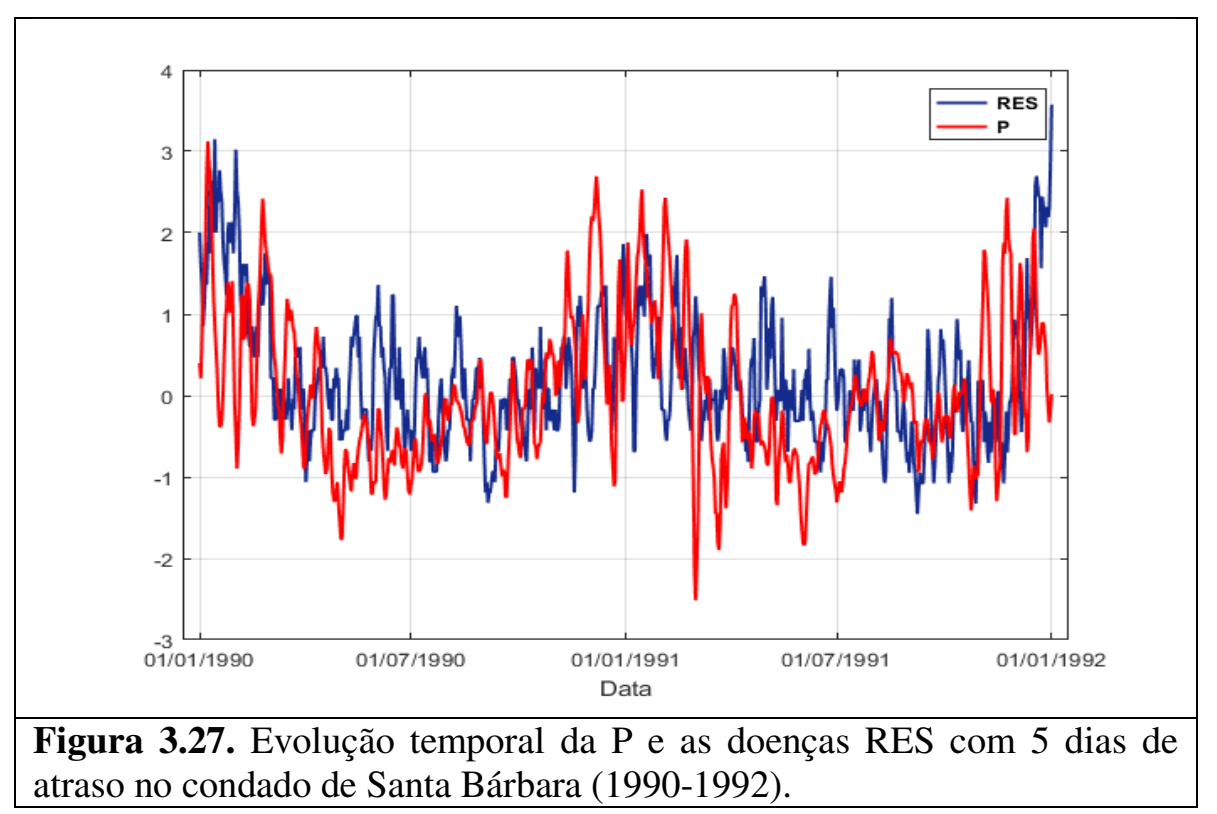

Na figura 3.28 apresenta-se a variação temporal das $\mathrm{DCV}$ e o $\mathrm{IDK}_{\mathrm{K}}$ para o caso onde foram utilizados 5 dias com atraso. Observa-se, que há uma tendência de variação inversa na maioria do período entre estas duas variáveis, indicada pelo sinal negativo da correlação, durante o período apresentado.

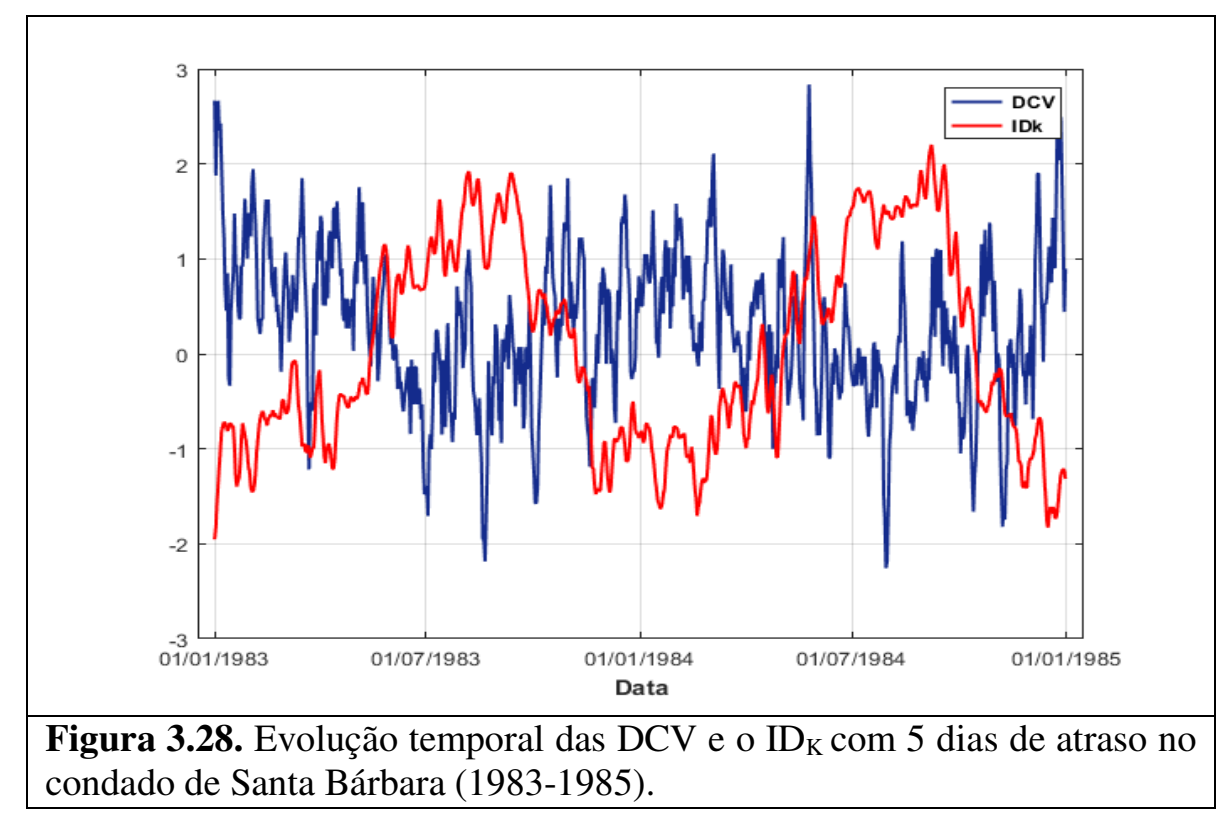




\subsection{Análises de componentes principais (ACP)}

Neste subcapitulo, será aplicado a ACP com o objetivo de investigar os padrões de variabilidade relacionados às DCV e RES, poluição do ar, variáveis meteorológicas e índices de conforto térmico e separá-los em fatores independentes distintos. Os dados de entrada para a ACP são, portanto, uma série temporal representada pela matriz de correlação. Inicialmente a análise foi feita considerando apenas as variáveis meteorológicas e os poluentes atmosféricos; e posteriormente considerando os índices de conforto térmico.

\subsubsection{ACP aplicada às variáveis meteorotrópicas}

Nas tabelas 3.19 e 3.20 são mostrados os pesos das componentes principais após da rotação VARIMAX para a mortalidade por DCV e RES, respectivamente, com respeito aos níveis de poluição e algumas variáveis meteorológicas considerando primeiramente a mortalidade sem dias de atraso e logo após de 5 dias de atraso, no condado de Los Angeles.

A ACP foi efetiva quanto à redução da massa de dados, tendo reduzido a quantidade de variáveis em 3 fatores, permitindo a análise dos dados, os resultados para as DCV considerando os dados do dia em questão ou com atraso (5 dias de atraso) apresentam uma variância acumulativa nos primeiros 3 fatores de 73,13\% (72,97 \%). Onde o fator 1 observou-se variância explicada de 40,36 \% (40,42\%), apresentando altos pesos positivos entre as variáveis meteorológicas $\left(\mathrm{T}_{\mathrm{d}}\right.$, UR e q) variando entre 0,79 a $0,90(0,80$ a 0,90$)$ opostos às DCV com -0,48 (-0,50). Indicando que um decaimento na umidade e a temperatura podem contribuir no aumento da mortalidade por DCV.

Entretanto no fator 2 observou-se variância explicada de 21,43 \% (21,24 \%) apresentando altos pesos positivos (negativos) para os poluentes, com exceção do $\mathrm{O}_{3}$, variando de 0,71 a $0,85(-0,70$ a $-0,84)$ e alto peso negativo (positivo) para a velocidade do vento (V) de $-0,71(0,72)$, em relação as DCV com $0,40(-0,33)$, sendo este valor associado a mortalidade ainda que não significativo acima de 0,70. Embora com base neste fator, acredita-se que um aumento na concentração dos poluentes pode acarretar em um aumento na mortalidade por DCV, com uma explicação de variância de $21 \%$.

Já no fator 3 observou-se variância explicada de 11,34 \% (11,32 \%) apresentando altos pesos negativos para a $\mathrm{T}$ com $-0,86(-0,82), \mathrm{o}_{3} \mathrm{com}-0,79(-0,79)$ e alto peso positivo 
para a $\mathrm{P}$ com $0,66(0,65)$ por sua parte as $\mathrm{DCV}$ ficaram com valores muito fracos de apenas $0,03(0,08)$, não havendo nenhuma associação.

Para conhecer quanto explica cada variável representada nos três fatores do total, foram calculadas as comunalidades das variáveis mais correlacionadas com as DCV (com peso maior que 0,30 ) só para os dias sem atraso, devido às grandes similitudes dos resultados para 5 dias de atraso. Nesta análise as mais representadas constituíram a Td, q, UR, $\mathrm{NO}_{2}, \mathrm{CO}$ e $\mathrm{SO}_{2}$ respectivamente com valores de 0,96, 0,96, 0,82, 0,80, 0,78 e 0,75 (valores $>0,50$ ) por outro lado o as DCV apresentaram um valor de 0,39.

Tabela 3.19 - Pesos das componentes principais após a rotação VARIMAX na análise de DCV considerando a) dias sem atraso e b) 5 dias de atraso para o condado de Los Angeles.

\begin{tabular}{|c|c|c|c|c|c|c|c|}
\hline Variável & Fator1 & Fator2 & Fator3 & Variável & Fator1 & Fator2 & Fator3 \\
\hline DCV & $-0,48$ & 0,40 & 0,03 & DCV & $-0,50$ & $-0,33$ & 0,08 \\
\hline CO & $-0,47$ & 0,71 & 0,25 & $\mathrm{CO}$ & $-0,49$ & $-0,70$ & 0,23 \\
\hline $\mathrm{O}_{3}$ & 0,04 & 0,16 & $-0,79$ & $\mathrm{O}_{3}$ & 0,05 & $-0,15$ & $-0,79$ \\
\hline $\mathrm{NO}_{2}$ & $-0,25$ & 0,84 & $-0,17$ & $\mathrm{NO}_{2}$ & $-0,27$ & $-0,83$ & $-0,19$ \\
\hline $\mathrm{SO}_{2}$ & $-0,16$ & 0,85 & $-0,07$ & $\mathrm{SO}_{2}$ & $-0,18$ & $-0,84$ & $-0,08$ \\
\hline $\mathbf{P}$ & $-0,21$ & 0,36 & 0,66 & $\mathbf{P}$ & $-0,23$ & $-0,36$ & 0,65 \\
\hline $\mathbf{T}$ & 0,20 & 0,00 & $-0,86$ & $T$ & 0,21 & 0,00 & $-0,82$ \\
\hline$T_{d}$ & 0,83 & $-0,07$ & $-0,51$ & $T_{d}$ & 0,84 & 0,06 & $-0,50$ \\
\hline UR & 0,90 & $-0,09$ & $-0,03$ & UR & 0,90 & 0,07 & $-0,01$ \\
\hline$q$ & 0,79 & $-0,09$ & $-0,57$ & $q$ & 0,80 & 0,07 & $-0,56$ \\
\hline v & $-0,28$ & $-0,71$ & $-0,19$ & v & $-0,26$ & 0,72 & $-0,19$ \\
\hline Autovalor & 4,44 & 2,36 & 1,25 & Autovalor & 4,45 & 2,34 & 1,24 \\
\hline Var expl. & 40,36 & 21,43 & 11,34 & Var expl. & 40,42 & 21,24 & 11,32 \\
\hline
\end{tabular}

No caso da mortalidade por doenças RES o comportamento dos fatores em geral foi similar às DCV, embora o maior peso das doenças RES caiu no terceiro fator. Os primeiros 3 fatores apresentaram variância acumulativa sem considerar dias de atraso (5 dias de atraso) de 72,36 \% (72,56 \%). No fator 1 observou-se variância explicada de $39,55 \%(39,81 \%)$, apresentando altos pesos positivos entre as variáveis meteorológicas Td, UR e q variando entre 0,81 e $0,94(0,79$ e 0,94$)$, com resultados não significativos em relação às doenças RES $-0,06(-0,11)$. 
No fator 2 observou-se variância explicada de 21,14\% (21,18\%), com altos pesos positivos entre os poluentes (com exceção de $\mathrm{O}_{3}$ ) variando entre 0,71 e 0,86 e alto peso negativo para a $\mathrm{V}$ de $-0,70$, tanto no próprio dia em questão quanto com 5 dias de atraso. Igualmente neste fator o peso foi baixo em relação às doenças RES com 0,18 $(0,16)$.

Já no fator 3 a variância explicada foi de 11,67 \% (11,57 \%) apresentando associação positiva entre a $\mathrm{P}$ de $0,63(0,63)$ e as doenças RES de 0,55 , assim como negativa para o $\mathrm{O}_{3}(-0,74)$ e para a $\mathrm{T}(-0,83(-0,84))$. O fator é pode ser representativo no inverno no(s) condado(s), ou seja, com a chegada das massas de ar polar a pressão sobe e a temperatura cai, condicionando a um aumento de doenças RES. Entretanto em relação aos níveis de ozônio, que caem durante o inverno, devido às baixas temperaturas. Mais detalhes nos estudos sazonais são abordados na seção 3.5.3.

No caso das comunalidades entre as variáveis mais correlacionadas com as doenças RES encontrassem a $\mathrm{T}, \mathrm{O}_{3}$, e P com valores de 0,73, 0,57 e 0,60 respectivamente, as doenças RES o valor foi de 0,35, nota-se maiores representações das variáveis correlacionadas com a mortalidade por DCV.

Tabela 3.20 - Pesos das componentes principais após a rotação VARIMAX na análise da mortalidade por doenças RES considerando a) dias sim atraso e b) 5 dias de atraso para o condado de Los Angeles.

\begin{tabular}{|c|c|c|c|c|c|c|c|}
\hline Variável & Fator1 & Fator2 & Fator3 & Variável & Fator1 & Fator2 & Fator3 \\
\hline RES & $-0,06$ & 0,18 & 0,55 & RES & $-0,11$ & 0,16 & 0,55 \\
\hline $\mathrm{CO}$ & $-0,46$ & 0,71 & 0,27 & $\mathrm{CO}$ & $-0,45$ & 0,71 & 0,28 \\
\hline $\mathrm{O}_{3}$ & 0,11 & 0,20 & $-0,74$ & $\mathrm{O}_{3}$ & 0,09 & 0,19 & $-0,74$ \\
\hline $\mathrm{NO}_{2}$ & $-0,22$ & 0,86 & $-0,13$ & $\mathrm{NO}_{2}$ & $-0,22$ & 0,86 & $-0,13$ \\
\hline $\mathrm{SO}_{2}$ & $-0,12$ & 0,85 & $-0,02$ & $\mathrm{SO}_{2}$ & $-0,12$ & 0,85 & $-0,03$ \\
\hline $\mathbf{P}$ & $-0,25$ & 0,33 & 0,63 & $\mathbf{P}$ & $-0,23$ & 0,34 & 0,63 \\
\hline $\mathbf{T}$ & 0,18 & 0,05 & $-0,83$ & $\mathbf{T}$ & 0,16 & 0,04 & $-0,84$ \\
\hline Td & 0,86 & $-0,07$ & $-0,48$ & Td & 0,84 & $-0,08$ & $-0,50$ \\
\hline UR & 0,94 & $-0,13$ & 0,02 & UR & 0,94 & $-0,13$ & 0,00 \\
\hline$q$ & 0,81 & $-0,08$ & $-0,54$ & $q$ & 0,79 & $-0,09$ & $-0,56$ \\
\hline v & $-0,23$ & $-0,70$ & $-0,18$ & V & $-0,25$ & $-0,70$ & $-0,17$ \\
\hline Autovalor & 4,35 & 2,33 & 1,28 & Autovalor & 4,38 & 2,33 & 1,27 \\
\hline Var expl. & 39,55 & 21,14 & 11,67 & Var expl. & 39,81 & 21,18 & 11,57 \\
\hline
\end{tabular}


Do mesmo modo, nas tabelas 3.21 e 3.22 são mostrados os pesos das componentes principais após da rotação VARIMAX para a mortalidade por DCV e RES, respectivamente, com respeito aos níveis de poluição e algumas variáveis meteorológicas considerando primeiramente a mortalidade sem dias de atraso e logo após de 5 dias de atraso, no condado de Orange.

Tanto para a análise das DCV, quanto para as doenças RES, foram utilizados 4 fatores, acima/igual de autovalor de 1 . Na análise das DCV os fatores apresentaram variância acumulativa quando não há atraso na mortalidade (5 dias de atraso) de 76,78 \% (76,74 \%). No fator 1, diferentemente dos resultados acima, observou-se variância explicada de $38,73 \%(38,76 \%)$, apresentando uma associação positiva, ou seja, todos são negativos, entre os poluentes (com exceção de $\mathrm{O}_{3}$ ) variando entre -0,73 e - 0,80 (-0,73 e - 0,81) e as DCV com -0,50 (-0,47). Com base neste fator, acredita-se que um aumento na concentração dos poluentes pode acarretar em um aumento na mortalidade por DCV, com uma explicação da variância maior do que a encontrada no resultado da tabela 3.19, onde somente cerca de $21 \%$ da explicação ocorreu contra $39 \%$ nesta tabela 3.21 .

Já no fator 2 observou-se variância explicada de 18,14 \% (18,21\%), apresentando altos pesos positivos para o $\mathrm{O}_{3}$ e a $\mathrm{T}$ de 0,74 e $0,73(0,73$ e 0,74$)$ respectivamente, bem como alto peso negativo para a UR com $-0,83$ tanto do próprio dia em questão quanto com 5 dias de atraso, por sua parte neste fator as DCV tiveram um peso de $-0,36(-0,39)$, evidenciando uma associação fraca, porém negativa com respeito à temperatura e positiva com respeito à umidade. Neste sentido o fator pode representar muito bem o período de verão no sul de Califórnia, quando uma ligeira diminuição das DCV pode ser provocada por um aumento da temperatura e dos níveis de $\mathrm{O}_{3}$ assim como de uma diminuição da UR. Mais detalhes nos estudos sazonais discutidos na seção 3.5.3.

Por último, nos fatores 3 e 4 observou-se variância explicada de 11,06 \% e 8,75\% $(11,07 \%$ e $8,71 \%)$ respectivamente, apresentando altos pesos positivos para a $T_{d}$ de $0,96(0,95)$ e a q de 0,93 tanto sem atraso como com 5 dias de atraso. Por sua parte as DCV ficaram com valores de -0,18 (-0,19), ou seja, sem associação significativa. Já no quarto fator os maiores pesos foram para a V com $0,83(0,84)$ e a P com -0,56 (-0,57); em associação positiva (V) e negativa $(\mathrm{P})$ às DCV com $0,37(0,35)$. Neste caso, vento e queda na pressão podem contribuir para os casos de DCV, o que é suportado na literatura médica onde a má termorregulação dos enfermos pode gerar estresse. 
Tabela 3.21 - Pesos das componentes principais após a rotação VARIMAX na análise de DCV considerando a) dias sim atraso e b) 5 dias de atraso para o condado de Orange.

\begin{tabular}{|c|c|c|c|c|c|c|c|c|c|}
\hline Variável & $\begin{array}{c}\text { Fator } \\
1\end{array}$ & $\begin{array}{c}\text { Fator } \\
2\end{array}$ & $\begin{array}{c}\text { Fator } \\
3\end{array}$ & $\begin{array}{c}\text { Fator } \\
4\end{array}$ & Variável & $\begin{array}{c}\text { Fator } \\
1\end{array}$ & $\begin{array}{c}\text { Fator } \\
2\end{array}$ & $\begin{array}{c}\text { Fator } \\
3\end{array}$ & $\begin{array}{c}\text { Fator } \\
4\end{array}$ \\
\hline DCV & $-0,50$ & $-0,36$ & $-0,18$ & 0,37 & DCV & $-0,47$ & $-0,39$ & $-0,19$ & 0,35 \\
\hline CO & $-0,73$ & $-0,13$ & $-0,37$ & $-0,32$ & $\mathrm{CO}$ & $-0,73$ & $-0,14$ & $-0,37$ & $-0,32$ \\
\hline $\mathrm{O}_{3}$ & $-0,16$ & 0,74 & 0,29 & 0,04 & $\mathrm{O}_{3}$ & $-0,16$ & 0,73 & 0,28 & 0,05 \\
\hline $\mathrm{NO}_{2}$ & $-0,73$ & 0,11 & $-0,30$ & $-0,32$ & $\mathrm{NO}_{2}$ & $-0,73$ & 0,11 & $-0,30$ & $-0,33$ \\
\hline $\mathrm{SO}_{2}$ & $-0,80$ & 0,17 & $-0,02$ & $-0,09$ & $\mathrm{SO}_{2}$ & $-0,81$ & 0,16 & $-0,02$ & $-0,08$ \\
\hline $\mathbf{P}$ & $-0,30$ & $-0,05$ & $-0,42$ & $-0,56$ & $\mathbf{P}$ & $-0,30$ & $-0,05$ & $-0,42$ & $-0,57$ \\
\hline $\mathbf{T}$ & 0,16 & 0,73 & 0,56 & 0,13 & $T$ & 0,16 & 0,74 & 0,55 & 0,14 \\
\hline $\mathrm{Td}$ & 0,22 & 0,08 & 0,96 & 0,10 & $\mathrm{Td}$ & 0,22 & 0,09 & 0,95 & 0,10 \\
\hline UR & 0,07 & $-0,83$ & 0,45 & $-0,03$ & UR & 0,07 & $-0,83$ & 0,46 & $-0,03$ \\
\hline$q$ & 0,23 & 0,11 & 0,93 & 0,11 & $q$ & 0,23 & 0,12 & 0,93 & 0,12 \\
\hline v & 0,17 & 0,09 & 0,05 & 0,83 & v & 0,16 & 0,09 & 0,05 & 0,84 \\
\hline Autovalor & 4,26 & 2,00 & 1,22 & 0,96 & Autovalor & 4,26 & 2,00 & 1,22 & 0,96 \\
\hline Var expl. & 38,73 & 18,14 & 11,06 & 8,75 & Var expl. & 38,76 & 18,21 & 11,07 & 8,71 \\
\hline
\end{tabular}

Na ACP para a mortalidade por doenças RES a distribuição dos fatores mostrou um comportamento muito similar do que no caso das DCV, o notável foi que a associação das variáveis com as doenças RES foi bem mais fraca (tabela 3.22), os resultados estão em correspondência aos obtidos para o condado de Los Angeles onde também foram observados maiores correlações entre o conjunto de variáveis e as DCV.

Os quatro fatores apresentam uma explicação da variância acumulada de 76,61\% (76,65\%). No fator 1 observou-se variância explicada de 38,26 \% (38,34 \%), apresentando altos pesos negativos entre os poluentes (com exceção de $\mathrm{O}_{3}$ ) variando entre $-0,78$ e $-0,80(-0,77$ e - $-0,81)$ com nenhuma associação clara às doenças RES com peso apenas de $-0,22(-0,24)$. No entanto, com base neste fator, acredita-se que um aumento na concentração dos poluentes pode acarretar um aumento na mortalidade por RES, ainda que os resultados sejam muito abaixo do significativo.

No fator 2 observou-se variância explicada de 18,38 \% (18,45 \%) apresentando altos pesos para o $\mathrm{O}_{3}$ e $\mathrm{T}$ com $-0,74(0,74)$ e para a UR de $0,86(-0,86)$. Neste fator a mortalidade por doenças RES não apresentaram resultados claros com um valor de apenas $0,09(-0,11)$. 
Tabela 3.22 - Pesos das componentes principais após a rotação VARIMAX na análise da mortalidade por doenças RES considerando a) dias sim atraso e b) 5 dias de atraso para o condado de Orange.

\begin{tabular}{|c|c|c|c|c|c|c|c|c|c|}
\hline Variável & $\begin{array}{c}\text { Fator } \\
1\end{array}$ & $\begin{array}{c}\text { Fator } \\
2\end{array}$ & $\begin{array}{c}\text { Fator } \\
3\end{array}$ & $\begin{array}{c}\text { Fator } \\
4\end{array}$ & Variável & $\begin{array}{c}\text { Fator } \\
1\end{array}$ & $\begin{array}{c}\text { Fator } \\
2\end{array}$ & $\begin{array}{c}\text { Fator } \\
3\end{array}$ & $\begin{array}{c}\text { Fator } \\
4\end{array}$ \\
\hline RES & 0,22 & 0,09 & $-0,21$ & $-0,72$ & RES & 0,24 & $-0,11$ & $-0,23$ & 0,68 \\
\hline CO & $-0,78$ & 0,15 & $-0,36$ & $-0,16$ & $\mathrm{CO}$ & $-0,77$ & $-0,15$ & $-0,36$ & 0,21 \\
\hline $\mathrm{O}_{3}$ & $-0,12$ & $-0,74$ & 0,29 & 0,07 & $\mathrm{O}_{3}$ & $-0,13$ & 0,74 & 0,29 & $-0,07$ \\
\hline $\mathrm{NO}_{2}$ & $-0,78$ & $-0,10$ & $-0,28$ & $-0,18$ & $\mathrm{NO}_{2}$ & $-0,77$ & 0,10 & $-0,28$ & 0,22 \\
\hline $\mathrm{SO}_{2}$ & $-0,80$ & $-0,12$ & $-0,05$ & 0,14 & $\mathrm{SO}_{2}$ & $-0,81$ & 0,12 & $-0,05$ & $-0,11$ \\
\hline $\mathbf{P}$ & $-0,45$ & 0,01 & $-0,34$ & $-0,50$ & $\mathbf{P}$ & $-0,42$ & $-0,01$ & $-0,34$ & 0,53 \\
\hline $\mathbf{T}$ & 0,19 & $-0,74$ & 0,56 & 0,15 & $\mathbf{T}$ & 0,19 & 0,74 & 0,56 & $-0,16$ \\
\hline $\mathrm{Td}$ & 0,26 & $-0,06$ & 0,96 & 0,13 & $\mathrm{Td}$ & 0,25 & 0,06 & 0,94 & $-0,14$ \\
\hline UR & 0,08 & 0,86 & 0,42 & $-0,01$ & UR & 0,08 & $-0,86$ & 0,43 & 0,01 \\
\hline$q$ & 0,27 & $-0,10$ & 0,93 & 0,14 & $\mathbf{q}$ & 0,26 & 0,10 & 0,92 & $-0,15$ \\
\hline $\mathbf{v}$ & 0,43 & $-0,06$ & $-0,08$ & 0,67 & V & 0,39 & 0,05 & $-0,07$ & $-0,70$ \\
\hline Autovalor & 4,38 & 2,33 & 1,27 & 0,98 & Autovalor & 4,22 & 2,03 & 1,22 & 0,97 \\
\hline Var expl. & 38,26 & 18,38 & 11,08 & 8,89 & Var expl. & 38,34 & 18,45 & 11,08 & 8,78 \\
\hline
\end{tabular}

Por sua vez, nos fatores 3 e 4 observou-se variância explicada de 11,08 \% e 8,89 \% $(11,08 \%$ e $8,78 \%)$ respectivamente. No fator 3 apresentam-se associações positivamente com a Td de $0,96(0,94)$ e a q de $0,93(0,92)$, como era de se esperar, por sua parte as doenças RES ficaram com valores de somente $-0,21(-0,23)$. Por último, o quarto fator teve alto peso negativo (positivo) para as doenças RES com -0,72 $(0,68)$ e peso positivo (negativo) da $\mathrm{V}$ com $0,67(-0,70)$ assim como peso negativo (positivo) ainda não significativo da P com -0,50 (0,53). Resultado semelhante ao da tabela 3.19, sistemas de alta pressão com pouco vento estariam associados às doenças RES, neste caso.

A comunalidade no condado de Orange esteve maior representada do que no caso de Los Angeles devido a que a variância explicada foi maior de 0,70 com um maior número de fatores (4 em Orange contra 3 em Los Angeles). As maiores comunalidades das variáveis ocorreram para a $\mathrm{UR}, \mathrm{T}, \mathrm{CO}, \mathrm{NO}_{2}, \mathrm{~V}, \mathrm{SO}_{2}, \mathrm{O}_{3}$ e $\mathrm{P}$ com $0,90,0,89,0,78$, $0,74,0,73,0,68,0,65$ e 0,58 , respectivamente no caso das DCV $(0,55)$, para as doenças RES $(0,62)$ as variáveis foram a V e $\mathrm{P}$ com valores de 0,64 e 0,67 , respectivamente. Embora a mortalidade neste condado tiver maior representação na análise, encontraramse menos associadas às variáveis metereotrópicas do que no condado de Los Angeles. 
Nas tabelas 3.23 e 3.24 são mostrados os pesos das componentes principais após da rotação VARIMAX para a mortalidade por DCV e RES, respectivamente, com respeito aos níveis de poluição e algumas variáveis meteorológicas considerando primeiramente a mortalidade sem dias de atraso e logo após de 5 dias de atraso, no condado de Santa

\section{Bárbara.}

Em ambos os casos foram considerados 5 fatores. No caso da mortalidade por DCV os fatores apresentam variância acumulativa considerando o dia em questão (5 dias de atraso) de 76,59 \% (77,13\%). No fator 1 observou-se variância explicada de 31,42 \% $(31,43 \%)$, apresentando altos pesos positivos entre as variáveis meteorológicas $\mathrm{T}, \mathrm{Td}, \mathrm{e}$ q variando entre 0,72 e 0,89 tanto no próprio dia em questão quanto com 5 dias de atraso. Neste fator as DCV não apresentaram resultados significativos com peso de apenas $-0,18$ resultados que diferem claramente dos demais condados.

No fator 2 observou-se variância explicada de 16,82 \% apresentando alto peso positivo para a UR com valor de 0,78, assim como peso negativo para o $\mathrm{O}_{3}$ com valor de -0,67 (0,69). A correlação negativa entre ambos mostra que no condado de Santa Bárbara os dias com a umidade do ar elevada som pouco propícios para a formação de $\mathrm{O}_{3}$, como era de se esperar. Novamente, não há relação alguma com as DCV (abaixo de 0,1 neste fator). Adicionalmente, o fator três, apresentando uma variância explicada de 11,11 \% $(11,15 \%)$, com alto peso negativo (positivo) para a $\mathrm{V}$ de $-0,79(0,78)$, sem associação significativa em relação ás DCV com peso de $0,21(-0,24)$.

Já no quarto fator apresentando uma variância explicada de um 9,34 \% (9,36 \%) esteve relacionado com as DCV com um alto peso positivo e valor de 0,80 $(0,78)$, as demais variáveis não tiveram clara associação neste fator, embora o vento e a pressão apareçam com pesos de $0,40(0,43)$ e $-0,27(-0,30)$, respectivamente. Estes são indicativos diferentes aos apresentados no condado de Los Angeles e similares com o condado de Orange, onde dias ventosos e de baixa pressão estão associados aos óbitos por DCV. Por último, no quinto fator com variância explicada de 8,37 \% (8,38\%) observa-se um alto peso negativo para o $\mathrm{SO}_{2}$ com um valor de $-0,90(-0,91)$ tendo quase nenhuma correlação com as demais variáveis. 
Tabela 3.23 - Pesos das componentes principais após a rotação VARIMAX na análise de DCV considerando a) dias sim atraso e b) 5 dias de atraso para o condado de Santa Bárbara.

\begin{tabular}{|c|c|c|c|c|c|c|c|c|c|c|c|}
\hline Var & $\begin{array}{c}\text { Fator } \\
1\end{array}$ & $\begin{array}{c}\text { Fator } \\
\mathbf{2}\end{array}$ & $\begin{array}{c}\text { Fator } \\
\mathbf{3}\end{array}$ & $\begin{array}{c}\text { Fator } \\
4\end{array}$ & $\begin{array}{c}\text { Fator } \\
5\end{array}$ & Var & $\begin{array}{c}\text { Fator } \\
1\end{array}$ & $\begin{array}{c}\text { Fator } \\
2\end{array}$ & $\begin{array}{c}\text { Fator } \\
\mathbf{3}\end{array}$ & $\begin{array}{c}\text { Fator } \\
4\end{array}$ & $\begin{array}{c}\text { Fator } \\
5\end{array}$ \\
\hline DCV & $-0,18$ & 0,02 & 0,21 & 0,80 & $-0,05$ & DCV & $-0,18$ & 0,05 & $-0,24$ & 0,78 & $-0,04$ \\
\hline CO & $-0,59$ & $-0,18$ & 0,41 & 0,16 & 0,08 & CO & $-0,59$ & $-0,18$ & $-0,42$ & 0,17 & 0,12 \\
\hline $\mathrm{O}_{3}$ & 0,01 & $-0,67$ & $-0,13$ & 0,25 & $-0,04$ & $\mathrm{O}_{3}$ & 0,01 & $-0,69$ & 0,12 & 0,26 & 0,00 \\
\hline $\mathrm{NO}_{2}$ & $-0,58$ & $-0,40$ & 0,30 & 0,17 & 0,10 & $\mathrm{NO}_{2}$ & $-0,58$ & $-0,40$ & $-0,31$ & 0,16 & 0,14 \\
\hline $\mathrm{SO}_{2}$ & $-0,22$ & $-0,25$ & 0,21 & $-0,19$ & $-0,90$ & $\mathrm{SO}_{2}$ & $-0,22$ & $-0,25$ & $-0,22$ & $-0,13$ & $-0,91$ \\
\hline $\mathbf{P}$ & $-0,67$ & 0,03 & 0,24 & $-0,27$ & 0,13 & $\mathbf{P}$ & $-0,67$ & 0,03 & $-0,23$ & $-0,30$ & 0,10 \\
\hline$T$ & 0,72 & $-0,63$ & 0,02 & $-0,04$ & 0,07 & $T$ & 0,72 & $-0,63$ & $-0,03$ & $-0,04$ & 0,05 \\
\hline $\mathrm{Td}$ & 0,89 & $-0,05$ & 0,44 & 0,00 & 0,02 & $\mathrm{Td}$ & 0,89 & $-0,04$ & $-0,44$ & $-0,01$ & 0,02 \\
\hline UR & 0,09 & 0,78 & 0,47 & 0,07 & $-0,08$ & UR & 0,09 & 0,78 & $-0,47$ & 0,05 & $-0,05$ \\
\hline$q$ & 0,89 & $-0,07$ & 0,43 & $-0,01$ & 0,03 & $q$ & 0,89 & $-0,07$ & $-0,43$ & $-0,02$ & 0,03 \\
\hline v & 0,37 & 0,35 & $-0,79$ & 0,40 & $-0,26$ & v & 0,37 & 0,35 & 0,78 & 0,43 & $-0,21$ \\
\hline A. val & 3,46 & 1,85 & 1,22 & 1,03 & 0,92 & A. val & 3,46 & 1,85 & 1,23 & 1,03 & 0,92 \\
\hline V.expl & 31,42 & 16,82 & 11,11 & 9,34 & 8,37 & V.expl & 31,43 & 16,82 & 11,15 & 9,36 & 8,38 \\
\hline
\end{tabular}

Por outro lado, os resultados para a mortalidade por RES não ficaram muito diferentes aos obtidos para as DCV (tabela 3.24). Os cinco fatores apresentaram uma variância acumulativa para dias sem atraso (5 dias de atraso) de 76,59 \% (76,56\%). No fator 1 observou-se variância explicada de 31,35 \% (31,39 \%), apresentando alta associação entre as variáveis meteorológicas $\mathrm{T}, \mathrm{Td}$, e q, variando entre -0,72 e -0,89. Em relação às doenças RES este fator não apresentou nenhum peso significativo com um valor de apenas 0,15 considerando a mortalidade sem dias de atraso e 0,17 com 5 dias de atraso.

Igualmente às DCV a tabela 3.24 no fator 2 com variância explicada de 16,88 \% apresentou alto peso negativo para a UR com valor de $-0,78$, seguido do $\mathrm{O}_{3}$ com peso positivo de $0,63(0,67)$, sem relação com às doenças RES. Por sua vez o fator 3 apresentou sem dias atraso (5 dias de atraso) uma variância explicada de 11,04 \% com alto peso positivo (negativo) apenas para a V com $0,75(-0,69)$. Novamente sem relação às RES.

Entretanto o fator 4 com variância acumulativa de 8,99 \% (8,87 \%) apresentou alto peso negativo para a mortalidade por doenças RES com valor de $-0,91(-0,95)$, com uma fraca associação positiva ao $\mathrm{SO}_{2}$ de $-0,29(-0,19)$. Por último o quinto fator esteve 
associado com o $\mathrm{SO}_{2}$ com valor $-0,83(-0,88)$, sem correlações importantes com as outras variáveis.

Por sua vez a comunalidade teve um comportamento similar ao observado no condado de Orange em quanto aos altos valores das DCV e RES com 0,72 e 0,91, respectivamente. No entanto como observou-se na ACP para este condado não houve uma associação clara com nenhuma variável, embora de estar bem representada nos cinco fatores (comunalidade $>0,50$ ).

Tabela 3.24 - Pesos das componentes principais após a rotação VARIMAX na análise da mortalidade por doenças RES considerando a) dias sim atraso e b) 5 dias de atraso para o condado de Santa Bárbara.

\begin{tabular}{|c|c|c|c|c|c|c|c|c|c|c|c|}
\hline Var & $\begin{array}{c}\text { Fator } \\
1\end{array}$ & $\begin{array}{c}\text { Fator } \\
2\end{array}$ & $\begin{array}{c}\text { Fator } \\
\mathbf{3}\end{array}$ & $\begin{array}{c}\text { Fator } \\
4\end{array}$ & $\begin{array}{c}\text { Fator } \\
5\end{array}$ & Var & $\begin{array}{c}\text { Fator } \\
1 \\
\end{array}$ & $\begin{array}{c}\text { Fator } \\
\mathbf{2}\end{array}$ & $\begin{array}{c}\text { Fator } \\
\mathbf{3} \\
\end{array}$ & $\begin{array}{c}\text { Fator } \\
4 \\
\end{array}$ & $\begin{array}{c}\text { Fator } \\
5 \\
\end{array}$ \\
\hline RES & 0,15 & $-0,12$ & $-0,06$ & $-0,91$ & 0,22 & RES & 0,17 & $-0,13$ & $-0,01$ & $-0,95$ & 0,20 \\
\hline CO & 0,59 & 0,18 & $-0,39$ & 0,19 & $-0,02$ & CO & 0,59 & 0,19 & 0,40 & 0,10 & 0,19 \\
\hline $\mathrm{O}_{3}$ & $-0,01$ & 0,63 & 0,16 & 0,00 & $-0,07$ & $\mathrm{O}_{3}$ & $-0,01$ & 0,67 & $-0,16$ & 0,04 & 0,06 \\
\hline $\mathrm{NO}_{2}$ & 0,57 & 0,41 & $-0,29$ & 0,16 & 0,00 & $\mathrm{NO}_{2}$ & 0,57 & 0,41 & 0,29 & 0,08 & 0,21 \\
\hline $\mathrm{SO}_{2}$ & 0,22 & 0,24 & $-0,23$ & $-0,29$ & $-0,83$ & $\mathrm{SO}_{2}$ & 0,22 & 0,25 & 0,23 & $-0,19$ & $-0,88$ \\
\hline $\mathbf{P}$ & 0,67 & $-0,03$ & $-0,27$ & $-0,04$ & 0,19 & $\mathbf{P}$ & 0,67 & $-0,03$ & 0,27 & 0,00 & 0,01 \\
\hline$T$ & $-0,72$ & 0,63 & $-0,03$ & $-0,07$ & 0,10 & $T$ & $-0,72$ & 0,63 & 0,02 & $-0,10$ & 0,05 \\
\hline $\mathrm{Td}$ & $-0,89$ & 0,04 & $-0,43$ & 0,00 & 0,01 & $\mathrm{Td}$ & $-0,89$ & 0,04 & 0,43 & $-0,03$ & 0,04 \\
\hline UR & $-0,09$ & $-0,78$ & $-0,46$ & 0,10 & $-0,13$ & UR & $-0,09$ & $-0,78$ & 0,47 & 0,09 & $-0,02$ \\
\hline$q$ & $-0,89$ & 0,07 & $-0,42$ & 0,00 & 0,03 & $q$ & $-0,89$ & 0,06 & 0,42 & $-0,04$ & 0,05 \\
\hline v & $-0,37$ & $-0,35$ & 0,75 & 0,06 & $-0,34$ & v & $-0,37$ & $-0,35$ & $-0,69$ & 0,07 & $-0,09$ \\
\hline A. val & 3,45 & 1,86 & 1,21 & 0,99 & 0,92 & A. val & 3,45 & 1,86 & 1,21 & 0,98 & 0,92 \\
\hline V. expl & 31,35 & 16,88 & 11,04 & 8,99 & 8,32 & V. expl & 31,39 & 16,88 & 11,04 & 8,87 & 8,37 \\
\hline
\end{tabular}

Em geral os resultados da ACP para os três condados usando apenas as variáveis meteorológicas e os níveis de poluição não mostraram altas correlações com respeito às doenças, tanto DCV quanto RES. No entanto observou-se para os condados de Los Angeles e Orange que o aumento dos níveis de poluição pode acarretar um aumento nas DCV, com uma explicação de variância maior no condado de Orange (39 \%) comparado com o condado de Los Angeles (21\%). Além disso, foi observado no condado de Los Angeles que o aumento da umidade está associado negativamente com as DCV, por sua vez no condado de Orange observou-se que o aumento da temperatura e a diminuição da umidade diminuem as DCV, e por outro lado dias ventosos e de baixa 
pressão estão associados ao aumento de óbitos por DCV. No caso de Santa Bárbara observou-se apenas uma correlação negativa baixa entre as DCV e a temperatura e umidade, assim como uma ligeira correlação positiva com a $\mathrm{V}$ e negativa com a $\mathrm{P}$ no quarto fator. No entanto comparado com os outros dois condados os resultados não foram muito significativos.

Por sua vez as doenças RES nos três condados apresentaram maiores pesos nos fatores com menor variância explicada. Para o condado de Los Angeles caiu para o terceiro fator com 0,55, neste fator observou-se que um aumento de número de óbitos por doenças RES pode estar condicionado com a chegada das massas de ar polar (onde a pressão sobe e a temperatura cai), igualmente em relação aos níveis de ozônio, que caem durante o inverno, devido às baixas temperaturas. Entretanto para o condado de Orange diferentemente do observado para as DCV, no quarto fator observou-se que os sistemas de alta pressão com pouco vento podem estar associados às doenças RES. Nestes dois condados não houve relação significativa em relação aos níveis de poluentes. Por sua parte no condado de Santa Bárbara não se estabeleceram correlações importante entre a mortalidade por doenças RES e as outras variáveis, embora no quarto fator houve uma ligeira correlação positiva com o $\mathrm{SO}_{2}$.

\subsubsection{ACP aplicada aos Índices de conforto térmico}

Com o objetivo de encontrar associações entre as doenças e o desconforto das pessoas durante condições adversas foi aplicada a ACP para os três condados durante o período de estudo; mas diferentemente da análise anterior, as variáveis meteorológicas foram utilizadas para calcular os índices de conforto térmico, além disso, foram mantidos os poluentes.

Os resultados obtidos da $\mathrm{ACP}$ para o condado de Los Angeles aplicada à mortalidade por DCV e RES, considerando primeiramente a mortalidade sem dias de atraso e logo após de 5 dias de atraso, observam-se nas tabelas 3.25 e 3.26, respectivamente. No caso das DCV os primeiros três fatores apresentam uma variância explicada de 78,51\% $(78,39 \%)$. O primeiro fator explica um 38,92 \% (39,26 \%) do total da variância, depois de fazer a rotação VARIMAX nota-se altos pesos positivos entre os índices ID, IC e $\mathrm{TE}_{\mathrm{v}}$ variando entre 0,70 e 0,90 (0,69 e 0,89) e um alto peso negativo com o índice $\mathrm{H}$ de $-0,90(-0,89)$, por sua vez as DCV apresentaram um peso negativo, antagônico, de - 0,32 
$(-0,40)$. Este valor é estatisticamente fraco, porém evidenciando que quando os índices mostram desconforto para o frio a mortalidade aumenta.

Por outro lado, o fator 2 explica para dias sem atraso (5 dias de atraso) 30,30 \% (29,81 $\%$ ) do total da variância, mostrando uma forte associação com os poluentes (com exceção do $\left.\mathrm{O}_{3}\right)$, variando de 0,83 a $0,88(0,84$ a 0,88$)$ com uma correlação perto de estar estatisticamente significativa com a mortalidade por DCV de 0,64 (0,60). Todos positivos, como era de se esperar, maior poluição maior DCV. É importante destacar que o fator 2 (relacionados com os poluentes) permanece com pesos mais significativos em relação à mortalidade por DCV do que o fator 1 (associado aos índices de conforto térmico). Além disso, comparado com a tabela 3.19, onde a ACP é aplicado às variáveis meteorológicas, aumentou a explicação da variância do fator e o peso da mortalidade.

Já o fator 3 explica só um 9,30 \% (9,32 \%) do total da variância, relacionado unicamente com o $\mathrm{O}_{3}$ com valor de $0,85(0,86)$ levando-se todo o peso do fator, sem associação às DCV, com valores de $0,15(0,16)$.

Tabela 3.25 - Pesos das componentes principais após a rotação VARIMAX incluindo os índices de conforto térmico na análise da mortalidade por DCV, considerando a) dias sim atraso e b) 5 dias de atraso para o condado de Los Angeles.

\begin{tabular}{|c|c|c|c|c|c|c|c|}
\hline Variável & Fator1 & Fator2 & Fator3 & Variável & Fator1 & Fator2 & Fator3 \\
\hline DCV & $-0,32$ & 0,64 & 0,15 & DCV & $-0,40$ & 0,60 & 0,16 \\
\hline CO & $-0,04$ & 0,83 & $-0,38$ & $\mathrm{CO}$ & $-0,05$ & 0,84 & $-0,37$ \\
\hline $\mathrm{O}_{3}$ & 0,29 & 0,15 & 0,85 & $\mathrm{O}_{3}$ & 0,27 & 0,13 & 0,86 \\
\hline $\mathrm{NO}_{2}$ & 0,15 & 0,88 & 0,08 & $\mathrm{NO}_{2}$ & 0,14 & 0,88 & 0,10 \\
\hline $\mathrm{SO}_{2}$ & 0,07 & 0,84 & 0,08 & $\mathrm{SO}_{2}$ & 0,06 & 0,84 & 0,09 \\
\hline ID & 0,90 & $-0,13$ & 0,36 & ID & 0,89 & $-0,12$ & 0,38 \\
\hline IC & 0,70 & 0,29 & $-0,18$ & IC & 0,69 & 0,30 & $-0,16$ \\
\hline TEv & 0,73 & $-0,36$ & 0,47 & TEv & 0,73 & $-0,36$ & 0,48 \\
\hline H & $-0,90$ & 0,00 & $-0,31$ & H & $-0,89$ & $-0,01$ & $-0,33$ \\
\hline Autovalor & 3,50 & 2,73 & 0,84 & Autovalor & 3,53 & 2,68 & 0,84 \\
\hline Var expl. & 38,92 & 30,30 & 9,30 & Var expl. & 39,26 & 29,81 & 9,32 \\
\hline
\end{tabular}

No caso da mortalidade por doenças RES (tabela 3.26), três fatores foram extraídos o que apresenta uma variância acumulativa de 77,43\% (77,73\%). No fator 1 observou-se variância explicada de 39,45\% (39,74\%), apresentando altos pesos positivos para os índices de conforto térmico ID e TEV com valores de 0,96 e 0,93 (0,95 e 0,93) 
respectivamente, e alto peso negativo para o $\mathrm{H}$ com -0,89 tanto para o próprio dia em questão quanto com 5 dias de atraso, o valor do $\mathrm{O}_{3}$ também foi elevado com valor de 0,61, perto de ser estatisticamente significativo. Por outra parte, as doenças RES apresentaram para este fator um peso de $-0,47(-0,51)$, positivo com $\mathrm{H}$, mas negativo com os demais índices, o que indica o impacto do frio. Ou seja, como foi obtido para as DCV com base a este fator o aumento dos índices de conforto que representam o estresse com relação ao frio pode contribuir com um aumento das doenças RES, com um peso para a mortalidade por doenças RES maior do que a mortalidade por DCV, principalmente com 5 dias de atraso $(0,51$ contra 0,40$)$. Igualmente este resultado comparado com a ACP aplicado às variáveis meteorológicas (tabela 3.20) foi melhor.

No fator 2 observou-se variância explicada de 28,13\% (28,10\%) apresentando altos pesos positivos entre os poluentes (com exceção de $\mathrm{O}_{3}$ ) variando entre 0,78 e 0,90, em relação à mortalidade por doenças RES com $0,18(-0,17)$. Entretanto no fator 3 a variância explicada foi de 9,85\% (9,89\%) apresentando pesos positivos entre a mortalidade por doenças RES e o IC com valores de 0,61 e $0,50(-0,57$ e $-0,53)$ respectivamente. Logo com base neste fator percebe-se que, além das baixas temperaturas, as altas temperaturas (ou estresse devido ao calor) também afetam, mas de maneira menos pronunciada, a mortalidade por doenças RES.

Tabela 3.26 - Pesos das componentes principais após a rotação VARIMAX incluindo os índices de conforto térmico na análise da mortalidade por doenças RES, considerando a) dias sim atraso e b) 5 dias de atraso para o condado de Los Angeles.

\begin{tabular}{|c|c|c|c|c|c|c|c|}
\hline Variável & Fator1 & Fator2 & Fator3 & Variável & Fator1 & Fator2 & Fator3 \\
\hline RES & $-0,47$ & 0,18 & 0,61 & RES & $-0,51$ & $-0,17$ & $-0,57$ \\
\hline CO & $-0,43$ & 0,78 & 0,09 & $\mathrm{CO}$ & $-0,43$ & $-0,78$ & $-0,10$ \\
\hline $\mathrm{O}_{3}$ & 0,61 & 0,23 & $-0,35$ & $\mathrm{O}_{3}$ & 0,61 & $-0,24$ & 0,36 \\
\hline $\mathrm{NO}_{2}$ & $-0,06$ & 0,90 & $-0,20$ & $\mathrm{NO}_{2}$ & $-0,06$ & $-0,90$ & 0,20 \\
\hline $\mathrm{SO}_{2}$ & $-0,12$ & 0,84 & $-0,23$ & $\mathrm{SO}_{2}$ & $-0,12$ & $-0,84$ & 0,24 \\
\hline ID & 0,96 & 0,13 & 0,15 & ID & 0,95 & $-0,13$ & $-0,16$ \\
\hline IC & 0,44 & 0,44 & 0,50 & IC & 0,43 & $-0,45$ & $-0,53$ \\
\hline TEv & 0,93 & $-0,14$ & 0,02 & TEv & 0,93 & 0,13 & $-0,02$ \\
\hline H & $-0,89$ & $-0,27$ & $-0,14$ & H & $-0,89$ & 0,27 & 0,14 \\
\hline Autovalor & 3,55 & 2,53 & 0,89 & Autovalor & 3,58 & 2,53 & 0,89 \\
\hline Var expl. & 39,45 & 28,13 & 9,85 & Var expl. & 39,74 & 28,10 & 9,89 \\
\hline
\end{tabular}


Com relação à comunalidade os resultados com a inclusão dos índices de conforto térmico foram também melhores do que no caso das variáveis meteorológicas e poluentes, com valores para as DCV e RES de 0,54 e 0,63 respectivamente. Neste caso todas as variáveis foram bem representadas nos três fatores. Com base nos índices e os poluentes maiores associados as DCV, a comunalidade foi de 0,95, 0,90, 0,88, 0,88, 0,84 e 0,83 para ID, H, TEv, $\mathrm{NO}_{2}, \mathrm{SO}_{2}$ e $\mathrm{CO}$ respectivamente. Por sua vez, os valores para variáveis relacionadas com as doenças RES foram de 0,95, 0,88, 0,88, 0,63 e 0,55 para ID, TEv, $\mathrm{H}, \mathrm{IC}$ e $\mathrm{O}_{3}$.

Em geral, o agrupamento das variáveis meteorológicas e sua utilização na formação de índices de conforto térmico para o condado de Los Angeles, permite explicar mais da variância relacionada à diminuição/aumento da mortalidade por DCV ou RES. Neste sentido, a ACP mostrou o aumento da mortalidade por DCV no período de inverno, quando as pessoas sofrem de estresse devido às temperaturas baixas, pois no primeiro fator se estabeleceram relações inversas entre mortalidade por DCV e os índices de conforto térmico ID, IC e TEv (que a maioria dos autores associam com estresse por calor) assim como uma relação positiva com H (indicador de estresse por frio), logo com o decaimento das temperaturas as pessoas podem ficar muito susceptíveis. Além disso, o segundo fator mostrou relações positivas entre as DCV e os níveis de poluição (com exceção do $\mathrm{O}_{3}$ ) os quais também apresentam maiores concentrações no inverno, neste sentido observou-se maior peso das DCV para este fator. Comparado com os resultados obtidos para ACP sem a inclusão dos índices (tabela 3,19), houve um aumento tanto do peso das DCV (0,64 contra 0.40) quanto da variância explicada pelo fator $(30,30 \%$ contra 21,43$)$.

Quanto à mortalidade por doenças RES, verificou-se uma sazonalidade menos marcada do que no caso das DCV. Por outro lado o primeiro fator reflete as características do inverno no condado, onde as correlações inversas entre os índices de conforto térmico e a mortalidade indicam que uma diminuição das temperaturas pode trazer consigo aumentos do número de óbitos por doenças RES. O segundo fator, também como no caso das DCV, mostrou fortes correlações entre os poluentes $\mathrm{CO}, \mathrm{NO}_{2}$ e $\mathrm{SO}_{2}$, mas seu impacto nas doenças RES não é estatisticamente claro. Entretanto o terceiro fator estabeleceu uma relação positiva entre a mortalidade por doenças RES e o IC, sendo um indicador do clima do verão em Los Angeles, em que as altas temperaturas podem incidir no aumento da mortalidade, mas de maneira menos pronunciada, refletida na 
menor explicação da variância deste fator. Ou seja, quando as pessoas sentem estresse devido ao calor, por exemplo, pode aumentar o número de mortes por doenças RES. Concluindo-se a mortalidade por doenças RES está mais associada neste condado às variações meteorológicas do que às concentrações de poluentes.

Por sua vez nas tabelas 3.27 e 3.28 observam-se os pesos das componentes principais incluindo os índices de conforto térmico, na análise da mortalidade por DCV e RES, respectivamente, para o condado de Orange. Onde foi considerado primeiramente a mortalidade sem dias de atraso e logo após de 5 dias de atraso, do mesmo modo anterior. Foram usados tanto para a mortalidade por DCV quanto a mortalidade por doenças RES apenas 3 fatores, comparado com as tabelas 3.21 e 3.22 (resultados da ACP aplicados às variáveis meteorológicas) aumentou a explicação da variância acumulada.

No caso das DCV os primeiros três fatores apresentam variância acumulativa de 75,57 $\%(75,83 \%)$. A pós de rotar a matriz pelo método VARIMAX no fator 1 observou-se variância explicada de 42,16\% (42,29\%), apresentando altos pesos positivos para os índices de conforto térmico ID e TEv, com valores de 0,94 e 0,96, respectivamente, e de $\mathrm{O}_{3}$ com 0,71 , tanto sem dias de atraso quanto com 5 dias, assim como alto peso negativo para o $\mathrm{H}$ com $-0,94$. Neste fator as DCV apresentaram um valor de $-0,35(-0,37)$, semelhante ao condado de Los Angeles, com uma associação fraca antagônica aos índices de conforto e ao $\mathrm{O}_{3}$, mas positiva em relação a $\mathrm{H}$. $\mathrm{O} \mathrm{O}_{3}$ como na tabela 3.25 , se apresenta contrário às doenças, mas sem uma relação causal direta ás DCV, apenas devido ao fato de estar associado às condições meteorológicas específicas.

No fator 2 observou-se variância explicada de 22,44\% (22,40 \%) apresentando altos pesos positivos entre os poluentes (com exceção de $\mathrm{O}_{3}$ ) variando entre 0,80 e 0,88, muito fracamente associados positivamente às DCV com $0,20(0,18)$, sem significância estatística. Por último, no fator 3, a variância explicada foi de 10,97 \% (11,14 \%) apresentando pesos positivos (negativos) para as DCV e o IC com valores de 0,50 e $0,81(-0,52$ e $-0,86)$ respectivamente, mostrando uma associação positiva clara. Com base neste fator, a mortalidade por DCV no condado de Orange pode estar ligeiramente associada com o estresse devido ao calor. Diferentemente ao condado de Los Angeles onde as concentrações de poluição tinham um maior peso no número de óbitos. 
Tabela 3.27 - Pesos das componentes principais após a rotação VARIMAX incluindo os índices de conforto térmico na análise da mortalidade por DCV, considerando a) dias sim atraso e b) 5 dias de atraso para o condado de Orange.

\begin{tabular}{|c|c|c|c|c|c|c|c|}
\hline Variável & Fator1 & Fator2 & Fator3 & Variável & Fator1 & Fator2 & Fator3 \\
\hline DCV & $-0,35$ & 0,20 & 0,50 & DCV & $-0,37$ & 0,18 & 0,52 \\
\hline CO & $-0,31$ & 0,84 & 0,11 & $\mathrm{CO}$ & $-0,31$ & 0,84 & 0,11 \\
\hline $\mathrm{O}_{3}$ & 0,71 & 0,18 & $-0,03$ & $\mathrm{O}_{3}$ & 0,71 & 0,18 & $-0,03$ \\
\hline $\mathrm{NO}_{2}$ & $-0,08$ & 0,88 & 0,01 & $\mathrm{NO}_{2}$ & $-0,08$ & 0,88 & 0,00 \\
\hline $\mathrm{SO}_{2}$ & 0,11 & 0,80 & 0,02 & $\mathrm{SO}_{2}$ & 0,10 & 0,80 & 0,03 \\
\hline ID & 0,94 & $-0,22$ & $-0,01$ & ID & 0,94 & $-0,22$ & $-0,01$ \\
\hline IC & 0,23 & $-0,04$ & 0,87 & IC & 0,24 & $-0,03$ & 0,86 \\
\hline TEv & 0,96 & $-0,17$ & 0,03 & TEv & 0,96 & $-0,18$ & 0,03 \\
\hline H & $-0,94$ & 0,11 & $-0,05$ & H & $-0,94$ & 0,11 & $-0,05$ \\
\hline Autovalor & 3,79 & 2,02 & 0,99 & Autovalor & 3,81 & 2,01 & 1,00 \\
\hline Var expl. & 42,16 & 22,44 & 10,97 & Var expl. & 42,29 & 22,40 & 11,14 \\
\hline
\end{tabular}

Similar comportamento observa-se depois de rotar a matriz pelo método VARIMAX na análise da mortalidade por doenças RES (tabela 3.28). Neste caso os três primeiros fatores apresentam uma variância acumulativa de 75,15 \% (75,45 \%). O primeiro fator com variância explicada de 41,54 \% (41,70 \%) está relacionado com os índices de conforto térmico (com a exceção do IC) e o $\mathrm{O}_{3}$ com valor de 0,70. Bem como no caso da análise das DCV, as doenças RES apresentam associação fraca neste fator -0,32 (0,34), mesmo assim observa-se uma relação negativa com os índices de conforto ID e TEv, e positiva com $\mathrm{H}$.

Já o segundo fator com variância explicada de 22,41 \% (22,40 \%) apresenta maiores pesos para os poluentes $\mathrm{CO}, \mathrm{NO}_{2}$ e $\mathrm{SO}_{2}$ variando entre 0,80 e 0,88 , neste fator o peso da mortalidade por doenças RES foi muito fraco apenas de -0,02 (-0,01). Entretanto o fator três com variância acumulativa de 11,20 \% (11,36 \%) estabelece forte correlação entre a mortalidade por doenças RES com valores de 0,66 $(0,65)$ e o índice IC com valor de 0,74 (0,76). Comparado com Los Angeles, Orange apresenta valores maiores de correlação entre a mortalidade por doenças RES e o IC, além de uma variância explicada maior, principalmente com 5 dias de atraso $(11,36 \%$ nesta tabela contra 9,89 $\%$ da tabela 3.26). 
Tabela 3.28- Pesos das componentes principais após a rotação VARIMAX incluindo os índices de conforto térmico na análise da mortalidade por doenças RES, considerando a) dias sim atraso e b) 5 dias de atraso para o condado de Orange.

\begin{tabular}{|c|c|c|c|c|c|c|c|}
\hline Variável & Fator1 & Fator2 & Fator3 & Variável & Fator1 & Fator2 & Fator3 \\
\hline RES & $-0,32$ & $-0,02$ & 0,66 & RES & $-0,34$ & $-0,01$ & 0,65 \\
\hline CO & $-0,30$ & 0,85 & 0,10 & CO & $-0,30$ & 0,85 & 0,11 \\
\hline $\mathrm{O}_{3}$ & 0,70 & 0,17 & $-0,03$ & $\mathrm{O}_{3}$ & 0,70 & 0,17 & $-0,03$ \\
\hline $\mathrm{NO}_{2}$ & $-0,09$ & 0,88 & 0,05 & $\mathrm{NO}_{2}$ & $-0,09$ & 0,88 & 0,05 \\
\hline $\mathrm{SO}_{2}$ & 0,11 & 0,80 & $-0,09$ & $\mathrm{SO}_{2}$ & 0,11 & 0,80 & $-0,09$ \\
\hline ID & 0,94 & $-0,23$ & $-0,04$ & ID & 0,94 & $-0,23$ & $-0,04$ \\
\hline IC & 0,29 & 0,04 & 0,74 & IC & 0,29 & 0,04 & 0,76 \\
\hline TEv & 0,96 & $-0,18$ & 0,00 & TEv & 0,96 & $-0,18$ & 0,00 \\
\hline H & $-0,94$ & 0,12 & $-0,03$ & H & $-0,94$ & 0,12 & $-0,03$ \\
\hline Autovalor & 3,74 & 2,02 & 1,01 & Autovalor & 3,76 & 2,01 & 1,02 \\
\hline Var expl. & 41,54 & 22,41 & 11,20 & Var expl. & 41,70 & 22,40 & 11,36 \\
\hline
\end{tabular}

Devido a que as principais associações entre as variáveis e a mortalidade permaneceram similares à de Los Angeles, embora em menor medida, a comunalidade para o condado de Orange implicou as mesmas variáveis. As DCV/RES com comunalidade de 0,41/0,54 (0,55/0,65 sem índices de conforto), os índices de conforto térmico ID, TEv, H e IC com valores de 0,95/0,94, 0,94/0,95, 0,91/0,90 e 0,81/0,64, respectivamente, assim como os poluentes (para DCV o $\mathrm{CO}, \mathrm{NO}_{2}$ e $\mathrm{SO}_{2}$ com valores de 0,81, 0,79 e 0,65 respectivamente e para as doenças $\mathrm{RES}$ o $\mathrm{O}_{3}$ com valor de 0,53 ). Por outro lado, embora a mortalidade tiver menor comunalidade, as outras variáveis estiveram mais representativas nestes três fatores do que no estudo para variáveis meteorológicas e poluentes com quatro fatores, daí que se apresentaram melhores resultados das ACP quando substituímos as variáveis meteorológicas por os índices de conforto térmico.

Note-se que o comportamento da mortalidade por DCV não tem uma sazonalidade em Orange tão marcada como no caso de Los Angeles. No primeiro fator estabelece relações típicas de inverno onde o aumento da mortalidade por DCV estão associadas com o estresse por frio e a umidade (via índices de conforto ID) ou vento (via índice H), ou seja, uma queda das temperaturas pode ocasionar um acrescimento na mortalidade por DCV. Entretanto o segundo fator apresenta associações positivas entre os poluentes (exceto $\mathrm{o}_{3}$ ) e a mortalidade, embora com baixos valores. Comparado com Los Angeles as baixas associações podem ser devidas ao fato do que a contaminação por 
poluentes no condado é muito menor, por exemplo, as concentrações médias de $\mathrm{CO}$, $\mathrm{NO}_{2}$ e $\mathrm{SO}_{2}$ neste condado são de 2,50 ppm, 0,046 ppm e 0,0028 ppm, respectivamente, entretanto em Los Angeles são de 5,55 ppm, 0,070 ppm e 0,0044 ppm, respectivamente. Por último o fator 3 relaciona às DCV com o estresse por calor (através do IC), por exemplo, em episódios de ondas de calor a população fica mais exposta e acrescenta o número de óbitos por DCV. É importante destacar que o maior peso das DCV foi para este fator, diferentemente ao condado de Los Angeles. Ou seja, as DCV em Orange estão mais associadas com os índices de conforto (principalmente o IC) que com os níveis de poluição, embora com menor variância explicada.

No caso das doenças RES reflete-se o comportamento obtido para o condado de Los Angeles. O primeiro fator estabelece as relações invernais expostas anteriormente, ou seja, uma queda de temperatura pode aumentar o estresse por frio e consigo um aumento da mortalidade por doenças RES. O fator 2 está associado aos poluentes (exceto $\mathrm{O}_{3}$ ) e sua correlação com as doenças RES é praticamente inexistente. Por último o fator três estabelece a relação direta entre o número de óbitos por doenças RES e o IC, logo devido ao um aumento da temperatura, o qual pode acontecer também com uma onda de calor, pode aumentar a mortalidade. Logo no condado de Orange a mortalidade por RES também pode ser mais condicionada por as influências do tempo sobre a população idosa do que devido à contaminação do ar.

Por último para o condado de Santa Bárbara a ACP aplicado à mortalidade por DCV e RES incluindo os índices de conforto térmico são observados nas tabelas 3.29 e 3.30 , respectivamente. Igualmente para este condado aumentou a variância acumulada dos primeiros fatores, comparado com as tabelas 3.23 e 3.24 (resultados da ACP aplicadas às variáveis meteorológicas). No caso das DCV foram extraídos quatro fatores com variância acumulada de 77,36 \% (77,37 \%). No primeiro fator relacionado com os índices de conforto térmico, teve uma variância explicada de 36,95 \% (37,01 \%), apresentando altos pesos negativos (de -0,96) para o ID e $\mathrm{TE}_{\mathrm{V}}$, assim como alto peso positivo para o $\mathrm{H}$ com 0,94 , o IC esteve também correlacionado positivamente com os outros índices que representam o estresse por calor com peso de -0,51. Em relação as DCV este fator apresentou um peso de apenas $0,16(0,18)$ longe de ser estatisticamente significativo. 
No fator 2, com variância explicada de 19,47 \% (19,45 \%) esteve com peso negativo para os poluentes $\mathrm{CO}$ e $\mathrm{NO}_{2}$ com valores de $-0,72$ e - $-0,82$, respectivamente, em relação as DCV com uma associação positiva, porém muito fraca, no valor de $-0,25(-0,24)$. No fator três, com variância explicada de 10,82 \% (10,73\%) esteve seu peso quase tudo o relacionado com as DCV com valor de 0,82 (0,84), seguido do $\mathrm{SO}_{2}$ com valor de 0,53 $(0,50)$, com uma associação positiva. Comparada com a tabela 3.23 a associação ternouse mais evidente. Por último o fator 4, teve uma variância explicada de 10,12 \% (10,18 $\%$ ), com um alto peso positivo para o $\mathrm{SO}_{2}$ com valor de $0,75(0,77)$ seguido das DCV, com peso negativo de $-0,47(-0,45)$, sem explicação casual.

Tabela 3.29 - Pesos das componentes principais após a rotação VARIMAX incluindo os índices de conforto térmico na análise da mortalidade por DCV, considerando a) dias sim atraso e b) 5 dias de atraso para o condado de Santa Bárbara.

\begin{tabular}{|c|c|c|c|c|c|c|c|c|c|}
\hline Variável & $\begin{array}{c}\text { Fator } \\
1\end{array}$ & $\begin{array}{c}\text { Fator } \\
2\end{array}$ & $\begin{array}{c}\text { Fator } \\
\mathbf{3}\end{array}$ & $\begin{array}{c}\text { Fator } \\
4\end{array}$ & Variável & $\begin{array}{c}\text { Fator } \\
1\end{array}$ & $\begin{array}{c}\text { Fator } \\
2\end{array}$ & $\begin{array}{c}\text { Fator } \\
\mathbf{3}\end{array}$ & $\begin{array}{c}\text { Fator } \\
4\end{array}$ \\
\hline DCV & 0,16 & $-0,25$ & 0,82 & $-0,47$ & DCV & 0,18 & $-0,24$ & 0,84 & $-0,45$ \\
\hline $\mathrm{CO}$ & 0,32 & $-0,72$ & 0,00 & 0,19 & $\mathrm{CO}$ & 0,32 & $-0,72$ & 0,02 & 0,17 \\
\hline $\mathrm{O}_{3}$ & $-0,35$ & $-0,46$ & 0,05 & 0,05 & $\mathrm{O}_{3}$ & $-0,35$ & $-0,46$ & 0,03 & 0,08 \\
\hline $\mathrm{NO}_{2}$ & 0,17 & $-0,82$ & $-0,02$ & 0,24 & $\mathrm{NO}_{2}$ & 0,17 & $-0,82$ & $-0,03$ & 0,25 \\
\hline $\mathrm{SO}_{2}$ & 0,02 & $-0,39$ & 0,53 & 0,75 & $\mathrm{SO}_{2}$ & 0,02 & $-0,39$ & 0,50 & 0,77 \\
\hline ID & $-0,97$ & 0,04 & 0,05 & $-0,03$ & ID & $-0,97$ & 0,04 & 0,06 & $-0,03$ \\
\hline IC & $-0,51$ & $-0,37$ & $-0,03$ & 0,15 & IC & $-0,51$ & $-0,37$ & $-0,03$ & 0,13 \\
\hline TEv & $-0,98$ & $-0,02$ & 0,04 & $-0,02$ & TEv & $-0,98$ & $-0,02$ & 0,05 & $-0,03$ \\
\hline H & 0,94 & 0,09 & $-0,03$ & 0,03 & H & 0,94 & 0,09 & $-0,04$ & 0,03 \\
\hline Autovalor & 3,33 & 1,75 & 0,97 & 0,91 & Autovalor & 3,33 & 1,75 & 0,97 & 0,91 \\
\hline Var expl. & 36,95 & 19,47 & 10,82 & 10,12 & Var expl. & 37,01 & 19,45 & 10,73 & 10,18 \\
\hline
\end{tabular}

Igualmente os resultados para a mortalidade por doenças RES quando são incluídos os índices de conforto térmico (tabela 3.30) reflete um comportamento quase idêntico às DCV. As principais diferenças estão no fator 2, onde as associações entre as doenças RES e os níveis de poluição ficaram bem mais fracas, com valores apenas de -0,05 considerando o dia em questão e -0,06 para 5 dias de atraso, comparado com as DCV com valores de $-0,25$ e - $-0,24$ respectivamente. Além disso, no fator 3 aumentou o peso da mortalidade por doenças $\operatorname{RES}$ com $0,93(0,96)$ e diminuiu o peso de $\mathrm{SO}_{2}$ principalmente considerando 5 dias de atraso $(0,13)$. Por último no fator 4 quase tudo o peso foi relacionado com o $\mathrm{SO}_{2}$ com valor de $0,87(-0,91)$, sem correlações importantes com as outras variáveis. 
Tabela 3.30 - Pesos das componentes principais após a rotação VARIMAX incluindo os índices de conforto térmico na análise da mortalidade por doenças RES, considerando a) dias sim atraso e b) 5 dias de atraso para o condado de Santa Bárbara.

\begin{tabular}{|c|c|c|c|c|c|c|c|c|c|}
\hline Variável & $\begin{array}{c}\text { Fator } \\
1\end{array}$ & $\begin{array}{c}\text { Fator } \\
2\end{array}$ & $\begin{array}{c}\text { Fator } \\
3\end{array}$ & $\begin{array}{c}\text { Fator } \\
4\end{array}$ & Variável & $\begin{array}{c}\text { Fator } \\
1\end{array}$ & $\begin{array}{c}\text { Fator } \\
2\end{array}$ & $\begin{array}{c}\text { Fator } \\
3\end{array}$ & $\begin{array}{c}\text { Fator } \\
4\end{array}$ \\
\hline RES & 0,15 & $-0,05$ & 0,93 & $-0,31$ & RES & 0,17 & $-0,06$ & 0,96 & 0,14 \\
\hline $\mathrm{CO}$ & 0,31 & $-0,72$ & $-0,10$ & $-0,15$ & Co & 0,31 & $-0,72$ & $-0,04$ & 0,17 \\
\hline $\mathrm{O}_{3}$ & $-0,36$ & $-0,45$ & $-0,07$ & $-0,06$ & $\mathrm{O}_{3}$ & $-0,36$ & $-0,45$ & $-0,14$ & 0,06 \\
\hline $\mathrm{NO}_{2}$ & 0,16 & $-0,83$ & $-0,10$ & $-0,18$ & $\mathrm{NO}_{2}$ & 0,16 & $-0,83$ & $-0,06$ & 0,20 \\
\hline $\mathrm{SO}_{2}$ & 0,02 & $-0,40$ & 0,30 & 0,87 & $\mathrm{SO}_{2}$ & 0,02 & $-0,40$ & 0,13 & $-0,91$ \\
\hline ID & $-0,97$ & 0,05 & 0,03 & $-0,01$ & ID & $-0,97$ & 0,05 & 0,05 & 0,01 \\
\hline IC & $-0,51$ & $-0,37$ & 0,05 & $-0,13$ & IC & $-0,51$ & $-0,37$ & 0,07 & 0,11 \\
\hline TEv & $-0,98$ & 0,00 & 0,03 & $-0,01$ & TEv & $-0,98$ & 0,00 & 0,05 & 0,01 \\
\hline H & 0,94 & 0,08 & $-0,04$ & 0,00 & H & 0,94 & 0,08 & $-0,06$ & 0,00 \\
\hline Autovalor & 3,33 & 1,73 & 0,98 & 0,93 & Autovalor & 3,33 & 1,73 & 0,98 & 0,93 \\
\hline Var expl. & 36,98 & 19,17 & 10,94 & 10,29 & Var expl. & 36,98 & 19,17 & 10,94 & 10,29 \\
\hline
\end{tabular}

A comunalidade para este condado, além de ter altos valores para as DCV e RES (0,99 em ambas) não tiveram uma associação clara com o resto das variáveis (similar ao estudo com variáveis meteorológicas e poluentes) com exceção do $\mathrm{SO}_{2}$, o qual na ACP ao igual que a mortalidade representou todos os valores desse poluente $(0,99)$. Por isso é observado o forte peso deles anteriormente.

Em geral os resultados da ACP utilizando os índices de conforto térmico no condado de Santa Bárbara mostraram que tantos episódios de frio quanto de calor podem não causar impactos claros na população idosa, com respeito a ambos os grupos de doenças. Neste sentido observou-se que o número de óbitos por DCV pode estar mais associado com correlações positivas entre os poluentes, embora as correlações sejam mais baixas do que nos condados anteriores, devido possivelmente aos níveis de poluição ser mais baixos em Santa Bárbara. O mais relevante deste condado é que apesar das concentrações de $\mathrm{SO}_{2}$ sejam as mais baixas das estudadas (média de 0,29 ppb), apresentou boas correlações positivas principalmente com as DCV.

Contudo observou-se que a ACP utilizando os índices de conforto térmico apresentou melhores resultados tanto em variância acumulada e comunalidade quanto em peso da mortalidade em ambos os grupos de doenças para os três condados de interesse. No caso do condado de Los Angeles as DCV apresentaram altos pesos positivos com as 
concentrações de poluentes com variância explicada maior que no caso da ACP usando apenas as variáveis meteorológicas. Por outro lado, as doenças RES apresentaram associações com os índices de conforto térmico, no primeiro fator as correlações inversas entre eles indicam que a diminuição de temperatura aumenta o número de óbitos por doenças RES, e o terceiro fator embora com menor variância explicada segurem associações positivas entre o número de óbitos e o IC. Para o condado de Orange tanto as DCV quanto as doenças RES mostraram associações com os índices de conforto, principalmente associações positivas com o IC no fator 3, com maior peso e variância explicada para as doenças RES neste fator comparado com as DCV. Por último no caso de Santa Bárbara os resultados foram diferentes em relação aos outros dois condados, mostrando apenas associações positivas entre os níveis de $\mathrm{SO}_{2}$ e o número de óbitos por DCV.

\subsubsection{ACP aplicado às estações inverno e verão}

Nestas análises foram utilizados apenas os meses de inverno e verão de todo o período para os três condados, com o objetivo de encontrar novas influências das variáveis associadas com as doenças não apreciadas nos casos anteriores.

Na tabela 3.31 apresentam-se os resultados obtidos das DCV para o condado de Los Angeles tanto para os meses de inverno quanto os de verão. Observa-se como os pesos das componentes principais para as duas estações, refletem os resultados obtidos anteriormente para todo o período (vide tabela 3.25).

Neste caso no inverno, o primeiro fator explicou $35,68 \%$. As DCV $(0,68)$ tiveram uma forte associação positiva com todos os poluentes (variando de 0,56 a 0,81 ) nota-se a influência do $\mathrm{O}_{3}$ na mortalidade por DCV, o qual havia passado despercebido até o momento, resultados que podem estar em concordância, por exemplo, com as elevadas concentrações nos níveis de ozônio do condado de Los Angeles. Similar resultado foi obtido por Crouse et al., (2015) na Canadá, onde foram observadas associações entre as concentrações ambientais de $\mathrm{O}_{3}$ e o risco de mortalidade por várias causas importantes, incluindo doenças cardiometabólicas, diabetes, DCV e doença isquêmica do coração. Por outro lado no fator 2 com uma variância explicada de 23,93 \% esteve associado com os índices de conforto térmico com exceção do IC, com pesos positivos para o ID $(0,94)$ e a TEv $(0,78)$ e negativo para o H $(-0,91)$. Em relação às DCV este fator apresentou um peso de apenas $-0,11$, longe de ser estatisticamente significativo; comparado com os 
resultados observados na tabela 3.25 , considerando todo o período com 5 dias de atraso, observou-se uma diminuição do peso das DCV (-0,40 contra -0,11) e a variância explicada $(39,26 \%$ contra $23,93 \%)$. Por último o fator 3 com uma variância explicada de $11,48 \%$ esteve relacionado com o IC $(-0,75)$, sem associação com as DCV $(-0,01)$.

Por sua vez no verão (tabela $3.31 \mathrm{~b}$ ), no fator 1 as DCV não tiveram nenhum peso, o fator esteve relacionado apenas com os índices de estresse térmico. Igualmente no fator 2 com fortes pesos positivos para os poluentes $\mathrm{CO}(0,83), \mathrm{NO}_{2}(0,80)$ e $\mathrm{SO}_{2}(0,85)$, as DCV tiveram uma associação muito fraca com um valor de 0,15. Entretanto no terceiro fator, com variância explicada de $9,28 \%$, bem mais fraca do que nos outros dois fatores (43,44\% e $27,17 \%$ respectivamente), observou-se o maior peso das DCV com um valor de 0,89 ; novamente notou-se uma forte ralação positiva com o $\mathrm{O}_{3}(0,69)$, no entanto com variância explicada menor do que a encontrada para o inverno. Contudo notou-se para o condado de Los Angeles a influência das altas concentrações de poluentes na mortalidade por DCV principalmente no inverno, e uma associação menos forte no verão.

Tabela 3.31 - Pesos das componentes principais após a rotação VARIMAX incluindo os índices de conforto térmico na análise da mortalidade por DCV, considerando as estações de a) inverno e b) verão para o condado de Los Angeles.

\begin{tabular}{|c|c|c|c|c|c|c|c|}
\hline Variável & Fator 1 & Fator 2 & Fator 3 & Variável & Fator1 & Fator2 & Fator 3 \\
\hline DCV & 0,68 & $-0,11$ & $-0,01$ & DCV & 0,00 & 0,15 & 0,89 \\
\hline CO & 0,66 & 0,12 & $-0,56$ & Co & $-0,11$ & 0,83 & 0,18 \\
\hline $\mathrm{O}_{3}$ & 0,56 & 0,03 & 0,43 & $\mathrm{O}_{3}$ & $-0,13$ & 0,38 & 0,69 \\
\hline $\mathrm{NO}_{2}$ & 0,81 & 0,21 & $-0,27$ & $\mathrm{NO}_{2}$ & $-0,17$ & 0,80 & 0,35 \\
\hline $\mathrm{SO}_{2}$ & 0,81 & 0,21 & $-0,14$ & $\mathrm{SO}_{2}$ & 0,00 & 0,85 & 0,11 \\
\hline ID & 0,08 & 0,94 & $-0,05$ & ID & $-0,97$ & 0,14 & 0,08 \\
\hline IC & 0,13 & $-0,04$ & $-0,75$ & IC & $-0,82$ & 0,19 & 0,15 \\
\hline TEv & $-0,09$ & 0,78 & 0,45 & TEv & $-0,90$ & $-0,16$ & $-0,05$ \\
\hline $\mathrm{H}$ & $-0,22$ & $-0,91$ & 0,15 & H & 0,95 & $-0,18$ & $-0,04$ \\
\hline Autovalor & 3,21 & 2,15 & 1,03 & Autovalor & 3,91 & 2,45 & 0,84 \\
\hline Var expl & 35,68 & 23,93 & 11,48 & Var expl & 43,44 & 27,17 & 9,28 \\
\hline
\end{tabular}

No caso do estudo para a mortalidade por doenças RES nos meses de inverno (Tabela 3.32 a) a variância explicada por cada fator foi bem similar ao obtido para todo o período (tabela 26). Porém no fator 1, esteve associado positivamente com os poluentes 
do que aos índices de conforto térmico, com relação bem fraca às doenças RES $(-0,14)$. O fator 2 relacionado com os índices de conforto térmico com exceção do IC não teve nenhuma influência como a anterior observada, ou seja, quando foi analisada toda a data as doenças RES apresentaram um valor de $-0,47$ (sem dias de atraso), entretanto considerando a estação de inverno o valor foi de apenas 0,03 . Por sua vez, o fator 3 mostrou como o observado anteriormente, a relação negativa entre as doenças RES $(0,82)$ e $\mathrm{O}_{3}(-0,59)$ com uma variância explicada de $9,85 \%$.

Já para o verão (tabela 3.32 b), aumentou a variância acumulada pelos três fatores comparados com todo período (78,74\% nesta tabela contra $77,43 \%$ na tabela 3.26$)$. No entanto,as associações das variáveis com a mortalidade por doenças RES baixou no fator 1 e 2 de $-0,47$ para $-0,01$ e de 0,18 para 0,02 , respectivamente. Por sua vez no fator 3 aumentou a 0,99 tendo todo o peso do fator, sem nenhuma associação com as demais variáveis. Diferentemente aos resultados obtidos para todo o período onde foram observadas correlações positivas com o IC. Neste sentido é possível que associação tão fraca esteja em correspondência ao fato de não incluir o período de outono; já que como foi explicado na seção 3.3 os maiores estresses por calor neste condado foram observados principalmente nos meses de setembro e outubro.

Tabela 3.32 - Pesos das componentes principais após a rotação VARIMAX incluindo os índices de conforto térmico na análise da mortalidade por doenças RES, considerando as estações de a) inverno e b) verão para o condado de Los Angeles.

\begin{tabular}{|c|c|c|c|c|c|c|c|}
\hline Variável & Fator 1 & Fator 2 & Fator 3 & Variável & Fator1 & Fator2 & Fator3 \\
\hline RES & $-0,14$ & 0,03 & 0,82 & RES & $-0,01$ & 0,02 & 0,99 \\
\hline CO & $-0,81$ & 0,03 & 0,12 & CO & 0,10 & 0,81 & 0,02 \\
\hline $\mathrm{O}_{3}$ & $-0,29$ & 0,08 & $-0,59$ & $\mathrm{O}_{3}$ & 0,12 & 0,68 & $-0,08$ \\
\hline $\mathrm{NO}_{2}$ & $-0,91$ & 0,12 & $-0,11$ & $\mathrm{NO}_{2}$ & 0,16 & 0,89 & $-0,01$ \\
\hline $\mathrm{SO}_{2}$ & $-0,87$ & 0,13 & $-0,12$ & $\mathrm{SO}_{2}$ & $-0,01$ & 0,80 & 0,11 \\
\hline ID & $-0,11$ & 0,95 & $-0,04$ & ID & 0,97 & 0,17 & 0,01 \\
\hline IC & $-0,13$ & $-0,02$ & $-0,03$ & IC & 0,82 & 0,24 & 0,02 \\
\hline TEv & 0,13 & 0,81 & $-0,08$ & TEv & 0,90 & $-0,15$ & $-0,03$ \\
\hline H & 0,34 & $-0,87$ & $-0,03$ & $\mathbf{H}$ & $-0,95$ & $-0,19$ & 0,01 \\
\hline Autovalor & 3,58 & 2,53 & 0,89 & Autovalor & 3,81 & 2,27 & 1,00 \\
\hline Var expl & 39,74 & 28,10 & 9,89 & Var expl & 42,41 & 25,17 & 11,16 \\
\hline
\end{tabular}


De acordo aos resultados da ACP a comunalidade representada pela DCV em inverno/verão foi de $0,47 / 0,81$. Os valores dos poluentes em inverno nos três fatores foram de $0,77,0,76,0,72,0,50$ para $\mathrm{NO}_{2}, \mathrm{CO}, \mathrm{SO}_{2}$ e $\mathrm{O}_{3}$, no verão o valor de $\mathrm{O}_{3}$ foi de 0,64 . Nota-se como o valor da comunalidade da mortalidade em verão é maior, mas apenas associado no fator $3 \mathrm{com} \mathrm{o} \mathrm{O}_{3}$, por outro lado em inverno embora as DCV não representar a metade dos dados (comunalidade $<0,50$ ) estão fortemente associadas aos poluentes. Por sua vez, as doenças RES em inverno tiveram similar comunalidade às DCV do verão, com valores para a mortalidade por doenças RES e $\mathrm{O}_{3}$ de 0,70 e 0,45 respectivamente. No verão além das RES ter um alto valor $(0,99)$ não esteve associado com as outras variáveis.

Entretanto para o condado de Orange os resultados para as DCV conservaram a mesma distribuição para os primeiros dois fatores (tabela 3.33), comparado com todo o período (tabela 3.27), ou seja, o primeiro fator esteve relacionado aos índices de conforto térmico e o segundo fator com os poluentes, embora com uma ligeira diminuição da variância acumulada para o inverno $(73,4 \%$ nesta tabela contra $75,82 \%$ na tabela 3.27 considerando 5 dias de atraso), e um aumento para o verão (79,32 \%). Por outro lado a correlação positiva/negativa entre DCV com ID, TEv e H caiu de $-0,37$ para um valor bem fraco de 0,02 em inverno e 0,01 em verão.

Tabela 3.33 - Pesos das componentes principais após a rotação VARIMAX incluindo os índices de conforto térmico na análise da mortalidade por DCV, considerando as estações de a) inverno e b) verão para o condado de Orange.

\begin{tabular}{|c|c|c|c|c|c|c|c|}
\hline Variável & Fator1 & Fator2 & Fator3 & Variável & Fator1 & Fator2 & Fator3 \\
\hline DCV & 0,02 & 0,17 & 0,98 & DCV & 0,01 & $-0,17$ & $-0,94$ \\
\hline CO & 0,37 & 0,77 & $-0,06$ & $\mathrm{CO}$ & 0,33 & $-0,78$ & $-0,05$ \\
\hline $\mathrm{O}_{3}$ & 0,38 & 0,26 & $-0,03$ & $\mathrm{O}_{3}$ & 0,50 & $-0,38$ & 0,31 \\
\hline $\mathrm{NO}_{2}$ & 0,56 & 0,67 & $-0,06$ & $\mathrm{NO}_{2}$ & 0,43 & $-0,71$ & 0,14 \\
\hline $\mathrm{SO}_{2}$ & 0,47 & 0,66 & $-0,05$ & $\mathrm{SO}_{2}$ & 0,39 & $-0,60$ & $-0,09$ \\
\hline ID & 0,88 & $-0,37$ & 0,04 & ID & 0,94 & 0,28 & $-0,05$ \\
\hline IC & $-0,65$ & 0,48 & $-0,04$ & IC & 0,89 & 0,30 & $-0,06$ \\
\hline TEv & 0,92 & $-0,29$ & 0,02 & TEv & 0,96 & 0,24 & $-0,04$ \\
\hline H & $-0,82$ & 0,20 & 0,01 & $\mathbf{H}$ & $-0,95$ & $-0,23$ & 0,03 \\
\hline Autovalor & 3,55 & 2,07 & 0,98 & Autovalor & 4,21 & 1,92 & 1,01 \\
\hline Var expl & 39,48 & 22,98 & 10,94 & Var expl & 46,74 & 21,32 & 11,26 \\
\hline
\end{tabular}


No fator 2, a correlação positiva dos poluentes nos meses de inverno/verão caiu com respeito a todo o período, as principais variações foram para o $\mathrm{NO}_{2} \mathrm{e} \mathrm{SO}_{2}$, na tabela 3.27 observam-se valores de 0,88 e 0,80 respectivamente, agora os valores ficaram em 0,67/-0,71 e 0,66/-0,60, respectivamente, igualmente neste fator o peso das DCV diminuiu, de 0,20 (todo o período) para 0,17/-0,17 (inverno/verão).

Por sua vez, o fator 3 esteve relacionado tanto em inverno quanto em verão com as DCV, sem mostrar nenhuma informação com as outras variáveis, diferentemente do observado para todo o período onde foram encontradas associações com o IC, mostrando assim, como no condado de Los Angeles, que as estações intermediárias possuem uma relação mais robusta com a doenças do que o esperado. Por outro lado observaram-se neste fator correlações negativas com o $\mathrm{O}_{3}$ no inverno e positivas no verão.

Por outro lado, a análise feita para as doenças RES tanto para os meses de inverno quanto os de verão não mantiveram o padrão observado (tabela 3.34), praticamente as doenças RES não tiveram associações com os poluentes e índices de conforto térmico tendo um peso apenas de 0,05 e 0,09 nos primeiros dois fatores.

Neste sentido, todo o peso nas duas estações foi para o fator 3 com valores $0,89 / 0,88$, respectivamente; igualmente sem associações com o IC (diferente dos resultados observados na tabela 3.28 para todo o período). Ou seja, a ACP para a mortalidade por doenças RES no condado de Orange apresentou um comportamento similar ao observado no verão para o condado de Los Angeles.

A comunalidade para as estações neste condado de acordo com a ACP, apenas mostrou relação entre as doenças RES e $\mathrm{O}_{3}$ (similar às doenças RES em inverno do condado de Los Angeles), daí que os valores da comunalidade foram 0,73 e 040 para mortalidade e $\mathrm{O}_{3}$ respectivamente. 
Tabela 3.34 - Pesos das componentes principais após a rotação VARIMAX incluindo os índices de conforto térmico na análise da mortalidade por doenças RES, considerando as estações de a) inverno e b) verão para o condado de Orange.

\begin{tabular}{|c|c|c|c|c|c|c|c|}
\hline Variável & Fator1 & Fator2 & Fator3 & Variável & Fator1 & Fator2 & Fator3 \\
\hline RES & 0,05 & 0,04 & 0,89 & RES & 0,05 & 0,09 & 0,88 \\
\hline CO & $-0,03$ & 0,88 & 0,03 & Co & $-0,02$ & $-0,84$ & $-0,14$ \\
\hline $\mathrm{O}_{3}$ & 0,19 & 0,30 & $-0,52$ & $\mathrm{O}_{3}$ & $-0,31$ & $-0,54$ & 0,37 \\
\hline $\mathrm{NO}_{2}$ & 0,18 & 0,87 & $-0,04$ & $\mathrm{NO}_{2}$ & $-0,13$ & $-0,83$ & 0,18 \\
\hline $\mathrm{SO}_{2}$ & 0,09 & 0,77 & 0,28 & $\mathrm{SO}_{2}$ & $-0,05$ & $-0,64$ & $-0,28$ \\
\hline ID & 0,95 & 0,08 & $-0,08$ & ID & $-0,98$ & $-0,09$ & 0,00 \\
\hline IC & $-0,80$ & 0,13 & 0,07 & IC & $-0,94$ & $-0,06$ & $-0,01$ \\
\hline TEv & 0,95 & 0,17 & $-0,05$ & TEv & $-0,98$ & $-0,13$ & 0,01 \\
\hline H & $-0,82$ & $-0,23$ & $-0,03$ & H & 0,97 & 0,14 & $-0,01$ \\
\hline Autovalor & 3,56 & 2,07 & 1,06 & Autovalor & 4,15 & 1,87 & 1,04 \\
\hline Var expl & 39,52 & 22,95 & 11,74 & Var expl & 46,06 & 20,81 & 11,58 \\
\hline
\end{tabular}

Por último no condado de Santa bárbara a ACP feita para a estação de inverno (tabela 3.35) apresentou menor variância comparado com todo o período $(73,9$ \% nesta tabela contra $77,36 \%$ na tabela 3.29$)$, entretanto para verão foi bem similar $(77,4 \%)$. No entanto em ambas as estações (inverno/verão) o fator 1 permaneceu associado aos índices de conforto térmico ID, TEv, e H, igualmente com pouca associação com as DCV, mas comparado com todo o período com um peso mais fraco $(-0,05$ contra 0,16$)$.

$\mathrm{O}$ fator 2 continuou associado com os poluentes $\mathrm{CO}$ e $\mathrm{NO}_{2}$, só que com pesos mais fracos (valores de 0,65/0,77 e 0,65/0,66 nesta tabela contra -0,72 e -0,82, respectivamente), por sua vez no inverno este fator também esteve associado ao IC com um peso de 0,61 , por outro lado o peso da mortalidade por DCV para as duas estações (inverno e verão) foi de 0,21 e 0,27 respectivamente. Com base no fator acredita-se que no inverno, fortes contrastes de temperatura interagindo com a umidade podem influenciar tanto como os poluentes $\left(\mathrm{CO}\right.$ e $\left.\mathrm{NO}_{2}\right)$ na ocorrência de óbitos por DCV.

No fator 3 no inverno, com variância explicada $12,06 \%$, esteve relacionado com o $\mathrm{O}_{3}$ $(0,71)$ correlacionado negativamente com as $\operatorname{DCV}(-0,48)$, fenômeno característico da estação quando os níveis de $\mathrm{O}_{3}$ são mínimos. Por sua vez no verão houve uma correlação positiva entre o $\mathrm{SO}_{2}(0,76)$ e as $\mathrm{DCV}(0,58)$, resultados similares aos obtidos considerando todo o período (vide tabela 3.29). Neste sentido a pesar dos máximos 
deste poluente ocorrer na estação de inverno, também no verão com um aumento das concentrações pode se influenciar positivamente a aparição de óbitos por DCV.

Por último o fator 4 apresentou características opostas entre as DCV e os poluentes com maior peso do fator 3 para as duas estações (inverno/verão), embora as DCV ter o maior peso neste fator $-0,85 /-0,75$ as correlações com os poluentes foi menor $-0,40 / 0,52$, assim como a variância explicada $(10,59 / 10,56 \%)$.

Tabela 3.35 - Pesos das componentes principais após a rotação VARIMAX incluindo os índices de conforto térmico na análise da mortalidade por DCV, considerando as estações de a) inverno e b) verão para o condado de Santa Bárbara.

\begin{tabular}{|c|c|c|c|c|c|c|c|c|c|}
\hline Variável & $\begin{array}{c}\text { Fator } \\
1 \\
\end{array}$ & $\begin{array}{c}\text { Fator } \\
\mathbf{2} \\
\end{array}$ & $\begin{array}{c}\text { Fator } \\
\mathbf{3} \\
\end{array}$ & $\begin{array}{c}\text { Fator } \\
4 \\
\end{array}$ & Variável & $\begin{array}{c}\text { Fator } \\
1\end{array}$ & $\begin{array}{c}\text { Fator } \\
\mathbf{2}\end{array}$ & $\begin{array}{c}\text { Fator } \\
\mathbf{3}\end{array}$ & $\begin{array}{c}\text { Fator } \\
4\end{array}$ \\
\hline DCV & $-0,05$ & 0,21 & $-0,48$ & $-0,85$ & DCV & $-0,05$ & 0,27 & 0,58 & $-0,75$ \\
\hline CO & $-0,29$ & 0,65 & $-0,38$ & 0,22 & $\mathrm{CO}$ & $-0,24$ & 0,77 & $-0,14$ & 0,09 \\
\hline $\mathrm{O}_{3}$ & $-0,35$ & 0,07 & 0,71 & $-0,40$ & $\mathrm{O}_{3}$ & $-0,43$ & 0,53 & 0,15 & 0,24 \\
\hline $\mathrm{NO}_{2}$ & 0,48 & 0,65 & 0,00 & 0,10 & $\mathrm{NO}_{2}$ & $-0,35$ & 0,66 & $-0,25$ & 0,01 \\
\hline $\mathrm{SO}_{2}$ & $-0,26$ & 0,38 & $-0,04$ & 0,13 & $\mathrm{SO}_{2}$ & $-0,23$ & 0,01 & 0,76 & 0,52 \\
\hline ID & $-0,87$ & $-0,37$ & $-0,08$ & 0,00 & ID & $-0,94$ & $-0,26$ & $-0,05$ & $-0,05$ \\
\hline IC & $-0,14$ & 0,61 & 0,43 & $-0,07$ & IC & $-0,54$ & 0,09 & $-0,08$ & $-0,22$ \\
\hline TEv & $-0,95$ & $-0,26$ & $-0,03$ & 0,01 & TEv & $-0,96$ & $-0,24$ & $-0,04$ & $-0,03$ \\
\hline H & 0,88 & 0,17 & 0,07 & $-0,05$ & $\mathbf{H}$ & 0,95 & 0,25 & 0,02 & 0,01 \\
\hline Autovalor & 2,95 & 1,66 & 1,09 & 0,95 & Autovalor & 3,41 & 1,58 & 1,02 & 0,95 \\
\hline Var expl. & 32,83 & 18,42 & 12,06 & 10,59 & Var expl. & 37,93 & 17,57 & 11,34 & 10,56 \\
\hline
\end{tabular}

No caso das doenças RES (Tabela 3.36) os resultados tiveram a mesma distribuição comparado com as $\mathrm{DCV}$, os pesos das variáveis quase se conservaram nos quatro fatores, com exceção da mortalidade por doenças RES, a qual em inverno pelo menos nos dois primeiros fatores não guardou nenhuma relação com as demais variáveis com peso apenas de -0,01 em ambos os casos. Igualmente no verão o fator 1 não apresentou associações com a mortalidade por doenças RES $(-0,02)$. No fator 2 além da correlação seja negativa com as variáveis, o peso das doenças RES foi fraca $(-0,13)$. Por sua vez o fator 3 apresentou correlação positiva entre a mortalidade por doenças RES e o $\mathrm{SO}_{2}$, no verão, diferentemente ao observado no condado quando foi usado todo o período (vide tabela 3.30). Por outro lado na estação de inverno observaram-se correlações positivas da mortalidade com o $\mathrm{O}_{3}(073)$ e o IC $(0,36)$. 
Por último no fator 4 houve um comportamento diferente ao observado no fator 3 , neste caso observaram-se correlações negativas com o $\mathrm{SO}_{2}$ para o verão, no entanto comparado com o fator 3 a variância explicada foi menor (10,87 \% contra 11,30 \%), assim como o peso das doenças RES.

Tabela 3.36 - Pesos das componentes principais após a rotação VARIMAX incluindo os índices de conforto térmico na análise da mortalidade por doenças RES, considerando as estações de a) inverno e b) verão para o condado de Santa Bárbara.

\begin{tabular}{|c|c|c|c|c|c|c|c|c|c|}
\hline Variável & $\begin{array}{c}\text { Fator } \\
1\end{array}$ & $\begin{array}{c}\text { Fator } \\
2 \\
\end{array}$ & $\begin{array}{c}\text { Fator } \\
\mathbf{3}\end{array}$ & $\begin{array}{c}\text { Fator } \\
4\end{array}$ & Variável & $\begin{array}{c}\text { Fator } \\
1\end{array}$ & $\begin{array}{c}\text { Fator } \\
2\end{array}$ & $\begin{array}{c}\text { Fator } \\
\mathbf{3}\end{array}$ & $\begin{array}{c}\text { Fator } \\
4\end{array}$ \\
\hline RES & $-0,01$ & $-0,01$ & 0,47 & $-0,87$ & RES & $-0,02$ & $-0,13$ & $-0,73$ & 0,65 \\
\hline CO & $-0,29$ & $-0,65$ & $-0,41$ & $-0,18$ & Co & $-0,24$ & 0,78 & 0,01 & 0,05 \\
\hline $\mathrm{O}_{3}$ & $-0,35$ & $-0,08$ & 0,73 & 0,35 & $\mathrm{O}_{3}$ & $-0,43$ & 0,53 & $-0,18$ & $-0,20$ \\
\hline $\mathrm{NO}_{2}$ & 0,47 & $-0,66$ & $-0,07$ & 0,02 & $\mathrm{NO}_{2}$ & $-0,35$ & 0,68 & 0,06 & 0,19 \\
\hline $\mathrm{SO}_{2}$ & $-0,26$ & $-0,39$ & $-0,05$ & $-0,15$ & $\mathrm{SO}_{2}$ & $-0,23$ & $-0,01$ & $-0,65$ & $-0,65$ \\
\hline ID & $-0,87$ & 0,37 & $-0,06$ & $-0,03$ & ID & $-0,94$ & $-0,25$ & 0,09 & 0,02 \\
\hline IC & $-0,14$ & $-0,63$ & 0,36 & 0,20 & IC & $-0,54$ & 0,09 & 0,01 & 0,24 \\
\hline TEv & $-0,95$ & 0,26 & $-0,03$ & $-0,01$ & TEv & $-0,96$ & $-0,24$ & 0,07 & 0,01 \\
\hline H & 0,88 & $-0,16$ & 0,07 & 0,03 & H & 0,95 & 0,24 & $-0,06$ & 0,01 \\
\hline Autovalor & 2,95 & 1,64 & 1,08 & 0,98 & Autovalor & 3,21 & 1,38 & 1,02 & 0,98 \\
\hline Var expl. & 32,81 & 18,21 & 11,95 & 10,93 & Var expl. & 37,91 & 17,32 & 11,30 & 10,87 \\
\hline
\end{tabular}

Por sua vez, o condado de Santa Bárbara apresentou associações nas duas estações entre a mortalidade e um poluente como foi observado anteriormente, em inverno afetam as DCV e RES o $\mathrm{O}_{3}$ e em verão o $\mathrm{SO}_{2}$. As comunalidades dessas variáveis em inverno foram de 0,99 e 0,97 para a mortalidade por DCV e RES, e o valor de $\mathrm{O}_{3}$ varia de 0,79 e 0,78 com relação as DCV e RES respectivamente. Em verão as comunalidades do $\mathrm{SO}_{2}$ foram de 0,89 para as $\operatorname{DCV}(0,98)$ e 0,90 para as $\operatorname{RES}(0,97)$.

Em geral os resultados obtidos aplicando a ACP às estações de verão e inverno mostraram algumas variações comparadas com os resultados obtidos da ACP para todo o período, nos três condados de interesse. No condado de Los Angeles considerando apenas a estação de inverno observou-se forte associação das DCV com os poluentes, aumentando a variância explicada (35,68 \% contra 22,44 \%), como era de esperar levando em conta que as maiores concentrações de poluentes ocorrem nesta estação do ano, por outro lado observaram-se também correlações positivas com o $\mathrm{O}_{3}$, tanto no inverno quanto no verão, não observadas nas análises anteriores. Porém para as doenças 
RES não foram observadas as associações positivas com o IC, obtidas anteriormente considerando todo o período. Este comportamento também foi observado em o condado de Orange, tanto para a mortalidade por DCV quanto para as doenças RES, ou seja, ao analisar apenas as estações de inverno e verão, as associações observadas devido ao estresse por frio ou calor em estes dois condados, foram perdidas. Mostrando assim, que as estações intermediárias possuem uma relação mais robusta com as doenças do que o esperado. Por outro lado, no condado de Orange observaram-se também correlações positivas em inverno e negativas em verão entre os níveis de $\mathrm{O}_{3}$ e o número de óbitos por doenças RES. Por último no condado de Santa Bárbara as DCV apresentaram maiores correlações com o $\mathrm{SO}_{2}$ no verão, assim como correlações negativas no inverno com o $\mathrm{O}_{3}$, por sua vez a mortalidade por doenças RES apresentaram correlações positivas com o $\mathrm{O}_{3}$, principalmente em inverno, e com o $\mathrm{SO}_{2}$ em verão. Diferentemente aos obtidos para todo o período, onde apenas foram observadas associações positivas do $\mathrm{SO}_{2}$ com a mortalidade por DCV. Contudo os resultados após da ACP mostraram que os condados possuem estruturas sociais diferentes, apesar da semelhança do clima, fazendo com que os resultados sejam bastante dispares entre os mesmos. 


\section{CONCLUSÕES}

Durante o período 1975-2005, a variação temporal da mortalidade por doenças RES e DCV refletira tendências opostas. Enquanto as doenças RES tiveram um aumento bastante lento, cerca de um caso por década nos três condados; as DCV apresentaram uma ligeira diminuição nos condados de Orange e Santa Bárbara, aproximadamente um caso por década, e uma diminuição constante no condado de Los Angeles, com 14 casos por década.

Verificou-se uma variação sazonal significativa tanto para as doenças RES quanto para as DCV, nos três condados: Los Angeles, Santa Bárbara e Orange no período 19752005. Com uma queda da mortalidade nos meses de verão e um aumento nos meses de inverno.

As distribuições temporais dos níveis de poluição $\left(\mathrm{CO}, \mathrm{SO}_{2}, \mathrm{NO}_{2}\right.$ e $\left.\mathrm{O}_{3}\right)$ durante o período de estudo (1980-2005) mostraram uma queda generalizada e acentuada nos três condados. Adicionalmente, as concentrações de $\mathrm{CO}, \mathrm{SO}_{2}$ e $\mathrm{NO}_{2}$ apresentaram igualmente um aumento no inverno e uma diminuição durante o verão. Por sua parte o $\mathrm{O}_{3}$ apresentou uma distribuição temporal diferente, observaram-se as maiores concentrações durante o verão/outono nos condados de Los Angeles e Orange com média de 0,25/0,18 ppm e 0,19/0,18 ppm respectivamente, e em outono/primavera para o condado de Santa Bárbara com média de 0,16/015 ppm; mostrando uma aparente queda durante no inverno, média de 0,08 ppm para o condado de Los Angeles, 0,11 ppm para o condado de Orange e 0,13 ppm para o condado de Santa Bárbara.

Com respeito aos eventos extremos de poluição, o condado de Los Angeles ultrapassou os padrões nacionais de qualidade do ar para o poluente CO (20 ppm) 136 vezes no período, para o $\mathrm{NO}_{2}(0,19 \mathrm{ppm}) 154$ vezes, para o $\mathrm{O}_{3}(0,09 \mathrm{ppm}) 1443$ vezes e para o $\mathrm{SO}_{2}(0,04 \mathrm{ppm})$ duas vezes. Por sua vez o condado de Orange teve uma ultrapassagem para o $\mathrm{CO}, 43$ para o $\mathrm{NO}_{2}$ e 771 para o $\mathrm{O}_{3}$. Entretanto o condado de Santa Bárbara apresentou apenas violações do padrão de qualidade do ar para o $\mathrm{O}_{3}$ com 114 .

Com relação aos índices biometeorológicos analisados, notou-se que todos seguem um padrão sazonal semelhante, com um aumento do estresse de calor durante o verão e o outono e uma diminuição do estresse de calor durante o inverno e vice-versa (aumento do estresse devido ao frio). 
Nos índices de conforto calculados usando combinações entre a temperatura e a umidade, verificaram o maior estresse de calor durante o período da tarde (temperatura máxima e umidade relativa mínima) no verão e outono. Bem como o maior estresse térmico devido ao frio durante o período da manhã (temperatura mínima e a umidade relativa máxima) no inverno.

A partir dos índices de conforto térmico notou-se que o condado mais estressante devido ao calor foi Los Angeles, comparado com Orange e Santa Bárbara. Por exemplo, considerando o índice de desconforto de Thom (ID) e o índice de desconforto de Kawamura (IDK) houve 74 dias acima do limite crítico de $29^{\circ} \mathrm{C}$ para ID e 65 dias com valores superiores a $80^{\circ} \mathrm{C}$ para $\mathrm{ID}_{\mathrm{K}}$. Usando a temperatura aparente (TA) o intervalo de forte estresse (valores entre $35^{\circ} \mathrm{C}$ e $40^{\circ} \mathrm{C}$ ) foi atingido 22 vezes no condado de Los Angeles, majoritariamente no mês de setembro (9), 15 vezes em Santa Bárbara e 17 vezes em Orange, principalmente no mês de julho (5 e 7 vezes respectivamente). Quando foi usado o índice de calor (IC) observou-se 6 dias durante todo o período de extremo perigo para o calor (maior que $54^{\circ} \mathrm{C}$ ), 3 dias no condado de Los Angeles (18 de Junho de 1981, 5 de setembro de 1988 e 4 de maio de 2004) e 3 dias no condado de Santa Bárbara (2, 3 de novembro e 7 de julho de 1992).

Utilizando o índice temperatura efetiva (TE) e o índice de temperatura efetiva em função do vento $\left(\mathrm{TE}_{\mathrm{v}}\right)$ verificou-se que o maior estresse devido ao calor (valores maiores que $25^{\circ} \mathrm{C}$ ) ocorreram principalmente durante o período de verão no condado de Orange (568 dias usando TE e 99 dias usando $\mathrm{TE}_{\mathrm{v}}$ ), e em outono para os condados de Santa Bárbara (82 dias usando TE e 24 dias usando $\mathrm{TE}_{\mathrm{v}}$ ) e Los Angeles (375 dias usando TE e 84 dias usando $\mathrm{TE}_{\mathrm{v}}$ ).

Para os três condados o mês mais estressante respeito ao calor foi setembro, alcançando valores de até $33,42^{\circ} \mathrm{C}$ e $87,8^{\circ} \mathrm{C}$ para ID e ID $_{\mathrm{K}}$ respectivamente, usando o TE neste mês houve um um total de 277 ultrapassagens em Orange, seguido de 187 em Los Angeles e 40 em Santa Bárbara. Por sua parte usando $\mathrm{TE}_{\mathrm{v}}$ os condados de Los Angeles e Santa Bárbara tiveram um total de 80. Também observou-se nos meses de julho e agosto estresse por calor em Orange e em outubro em Los Angeles e Santa Bárbara, por exemplo usando $\mathrm{TE}_{\mathrm{v}}$ nesses meses houveram um total de 89 dias com ultrapassagens, já para os condados de Los Angeles e Santa Bárbara 21 dias respectivamente. 
Verificou-se durante todo o período uma maior concentração de dias estressantes em relação ao frio. Neste sentido quando é utilizado o índice $\mathrm{TE}_{\mathrm{v}}$ houve um total de 8890 dias estressantes devido ao frio no condado de Santa Bárbara, 8811 dias no condado de Orange e 8800 dias no condado de Los Angeles.

Por sua parte utilizando o índice de temperatura e resfriamento pelo o vento "Windchill" $(\mathrm{H})$ observou-se muitos dias com condições desconfortáveis em relação ao frio, ultrapassando o limite de $600 \mathrm{Kcalm}^{-2} \mathrm{hr}^{-1}$ principalmente no inverno. O condado com maior número de dias de ultrapassagens foi Orange com 2663, seguido de Santa Bárbara com 1863 e Los Angeles com 1809. Ainda Orange teve 15 dias onde foi excedido o limite de $1000 \mathrm{Kcalm}^{-2} \mathrm{hr}^{-1}$, apresentando valores de até $1067.9 \mathrm{Kcalm}^{-2} \mathrm{hr}^{-1} \mathrm{e}$ 1014.6 Kcalm ${ }^{-2} \mathrm{hr}^{-1}$ nos dias 5 e 6 de fevereiro de 1997.

Com respeito aos impactos destas variáveis ambientais na mortalidade, analisando a média de óbitos por sensação térmica notou-se que, com base no índice TE houve um aumento das doenças nos extremos, principalmente quando a sensação é Muito Frio, com valores médios por doenças RES de 16,42, 3,31 e 0,81 e por DCV de 77,32, 15,37 e 2,92 para os condados de Los Angeles, Orange e Santa Bárbara, respectivamente.

Em relação ao calor o condado de Los Angeles teve 18 dias quente e 1 dia muito quente onde a media para doenças RES foi de 10,32 e 11,88 respectivamente, por sua vez a média de óbitos por DCV foi de 67,91 e 89,12 respectivamente, nestes mesmos extremos. O condado de Santa Bárbara teve 5 dias quentes, onde houve 17 óbitos por DCV, sob esta sensação térmica ocorreu a maior média com 3,49. Já o condado de Orange não teve nenhum dia com condições quente ou muito quente.

Analisando a porcentagem de doenças RES e DCV por sensação térmica observou-se que, com base no índice TE, há um aumento das doenças quando a sensação térmica é Ligeiramente Fria (33,10 \% e 33,52 \%), seguido de Frio Moderado (26,52 \% e 25,80 \%) no condado de Los Angeles, para Orange a maior quantidade de óbitos acontece quando a sensação térmica é de Frio (22,05 \% e 20,74 \%), seguido de Frio Moderado (19,94 \% e 20,60\%), entretanto para Santa Bárbara a sensação térmica que apresenta maior quantidade de óbitos é de Frio Moderado (37,45\% e 38,87\%) seguido de Ligeiramente Frio $(35,35 \%$ e $32,74 \%)$. 
Com base na análise de correlação entre as variáveis, observaram-se as melhores correlações entre as variáveis e as doenças tanto RES quanto DCV no condado de Los Angeles, assim como as correlações mais baixas para o condado de Santa Bárbara.

Para o condado de Los Angeles verificou-se melhores associações entre os poluentes $\mathrm{CO}$ e $\mathrm{NO}_{2}$ com as $\mathrm{DCV}$ principalmente considerando o próprio dia em questão $(\mathrm{r}=0,446$ e $r=0,380$ ). Por sua vez as variáveis meteorológicas estiveram mais bem correlacionadas para o segundo dia (temperatura mínima $(\mathrm{r}=-0,375)$, temperatura de ponto de orvalho $(\mathrm{r}=-0,389)$ e umidade específica $(\mathrm{r}=-0,407))$. Entretanto os índices mostraram melhores associações para o quinto dia, exceto quando são calculados usando a temperatura mínima, neste caso as correlações estão no segundo e terceiro dia (IDK_MIN $(r=0,399))$. Com respeito às doenças RES verificou-se melhores correlações embora negativas com a temperatura mínima ( $\mathrm{r}=-0,409)$, os índices ID e IDK quando são calculados a partir da temperatura mínima ID_MIN $(r=-0,401)$ e ID $_{\text {K_MIN }}(r=-0,410)$ para o quinto dia de atraso.

Para o condado de Orange a análise de correlação para as DCV mostrou as maiores associações com os índices de conforto térmico (exceção do IC) e a temperatura do ar com valores de $r$ entre 0,28 e 0,31 para 4 e 5 dias de atraso. Para os poluentes o CO foi o maior correlacionado principalmente com 3 dias de atraso $(r=0,254)$. Considerando a mortalidade por doenças RES verificaram-se melhores associações com a temperatura média $(r=-0,264)$, os índices ID, ID $_{K}$ e TE, com valores de $r=-0,268,-0,270$ e $-0,269$ respectivamente, quando utilizamos 5 dias de atraso.

Para o condado de Santa Bárbara observou-se que as correlações entre as variáveis e as DCV jamais excederam a 0,133, de forma geral as correlações menos baixas foram para os poluentes $\mathrm{CO}$ e $\mathrm{NO}_{2}$, com valores de $\mathrm{r}$ no quinto dia de atraso de 0,132 e 0,88 respectivamente, e para a $\mathrm{T}_{\min }$ no segundo dia de atraso $(\mathrm{r}=-0,126)$ e para os índices de conforto térmico (com exceção do IC) oscilando entre $0,102<|r|<0,132$. No caso das doenças RES observou-se um comportamento bem similar ao obtido para as DCV, com a exceção dos poluentes onde a associação foi mais fraca, a T, Td e índices de conforto oscilaram entre $0,102<|\mathrm{r}|<0,133$ a maior correlação correspondeu ao índice $\mathrm{ID}_{\mathrm{K}}$.

Ainda com base na análise de correlação entre as variáveis, os resultados nos três condados considerando as estruturas de defasagens não mostraram diferenças muito significativas considerando tanto o próprio dia em questão como com 5 dias de atraso. 
Por outro lado quando são usadas médias móveis verificou-se nos três condados que os coeficientes de correlação tendem a crescer à medida que aumenta o número de termos da média móvel.

Os resultados da ACP para os três condados usando apenas as variáveis meteorológicas e os níveis de poluição não mostraram altas correlações com respeito às doenças, tanto DCV quanto RES. No entanto observou-se para os condados de Los Angeles e Orange que o aumento dos níveis de poluição pode acarretar um aumento nas DCV, com uma explicação de variância maior no condado de Orange (39 \%) comparado com o condado de Los Angeles (21\%). Além disso, foi observado no condado de Los Angeles no primeiro fator (variância explicada de 72,97 \%) que o aumento da umidade está associado negativamente com as DCV, por sua vez no condado de Orange observou-se que o aumento da temperatura e a diminuição da umidade diminuem as DCV, e por outro lado dias ventosos e de baixa pressão estão associados ao aumento de óbitos por DCV. No caso de Santa Bárbara observou-se apenas uma correlação negativa baixa entre as DCV e a temperatura e umidade, assim como uma ligeira correlação positiva com a velocidade do vento $(\mathrm{V})$ e negativa com a pressão atmosférica $(\mathrm{P})$ no quarto fator. No entanto comparado com os outros dois condados os resultados não foram muito significativos.

As doenças RES nos três condados apresentaram maiores pesos nos fatores com menor variância explicada. Para o condado de Los Angeles caiu para o terceiro fator (variância explicada de 11,67\%) com 0,55, neste fator observou-se que um aumento de número de óbitos por doenças RES pode estar condicionado com a chegada das massas de ar polar (onde a $\mathrm{P}(0,63)$ sobe e a temperatura cai $(-0,84)$ ), igualmente em relação aos níveis de $\mathrm{O}_{3}(-0,74)$, que caem durante o inverno, devido às baixas temperaturas. Entretanto para o condado de Orange diferentemente do observado para as DCV, no quarto fator observou-se que os sistemas de alta pressão com pouco vento podem estar associados às doenças RES. Nestes dois condados não houve relação significativa em relação aos níveis de poluentes. Por sua parte no condado de Santa Bárbara não se estabeleceram correlações importante entre a mortalidade por doenças RES e as outras variáveis, embora no quarto fator houvesse uma ligeira correlação positiva com o $\mathrm{SO}_{2}$. 
Considerando a ACP utilizando os índices de conforto térmico observaram-se melhores resultados tanto em variância acumulada e comunalidade quanto em peso da mortalidade em ambos os grupos de doenças para os três condados de interesse.

No caso do condado de Los Angeles as DCV apresentaram altos pesos positivos com as concentrações de poluentes com variância explicada maior que no caso da ACP usando apenas as variáveis meteorológicas (30,30 \% contra 21,43\%). Além disso, o primeiro fator mostrou relações inversas com os índices de conforto térmico ID, IC e TEv (que a maioria dos autores associam com estresse por) assim como uma relação positiva com $\mathrm{H}$ (indicador de estresse por frio), logo com o decaimento das temperaturas as pessoas são mais susceptíveis a mortalidade por DCV, embora com peso menor da mortalidade neste fator comparado com as correlações entre os poluentes.

Por outro lado, as doenças RES apresentaram associações com os índices de conforto térmico, no primeiro fator (variância explicada de 39,45\%) as correlações inversas entre eles indicam que a diminuição de temperatura aumenta o número de óbitos por doenças RES, e o terceiro fator com maior peso das doenças RES $(0,61$ contra $-0,41)$ segurem associações positivas entre o número de óbitos e o IC, sendo um indicador do clima do verão em Los Angeles, onde as altas temperaturas podem incidir no aumento da mortalidade, mas de maneira menos pronunciada, na menor explicação da variância deste fator $(9,85 \%)$. Contudo a mortalidade por doenças RES está mais associada neste condado às variações meteorológicas do que às concentrações de poluentes, como no caso das DCV, ainda que com menos explicação da variância.

Para o condado de Orange tanto as DCV quanto as doenças RES mostraram associações com os índices de conforto, no primeiro fator (variância explicada de 42,16 \% e 41,54 \% para as DCV e RES, respectivamente) estabeleceram as características invernais do condado, onde uma queda da temperatura aumenta o estresse por frio e consigo um aumento da mortalidade. Igualmente foram observadas no terceiro fator relações positivas da mortalidade com o estresse por calor (através do IC), principalmente para as doenças RES tanto em peso $(0,66$ contra 0,55$)$ quanto em variância explicada $(11,20$ \% contra 10,97 \%). Igualmente comparado com Los Angeles, as doenças RES também mostraram maior variância explicada neste fator associado com IC. Por outro lado, a mortalidade em Orange tanto por DCV quanto por doenças RES estive fracamente associada aos níveis de poluição. 
Para o condado de Santa Bárbara, os resultados da ACP utilizando os índices de conforto térmico foram muito diferentes, comparados com os obtidos nos condados de Los Angeles e Orange. Já que tanto episódios de frio quanto de calor não mostraram impactos claros na população idosa, com respeito a ambos os grupos de doenças. $\mathrm{O}$ mais relevante deste condado é que apesar das concentrações de $\mathrm{SO}_{2}$ sejam as mais baixas das estudadas (média de 0,29 ppb), apresentou boas correlações positivas principalmente com as DCV.

Com respeito aos resultados obtidos aplicando a ACP às estações de verão e inverno nos três condados, observaram-se algumas variações comparadas com os resultados obtidos da ACP para todo o período. No condado de Los Angeles considerando apenas a estação de inverno observou-se forte associação das DCV com os poluentes, aumentando a variância explicada (35,68 \% contra 22,44 \%), como era de esperar levando em conta que as maiores concentrações de poluentes ocorrem nesta estação do ano, por outro lado observaram-se também correlações positivas com o $\mathrm{O}_{3}$, tanto no inverno quanto no verão, não observadas nas análises anteriores. Porém as doenças RES não foram observadas as associações positivas com o IC, obtidas anteriormente considerando todo o período.

Os resultados da ACP para as estações de inverno e verão no condado de Orange refletem o comportamento observado em Los Angeles para as doenças RES. Ou seja, tanto para a mortalidade por DCV quanto para as doenças RES, as associações observadas devido ao estresse por frio ou calor em estes dois condados, foram perdidas. Mostrando assim, que as estações intermediárias possuem uma relação mais robusta com as doenças do que o esperado. Por outro lado, no condado de Orange observaramse também correlações positivas em inverno e negativas em verão entre os níveis de $\mathrm{O}_{3}$ e o número de óbitos por doenças RES.

No caso do condado de Santa Bárbara as DCV apresentaram maiores correlações com o $\mathrm{SO}_{2}$ no verão, assim como correlações negativas no inverno com o $\mathrm{O}_{3}$, por sua vez a mortalidade por doenças RES apresentaram correlações positivas com o $\mathrm{O}_{3}$, principalmente em inverno, e com o $\mathrm{SO}_{2}$ em verão. Diferentemente aos obtidos para todo o período, onde apenas foram observadas associações positivas do $\mathrm{SO}_{2}$ com a mortalidade por DCV. 
Em geral nos três condados a ACP aplicada às estações de inverno e verão não mostraram fortes associações na mortalidade por DCV ou RES devido ao estresse por frio ou calor, em comparação ao período todo. Pode ser que as estações de transição, outono e primavera, tenham um impacto maior, pois é quando as condições atmosféricas mudam, gerando maior aumento de mortalidade dos idosos.

Contudo os resultados após da ACP mostraram que os condados possuem estruturas sociais diferentes, apesar da semelhança do clima, fazendo com que os resultados sejam bastante dispares entre os mesmos. Logo as perspectivas deste estudo pretende colocar estes resultados para climas futuros, pois diversos episódios de ondas de calor ocorreram após o ano de 2005. 


\section{REFERÊNCIAS BIBLIOGRÁFICAS}

Alberdi, E; Hyde, C. C. e Becerra, S. P.; 1998. Pigment Epithelium-Derived Factor (PEDF) Binds to Glycosaminoglycans: Analysis of the Binding Site. Biochemistry, 37 (30): 10643-10652.

Amâncio, T. C.; Nascimento, C. F. L.; 2012: Asma e poluentes ambientais: um estudo de séries temporais. Revista da Associação Médica Brasileira, 58 (3): 302-307.

American Lung Association, State of the Air, 2016. Disponível em: www.stateoftheair.org/california2016

Anderson, B. G. e Bell M. L., 2009 Weather-Related Mortality How Heat, Cold, and Heat Waves Affect Mortality in the United States. Epidemiology, 20(2): 205213.

ARB, 2011. Air Resources Board. Disponível em: http://www.arb.ca.gov/research/aaqs/no2-rs.

Barnett, A. G.; Looper, M; Fraser J. F.; 2008)The seasonality in heart failure deaths and total cardiovascular deaths. Aust N Z J Public Health 32: 408-413.

Basu, R.; Feng, W. F e Ostro, B.; 2008. Characterizing temperature and mortality in nine California counties. Epidemiology, 19 (1): 138-145.

Batista, R. J. R.; 2017: Análise do risco de mortalidade por doenças cardiovasculares e respiratórias na população idosa da RMSP e sua projeção considerando o cenário RCP8.5 de mudanças climáticas. São Paulo. Tese de Doutorado. Instituto de Astronomia, Geofísica e Ciências Atmosféricas, Universidade de São Paulo.

Behrentz, E.; Ling, R.; Rieger, P.; Winder, A. M.; 2004. Measurements of nitrous oxide emissions from light-duty motor vehicle: a pilot study. Atmospheric Envioronment, 38: 4291-4303.

Belding, H. S.;1970. The search for a universal heat stress index. In: Physiological and Behavioral Temperature Regulation, J. D. Hardy, A. P. Gagge, and J. J. Stolwijk (Eds.). Chicago: Charles C Thomas, 193-202.

Blatteis, C. M.; 2012. Age-Dependent Changes in Temperature Regulation. Gerontology, 58:289-295.

Bolton D.; 1980. The Computation of Equivalent Potential Temperature.

Braga A. L. F.; 1998. Quantificação dos efeitos da poluição do ar sobre a saúde da população pediátrica da cidade de São Paulo e proposta de monitorização. Tese de Doutorado. Faculdade de Medicina da Universidade de São Paulo. 
Braga A. L. F; Zanobetti A., Schwartz J.; 2002: The effect of weather on respiratory and cardiovascular deaths in 12 U.S. cities. Environ Health Perspect, 110(9): 859-863.

Braun, S.; 2003: Influências meteorotrópicas nas doenças cardiovasculares na cidade de São Paulo. Dissertação de mestrado. Instituto de Astronomia, Geofísica e Ciências Atmosféricas, Universidade de São Paulo, São Paulo.

Brazol, D.; 1954: Bosquejo bioclimático de la República Argentina. Meteoros 4, 381394.

Bunchaft e Kellner, 1999 Estatística sem mistérios. 1999.

Bureau de Censo dos Estados Unidos: disponível em: https://www.census.gov/

California Department of Public Health, California Tobacco Control Program. California Tobacco Facts and Figures: A Retrospective Look at 2017. Sacramento, CA: California Department of Public Health; 2018.

Carey M.; Atkinson R. W.; Kent, A. J; Staa, T.; Cook, D. J e Anderson, H. R.; 2013. Mortality Associations with Long-Term Exposure to Outdoor Air Pollution in a National English Cohort. All AJRCCM Issues, 187 (11).

Cena, K. e Dear, R.; 2001. Thermal comfort and behavioural strategies in office buildings located in a hot-arid climate. Journal of Thermal Biology, 26 (4): 409414.

Coelho, S. Z. S. M.; 2007. Uma análise estatística com vistas a previsibilidade de internações por doenças respiratórias em função de condições meteorotrópicas na cidade de São Paulo. Tese de Doutorado em Ciências. Universidade de São Paulo. São Paulo.

Colbeck e Mackenzie; 1994. Air Pollution by Photochemical Oxidants. Elsevier, Amsterdam, p. 232.

Conde, F. C.; 2001. Uma análise de componentes principais de efeitos ambientais sobre a morbidade de doenças respiratórias em São Paulo. Dissertação de mestrado. Instituto de Astronomia, Geofísica e Ciências Atmosféricas, Universidade de São Paulo.

Coronato, F. R.; 1993: Windchill factor applied to Patagonian climatology. Int. J. Biometeorol., 7: 1-6.

Crouse, D. L.; Peters P. A.; Hystad P.; Brook J. R.; Donkelaar A.; Martin, R. V.; Jerret, M.; Goldberg, M. S; Pope C. A.; Brauer, M.; Brook, R. D.; Robichaud, A.; Menard, R. e Burnett, R. T.; 2015. Ambient PM2.5, O3, and NO2 Exposures and Associations with Mortality over 16 Years of Follow-Up in the Canadian Census Health and Environment Cohort (CanCHEC). Environ Health Perspect. 123 (11): 1180-1186.

Court, A.; 1948. Windchill. Bull. Am. Meteorology C. 29: 487-493. 
Davies, C.; 1979: Thermoregulation during exercise in relation to sex and age. European Journal of Applied Physiology and Occupational Physiology, 2: 7179.

Davis, R. E.; Knappenberger P. C.; Novicoff W. M.; Michaels P. J.; 2003. Decadal changes in summer mortality in US cities. International Journal of Biometeorology 47(3): 166-175.

Departamento de Envelhecimento na Califórnia. Disponível em: https://www.aging.ca.gov/data_and_statistics

Dien, J.; 2010. Evaluating two $\square$ step PCA of ERP data with Geomin, Infomax, Oblimin, Promax and Varimax rotations. Psychophysiology, 47(1): 170-183.

Efron, B.; 1979. Bootstrap Methods: Another Look at the Jackknife. Ann. Statist.,7 (1): $1-26$.

Fanger, P. O.; 1970: Thermal comfort: analysis and applications in environmental engineering. New York, McGraw-Hill Book Company. 244p.

Ferreira; 2013. Modelos de regressão: uma aplicação em medicina dentária. Dissertação de Mestrado. Universidade Aberta, Lisboa.

Frota e Schiffer; 2001. Manual de Conforto Térmico. 5a edição, Studio Nobel, São Paulo.

Fuentes, M.; Howard, H. C.; Jingwen, Z., 2010. Impact of Climate Change on Ambient Ozone Level and Mortality in Southeastern United States. Int. J. Environ. Res. Public Health, 7: 2866-2880.

Gavinier, S.; Nascimento, C. F. L.; 2014. Poluentes atmosféricos e internações por acidente vascular encefálico. Ambiente \& Água - An Interdisciplinary Journal of Applied Science, 9: (3).

Gershunov, A e Guirguis, K; 2012. Calfornia Heat Waves in the present and future. Geophysical Research Letters,39(18).

Giles, B. D. et al.; 1990: Too hot for comfort. The heat waves in Greece in 1987 and 1988. Int J Biometeorol, 34: 98-104.

Givoni e Noguchi; 2004. Outdoor comfort research issues. Energy and Buildings, 35 (1): 77-86.

Gobo, 2018.Bioclimatologia Subtropical e Modelização do Conforto Humano: De Escala Local á Regional. Tese de Doutorado. Faculdade de Filosofia, Letras e Ciências Humanas, Departamento de Geogrfía USP, SP.

Goldman, R.; 1978. Prediction of human heath tolerance. In: Folinsdbee S (ed.) Environmental stress. Academic Press, New York. 
Gonçalves, F. L. T.; Carvalho L. M. V.; Conde F. C.; Latorre M. R. Saldiva P. H. N.; Braga A. L. F.; 2005. The effects of air pollution and meteorological parameters on respiratory morbidity during the summer in São Paulo City. Environment International, 31 (3): 343-349.

Gouveia, N.; Freitas, C. U.; Martins, L. C. e Marcilo, I. O.; 2006: Hospitalizações por causas respiratórias e cardiovasculares associadas à contaminação atmosférica no Município de São Paulo. Cadernos de Saúde Pública, Rio de Janeiro, 22 (12): 2669-77.

Green, R. S.; Basu, R.; Broadwin, R.; Kim, J. J. e Ostro, B.; 2010. The effect of temperature on hospital admissions in nine California counties. International journal of public health 55(2): 113-121.

Guo,Y.; Barnett A.G.; Yu, W.; Pan, X.; Ye. X.; Huang, C.; Tong, S.; 2011: A large change in temperature between neighbouring days increases the risk of mortality. PLoS One 6 (2): 16511.

Gurjar, B. R.; Jain, A.; Sharma, A.; Agarwal, A.; Gupta, P.; Nagpure, A. S.; Lelieveld, J.; 2010: Human health risks in megacities due to air pollution. Atmospheric Environment. 44: 4606-4613.

Gutierres, J. S.; Reyes, E. S. e Bautista, E. B.; 2011. Pulmonary Diseases: First Cause in the Word. Chest, 139 (6): 1550

Hajek, E. R.; Gutierrez, J. R.; Esppinosa, G., 1981: Seasonality of conception in human populations in Chile. Int. J. Biometeor. 25: 281-291.

Hajek, E. R.; Rubio, O. P., 1982: Bioclimatología de montaña en Chile. II. Entalpia del aire. Rev. Med. Chile, 110, 228-232.

Haq, G; Whitelegg, L.; Kohler, M.; 2008. Growing old in a changing climate. New York: Stockholm Environment Institute.

Harris, S. M. e Carvalho, L. V.; 2017. Characteristics of southern California atmospheric rivers. Theor Appl Climatol.

Harrison, A. T.; Small, E. e Mooney, H. S.; 1971. Drought Relationships and Distribution of Two Mediterranean $\square$ Climate California Plant Communities. Ecology,52(5).

Hensen, J. L. M. (1991). On the thermal interaction of building structure and heating and ventilating system Eindhoven: Technische Universiteit Eindhoven.

Humphreys, M. A.; Nicol, J. F., 1998: Understanding the adaptive approach to thermal comfort. ASHRAE Transactions; Atlanta 104: 991.

Hoshiko, S.; English, S. P.; Smith, D.e Trent, R.; 2010. A simple method for estimating excess mortality due to heat waves, as applied to the 2006 California heat wave. International journal of public health 55(2): 133-137. 
Hwang R. L. e Lin T. P., 2007. Thermal Comfort Requirements for Occupants of SemiOutdoor and Outdoor Environments in Hot-Humid Regions. Journal Architectural Science Review, 50 (4): 357-364.

Inoue, Y.; Nakao, M.; Akagi, T. e Veda, H.; 1992. Thermoregulatory responses of young and older men to cold exposure. Eur J Appl Physiol;65: 492-498.

Jemal, A.; Ward, E.; Hao Y. e Thun, M.; 2005. Trends in the leading causes of death in the United States, 1970-2002. JAMA, 294: 1255-1259.

Jendritzky, G.; 1977. Zur Problematik der medizinmeteorologischen Bewertung des thermischen Milieus. Z. angew. Boeder u. Klimaheilk, 24: 407-414.

Jendritzky, G.; Soenning, W.; 1979: Der Einfluss der Strahlung auf die thermischen Bedingungen in der Klimatherapie. Z. Phys. Med, 6: 283-291.

Jerrett, M.; Burnett, R. T.; Beckerman, B. S.; Turner, M. C.; Krewski, D; Thurston, G.; Martin, R. V.; Donkelaar A.; Hughes, E.; Shi, Y. e Gapstur, S. M.; 2013. Spatial Analysis of Air Pollution and Mortality in California. All AJRCCM Issues, 188 (5).

Jerrett, M.; Burnet, R. T.; Pope, C. A.; Ito, K.; 2009. Long-Term Ozone Exposure and Mortality. N Engl J Med, 360:1085-1095.

Kalkstein, A.J.; 2013: Regional similarities in seasonal mortality across the United States: an examination of 28 metropolitan statistical areas. PLoS One, 8: 63971.

Kalkstein, L.S.; Valimont, K. M.; 1986: An evaluation of summer discomfort in the United States using a relative climatological index. Bulletin of the American Meteorological Society, 7: 842-848.

Karl Pearson 1901. LIII. On lines and planes of closest fit to systems of points in space. The London, Edinburgh, and Dublin Philosophical Magazine and Journal of Science. Series 6, 2 (11): 559-572.

Kawamura; 1965. Distribution of discomfort index in Japan in summer season. $J$ Met Res., 17 (7): 460-466.

Khan F.; Spence, V. e Belch, J.; 1992. Cutaneous vascular responses and thermoregulation in relation to age. Clin Sci, 82: 521-8.

LaDochy, S.; Medina, R. e Patzert, W.; 2007. Recent California climaty variability: spatial and temporal patterns in temperature trends. Inter-Research, 33: 159-169.

Krewski, D.; Jerrett, M.; Burnett, R. T.; Ma, R.; Hughes, E.; Shi Y; et al.; 2009. Extended Follow-up and Spatial Analysis of the American Cancer Society Study Linking Particulate Air Pollution and Mortality. Res Rep Health Eff Inst, 140: 5114. 
Laden, F.; Schwartz, J.; Speizer, F. E. e Dockery, D. W.; 2006. Reduction in Fine Particulate Air Pollution and Mortality Extended Follow-up of the Harvard Six Cities Study. All AJRCCM Issues. 173 (6).

Larsen, U.; 1990: The effects of monthly temperature fluctuations on mortality in the United States from 1921 to 1985. Int J Biometeorol. 34 (3): 136-145.

Lecha, L. B. E.; 2009. Bioclimatologia Humana - texto não publicado.

Lee, C. C.; 2015: A systematic evaluation of the lagged effects of spatiotemporally relative surface weather types on wintertime cardiovascular-related mortality across 19 US cities. - Int. J. Biometeor. 59: 1633-1645.

Lowe, G. D. O.; Lee, A. J.; Rumley, A.; Price, J. F. e Fowkes, F. G. R.; 1997. Blood viscosity and risk of cardiovascular events: the Edinburgh Artery Study. British Journal of Haematology, 96 (1) 168-173.

Maia, J. A.; 2002: Uma análise do conforto térmico e suas relações meteorotrópicas na cidade de São Paulo. Dissertação de mestrado. Instituto de Astronomia, Geofísica e Ciências Atmosféricas, Universidade de São Paulo, SP.

Martins, L. C. et al.; 2001: Relação entre poluição atmosférica e atendimentos por infecção de vias aéreas superiores no município de São Paulo: avaliação do rodízio de veículos. Revista Brasileira de Epidemiologia, 4 (3): 220-229.

Martins, L. C. et al.; 2002: Poluição atmosférica e atendimentos por pneumonia e gripe em São Paulo, Brasil. Revista de Saúde Pública, 36 (1): 88-94.

Matsudo, S. M.; Matsudo, V. K. R. e Barros Neto, T. L.; 1996. Atividade física e envelhecimento: aspectos epidemiológicos. Revista Brasileira de Medicina do Esporte, 7 (1).

McAdie, A.; 1902. Climatology of California. Trans Am Climatol Assoc, 18: 103-112.

Missenard A.; 1937. L'home et lê climat. Paris

Moraes, A. C. L.; Ignotti, E.; Netto, P.; Jacobson, L.; Castro, H.; Hacon, S.; 2010. Sibilância em crianças e adolescentes vizinhos a uma indústria petroquímica no Rio Grande do Norte, Brasil. Jornal de Pediatria, v.86, n.4, p.337-44.

Moran, E. F; 1994. Adaptabilidade Humana. São Paulo: Edusp.

Munn, R. E.; 1970: Biometeorological Methods. Academic Press. New York.

Nikolopoulu, M.; 2004. Projetando Espaços Abertos no Ambiente Urbano: uma Abordagem Bioclimática. Centro de Fontes de Energia Renováveis, EESD, FP5.

NOAA, 2015. Heat Index Calculator, Washington DC. Disponível em: http://www.wpc.ncep.noaa.gov/html/heatindex.shtml.

NOAA. Disponível em: http://w2.weather.gov/climate/xmacis.php?wfo=lox 
Ogbonna, A. C. e Harris, D. J.; 2008. Thermal comfort in sub-Saharan Africa: Field study report in Jos-Nigeria. Applied Energy, 85 (1): 1-11.

OMS, 2012. ¿Cuál es la enfermedad que causa más muertes en el mundo? Disponible em: http://www.who.int/features/qa/18/es/

Organização Mundial da Saúde, 2005: Preventing chronic diseases: a vital investment: WHO global report. 1.Chronic disease - therapy 2.Investments 3.Evidencebased medicine 4.Public policy 5.Intersectoral cooperation I.Title. ISBN 924 1563001.

Ono, H. S. P. e Kawamura, T.; 1991. Sensible climates in monsoon Ásia. Int. J. Biometeorol., 35: 39-47.

Oyarzun, C. E.; 1978: Influencia de factores bioclimáticos sobre el balance energético por respiración en $\mathrm{El}$ hombre, en tres lugares (Isla Teja, bosque y pradera). Tesis. Universidad Austral de Chile.

Pallotta; Herdies e Gonçalves; 2015. Estudo das condições de tempo e conforto térmico no desempenho esportivo aplicado à maratona da cidade do Rio de Janeiro. Rev. bras. meteorol., 30 (2).

Pereira, L. A.; 1999. Associação entre poluição atmosférica e perdas fetais tardias no município de São Paulo. Tese de Doutorado. Faculdade de medicina, Universidade de São Paulo, SP.

Pinheiro, S. L.; Nascimento, S.; Schwartz, J. e Zanobetti, A.; 2014. Efeitos isolados e sinérgicos do MP10 e da temperatura média na mortalidade por doenças cardiovasculares e respiratórias. Rev. Saúde Pública, 48 (6): 881-888.

Regazzi A. J.; 2000. Análise multivariada, notas de aula INF 766, Departamento de Informática da Universidade Federal de Viçosa, 2.

Revista de Saúde Meio Ambiente e Sustentabilidade, 2011. Interações entre o Clima, o Tempo e a Saúde Humana, 6 (2).

Rogot, E. e Padgett, S. T.; 1976. Associations of coronary and stroke mortality with temperature and snowfall in selected areas of the United States, 1962-1966. American Journal of Epidemiology, 103 (6): 565-575.

Rosenlund, M.; Forastiere, F.; Sario, M.; Badaloni, C. e Perucci, C. A.; 2009. Trafficrelated air pollution in relation to respiratory symptoms, allergic sensitisation and lung function in schoolchildren. BMJ, 64 (7).

Sartori, M. G. B.; 2000: Clima e Percepção. (vol. 1 e 2). Tese de doutorado. Faculdade de Filosofia Letras e Ciências Humanas, Universidade de São Paulo, SP.

Sharovsky; 2001. Efeitos da temperatura e poluição do ar na mortalidade por infarto do miocárdio no município de São Paulo. Tese de doutorado. Faculdade de Medicina, Universidade de São Paulo, SP. 
Schwartz, J.; 2000: Daily deaths are associated with combustion particles rather than $\mathrm{SO}_{2}$ in Philadelphia. Occup Environ Med. 57, 692-697.

Shumway, R. H.; Azari, A. S. e Pawitan, Y.; 1988: Modeling Mortality Fluctuations in Los Angeles as Functions of Pollution and Weather Effects. Environmental Research, 45: 224-241.

Siple, P.A. e Passel, C. F.; 1945: Measurements of dry atmospheric cooling in subfreezing temperatures. Proc. Am. Philos. Soc., 89: 177-99.

Silva, C. M. A.; Matos, I. E.; Ignotti, E.; Hacon, S. S.; 2013. Material particulado originário de queimadas e doenças respiratórias. Revista de Saúde Pública, 47 (2): 345-352.

Sanhueza, P. H.; Vargas, C. R. e Jiménez, J. P.; 1999: Mortalidad diaria en Santiago y su relación con la contaminación del aire. Rev. Méd. Chile,127 (2): 235-242.

Schaanning J.; Finsen, H.; Lereim I. et al., 1986. Effects of cold air inhalation combined with prolonged sub-maximal exercise on airway function in healthy young males. European Journal of Respiratory Diseases, 68 (142): 74-77.

Smoyer, K. E.; 1998: A comparative analysis of heat waves and associated mortality in St.Louis, Missouri - 1980 and 1995. Int. J. Biometeorol., 42: 44-50.

Souza e Macedo; 2010 Etanol e Bioeletricidade: A cana de açúcar no futuro da matriz energética. UNICA - União da Indústria de Cana de açúcar.

Spengler et al.; 1994. Personal Exposure to Nitrogen Dioxide in the Los Angeles Basin. Journal Air \& Waste, 44 (1): 39-47.

Steadman, R.G.; 1979. The assessment of sultriness. Part I: a temperature-humidity index based on human physiology and clothing science. J. Appl. Meteorol., 18: 861-873.

Steadman R. G., 1984. A Universal Scale of Apparent Temperature. J. Clim. Appl. Meteorol., 23: 1674-1687.

Sugarek N., 1986 Temperature Lowering After Iced Water: Enhanced Effects in the Elderly. J Am Geriatrics Society, 34:526-529.

Suping, Z.; Guanglin, M.; Yanwen, W.; Ji, L.; 1992. Study of the relationships between weather conditions and the marathon race, and of meteorotropic effects on distance runners. Int. J. Biometeorol., 36: 63-68.

Tadano Y. S.; Ugaya C. M. L.; Franco A. T.; 2009. Método de regressão de Poisson: metodologia para avaliação do impacto da poluição atmosférica na saúde populacional. Ambient. soc., 12 (2).

Thom, E. C.; 1959. The discomfort index. Weatherwise 12: 57-60.

Tromp, S.W.; 1963a. Medical Biometeorology. Elsevier. Amsterdam. 
Tromp, S.W., 1963b. Human Biometeorology. Int. J.Biometeor. 7: 154-158.

Tromp, S.W.; 1964. A simple water bath test for estimating the thermoregulation efficiency of man. Int. J.Biometeor., 7 (3): 291-296.

United Nations, 2015. World Population Prospects: The 2015 Revision, Key Findings and Advance Tables. Department of Economic and Social Affairs, Population Division, Working Paper No. ESA/P/WP.241.

Vallerand, A; Jacobs, I.; 1989. Rates of energy substrates utilization during human cold exposure. Eur J Appl Physiol., 58: 873-878.

Westerling, A. L.; Cayan, D. R.; Brown, T. J. e Hall, B. L., 2004. Climate, Santa Ana Winds and autumn wildfires in southern California. AGU100, 85(31): 289-292.

Wilson, O.; 1963: Cooling effect of an antarctic climate on man. Norsk Polarinstitutt Skr. 128: 1-32.

World health statistics, 2018: monitoring health for the SDGs, sustainable development goals. Geneva: World Health Organization; 2018. Licence: CC BY-NC-SA 3.0 IGO.

Zanobetti, A; O'neill, M. S.; Gronlund, C. J. e Schwartz, J. D.; 2012: Summer temperature variability and long-term survival among elderly people with chronic disease. Proc Natl Acad Sci USA, 109 (17): 6608-6613.

Zhao, Y.; Ducharne, A.; Sultan, B.; Braconnot, P.; Vautard, R.; 2015. Estimating heat stress from climate-based indicators: present-day biases and future spreads in the CMIP5 global climate model ensemble. Environmental Research Letters, 10 (8): $1-12$. 